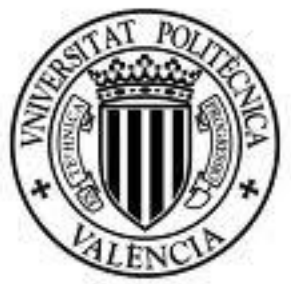

UNIVERSITAT POLITĖCNICA DE VALÈNCIA

Departamento de Tecnología de Alimentos

CONTRIBUCIÓN AL ESTUDIO DE LA INTENSIFICACIÓN DEL PROCESO DE SECADO DE TOMILLO (Thymus Vulgaris L.): APLICACIÓN DE ULTRASONIDOS DE POTENCIA Y SECADO INTERMITENTE

TESIS DOCTORAL

Presentada por

Jader Rodríguez Cortina

Dirigida por:

Dr. José Bon Corbín

Dr. Antonio Mulet Pons

Valencia, 2013 

D. JOSÉ BON CORBÍN, CATEDRÁTICO DE UNIVERSIDAD DEL DEPARTAMENTO DE TECNOLOGÍA DE ALIMENTOS, Y D. ANTONIO MULET PONS, CATEDRÁTICO DE UNIVERSIDAD DEL DEPARTAMENTO DE TECNOLOGÍA DE ALIMENTOS DE LA UNIVERSIDAD POLITECNICA DE VALENCIA.

CERTIFICAN: que la memoria titulada "CONTRIBUCIÓN AL ESTUDIO DE LA INTENSIFICACIÓN DEL PROCESO DE SECADO DE TOMILLO (Thymus Vulgaris L.): APLICACIÓN DE ULTRASONIDOS DE POTENCIA Y SECADO INTERMITENTE" que para aspirar al grado de Doctor en Ciencia, Tecnología y Gestión Alimentaria presenta D. Jader Rodriguez Cortina, realizada bajo nuestra dirección en el Departamento de Tecnología de Alimentos de la Universidad Politécnica de Valencia, cumple las condiciones adecuadas para su aceptación como tesis doctoral.

AUTORIZAN: Al interesado a su presentación en el Departamento de Tecnología de Alimentos de la Universidad Politécnica de Valencia.

Y para que conste a los efectos oportunos, presentamos la referida memoria, firmando el presente certificado en Valencia 12 de Junio 2013.

Fdo. D Dr. D. José Bon Corbín Dr. D. Antonio Mulet Pons 

La vida no es la que uno vivió, sino la que uno recuerda, $y$ cómo la recuerda para contarla.

A mis queridos Padres, hermanos y recordada Abuela 

Este trabajo de tesis doctoral se realizó en el Grupo de Análisis y Simulación de Procesos Agroalimentarios (ASPA) del Departamento de Tecnología de Alimentos de la Universidad Politécnica de Valencia, gracias al apoyo y colaboración de personas a las cuales quiero expresar mi más sincero agradecimiento:

Quisiera dedicar la finalización de esta Tesis Doctoral a todas aquellas personas que me han acompañado y facilitado su apoyo, consejo y ánimo a lo largo de este proceso, sin las cuales no hubiera sido posible lograr este objetivo.

Dr José Bon Corbín por su apoyo, experiencia, dedicación, valiosa ayuda y continua colaboración han sido imprescindibles para la realización de este trabajo, y al Dr. Antonio Mulet Pons, le agradezco que me haya abierto las puertas para formar parte del grupo de investigación ASPA, por ofrecerme sus valiosos conocimientos, experiencia profesional, buenos consejos y constante estímulo. Muchas gracias.

A mis amigos Brasileños Dr. Evandro de Castro Melo y familia, y Rony por haberme ofrecido su amistad y por su aporte en la fase experimental de este trabajo.

Quiero agradecer a Ramón y Nieves por su incondicional apoyo cada vez que los necesitaba.

Todos los compañeros y excompañeros del grupo ASPA, entre los que puedo mencionar a mi compi de laboratorio Neus Escobar, mis compañeros de almuerzo y risas Juan Carcel, Jose Vicente, Juanvi, Gabriela y Jose Benedito por todo el tiempo que compartimos y sobre todo por su amistad; a Neus Sanjuan por las buenas infusiones, y a mis compañeros de batalla Edith, Julian, Cesar, Marga, Carmina, Rosi, Marta e Ingrid por su incondicional amistad y por lo buenos momentos compartidos.

A Reme le quiero dar un especial agradecimiento por todos los detalles y muestra de cariño que ha tenido durante este tiempo, sus palabras siempre me han llegado.

Tambien quiero agradecer a las personas que durante todo este tiempo me han brindado su ayuda y amistad incondicional, Estrella Ibañez, gracias por ser como eres, a Jose Pinazo y Josiño gracias por ser mis hermanos, a Jose Montaras gracias por tus consejos, y todos mis compañeros de Bierwinkel por lo mucho que me quieren.

A mis amigos Antonio Martinez y Fernando Sampedro, gracias por su amistad incondicional.

A cada uno de mis amigos Colombianos que no hace falte que los nombre, ya que son muchos con los que he compartido mi vida y lucha por coseguir 
el este objetivo. Su apoyo y ayuda brindada en los momentos difíciles han hecho que toda adversidad fuera más llevadera.

A mis Padres Juana y Miguel Antonio, madre de ti aprendi a nunca perder la esperanza y de ti padre a trabajar y a luchar por lo que quiero.

A mis hermanos que son lo más grande que tengo, que siempre estaran ahí para lo que sea, y a mis demás familiares su muestra de cariño siempre las he valorado.

A mi abuela Alicia Cortina (Q.P.D), gracias por quererme y malcriarme tanto, estoy seguro que donde quieras que estes te sentiras orgullosa de mi.

Aquellas personas que han estado presentes en mi camino y, aunque ya no están, han puesto su granito de arena para que hoy sea quién y cómo soy.

A mis amigos en Colombia, que han sabido disculpar mis ausencias y siempre han tenido una palabra de ánimo. Estoy absolutamente convencido de que si de algo puedo presumir en esta vida es de los grandes amigos que tengo, lo que me hace sentir muy afortunado. No hace falta que los nombre, ellos saben quienes son y lo importantes que son para mi y, aunque la mayoría están lejos, tengo la suerte de poder sentirme siempre acompañado.

En especial a "Tr", por tu incomparable mezcla de paciencia, comprensión, y cariño, gracias por quererme, enamorarme y estar conmigo.

Y sobre todo muchas gracias a Dios. 




\section{TABLA DE CONTENIDO}

RESUMEN

RESUM

1. INTRODUCCIÓN

1.1. SECADO POR AIRE CALIENTE

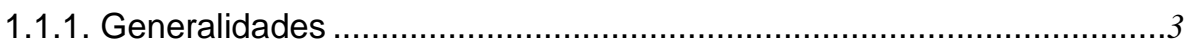

1.1.2. Fundamentos del secado por aire caliente ...................................4

1.1.3. Etapas de proceso ................................................................ 5

1.1.4. Aspectos relacionados con la calidad de los alimentos ....................6

1.1.5. Modelización del proceso ...........................................................

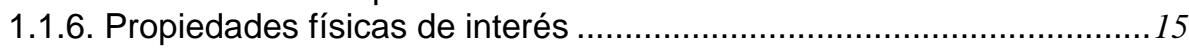

1.2. NUEVAS TECNOLOGÍAS APLICADAS AL SECADO CONVECTIVO 22

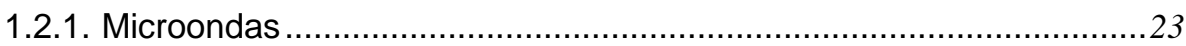

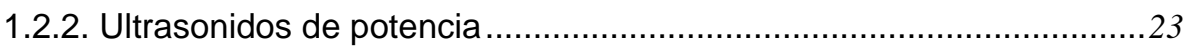

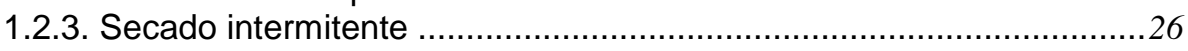

1.3. TOMILLO 31

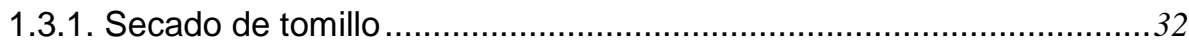

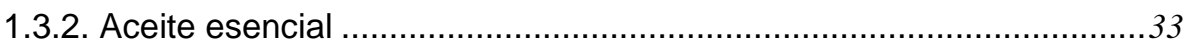

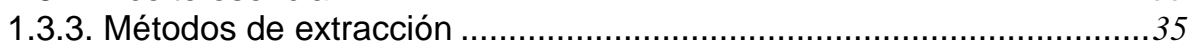

1.4. CONSIDERACIONES FINALES 36

2. OBJETIVOS Y ESTRUCTURA DE LA TESIS DOCTORAL 39

3. METODOLOGÍA 43

3.1. MATERIA PRIMA 46

3.2. EXPERIENCIAS DE SECADO 47

3.3. EXTRACCIÓN Y DETERMINACIÓN DE LA CAPACIDAD ANTIOXIDANTE DEL ACEITE ESENCIAL DE TOMILLO 51

3.4. ANALISIS DE LA CINÉTICA DE SECADO. MODELIZACION DEL PROCESO DE SECADO 52

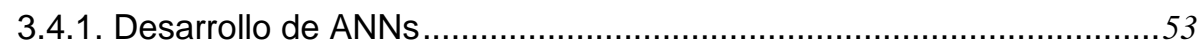

3.4.2. Modelo difusional de transferencia de materia y calor en una hoja y

en el lecho considerando resistencia externa ......................................54

3.5. ANALISIS DEL EFECTO DE LAS CONDICIONES DE OPERACIÓN SOBRE LA CAPACIDAD ANTIOXIDANTE DE LOS EXTRACTOS DE TOMILLO SECO 
4. RESULTADOS

4.1. MODELLING DRYING KINETICS OF THYME (Thymus Vulgaris L.): THEORETICAL AND EMPIRICAL MODELS, AND NEURAL NETWORKS

4.2. OPTIMIZATION OF THE ANTIOXIDANT CAPACITY OF THYME (Thymus Vulgaris L.) EXTRACTS: MANAGEMENT OF THE DRYING PROCESS

4.3. INFLUENCE OF HIGH-INTENSITY ULTRASOUND ON DRYING KINETICS IN FIXED BEDS OF HIGH POROSITY

4.4. OPTIMIZATION OF THE ANTIOXIDANT CAPACITY OF THYME (Thymus Vulgaris L.) EXTRACTS: MANAGEMENT OF THE CONVECTIVE DRYING PROCESS ASSISTED BY POWER ULTRASOUND

4.5. TWO PERIODS DRYING PROCESS MANAGEMENT OF THYME (Thymus vulgaris $\mathrm{L}$.)

5. DISCUSION DE RESULTADOS

6. CONCLUSIONES

7. RECOMENDACIONES

8. BIBLIOGRAFÍA

ANEXO 1. MODELO DE TRANSFERENCIA DE CALOR Y DE MATERIA EN EL LECHO

ANEXO 2. HERRAMIENTAS COMPUTACIONALES

ANEXO 3. HERRAMIENTA PARA LA SIMULACIÓN DEL PROCESO DE SECADO

ANEXO 4. HERRAMIENTA DE PROGRAMACIÓN DE UNA RED NEURONAL 
RESUMEN 



\section{RESUMEN}

\section{CONTRIBUCIÓN AL ESTUDIO DE LA INTENSIFICACIÓN DEL PROCESO DE SECADO DE TOMILLO (Thymus vulgaris L.): APLICACIÓN DE ULTRASONIDOS DE POTENCIA Y SECADO INTERMITENTE}

Los efectos del secado en los alimentos son frecuentemente el resultado de diferentes eventos los cuales tiene lugar consecutiva o simultáneamente. Entre ellas, se encuentra la remoción de la humedad y cambios importantes de sus propiedades, tales como sabor, color, degradación de vitaminas, componentes activos y textura.

A partir de estas consideraciones, los avances tecnológicos en los procesos de secado han centrado sus esfuerzos en la mejora de la calidad final de los productos y la reducción de los tiempos de proceso, se aborda la manera de reducir el consumo de energía lo que permitiría disminuir los costos de operación y el impacto ambiental. Uno de los procesos donde se persiguen tales intereses es el secado por aire caliente ya que, además de ocupar un importante lugar en la transformación de productos agroalimentarios y en los sistemas de tratamiento poscosecha, es una de las actividades industriales que supone mayor consumo energético e influye en diferentes parámetros de calidad.

En tal sentido, resultaría interesante poder estudiar la intensificación en una forma común de secado convectivo como son los lechos fijos y en un producto de gran interés para la industria de alimentos y farmacéutica como es el tomillo (Thymus Vulgaris L). El tomillo pertenece a la familia de las labiadas reconocidas por ser fuentes de compuesto fenólicos asociados a su actividad antioxidante. La capacidad antioxidante del tomillo (AC) se debe al aporte de monoterpenos fenólicos y compuestos aromáticos volátiles que contribuyen de manera significativa a la capacidad antioxidante. Los compuestos principales del aceite esencial de tomillo (thymol/carvacrol), pueden verse afectados por la magnitud de las condiciones de operación empleadas durante el proceso de secado, siendo necesario identificar condiciones óptimas de proceso que mejoren las cinéticas de secado y maximicen la capacidad antioxidante (AC).

La intensificación de los efectos del secado por aire caliente en lechos de hojas de tomillo, se puede abordar desde el punto de vista de mejora de las cinéticas de secado y la preservación de compuestos con actividad antioxidante sensibles al calor.

La introducción de nuevas tecnologías como fuentes adicionales de energía y la aplicación de un secado intermitente permitirían intensificar el proceso de secado. Dentro de las fuentes adiciones de energía, se puede destacar la aplicación de los ultrasonidos de potencia, los cuales pueden influir en la velocidad de secado sin producir un aumento significativo de la temperatura del material, favoreciendo su aplicación en el secado de materiales sensibles al calor. Como secado intermitente cabe destacar, el proceso de secado que es 
controlado por la temperatura de la superficie del sólido y se desarrolla con diferentes temperaturas del aire de secado.

Por lo tanto, el objetivo de este trabajo fue estudiar la intensificación del proceso de secado convectivo con el fin de reducir el tiempo de proceso y preservar la calidad final del producto seco.

Para abordar este objetivo, las hojas de tomillo se secaron siguiendo una metodología que consistió en secar hojas de tomillo bajo condiciones constantes de proceso, secado convectivo aplicando ultrasonidos de potencia y secado intermitente controlado por la temperatura de la superficie de la muestra secado, y posteriormente estudiar el efecto de cada método probado sobre las cinéticas de secado y sobre la AC, tal y como se presenta en los siguientes apartados:

\section{Secado convectivo bajo condiciones constantes}

Para el estudio de la intensificación del proceso de secado de hojas de tomillo en lecho fijo, como punto de partida se analizó el efecto del secado convectivo bajo condiciones de operación constantes sobre las cinéticas de secado y sobre la capacidad antioxidante de los extractos de hojas de tomillo secas.

Para el estudio de las cinéticas de secado, se realizaron experiencias de secado a diferentes temperaturas $\left(40,50,60,70^{\circ} \mathrm{C}\right)$ a $1 \mathrm{~m} \mathrm{~s}^{-1}$. Con el fin de poder describir la evolución de la humedad en función del tiempo y analizar el efecto de temperatura y la velocidad, se utilizaron modelos empíricos, un modelo teórico de lámina infinita basado en la ley particular de Fick y un modelo empírico "cajanegra" de red neuronal.

La velocidad de secado mostró una relación directa con la magnitud de la temperatura de secado aplicada. A partir del modelo teórico propuesto, se determinó la difusividad efectiva $\left(D / L^{2}\right)$ con valores entre $3.68 \times 10^{-5}$ y $2.12 \times 10^{-4}$ $\mathrm{s}^{-1}$ y la dependencia de la difusividad con la temperatura de secado fue representada con la ecuación tipo Arrhenius, obteniéndose una energía de activación de $49.42 \mathrm{~kJ} \mathrm{~mol}^{-1}$. La bondad del ajuste del modelo teórico no fue satisfactoria, lo cual se atribuye a las hipótesis consideradas para el desarrollo del modelo. En base a estos resultados y para posteriores estudios resultó necesario desarrollar un modelo teórico difusional que considere resistencia interna y externa simultáneamente a la transferencia de calor y materia.

Los modelos empíricos propuestos fueron ajustados a los datos experimentales; adicionalmente, la dependencia de los parámetros de cada modelo a la temperatura de secado fue determinada a partir de una relación polinómica. Ello permitió estimar la evolución del contenido de humedad a cualquier temperatura en el intervalo de tiempo establecido. Además, se realizó una comparación de la bondad del ajuste de los modelo utilizando el porcentaje de los errores relativos (ER) y la varianza explicada (VAR). Las redes neuronales desarrolladas mostraron ser más precisas que los modelos probados para predecir la evolución de humedad con VAR $>99.3 \%$ y un ER $<8.7 \%$. A partir de los resultados obtenidos se puede concluir que modelos desarrollados a través de redes 
neuronales podrían ser considerados de especial interés en la formulación y resolución de problemas de optimización en línea y en el control predictivo de proceso.

El efecto de las condiciones de operación sobre la capacidad antioxidante (AC) fueron estudias a temperaturas $\left(40,50,60,70,80{ }^{\circ} \mathrm{C}\right)$ y velocidad del aire de secado de $\left(1 \mathrm{y}_{2 \mathrm{~m} \mathrm{~s}^{-1}}\right)$. De las muestras secas se extrajo su aceite esencial por la técnica de extracción con $\mathrm{CO}_{2}$ supercrítico a $35 \times 10^{3} \mathrm{kPa}, 35 \stackrel{\circ}{\circ} \mathrm{C}$. En las muestras obtenidas, se determinó AC usando el método FRAP (ferric reducing activity power). A partir de los resultados de la medición de la AC y de los valores experimentales de las cinéticas de secado, se formuló un problema de optimización para determinar las condiciones de operación que maximizaran la AC de los extractos de tomillo seco. Para la formulación del problema de optimización la temperatura de secado (T), la velocidad del aire de secado (V) y el tiempo de secado (t) fueron consideradas como variables decisorias, y la capacidad antioxidante de los extractos de tomillo seco se definió como función objetivo. Debido a la complejidad implicada en el desarrollo de modelos teóricos, y que no existen referencias de modelos para predecir la evolución de la AC del producto en función de las condiciones de operación, un modelo de red neural (ANN) fue desarrollado para tal fin. Las restricciones que limitan la región de búsqueda de las variables decisorias se determinaron a partir de los valores experimentales de las condiciones de secado y de los resultados del proceso. Los límites de la $\mathrm{V}$ y $\mathrm{T}$ pueden establecerse directamente, y la restricción del tiempo de secado ( $t$ ) se fija indirectamente por los valores de las demás condiciones de funcionamiento y de la humedad final $\left(\mathrm{W}_{\mathrm{f}}\right)$ deseada. Para estimar el contenido final de humedad del producto seco en función de las condiciones de operación se desarrolló una ANN. Las ANNs se desarrollaron considerando una arquitectura multicapa, de alimentación hacia adelante y un proceso de aprendizaje de retro-propagación.

Los valores de la $A C$ de los extractos del producto seco variaron entre 21.0 y 107.2 [Trolox] (mmol/L). La AC se incrementó significativamente cuando la temperatura y la velocidad del aire aumentaban; sin embargo a temperaturas del aire superiores a $70{ }^{\circ} \mathrm{C}$ a $2 \mathrm{~m} / \mathrm{s}$ AC disminuyó, lo cual puede ser debido a la degradación de algunos compuestos con capacidad antioxidante.

Las ANNs desarrolladas mostraron una buena concordancia entre los valores experimentales y los calculados con un coeficiente de correlación mayor de 0.993 y un error relativo menor de $3.06 \%$.

El problema de optimización fue resuelto para diferentes casos experimentales y el resultado de la AC calculado con las condiciones óptimas obtenidas por la herramienta desarrollada aumentó entre $4.9 \%$ y $360.4 \%$ según diferentes casos considerados. Adicionalmente, la herramienta desarrollada fue validada, obteniendo diferencias entre los valores calculados y valores de experimentales de la AC entre el 2 y el 7\%. A partir de los resultados obtenidos cabría señalar que para maximizar la AC del tomillo seco resulta necesario llevar a cabo una gestión óptima del proceso. 


\section{Secado convectivo asistido por ultrasonidos de potencia}

La intensificación del secado convectivo mediante la aplicación de ultrasonidos de alta intensidad podría constituir una forma de mejorar sistemas tradicionales de secado por convección. Por lo tanto, el objetivo principal de este estudio fue evaluar la influencia de los ultrasonidos de alta intensidad en los fenómenos de transferencia durante el secado convectivo en un lecho de alta porosidad de materiales no porosos, como las hojas de tomillo, y evaluar la capacidad antioxidante de los extractos de las hojas secas.

Para el estudio del efecto de los ultrasonidos sobre los fenómenos de transferencia, se llevaron a cabo experiencias de secado a 1,2 y $3 \mathrm{~m} \mathrm{~s}^{-1}$ y diferentes temperaturas del aire $(40,50,60,70$, y $80 \pm 1.2 \circ \mathrm{C})$, y a diferentes niveles de densidad acústica $\left(0,6.2,12.3,18.5 \mathrm{~kW} \mathrm{~m}^{-3}\right)$. Para conocer el efecto de los ultrasonidos sobre la cinética de secado, fue desarrollado un modelo difusional con resistencia externa, considerando simultáneamente fenómenos de transferencia de materia y calor, tanto en el lecho como en las hojas de tomillo, resistencia interna y externa a los procesos de transporte y con condiciones de contorno variables en el tiempo. El modelo desarrollado compuesto por un sistema de ecuaciones de derivadas parciales, se resolvió aplicando el método numérico de elementos finitos.

De los resultados de las cinéticas de secado se observó que la velocidad de secado aumentó conforme la velocidad y temperatura del aire y la potencia aplicada de los ultrasonidos aumentaban. El efecto de los ultrasonidos se observó a temperaturas del aire menores o igual a $60{ }^{\circ} \mathrm{C}$. El efecto de los ultrasonidos sobre la intensificación de la cinética de secado también fue influenciado por la velocidad del aire: cuanto mayor fue la velocidad del aire, el efecto de los ultrasonidos fue menor.

El modelo difusional desarrollado, permitió entender mejor los mecanismos de transporte que ocurren durante el proceso de secado. El modelo desarrollado mostro un buen ajuste entre los valores experimentales y los calculados (VAR $\geq$ $99.4 \%$; ER $\leq 4.9 \%$ ); permitiendo identificar la difusividad efectiva $\left(D / L^{2}\right)$, el coeficiente de transferencia de materia $\left(h_{m v}\right)$, y el coeficiente de transferencia de calor $(h)$. Del análisis de los parámetros identificados se pudo observar que estos fueron afectados por la temperatura del aire, velocidad del aire y por los ultrasonidos.

Del análisis de la variación del parámetro $D / L^{2}$ en función de las condiciones de operación, se pudo determinar el efecto de estas condiciones sobre la resistencia interna a la transferencia de materia. El efecto de la velocidad del aire afecta a la resistencia externa. El efecto de la temperatura se pudo observar en que $D / L^{2}$ aumentó cuando la temperatura incrementó. Esto significa que la resistencia interna a la transferencia de materia disminuyó a medida que aumenta la temperatura del aire. El efecto de los ultrasonidos sobre $D / L^{2}$ sólo se observó para temperaturas menores o igual $60^{\circ} \mathrm{C}$. 
Con respecto a los valores de los parámetros $h_{m v}$, y $h$ se observó un efecto más marcado de la aplicación de los ultrasonidos que para los valores de $D / L^{2}$. Este comportamiento puede estar relacionado con los efectos de la energía acústica que incide sobre el lecho. El lecho, al ser muy poroso, permite que los ultrasonidos penetren y afecten a la capa limite y por lo tanto a la resistencia externa en las hojas. La hoja de tomillo, al ser un material poco poroso, con pequeños espacios intercelulares, característicos de estos productos, hace que sea menos propenso a la influencia de los ultrasonidos, por lo que el efecto sobre la resistencia interna fue menor.

El efecto de la velocidad del aire se vincula a la resistencia externa, el coeficiente de transferencia de materia aumentó a medida que la velocidad del aire aumentó. La resistencia externa a la transferencia de materia fue significativamente afectada por la aplicación de energía ultrasónica, esta tiene un mayor efecto para velocidades del aire bajas siendo despreciable a una velocidad de $3 \mathrm{~m} \mathrm{~s}^{-1}$. Esto sugiere que la resistencia externa está más influenciada por los ultrasonidos a velocidades de aire bajas, debido no sólo a un mayor espesor de la capa límite a bajas velocidades de aire, sino también a la perturbación del campo ultrasónico que se presenta a altas velocidades del aire.

Los parámetros $h_{m v}$, y $h$ relacionados con las resistencias externas, aumentaron conforme la temperatura aumentó, por lo que las resistencias a las transferencia de materia y calor disminuyeron a medida que la temperatura se elevó. Los coeficientes de transferencia de materia y calor aumentaron en función de la intensidad de los ultrasonidos aplicada, pero este efecto sólo se observó a temperaturas del aire menores a $70{ }^{\circ} \mathrm{C}$. Por lo tanto, la influencia de los ultrasonidos disminuyó a medida que la temperatura aumentaba.

Del mismo modo que se estudió el efecto de la aplicación de los ultrasonidos sobre los fenómenos de transporte en el proceso de secado, se analizó su posible efecto sobre la capacidad antioxidante de los extractos de las hojas secas. El aceite esencial fue extraído por medio de un método de extracción con fluido supercrítico, y la capacidad antioxidante de los extractos se midió por FRAP (ferric reducing activity power).

A partir de las condiciones experimentales y de los resultados obtenidos, se formuló un problema de optimización para determinar las condiciones de operación que maximizaran la AC de los extractos de tomillo seco (función objetivo). Como variables decisorias se consideraron las condiciones de operación controlables: temperatura del aire de secado $(T)$, la velocidad del aire de secado $\left(\mathrm{V}_{\mathrm{H}}\right)$, potencia de los ultrasonidos y el tiempo de secado (t). Las restricciones de las variables decisorias fueran establecidas a partir de los valores experimentales, de las condiciones de funcionamiento y de los resultados de las experiencias de secado. Para cuantificar la función objetivo en función de las condiciones de operación consideradas como variables decisorias, se desarrolló un modelo matemático. Debido a la complejidad involucrada en el desarrollo de modelos teóricos para predecir la evolución de la capacidad antioxidante durante el proceso de secado de tomillo y evitar largos cálculos para 
aplicaciones de gestión en tiempo real, fue desarrollada para tal fin una red neuronal (ANN).

Adicionalmente se analizó la influencia de los ultrasonidos (US) sobre la velocidad de secado $\left(\mathrm{r}_{\mathrm{d}}\right)$, la cual se calculó a partir de los valores experimentales de la evolución del contenido de humedad. La velocidad de secado aumentó con la temperatura y velocidad del aire, por lo tanto, el tiempo de secado se reduce para alcanzar el contenido deseado de humedad final. El efecto de los ultrasonidos sobre la $r_{d}$ se observó a temperaturas de secado de entre 40 y 60 ${ }^{\circ} \mathrm{C}$, y una velocidad de aire de entre 1 y $2 \mathrm{~m} \mathrm{~s}^{-1}$. Para temperaturas del aire mayores a $60 \stackrel{\circ}{ } \mathrm{C}$, una velocidad del aire de secado de $3 \mathrm{~m} \mathrm{~s}^{-1}$, la aplicación de US no aumentó $\mathrm{r}_{\mathrm{d}}$; por lo tanto, la influencia de los US bajo estas condiciones de operación fue despreciable. El hecho de que US no ejerciera ninguna influencia a velocidad de aire de $3 \mathrm{~m} \mathrm{~s}^{-1}$ se atribuye a la perturbación del campo acústico.

De las medidas de AC, se pudo observar que en general aumentó significativamente en función de la magnitud de las condiciones de operación aplicadas en el proceso de secado. Los valores de la AC son mayores para muestras secadas a $2 \mathrm{~m} \mathrm{~s}^{-1}$ que a $1 \mathrm{~m} \mathrm{~s}^{-1}$; disminuyendo en muestras secadas a $3 \mathrm{~m} \mathrm{~s}^{-1}$, lo que podría ser debido a un mayor calentamiento superficial. El efecto de la temperatura sobre la $A C$ muestra una relación directa; sin embargo a $2 \mathrm{~m} \mathrm{~s}$ ${ }^{1}$ y temperaturas de secado superiores a $70{ }^{\circ} \mathrm{C}$, la $\mathrm{AC}$ disminuyó, lo cual podría ser debido a la degradación del aceite esencial. El efecto US sobre la cinéticas de secado se observó a velocidades del aire 1 y $2 \mathrm{~m} \mathrm{~s}^{-1}$ y temperaturas menores o igual a $60 \stackrel{\circ}{\circ}$; para temperaturas superiores a $60 \stackrel{\circ}{\circ}$ y experiencias de secado a $3 \mathrm{~m} \mathrm{~s}^{-1}$ el efecto de los US fue despreciable, repercutiendo indirectamente sobre la variación de AC.

La variación de $A C$ en este estudio puede atribuirse principalmente al efecto de la temperatura, velocidad del aire y los ultrasonidos sobre la cinéticas de secado, y por tanto, en la degradación y formación de los compuestos fenólicos con capacidad antioxidante.

La herramienta de gestión desarrollada para determinar las condiciones óptimas de operación en función de las condiciones iniciales de la muestra y condiciones ambientales, mostró ser de gran utilidad. Permitía establecer los valores de las condiciones de operación para poder maximizar la AC. Para probar la fiabilidad de la herramienta de gestión desarrollada se realizaron tres ensayos de validación, con diferentes contenidos de humedad inicial de la muestra. La AC de los extractos de tomillo seco se midió y se comparó con los resultados calculados, obteniéndose una diferencia entre 3.3 y el $4.5 \%$.

\section{Secado intermitente controlado por la temperatura de la superficie de la muestra}

La selección de un adecuado método de secado, una buena gestión del proceso y el desarrollo de un adecuado modelo matemático que permitan determinar las condiciones óptimas de funcionamiento, son esenciales para obtener productos de una alta calidad, a un mínimo coste, con un rendimiento máximo. 
Como procedimiento de gestión se puede considerar la aplicación de una estrategia de secado con un perfil de temperatura variable durante el proceso. Este enfoque puede resultar en la reducción del tiempo de secado y la preservación de compuestos con capacidad antioxidante. El objetivo de este estudio en particular fue aplicar una estrategia de secado basado en dos periodos consecutivos de secado que permitiera gestionar el proceso, con el fin de disminuir el tiempo de secado y aumentar la capacidad antioxidante de los extractos de las hojas secas (AC). Para ello, se analizó la influencia de la velocidad del aire, la temperatura del aire, y la estrategia de secado propuesta sobre la cinética de secado así como sobre la AC.

A partir de las referencias bibliográficas, se encontró que $70 \stackrel{\circ}{\mathrm{C}}$ era la mejor temperatura de secado que favorece el incremento de compuestos con capacidad antioxidante, y temperaturas superiores a esta causan daños excesivos en la estructura del material y pérdida del aceite esencial. Con base a estas consideraciones se estableció una estrategia de secado consistente en aplicar dos períodos consecutivos de secado. En el primer período de secado el producto se somete a una temperatura de $80 \stackrel{\circ}{\circ}$ durante un tiempo dado, evitando que la superficie de las hojas supere los $70 \stackrel{\circ}{ } \mathrm{C}$. En el segundo período de secado, el producto se somete a una temperatura de aire inferior $(40,50,60$, $70 \stackrel{\circ}{\circ}$ ), hasta el contenido de humedad final deseada. La aplicación del primer período de secado a alta temperatura podría reducir el tiempo de secado total $(t)$, en comparación con procesos en los que el suministro de calor es continuo; por lo tanto, puede mejorar la eficiencia energética.

Para evitar daños o degradaciones de los compuestos de interés por exposición excesivo a temperaturas de $80 \stackrel{\circ}{\circ}$, fue necesario establecer el tiempo de exposición a $80{ }^{\circ} \mathrm{C}$ para que la superficie de la muestra alcance una temperatura de $68{ }^{\circ} \mathrm{C} \pm 2{ }^{\circ} \mathrm{C}$. Dada la dificultad de medición experimental de la temperatura de la superficie de las hojas durante el proceso de secado, la evolución de dicha temperatura se determinó a través de un modelo difusivo con resistencia interna y externa. El modelo desarrollado consideró simultáneamente fenómenos de transferencia de calor y de materia en el lecho y en las hojas de tomillo.

A partir de la modelización del proceso de secado se estableció el tiempo de exposición a $80^{\circ} \mathrm{C}$ para que la superficie de la muestra alcanzara una

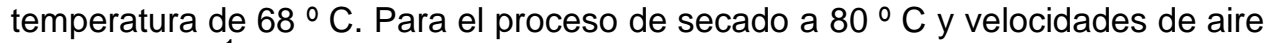
de 1 y $2 \mathrm{~m} \mathrm{~s}^{-1}$ no se encontraron diferencias significativas en la evolución de la temperatura superficial. Por lo tanto, el tiempo de exposición para la superficie de la muestra para llegar a una temperatura de aproximadamente $68{ }^{\circ} \mathrm{C}$ fue de 600 s.

Para extender la aplicación a otras temperaturas, corroborar los resultados a otras temperaturas de secado, y para probar la precisión del modelo desarrollado, la estrategia de secado considerada se llevó a cabo en dos períodos consecutivos de secado: el primer período de secado fue a $80{ }^{\circ} \mathrm{C}$ durante $300 \mathrm{~s}\left(T_{a 11}\right)$ ó $600 \mathrm{~s}\left(T_{a 12}\right)$ e inmediatamente se desarrolló el segundo periodo de secado $\left(40,50,60\right.$ y $\left.70 \stackrel{\circ}{\circ} \mathrm{C}\left(T_{a 2}\right)\right)$ hasta que el contenido final de humedad fuera inferior al $10 \%$ (d.b.) a 1 y $2 \mathrm{~m} \mathrm{~s}^{-1}$. Los resultados de esta 
estrategia de secado fueron comparados con el experimento de secado a temperatura constante del aire $(40,50,60$, y $70 \stackrel{\circ}{C})$.

Como era de esperar, el aumento del tiempo del primer periodo de secado aumentó la cinética de secado. Por lo tanto, el tiempo total de secado se redujo entre 7.9 y $39.2 \%$, en comparación con experiencias de secado a temperatura de aire constantes. El modelo desarrollado se ajustó a los resultados experimentales, mostrando una buena precisión (VAR $\geq 99.7 \%$; ER $\leq 5.9 \%$ ). El modelo matemático permitió identificar parámetros que se relacionan con los procesos de transporte interno y externo. Del análisis de los parámetros identificados se pudo concluir que los mecanismos de transferencia de calor y materia involucrados en el secado de las hojas de tomillo se vieron afectados significativamente por la velocidad y temperatura del aire. Estos resultados permitieron explicar el comportamiento de las cinéticas de secado obtenidas por la aplicación de dos periodos consecutivos de secado.

Valores de la AC mostraron una variación entre $39.9 \pm 0.6$ y $114.1 \pm 1.6$ $\mathrm{mmol} / \mathrm{LTrolox}$. La aplicación del primer período de secado permitió aumentar la AC entre el 4,7 y el $27,4 \%$ con respecto a los valores obtenidos bajo condiciones constantes de secado. Sin embargo, a temperatura constante del aire de $80 \cong \mathrm{C}$, se produjo una disminución de la $\mathrm{AC}$, que podría ser debido a la degradación de compuesto con capacidad antioxidante y a cambios en su estructura. En base a los resultados obtenidos, parece ser que el aumento de las actividades antioxidantes observadas cuando se aplican los dos períodos consecutivos de secado, se debe probablemente a la composición particular de estos aceites esenciales, y al efecto de tiempo/temperatura del primer periodo de secado sobre sus componentes principales, permitiendo la rápida formación de compuestos con propiedades antioxidantes.

Por lo tanto, a través de dicha estrategia de secado, se puede acortar el tiempo

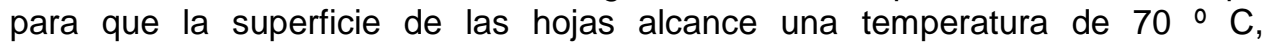
permitiendo aumentar la cantidad de compuestos con capacidad antioxidante y se puede reducir el tiempo total de secado, lo que se vincula al consumo de energía y la productividad.

Se puede concluir que la aplicación de ultrasonidos de potencia y la metodología de secado intermitente aplicada, permitió intensificar el proceso de secado reduciendo el tiempo de total de proceso y aumentando la capacidad antioxidante de los extractos de tomillo seco. Esto contribuye a aumentar la eficiencia, la productividad y reducir el consumo energético en comparación con procesos de secado bajo condiciones constantes.

A partir de los resultados obtenidos para cada metodología de secado aplicada cabría señalar que para maximizar la AC del tomillo seco resulta necesario llevar a cabo una gestión adecuada del proceso, estableciendo las condiciones óptimas de operación en cada caso. 


\section{RESUM}

\section{CONTRIBUCIÓ A L'ESTUDI DE LA INTENSIFICACIÓ DEL PROCÉS D'ASSECATGE DE TIMÓ (Thymus vulgaris L.): APLICACIÓ D’ULTRASONS DE POTĖNCIA I ASSECATGE INTERMITENT}

Els efectes de l'assecatge en els aliments són sovint el resultat de diversos esdeveniments, els quals tenen Iloc consecutivament o simultàniament. Entre aquests es troba la remoció de la humitat i els canvis importants de les propietats, com ara sabor, color, degradació de vitamines, components actius i textura.

A partir d'aquestes consideracions, els avenços tecnològics en els processos d'assecatge han centrat els esforços en la millora de la qualitat final dels productes i la reducció dels temps de procés. També s'aborda la forma de reduir el consum d'energia, la qual cosa permetria disminuir els costos d'operació i l'impacte ambiental. Un dels processos en què es persegueixen aquests interessos és l'assecatge mitjançant aire calent, ja que, a més d'ocupar un important lloc en la transformació de productes agroalimentaris i en els sistemes de tractament postcollita, és una de les activitats industrials que suposa major consum energètic i influeix en diferents paràmetres de qualitat.

En aquest sentit, resultaria interessant poder estudiar la intensificació en una forma comuna d'assecatge convectiu com és l'ús de llits fixos, i en un producte de gran interès per a la indústria d'aliments i farmacèutica com és el timó (Thymus vulgaris L). El timó pertany a la família de les labiades reconegudes per ser font de compostos fenòlics associats a la seua activitat antioxidant. La capacitat antioxidant del timó (AC) es deu a l'aportació de monoterpens fenòlics i compostos aromàtics volàtils que contribueixen significativament a la seua capacitat antioxidant. Els compostos principals de l'oli essencial de timó (timol/carvacrol) es poden veure afectats per la magnitud de les condicions d'operació emprades durant el procés d'assecatge, que fan necessari identificar condicions òptimes de procés per millorar les cinètiques d'assecatge i maximitzar I'AC.

La intensificació dels efectes de l'assecatge mitjançant aire calent en llits de fulles de timó es pot abordar des del punt de vista de la millora de les cinètiques d'assecatge i la preservació dels compostos amb activitat antioxidant, sensibles a la calor.

La introducció de noves tecnologies com a fonts addicionals d'energia i l'aplicació d'un assecatge intermitent permetrien intensificar el procés d'assecatge. Entre les fonts addicionals d'energia, es pot destacar l'aplicació dels ultrasons de potència, els quals poden influir en la velocitat d'assecatge sense produir un augment significatiu de la temperatura del material. Tot plegat n'afavoreix 
l'aplicació en l'assecatge de materials sensibles a la calor. Com a assecatge intermitent, cal destacar el procés d'assecatge que és controlat per la temperatura de la superfície i es desenvolupa amb diferents temperatures de l'aire d'assecatge.

Per tant, l'objectiu d'aquest treball ha sigut estudiar la intensificació del procés d'assecatge convectiu per tal de reduir el temps de procés i preservar la qualitat final del producte sec.

Per abordar aquest objectiu, les fulles de timó s'han assecat seguint una metodologia que ha consistit a assecar fulles de timó sota condicions constants de procés, un assecatge convectiu assistit per ultrasons de potència i un assecatge intermitent controlat per la temperatura de la superfície de la mostra, i posteriorment s'ha estudiat l'efecte de cada mètode provat sobre les cinètiques d'assecatge i sobre l'AC, tal com es presenta en els apartats següents:

\section{Assecatge convectiu sota condicions constants}

Com a punt de partida en l'estudi de la intensificació del procés d'assecatge de fulles de timó en llit fix, s'ha analitzat l'efecte de l'assecatge convectiu sota condicions d'operació constants sobre les cinètiques d'assecatge i sobre la capacitat antioxidant dels extractes de fulles de timó seques.

Per a l'estudi de les cinètiques d'assecatge, s'han dut a terme experiències d'assecatge a temperatures diferents $\left(40,50,60,70^{\circ} \mathrm{C}\right)$ a $1 \mathrm{~m} \mathrm{~s}^{-1}$. Amb l'objectiu de descriure l'evolució de la humitat en funció del temps i analitzar l'efecte de temperatura i la velocitat, s'hi han utilitzat models empírics, un model teòric de làmina infinita basat en la llei particular de Fick i un model empíric caixa-negra de xarxa neuronal.

La velocitat d'assecatge ha mostrat una relació directa amb la magnitud de la temperatura d'assecatge aplicada. A partir del model teòric proposat, s'ha determinat la difusivitat efectiva $\left(D / L^{2}\right)$ amb valors entre $3,68 \times 10^{-5}$ i $2,12 \times 10^{-4} \mathrm{~s}^{-1}$, i la dependència de la difusivitat amb la temperatura d'assecatge ha sigut representada amb una equació de tipus Arrhenius, amb una energia d'activació de 49,42 kJ mol-1. La bondat de l'ajust del model teòric no va ser satisfactòria, la qual cosa s'atribueix a les hipòtesis considerades per al desenvolupament del model. Basant-nos en aquets resultats i per a estudis posteriors, resulta necessari desenvolupar un model teòric difusional que considere la resistència interna i externa a la transferència de calor i matèria simultàniament.

Els models empírics proposats han sigut ajustats a les dades experimentals; addicionalment, la dependència dels paràmetres de cada model amb la temperatura d'assecatge ha sigut determinada a partir d'una relació polinòmica. Això ha permès estimar l'evolució del contingut d'humitat a qualsevol temperatura en l'interval de temps establit. A més, s'ha portat a terme una comparació de la bondat de l'ajust dels models utilitzant el percentatge dels errors relatius (ER) i la variància explicada (VAR). Les xarxes neuronals desenvolupades han mostrat ser més precises que els models empírics per 
predir l'evolució d'humitat amb VAR $>99,3 \%$ i un ER $<8,7 \%$. A partir dels resultats obtinguts, es pot concloure que els models desenvolupats a través de xarxes neuronals podrien ser considerats d'especial interès en la formulació $i$ resolució de problemes d'optimització en línia i en el control predictiu del procés.

L'efecte de les condicions d'operació sobre la capacitat antioxidant (AC) ha sigut estudiat a diferents temperatures $\left(40,50,60,70,80^{\circ} \mathrm{C}\right)$ i velocitats de l'aire

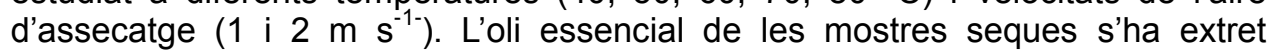
mitjançant la tècnica d'extracció amb $\mathrm{CO}_{2}$ supercrític a $35 \times 103 \mathrm{kPa}, 35^{\circ} \mathrm{C}$. En les mostres obtingudes s'ha determinat l'AC usant el mètode FRAP (ferric reducing activity power). A partir dels resultats de la mesura de l' AC i dels valors experimentals de les cinètiques d'assecatge, s'ha formulat un problema d'optimització per a determinar les condicions d'operació que maximitzaren l'AC dels extractes de timó sec. Per a la formulació del problema d'optimització, la temperatura d'assecatge $(T)$, la velocitat de l'aire d'assecatge $(V)$ i el temps d'assecatge ( $t$ ) han sigut considerades com a variables decisòries, i la capacitat antioxidant dels extractes de timó sec s'ha definit com a funció objectiu. A causa de la complexitat en el desenvolupament dels models teòrics, i també perquè no hi ha referències de models empírics per a predir l'evolució de l'AC del producte en funció de les condicions d'operació, s'ha hagut de desenvolupar un model de xarxa neural (ANN). Les restriccions que limiten la regió de cerca de les variables decisòries s'han determinat a partir dels valors experimentals de les condicions d'assecatge $\mathrm{i}$ dels resultats del procés. Els límits de $\mathrm{V}$ i $\mathrm{T}$ poden establir-se directament, i la restricció del temps d'assecatge (t) es fixa indirectament a partir dels valors de les altres condicions de funcionament $i$ de la humitat final $\left(\mathrm{W}_{\mathrm{f}}\right)$ desitjada. Per a estimar el contingut final d'humitat del producte sec en funció de les condicions d'operació, s'ha desenvolupat una ANN. Aquesta s'ha construït considerant una arquitectura multicapa, d'alimentació cap endavant, i un procés d'aprenentatge de retropropagació.

Els valors de l'AC dels extractes del producte sec han variat entre 21,0 i 107,2 [Trolox] (mmol/L). L'AC s'incrementava significativament a mesura que la temperatura i la velocitat de l'aire augmentaven; no obstant això, a temperatures de l'aire superiors a $70^{\circ} \mathrm{C}$ a $2 \mathrm{~m} \mathrm{~s}^{-1} \mathrm{AC}$ disminuïen, cosa que pot ser deguda a la degradació d'alguns compostos amb capacitat antioxidant.

Les ANN desenvolupades han mostrat una bona concordança entre els valors experimentals i els calculats amb un coeficient de correlació major de 0,993 i un error relatiu menor de 3,06\%.

El problema d'optimització ha sigut resolt per a diferents casos experimentals, i el resultat de l'AC calculat amb les condicions òptimes obtingudes amb l'eina desenvolupada ha augmentat entre $4,9 \%$ i $360,4 \%$ segons els diferents casos considerats. Addicionalment, l'eina ha sigut validada, i s'han obtingut diferències entre els valors calculats $\mathrm{i}$ els valors d'experimentals de l'AC entre el 2 i el $7 \%$. A partir dels resultats obtinguts, s'hauria d'assenyalar que per a maximitzar l'AC del timó sec pareix que cal dur a terme una gestió òptima del procés. 


\section{Assecatge convectiu assistit per ultrasons de potència}

La intensificació de l'assecatge convectiu per mitjà de l'aplicació d'ultrasons d'alta intensitat podria constituir una forma de millorar sistemes tradicionals d'assecatge per convecció. Per tant, l'objectiu principal d'aquest estudi ha sigut avaluar la influència dels ultrasons d'alta intensitat en els fenòmens de transferència durant l'assecatge convectiu en un llit d'alta porositat de materials no porosos, com les fulles de timó, i avaluar la capacitat antioxidant dels extractes de les fulles seques.

Per a l'estudi de l'efecte dels ultrasons sobre els fenòmens de transferència, s'han dut a terme experiències d'assecatge a 1,2 i $3 \mathrm{~m} \mathrm{~s}^{-1}$ i diferents temperatures de l'aire $\left(40,50,60,70\right.$, i $\left.80 \pm 1,2{ }^{\circ} \mathrm{C}\right)$, i a diferents nivells de densitat acústica $\left(0,6,2,12,3,18,5 \mathrm{~kW} \mathrm{~m}^{-3}\right)$. Per conèixer l'efecte dels ultrasons sobre la cinètica d'assecatge, s'ha desenvolupat un model teòric difusional, que considera simultàniament fenòmens de transferència de matèria i calor, tant en el llit com en les fulles de timó, de resistència interna i externa als processos de transport i amb condicions de contorn variables en el temps. El model matemàtic es compon d'un sistema d'equacions de derivades parcials, el qual s'ha resolt aplicant el mètode numèric d'elements finits.

Dels resultats de les cinètiques d'assecatge, s'ha observat que la velocitat d'assecatge augmentava a mesura que la velocitat i la temperatura de l'aire i la potència aplicada dels ultrasons augmentaven. L'efecte dels ultrasons s'ha observat a temperatures de l'aire inferiors a $70^{\circ} \mathrm{C}$. L'efecte dels ultrasons sobre la intensificació de la cinètica d'assecatge també ha sigut influenciat per la velocitat de l'aire: a major velocitat de l'aire, menor l'efecte dels ultrasons.

El model matemàtic desenvolupat, amb condicions de contorn variables amb el temps, ha permès entendre millor els mecanismes de transport que ocorren durant el procés d'assecatge. El model ha mostrat un bon ajust entre els valors experimentals i els calculats (VAR $\geq 99,4 \%$; ER $\leq 4,9 \%$ ); això ha permès identificar la difusivitat efectiva $\left(D / L^{2}\right)$, el coeficient de transferència de matèria $\left(h_{m v}\right)$, i el coeficient de transferència de calor $(h)$.

De l'anàlisi de la variació del paràmetre $D / L^{2}$ en funció de les condicions d'operació s'ha pogut determinar l'efecte d'aquestes condicions sobre la resistència interna a la transferència de matèria. L'efecte de la velocitat de l'aire afecta la resistència externa. L'efecte de la temperatura s'ha pogut observar en el fet que $D / L^{2}$ augmentava a mesura que la temperatura s'incrementava. Això significa que la resistència interna a la transferència de matèria disminueix a mesura que augmenta la temperatura de l'aire. L'efecte dels ultrasons sobre $D / L^{2}$ només s'ha observat per a temperatures menors o igual $60^{\circ} \mathrm{C}$.

Respecte als valors dels paràmetres $h_{m v}$, i $h$ s'ha observat un efecte més marcat de l'aplicació dels ultrasons que per als valors de $D / L^{2}$. Aquest comportament pot estar relacionat amb els efectes de l'energia acústica que incideix sobre el llit. El llit, com que és molt porós, permet que els ultrasons penetren i afecten la capa límit i per tant la resistència externa en les fulles. La fulla de timó, pel fet de ser 
un material poc porós, amb xicotets espais intercel-lulars característics d'aquests productes, fa que siga menys propensa a la influència dels ultrasons, per la qual cosa l'efecte sobre la resistència interna ha sigut menor.

L'efecte de la velocitat de l'aire es vincula a la resistència externa: el coeficient de transferència de matèria augmenta a mesura que la velocitat de l'aire augmenta. La resistència externa a la transferència de matèria s'ha vist significativament afectada per l'aplicació d'energia ultrasònica, que té un efecte major per a velocitats de l'aire baixes i és menyspreable a una velocitat de $3 \mathrm{~m} \mathrm{~s}^{-1}$. Això suggereix que la resistència externa està més influenciada pels ultrasons a velocitats d'aire baixes, a causa no sols d'una major grossària de la capa límit a velocitats d'aire baixes, sinó també per la pertorbació del camp ultrasònic que es presenta a velocitats de l'aire altes.

Els paràmetres $h_{m v}$, i $h$ relacionats amb les resistències externes augmenten a mesura que la temperatura augmenta, per la qual cosa les resistències a les transferència de matèria $\mathrm{i}$ calor disminueixen a mesura que la temperatura s'eleva. Els coeficients de transferència de matèria i calor augmenten en funció de la intensitat dels ultrasons aplicada, però aquest efecte només s'ha observat a temperatures de l'aire menors a $70^{\circ} \mathrm{C}$. Per tant, la influència dels ultrasons disminueix a mesura que la temperatura augmentava.

De la mateixa manera que s'ha estudiat l'efecte de l'aplicació dels ultrasons sobre els fenòmens de transport en el procés d'assecatge, se n'ha analitzat el possible efecte sobre la capacitat antioxidant dels extractes de les fulles seques. L'oli essencial s'ha extret mitjançant un mètode d'extracció amb fluid supercrític, i la capacitat antioxidant dels extractes s'ha mesurat amb FRAP (ferric reducing activity power).

A partir de les condicions experimentals i dels resultats obtinguts, s'ha formulat un problema d'optimització per determinar les condicions d'operació que maximitzaren l'AC dels extractes de timó sec (funció objectiu). Com a variables decisòries, s'han considerat les condicions d'operació controlables: temperatura de l'aire d'assecatge $(T)$, la velocitat de l'aire d'assecatge $\left(V_{H}\right)$, potència dels ultrasons i el temps d'assecatge (t). Les restriccions de les variables decisòries han sigut establides a partir dels valors experimentals, de les condicions de funcionament i dels resultats de les experiències d'assecatge. Per quantificar la funció objectiu en funció de les condicions d'operació considerades com a variables decisòries, s'ha desenvolupat un model matemàtic. A causa de la complexitat involucrada en el desenvolupament de models teòrics per predir l'evolució de la capacitat antioxidant durant el procés d'assecatge de timó i evitar llargs càlculs per a aplicacions de gestió en temps real, s'ha desenvolupat una ANN.

Addicionalment, s'ha analitzat la influència dels ultrasons (US) sobre la velocitat d'assecatge $\left(r_{d}\right)$, la qual s'ha calculat a partir dels valors experimentals de l'evolució del contingut d'humitat. La velocitat d'assecatge augmenta amb la temperatura i velocitat de l'aire, per tant, el temps d'assecatge es redueix per aconseguir el contingut desitjat d'humitat final. L'efecte dels ultrasons sobre la $r_{d}$ 
s'ha observat a temperatures d'assecatge entre 40 i $60^{\circ} \mathrm{C}$, i una velocitat d'aire entre $1 \mathrm{i} 2 \mathrm{~m} \mathrm{~s}^{-1}$. Per a temperatures de l'aire majors de $60^{\circ} \mathrm{C}$, una velocitat de l'aire d'assecatge de $3 \mathrm{~m} \mathrm{~s}^{-1}$, l'aplicació d'US no ha augmentat $r_{d}$; per tant, la influència dels US reduint aquestes condicions d'operació és menyspreable. El fet que US no exercira cap influència a velocitat d'aire de $3 \mathrm{~m} \mathrm{~s}^{-1} \mathrm{~s}^{\prime}$ atribueix a la pertorbació del camp acústic.

De les mesures d'AC, s'ha pogut observar que, en general, augmentava significativament en funció de la magnitud de les condicions d'operació aplicades en el procés d'assecatge. Els valors de l'AC eren majors per a mostres assecades a $2 \mathrm{~m} \mathrm{~s}^{-1}$ que a $1 \mathrm{~m} \mathrm{~s}^{-1}$; disminuïen en mostres assecades a $3 \mathrm{~m} \mathrm{~s}^{-1}$, la qual cosa podria ser causada per un major escalfament superficial. L'efecte de la temperatura sobre I'AC mostrava una relació directa; no obstant això, a $2 \mathrm{~m} \mathrm{~s}^{-1} \mathrm{i}$ temperatures d'assecatge superiors a $70^{\circ} \mathrm{C}$, l'AC disminuïa, la qual cosa podria ser deguda a la degradació de l'oli essencial. L'efecte US sobre la cinètiques d'assecatge s'ha observat a velocitats de l'aire 1 i $2 \mathrm{~m} \mathrm{~s}^{-1}$ i temperatures menors 0 iguals a $60^{\circ} \mathrm{C}$; per a temperatures superiors a $60^{\circ} \mathrm{C}$ i experiències d'assecatge a $3 \mathrm{~m} \mathrm{~s}^{-1}$ l'efecte dels US ha sigut menyspreable, de manera que repercutia indirectament sobre la variació d'AC.

La variació d'AC en aquest estudi pot atribuir-se principalment a l'efecte de la temperatura, de la velocitat de l'aire i dels ultrasons sobre la cinètiques d'assecatge i, per tant, en la degradació i formació dels compostos fenòlics amb capacitat antioxidant.

L'eina de gestió desenvolupada per determinar les condicions òptimes d'operació, en funció de les condicions inicials de la mostra i condicions ambientals, ha resultat de gran utilitat. Aquesta ha permès establir els valors de les condicions d'operació per poder maximitzar l'AC. S'han portat a terme tres assajos de validació, amb diferent contingut d'humitat de la mostra, per tal de provar la fiabilitat de l'eina de gestió desenvolupada. L'AC dels extractes de timó sec s'ha mesurat i s'ha comparat amb els resultats calculats, i s'ha obtingut una diferència entre 3,3 i 4,5\%.

\section{Assecatge intermitent controlat per la temperatura de la superfície de la mostra}

La selecció d'un mètode d'assecatge adequat, una bona gestió del procés i el desenvolupament d'un model matemàtic adequat que permeten determinar les condicions òptimes de funcionament són essencials per a obtenir productes d'alta qualitat, a un cost mínim, amb un rendiment màxim.

Com a procediment de gestió es pot considerar l'aplicació d'una estratègia d'assecatge amb un perfil de temperatura variable durant el procés. Aquest enfocament pot donar lloc a la reducció del temps d'assecatge i la preservació de compostos amb capacitat antioxidant. L'objectiu d'aquest estudi en particular ha sigut aplicar una estratègia d'assecatge basada en dos períodes consecutius d'assecatge que permetrà gestionar el procés, per tal de disminuir el temps d'assecatge i augmentar la capacitat antioxidant dels extractes de les fulles 
seques (AC). Amb aquest objectiu s'ha analitzat la influència de la velocitat de l'aire, la temperatura de l'aire, i l'estratègia d'assecatge proposades sobre la cinètica d'assecatge, com també sobre l'AC.

A partir de les referències bibliogràfiques, s'ha determinat que $70^{\circ} \mathrm{C}$ era la millor temperatura d'assecatge que afavoreix l'increment de compostos amb capacitat antioxidant, i temperatures superiors a aquesta causen danys excessius en l'estructura del material i pèrdua de l'oli essencial. Fonamentant-nos en aquestes consideracions, s'ha establit una estratègia d'assecatge consistent a aplicar dos períodes consecutius d'assecatge. En el primer període d'assecatge, el producte se sotmet a una temperatura de $80^{\circ} \mathrm{C}$ per un temps donat, tot evitant que la superfície de les fulles supere els $70^{\circ} \mathrm{C}$. En el segon període d'assecatge, el producte se sotmet a una temperatura d'aire inferior $\left(40,50,60,70^{\circ} \mathrm{C}\right)$, fins al contingut d'humitat final desitjada. L'aplicació del primer període d'assecatge a alta temperatura podria reduir el temps d'assecatge total ( $t$ ), en comparació amb processos en què el subministrament de calor és continu; per tant, pot millorar l'eficiència energètica.

Per evitar danys o degradacions dels compostos d'interès per exposició excessiva a temperatures de $80{ }^{\circ} \mathrm{C}$, ha sigut necessari establir el temps d'exposició a $80^{\circ} \mathrm{C}$ perquè la superfície de la mostra assolira una temperatura de $68^{\circ} \mathrm{C} \pm 2{ }^{\circ} \mathrm{C}$. Davant la dificultat de mesura experimental de la temperatura de la superfície de les fulles durant el procés d'assecatge, l'evolució d'aquesta temperatura s'ha determinat a través d'un model difusiu considerant resistència interna i externa. El model matemàtic considerava simultàniament fenòmens de transferència de calor i de matèria en el llit i en les fulles de timó.

A partir de la modelització del procés d'assecatge, s'ha establit el temps d'exposició a $80^{\circ} \mathrm{C}$ perquè la superfície de la mostra assolira una temperatura de $68{ }^{\circ} \mathrm{C}$. Per al procés d'assecatge a $80^{\circ} \mathrm{C}$ i velocitats d'aire d' 1 i $2 \mathrm{~m} \mathrm{~s}^{-1}$ no s'han trobat diferències significatives en l'evolució de la temperatura superficial. Per tant, el temps d'exposició per a la superfície de la mostra per arribar a una temperatura aproximadament de $68^{\circ} \mathrm{C}$ ha sigut de $600 \mathrm{~s}$.

Per poder aplicar-ho a altres temperatures, corroborar els resultats a altres temperatures d'assecatge, i per provar la precisió del model desenvolupat, l'estratègia d'assecatge considerada s'ha dut a terme en dos períodes consecutius d'assecatge: el primer període d'assecatge ha sigut a $80^{\circ} \mathrm{C}$ durant $300 \mathrm{~s}\left(T_{a l 1}\right)$ ○ $600 \mathrm{~s}\left(T_{a 12}\right)$, i immediatament s'ha desenvolupat el segon període d'assecatge $\left(40,50,60\right.$ i $\left.70{ }^{\circ} \mathrm{C}\left(T_{a 2}\right)\right)$, fins que el contingut final d'humitat fóra inferior al $10 \%$ (d. b.) a 1 i $2 \mathrm{~m} \mathrm{~s}^{-1}$. Els resultats d'aquesta estratègia d'assecatge han sigut comparats amb l'experiment d'assecatge a temperatura constant de l'aire $\left(40,50,60, \mathrm{i} 70^{\circ} \mathrm{C}\right)$.

Com calia esperar, l'augment del temps del primer període d'assecatge augmentava la cinètica d'assecatge. Per tant, el temps total d'assecatge s'ha reduït entre 7,9 i $39,2 \%$, en comparació amb experiències d'assecatge a temperatura d'aire constants. El model desenvolupat s'ajusta als resultats experimentals i mostrar una bona precisió (VAR $\geq 99,7 \%$; ER $\leq 5,9 \%$ ). El model 
matemàtic ha permès identificar paràmetres que es relacionaren amb els processos de transport intern i extern. De l'anàlisi dels paràmetres identificats, se n'ha pogut concloure que els mecanismes de transferència de calor i matèria implicats en l'assecatge de les fulles de timó es veien afectats significativament per la velocitat i la temperatura de l'aire. Aquests resultats han permès explicar el comportament de les cinètiques d'assecatge obtingudes per l'aplicació de dos períodes consecutius d'assecatge.

Valors de l'AC mostren una variació entre 39,9 \pm 0,6 i 114,1 \pm 1,6 mmol/LTrolox. L'aplicació del primer període d'assecatge ha permès augmentar l'AC entre el 4,7 al $27,4 \%$ respecte als valors obtinguts sota condicions constants d'assecatge. Malgrat això, a temperatura constant de l'aire de $80^{\circ} \mathrm{C}$, es produïa una disminució de l'AC que podria ser deguda a la degradació del compost amb capacitat antioxidant i a canvis en la seua estructura. Basant-nos en els resultats obtinguts, es dedueix que l'augment de les activitats antioxidants observades en aplicar els dos períodes consecutius d'assecatge es deu probablement a la composició particular d'aquests olis essencials, i a l'efecte de temps/temperatura del primer període d'assecatge sobre els seus components principals, que permet la ràpida formació de compostos amb propietats antioxidants.

Per tant, a través l'estratègia d'assecatge mencionada, es pot acurtar el temps perquè la superfície de les fulles assolisca una temperatura de $70^{\circ} \mathrm{C}$, cosa que permet augmentar la quantitat de compostos amb capacitat antioxidant. A més, es pot reduir el temps total d'assecatge, la qual cosa es vincula al consum d'energia i a la productivitat.

Es pot concloure que l'aplicació d'ultrasons de potència i la metodologia d'assecatge intermitent permet intensificar el procés d'assecatge, fet que redueix el temps de procés i augmenta la capacitat antioxidant dels extractes de timó $\mathrm{sec}$. Això contribueix a augmentar l'eficiència, la productivitat i redueix el consum energètic en comparació amb processos d'assecatge a temperatura constant.

A partir dels resultats obtinguts per a cada metodologia d'assecatge aplicada, cal assenyalar que per maximitzar l'AC cal dur a terme una gestió adient del procés, en què s'establisquen les condicions òptimes d'operació en casa cas. 


\section{ABSTRACT}

\section{CONTRIBUTION TO THE STUDY OF A STRENGTHENED PROCESS OF DRYING FOR THYME (Thymus vulgaris L.): APPLICATION OF POWER ULTRASOUNDS AND INTERMITENT DRYING}

The effects of drying in food are frequently the result of different events that take place consecutively or simultaneously. Among them there are the removal of humidity and important changes of their properties such as flavor, color, degradation of vitamins, active components and texture.

From these considerations, the technological advances in the drying process have focused their efforts on the improvement of the final quality of the products and the reduction of the processing time considering how to diminish energy consumption that would reduce operating costs and environmental impact. One of the processes where such interests are pursued is drying by hot air that not only has an important place in food processing and postharvest handling systems, but it is also one of the industrial activities involving higher energy consumption and influence different quality parameters.

In this regard, it would be interesting to study the intensification of a common way of convective drying such as fixed beds and thyme (Thymus Vulgaris L), which is a product of great interest for the food-processing and pharmaceutical industries. Thyme belongs to the Labiatae family and is well-known as phenolic compouds source associated with antioxidant activity. The thyme antioxidant capacity (AC) is due to the contribution of phenolic monoterpenes and volatile aromatic compounds that help significantly to the antioxidant capacity. The principal compounds of the thyme's (thymol/carvacrol) esential oil can be affected by the magnitude of the operating conditions used during the drying process which makes it necessary to identify optimal conditions for processing that improve the drying kinetics and maximize the antioxidant capacity (AC).

The intensification of the effects of drying by hot air in thyme leaves beds can be addressed from the point of view of the drying kinetics improvement and the preservation of compounds with antioxidant activity sensible to the heat.

The introduction of new technologies such as additional sources of energy and the application of an intermittent drying allow intensifying the drying process. Within the additional sources of energy to be considered, the application of power ultrasounds can be highlighted, which may influence the drying rate without producing a significant temperature increase of the material. This favors its application in the drying of materials sensitive to heat. As an intermittent drying process it is important to point to the process that is controlled through solid's surface temperature carried out with different temperatures of the drying air.

Therefore, the objective of this work was to intensify convective drying with the purpose of reducing the processing time and preserve the final quality of the dried product. 
To address this objective, the thyme leaves were dried following a methodology that consisted of applying a convective drying under constant conditions of process, a convective drying assisted by power ultrasounds, and and intermittent drying controlled by the temperature of the surface of the dried solid, and then analyze the effects each technique tested regarding the drying kinetics and the $A C$ as it is presented in the following sections:

\section{Convective Drying under constant conditions}

For the study of the intensification of the drying process of thyme leaves in fixed beds, the effect of the convective drying under conditions of constant operation in regard the drying kinetics and the antioxidant capacity of the dried thyme leaves extracts were analyzed as a starting point.

For the study of the drying kinetics, drying experiences were performed at different temperature $\left(40,50,60,70 \stackrel{\circ}{\circ}\right.$ ) per $1 \mathrm{~m} \mathrm{~s}^{-1}$. In order to describe the evolution of the moisture as a function of time and analyzing the effect of temperature and velocity, empirical models were used. A theoretical model of infinite sheet based upon the particular Fick law and an empirical model "blackbox" of neural network.

The drying rate showed a direct relation with the magnitude of the applied drying temperature. From the proposed theoretical model, was determined that the effective diffusivity $\left(D / L^{2}\right)$ is between $3.68 \times 10^{-5}$ and $2.12 \times 10^{-4} \mathrm{~s}^{-1}$, and the dependency of the diffusivity and the drying temperature was represented by the Arrhenius equation with an activation energy equal to $49.42 \mathrm{~kJ} \mathrm{~mol}^{-1}$. The goodness of fit of the theoretical model was not satisfactory, which is attributed to the hypothesis considered for the model development. Based on these results and for a later study it is necessary to develop a diffusional theoretical model that considers internal and external resistance to heat and mass transfer simultaneously.

The proposed empirical models were fitted to the experimental data; additionally, the dependency of each model's parameters to the drying temperature was determined from a polynomial relationship. This allowed estimating the evolution of the humidity contents at any temperature within the time interval established. Furthermore, a comparison of the goodness of fit from the models used was made using the percentage of relative errors (ER) and the explained variance (VAR). The neural network developed showed to be more accurate than the models tested to predict the evolution of humidity with VAR $>99.3 \%$ and an ER < $8.7 \%$. From these results it can be concluded that the models developed through neural network may be considered of special interest in the formulation and resolution of optimization problems on-line as well as the predictive process control.

The effect of operating conditions regarding the antioxidant capacity (AC) were studied at temperatures $\left(40,50,60,70,80^{\circ} \mathrm{C}\right.$ ) and a velocity of drying air ( 1 and $\left.2 \mathrm{~m} \mathrm{~s}^{-1}\right)$. The essential oil was extracted from the dried samples by means of the technique of extraction by $\mathrm{CO}_{2}$ supercritical to $35 \times 10^{3} \mathrm{kPa}, 35 \stackrel{\circ}{\circ} \mathrm{C}$. From the obtained samples, AC was determined by the Ferric Reducing Activity Power 
(FRAP) method. From the AC and the experimental values of the drying kinetics measures, an optimization problem was formulated to determine the operating conditions that would maximize the AC of the dried thyme extracts. In order to formulate the optimization problem, the drying temperature $(T)$, drying air velocity $(\mathrm{V})$ and the drying time ( $\mathrm{t}$ ) were considered as decision variables, and the antioxidant capacity of the dried thyme extracts were defined as the objective function. Due to the complexity involved in the development of theoretical models, and since there are no references of models to predict the evolution of the product AC in terms of the operating conditions, a neural network model (ANN) was developed for this purpose. The restrictions that limit the search region of the decision variables were determined from the experimental values of the drying conditions and the results from the process. The $V$ and $T$ limits can be established directly, and the restriction of drying time ( $t$ ) is fixed indirectly by the values of the remaining operating conditions and the desired final moisture $\left(\mathrm{W}_{\mathrm{f}}\right)$. To estimate the final moisture content of the dry product in terms of the operating conditions, an ANN was developed. The ANNs were developed considering multiple architecture, forward feeding and a retro-propagation learning process.

The AC values from the dried product extracts varied between 21.0 and 107.2 [Trolox] (mmol/L). The AC was significantly increased when the temperature and the velocity of the air increased; however, the AC decreased for air temperatures above $70 \stackrel{\circ}{\circ}$ at $2 \mathrm{~m} \mathrm{~s}^{-1}$, which may be due to the degradation of some compounds with antioxidant capacity.

The developed ANNs showed good accuracy between the experimental values and the ones calculated with a correlation coefficient greater than 0.993 and a relative error less than $3.06 \%$.

The optimization problem was solved for different experimental cases, and the AC result calculated at the optimal conditions obtained by the developed tool increased between $4.9 \%$ and $360.4 \%$ according to different cases considered. Additionally, the developed tool was validated obtaining differences between the calculated values and the experimental values of the AC between 2 and $7 \%$. From these results, it should be noted that to maximize dried thyme $A C$, an optimal management of the process should be performed.

\section{Convective Drying assisted by power ultrasounds}

Intensifying the effect of convective drying by application of high intensity ultrasound may be a way of improving traditional convective drying. Therefore, the main objective of this study was to evaluate the influence of high intensity ultrasound in transfer phenomena during convective drying on a high porosity bed of non-porous materials, such as leaves of thyme, and assessing the antioxidant capacity of the extracts of the dried leaves.

To study the effect of ultrasound on transfer phenomena, drying experiments were conducted at 1,2 , and $3 \mathrm{~m} \mathrm{~s}^{-1}$ and different temperatures of the air $(40,50$, 60,70 , and $\left.80 \pm 1.2^{\circ} \mathrm{C}\right)$, and to different acoustical density level $(0,6.2,12.3$, $18.5 \mathrm{~kW} \mathrm{~m}^{-3}$ ). In order to establish the effect of ultrasounds over the drying kinetics, a theoretical diffusional model was developed, considering mass and 
heat transfer phenomena simultaneously, in both the bed and thyme leaves, internal and external resistance to the transport processes with boundary conditions variable with time. The model consisting of a system of partial differential equations is solved using the finite element numerical method.

From the results of the drying kinetics, it was observed that the drying rate increased with the velocity and temperature of the air and the ultrasound power applied increased. The effect of ultrasound was observed at air temperatures below $70 \stackrel{\circ}{\circ}$. The effect of ultrasound on intensified drying kinetics was also influenced by the velocity of air: the higher the air velocity, the effect of ultrasound was lower.

The diffusional model with boundary conditions variable with time allowed us understand better the transport mechanisms that occur during the drying process. The developed model showed a good adjustment between the experimental values and the calculated ones (VAR $\geq 99.4 \%$; ER $\leq 4.9 \%$ ); this allowed us identify the effective diffusivity $\left(D / L^{2}\right)$, the transfer coefficient of mass $\left(h_{m v}\right)$, and the transfer coefficient of heat $(h)$. From the analysis of the identified parameters, it was observed that these were affected by the temperature of the air, velocity of the air and the ultrasounds.

From the analysis of the parameter variation $D / L^{2}$ as a function of the operating conditions, the effects of these conditions over the internal resistance to the mass transfer were determined. The effect of the velocity of the air affects the external resistance. The effect of the temperature was observed on $D / L^{2}$ that increased when the temperature increased which means that the internal resistance to the mass transfer decreased as the temperature increased. The effect of the ultrasounds on $D / L^{2}$ was only observed for temperatures lower or equal to $60{ }^{\circ} \mathrm{C}$.

In regard the value of the parameters $h_{m v}$ and $h$, a more marked effect in the application of ultrasounds was observed compared to the $D / L^{2}$ values. This behavior may be related to the effects of the acoustical energy incurred on the bed. The bed, which is very porous, allows the ultrasounds to penetrate and affects the external resistance on the leaves. The thyme leave, being a slightly porous material with small intercellular spaces characteristic of this product, makes it less prone to the influence of ultrasounds, so that the effect on the internal resistance was lower.

The effect of the air velocity is linked to the external resistance, the mass transfer coefficient increased as the air velocity increased. The external resistance to mass transfer was significantly affected by the application of ultrasonic energy, but US have a greater effect at low air velocity and remained negligible at a velocity of $3 \mathrm{~m} \mathrm{~s}-1$. This suggests that the external resistance is more influenced by ultrasounds at low air velocity, not only due to the larger thickness of the boundary layer at low air velocity but also due to the disturbance of the ultrasonic field presented at high air velocities.

The parameters $h_{m v}$, and $h$ related to the external resistances increased as the temperature increased, thus the resistances to mass and heat transfer decreased 
as the temperature increased. The mass and heat transfer coefficients increased in function of the intensity of the ultrasounds applied, but this effect was only observed when the air temperature was less than $70^{\circ} \mathrm{C}$. Therefore, the influence of ultrasounds decreased as the temperature increased.

The effect of the ultrasounds application on the antioxidant capacity of the dried leaves extracts was analyzed. For that purpose the essential oil was extracted by a supercritical fluid extraction method, and the antioxidant capacity of the extracts was measured by means of the Ferric Reducing Activity Power (FRAP).

From the experimental conditions and the results obtained, an optimization problem to determine the operating conditions that maximized the AC of dried thyme extracts (objective function) was formulated. As decision variables the controllable operating conditions were considered: temperature of the drying air $(\mathrm{T})$, the velocity of the drying air $\left(\mathrm{V}_{\mathrm{H}}\right)$, ultrasonic power and drying time (t). The restrictions of the decision variables were established from the experimental values of the operating conditions and results of drying experiments. To quantify the objective function in terms of the operating conditions considered as decision variables, a mathematical model was developed. Due to the complexity involved in the development of theoretical models to predict the evolution of antioxidant capacity during drying thyme process and to avoid long calculations for management applications in real time, a neural network (ANN) was developed for this purpose.

In addition, it was analyzed the influence of the ultrasound (US) on the drying rate $\left(\mathrm{r}_{\mathrm{d}}\right)$, this was calculated from the experimental values of the evolution of the moisture content. The drying rate increased with temperature and velocity of the air; therefore, the drying time is reduced to achieve the desired final moisture content. The effect of power ultrasounds on the $r_{d}$ was observed at drying temperatures between 40 and $60^{\circ} \mathrm{C}$ and an air velocity between 1 and $2 \mathrm{~m} \mathrm{~s}^{-1}$. For air temperatures above $60^{\circ} \mathrm{C}$, at a drying air velocity of $3 \mathrm{~m} \mathrm{~s}^{-1}$ and the application of US did not increase the $r_{d}$; therefore, the influence of the US under these operating conditions was negligible. The fact that US does not influence drying rate at an air velocity of $3 \mathrm{~m} \mathrm{~s}^{-1}$ is attributed to the perturbation of the acoustic field.

From the AC measurements, it was observed that, in general, it increased significantly in terms of the magnitude of the operating conditions applied in the drying process. The AC values are greater for drying samples at $2 \mathrm{~m} \mathrm{~s}^{-1}$ than at 1 $\mathrm{m} \mathrm{s}^{-1}$, which decreases in samples dried at $3 \mathrm{~m} \mathrm{~s}^{-1}$. This may be due to a greater surface heating. The effect of temperature on the AC shows a direct relationship; however, at $2 \mathrm{~m} \mathrm{~s}^{-1}$ and with drying temperatures above $70^{\circ} \mathrm{C}$, the $\mathrm{AC}$ decreased. This may be caused by the degradation of the essential oil. The US effect on the drying kinetics was observed at air velocities between 1 and $2 \mathrm{~m} \mathrm{~s}^{-1}$ at temperatures lower or equal to $60^{\circ} \mathrm{C}$; for temperatures over $60^{\circ} \mathrm{C}$ and drying air velocities $3 \mathrm{~m} \mathrm{~s}^{-1}$ the US effect was negligible, impacting indirectly on the variation of $A C$. 
The AC variation in this study may be attributed mainly to the effect of temperature, air velocity and ultrasound on the drying kinetics, and therefore, the degradation and formation of the phenolic compounds with antioxidant capacity.

The management tool developed to determine optimal operating conditions based on the initial conditions of the sample and environmental conditions, proved to be very useful. It allowed establishing the values of the operating conditions in order to maximize the AC. To test the reliability of the management tool developed three validation experiments were carried out with different moisture content of the samples. The AC of dried thyme extracts was measured and compared with the calculated results showed a difference between 3.3 and $4.5 \%$.

\section{Intermittent drying controlled by the temperature of the sample surface}

Selecting an appropriate drying method, good management of the process and development of a suitable mathematical model for determining the optimum operating conditions are essential to obtain products of high quality at a low cost, with a maximum yield.

As a management procedure, the application of a drying strategy with variable temperature profile during the process may be considered. This approach can result in reduced drying time and preservation of compounds with antioxidant capacity. The purpose of this particular study was to implement a drying strategy based on two consecutive drying periods that would allow to manage the process in order to reduce drying time and increase the antioxidant capacity of the extracts of dried leaves (AC). To do this, the influence of the air velocity, air temperature and drying strategy proposed on drying kinetics and on the AC were examined.

From the literature, it was found that $70{ }^{\circ} \mathrm{C}$ was the best drying temperature which favors the appearence of compounds with antioxidant capacity, and temperatures above this cause excessive damage to the structure of the material and loss of essential oil. Based on these considerations, a drying strategy was established consisting of applying two consecutive periods of drying. During the first drying period the product is subjected to a temperature of $80^{\circ} \mathrm{C}$ for a given time, preventing that the leaf surface exceeds $70^{\circ} \mathrm{C}$. In the second drying period, the product is subjected to a lower air temperature $(40,50,60,70 \stackrel{\circ}{\circ})$ until a desired final moisture content is reached. Applying the first drying period of high temperature may reduce the total drying time $(t)$ compared to processes in which the heat supply is continuous, and therefore, it can improve energy efficiency.

To prevent damage or degradation of the compounds of interest from exposure to excessive temperatures of $80^{\circ} \mathrm{C}$, it was necessary to set the exposure time at 80 ${ }^{\circ} \mathrm{C}$ for the time in which the surface of the sample reaches a temperature of $68{ }^{\circ} \mathrm{C}$ $\pm 2{ }^{\circ} \mathrm{C}$. Given the difficulty of experimental measurement of the surface temperature of the leaves during the drying process, the evolution of this temperature was determined using a diffusion model considering internal and 
external resistances. The model developed considered heat and matter transfer phenomena in the bed and thyme leaves simultaneously.

From the drying process model it is established an exposure time at $80^{\circ} \mathrm{C}$ so that the surface of the sample may reach a temperature of $68^{\circ} \mathrm{C}$. For the drying process at $80^{\circ} \mathrm{C}$ and air velocities 1 and $2 \mathrm{~m} \mathrm{~s}-1$ no significant differences in the evolution of the surface temperature were found. Therefore, the exposure time to the surface of the sample to reach a temperature of about $68^{\circ} \mathrm{C}$ was $600 \mathrm{~s}$.

To extend the application to other temperatures, corroborate the results for other drying temperatures, and test the accuracy of the model developed, the drying strategy considered was performed in two consecutive drying periods: the first drying period was $80{ }^{\circ} \mathrm{C}$ for $300 \mathrm{~s}\left(T_{a 11}\right)$ or $600 \mathrm{~s}\left(T_{a 12}\right)$, and the second drying period $\left(40,50,60\right.$ and $\left.70{ }^{\circ} \mathrm{C}\left(T_{a 2}\right)\right)$ was immediately developed until the final moisture content was lower than $10 \%$ (d.b.) at 1 and $2 \mathrm{~m} \mathrm{~s}^{-1}$. These strategy results of drying experiment were compared with the air drying at a constant temperature $\left(40,50,60\right.$, and $\left.70^{\circ} \mathrm{C}\right)$.

As expected, increasing the time of the first drying period increased drying kinetics. Therefore, the total drying time was reduced between 7.9 and $39.2 \%$, compared to experiences of drying at a constant air temperature. The model developed was fitted to the experimental results, showing good accuracy (VAR $\geq$ 99.7\%; ER $\leq 5.9 \%$ ). The mathematical model allowed identifying parameters related to the processes of internal and external transport. From the analysis of the identified parameters, it was concluded that the mechanisms of heat and mass transfer involved in drying thyme leaves were significantly affected by the velocity and air temperature. These results allowed explaining the behavior of the drying kinetics obtained by applying two consecutive drying periods.

AC values showed a variation between $39.9 \pm 0.6$ and $114.1 \pm 1.6 \mathrm{mmol} /$ LTrolox. The implementation of the first drying period allowed AC increase between 4.7 to $27.4 \%$ compared to the values obtained under constant drying conditions. However, at a constant air temperature of $80{ }^{\circ} \mathrm{C}$, there was a decrease in the $A C$, which may be due to degradation of the compound with antioxidant capacity and changes in their structure. Based on these results, it appears that the increased antioxidant activity observed when applying two consecutive drying periods is probably due to the particular composition of these essential oils, and the effect of time/temperature of the first period drying over its main components, allowing the rapid formation of compounds with antioxidant properties.

Therefore, through this drying strategy time could be shortened so that the leaf surface temperature reaches $70{ }^{\circ} \mathrm{C}$, allowing to increase the amount of compounds with antioxidant capacity and to reduce the total drying time, which is related to energy consumption and productivity.

It can be concluded that the use of power ultrasound and the intermittent drying strategy considered allowed intensifying the drying process reducing the drying time and increasing the antioxidant capacity of the extracts of dried thyme. These 
contributes to increase efficiency, productivity and to reduce energy consumption compared to constant temperature processes.

From the results obtained through each drying methodology it is worth to notice that to maximize the $A C$ of dried thyme it is necessary to carry out an adequate process management, establishing the optimal operating conditions for each particular case. 


\section{INTRODUCCIÓN}



El secado por aire caliente es un método de conservación muy utilizado en la transformación de productos agroalimentarios. Debido al alto contenido de agua que contienen los productos de origen vegetal y animal, el proceso de secado permite eliminar parte del agua contenida y poder alargar su vida útil para su posterior utilización.

A pesar de ser un método ampliamente utilizado, todavía presenta algunas limitaciones que afectan a la calidad de los productos y al consumo de energía. El deterioro de la calidad se corresponde con cambios en las propiedades bioquímicas de los productos secos, provocando el deterioro de los compuestos aromáticos (Timoumi et al., 2007), la degradación de las sustancias nutritivas (Santos \& Silva, 2009), reacción de pardeamiento y pérdida de color (Suvarnakuta et al., 2005), entre otras.

La introducción de nuevas tecnologías de secado podría conducir a una reducción del tiempo de procesamiento, mejorando tanto la eficiencia energetica en las operaciones de secado y la calidad de los productos secos (Chou \& Chua, 2001).

Existe una tendencia del consumidor moderno en la valoración de la calidad nutritiva o funcional de los productos alimentarios. Esto ha permitido que nuevas investigaciones se centren en el estudio del efecto las condiciones de operación sobre la calidad final de las materias primas de origen vegetal (raíces, bulbos, hojas, tallos, cortezas, maderas, flores, frutos y semillas), por su notable contribución en cuanto a valor energético, minerales, vitaminas y compuestos funcionales (Garau, 2008; Sablani, 2006).

Entre los productos de origen vegetal que aportan compuesto bioactivos de interés para la industria alimentaria y farmacéutica, se puede mencionar el tomillo, cuyo aporte de compuestos bioactivos con capacidad antioxidante 0 actividad antimicrobiana puede ser afectado durante el proceso de secado (Venskutonis, 1997).

Por lo tanto, resultaría interesante estudiar la aplicación de diferentes tecnologías en el secado convectivo que permitiera intensificar el proceso y resultara favorable para la calidad final del producto seco.

\subsection{SECADO POR AIRE CALIENTE}

\subsubsection{Generalidades}

El secado es uno de los procesos de conservación más antiguos y comunes, ocupando un importante lugar en la transformación de productos agroalimentarios. La disminución del contenido de agua en los alimentos reduce la susceptibilidad al deterioro de los mismos, convirtiéndolos en productos más estables. Por otra 
parte, los procesos de deshidratación se pueden considerar también como etapas previas y necesarias en el procesado de algunos alimentos; por ejemplo, la reducción del contenido de agua de la materia prima resulta esencial antes de ciertos procesos de extracción (Mulet et al., 2005).

El secado por aire caliente es unas de las actividades industriales que generan mayor consumo energético y, por ende, un impacto ambiental considerable, al mismo tiempo que influye sobre importantes parámetros de calidad nutricional y organoléptica.

Persiguiendo el objetivo de reducción del impacto medioambiental de los procesos y mejorar los parámetros de calidad de los productos deshidratados, tanto la utilización de pre-tratamientos como de fuentes adicionales de energía constituyen alternativas interesantes para aumentar la velocidad del proceso sin incrementar la carga medioambiental del mismo (Mulet et al., 2003; Walde et al., 2006).

\subsubsection{Fundamentos del secado por aire caliente}

Generalmente se define como la operación mediante la cual se elimina total o parcialmente el agua de los materiales, haciendo circular aire caliente sobre la superficie de un material húmedo.

Durante el secado ocurren dos procesos simultáneos, una transferencia de calor hacia el sólido y una transferencia de materia (agua) desde el sólido al fluido secante que determinan la velocidad de la operación (Hallström et al., 2007; Mujumdar, 2006).

La transferencia de calor desde el medio ambiente circundante hacia el sólido puede ocurrir por convección, conducción, radiación o como resultado de una combinación de estos mecanismos. Tales mecanismos suministran calor a la superficie del objeto que está siendo secado, de forma tal que el calor luego se difunde dentro del sólido esencialmente por conducción. En algunos casos, el calor es también suministrado de forma volumétrica mediante microondas o campos electromagnéticos de radio frecuencia.

La eliminación de agua en forma de vapor desde la superficie del material depende fundamentalmente de las condiciones externas de temperatura, humedad, velocidad y dirección del flujo de aire caliente, así como de la geometría del sólido. La evaporación es controlada por la difusión de vapor desde la superficie del sólido hacia el aire que lo circunda. El contacto entre el aire y el agua líquida proveniente de la matriz sólida involucra fenómenos de transporte interfacial, donde tienen especial consideración las características higroscópicas del material, los coeficientes de transferencia por convección y las propiedades termodinámicas de la mezcla aire-vapor (Váquiro, 2009).

El transporte de humedad desde el interior hacia la superficie del sólido se desarrolla fundamentalmente a través de uno 0 varios de los siguientes 
mecanismos: difusión líquida (si el líquido se evapora en la superficie del material), difusión de vapor (si el líquido se evapora dentro del material) y diferencias de presión hidrostática (por tensión interna debido al encogimiento del material). Los mecanismos de transferencia de humedad interna pueden variar durante el secado ya que son función de la estructura física, temperatura y humedad del material (Garau, 2008; García- Pérez, 2007a).

\subsubsection{Etapas de proceso}

El secado convectivo de productos alimentarios presenta un comportamiento típico caracterizado por la pérdida de humedad en función del tiempo. Estas representaciones son denominadas curvas de secado, permitiendo distinguir los mecanismos de secado predominantes. La clasificación se realiza en función de la variación de la velocidad de secado y se pueden distinguir tres periodos de velocidad de secado (Figura 1.1):

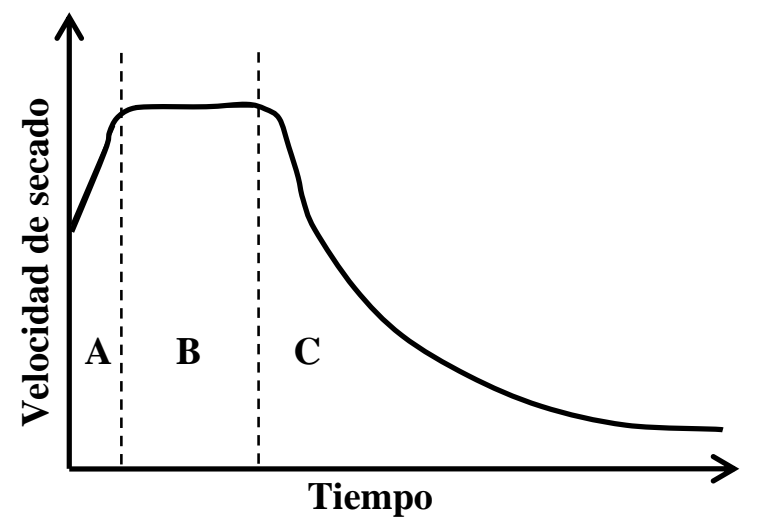

Figura 1.1. Curva de secado típica.

A. Periodo de inducción o de velocidad de secado creciente: en esta etapa se inicia el proceso de secado de manera que el producto se calienta y aumenta la temperatura de la interfase, produciéndose una adaptación del material a las condiciones de secado. La duración de este periodo es función del contenido inicial de humedad del sólido, de su temperatura y de la velocidad del aire.

B. Periodo de velocidad de secado constante: la velocidad con que se elimina agua de la superficie del sólido es igual que la velocidad con que llega a ella desde el interior del mismo. De esta manera, la superficie del material se mantiene saturada y se comporta como una masa de líquido. De aquí que la velocidad de secado sea igual a la velocidad de evaporación del agua, que será a su vez proporcional a la velocidad de flujo de calor que llega desde el aire al sólido. En tales condiciones, la temperatura de la interfase permanece 
constante y el calor que llega al sólido se invierte totalmente en evaporar el líquido.

C. Periodo de velocidad de secado decreciente: la humedad del producto sigue disminuyendo hasta alcanzar la humedad de equilibrio. En este periodo la velocidad del proceso depende principalmente de la estructura interna del sólido y de los mecanismos de migración de humedad.

\subsubsection{Aspectos relacionados con la calidad de los alimentos}

La calidad, en términos generales, es un concepto abstracto, de difícil definición, donde el consumidor se constituye como el principal elemento para su evaluación. Para el consumidor, algunos de los atributos fundamentales de la calidad de cualquier alimento son la ausencia de defectos, la textura, el aroma, el valor nutritivo y el aspecto, que incluye tamaño, color y forma (Jarén, 2005).

En el secado se producen cambios físicos y químicos que influyen en la calidad final; muchos de estos cambios son función de la temperatura, contenido de humedad y el tiempo de secado. Entre los cambios físicos se puede mencionar el encogimiento, la cristalización y la transición vítrea. En muchos casos también pueden ocurrir reacciones químicas o bioquímicas deseables o indeseables, que conducen a cambios en el color, la textura, el aroma-olor $u$ otras propiedades del producto, por lo que la producción de cualquier alimento deshidratado no sólo pasa por optimizar la operación en sí, en términos de volumen de producción o coste, sino que además es requisito fundamental ofrecer productos que satisfagan las necesidades y requerimientos del consumidor (Jayaraman \& Das Gupta, 2006).

Para el desarrollo de productos deshidratados de calidad se presentan como alternativas la utilización de tecnologías de secado novedosas, la selección apropiada de métodos de secado y la optimización de las condiciones de secado con el fin de maximizar los atributos de calidad ( Garau, 2008; Perera, 2005 y Sablani, 2006).

De este modo, la consideración de los criterios de calidad en el estudio de la cinética del proceso, por ejemplo vía modelización y optimización computacional, permite el establecimiento de condiciones de operación que favorecen la calidad del producto, tanto en el diseño de nuevos equipos, como en la mejora de los existentes (Raghavan \& Orsat, 2006). Así, los efectos indeseables podrían ser mejor controlados si las distribuciones de temperatura y humedad en los alimentos durante el secado se pudieran predecir con precisión.

\subsubsection{Modelización del proceso}

La modelización matemática y simulación de los procesos de secado en productos agroalimentarios, constituye una herramienta básica en los nuevos sistemas de producción. Resulta útil principalmente en la predicción de propiedades y en el 
estudio del comportamiento en función de las condiciones de operación (Bon, 1998).

La modelización se basa en construcciones abstractas, los modelos, que son sólo aproximaciones de la realidad (debido a la complejidad de los fenómenos involucrados) por medio de sistemas de ecuaciones y construcciones lógicomatemáticas que describen las diferentes leyes y teorías. Se puede decir que tanto la simulación como otras herramientas para el análisis y control de procesos se desarrollan con la ayuda de las representaciones matemáticas simplificadas del sistema real ofrecidas por los modelos.

Para optimizar el funcionamiento de un proceso agroalimentario, se requiere el desarrollo de modelos matemáticos para simular el proceso y poder formular y establecer las condiciones de operación (Váquiro, 2009).

La modelización de procesos se hace especialmente difícil cuando se trabaja con productos biológicos, dado su carácter heterogéneo, complejo y delicado (Chou \& Chua, 2001). En términos matemáticos, todos los procesos involucrados, aún en el secadero más simple, son altamente no lineales y por consiguiente el desarrollo de modelos representa cierta complejidad.

Los modelos de secado se pueden dividir en tres grandes grupos: (a) los relacionados con ecuaciones empíricas (sin ningún tipo de fundamento físico), válidas para procesos específicos; los modelos empíricos no buscan explicar el proceso, su único objetivo es su descripción y la identificación de las variables más relevantes (Mulet, 1994); (b) los desarrollados a partir de los principios físicos, por ejemplo los que se basan en modelos difusivos de materia y calor que forman sistemas de ecuaciones simultáneas; (c) los que conforman un grupo de modelos más exhaustivos que están asociados a la energía, materia y ecuaciones termodinámicas interactivas de transporte con todos los flujos (Hayakawa \& Furuta, 1988).

\subsubsection{Formulación del modelo}

El conjunto de consideraciones asumidas en la formulación del modelo matemático determinan el grado de complejidad requerido para su resolución. Adicionalmente, dependiendo de tipo de modelo que se vaya a emplear (empírico y/o teórico) para la representación de un proceso de secado convectivo, se pueden destacar algunos aspectos:

- Modelo empírico: son obtenidos a través del análisis matemático o estadístico de los datos del proceso, razón por la cual su sentido físico no es fácil de establecer.

- Modelo teórico: se establecen las ecuaciones de balance que representan las leyes naturales de conservación, usualmente escritas en términos de transferencia de materia y calor. Los modelos teóricos están constituidos por 
las siguientes ecuaciones: (i) Ecuaciones constitutivas, también denominadas ecuaciones cinéticas, que expresan los flujos del sistema con las correspondientes fuerzas impulsoras. Dentro de las más importantes se encuentran las leyes particulares de Fick y Fourier, para la definición de los mecanismos de transferencia difusionales de materia y calor, respectivamente. (ii) Relaciones de equilibrio, necesarias en la descripción de los fenómenos interfaciales que ocurren en el sistema, esencialmente aquellos que tienen lugar en la interfase sólido-aire. (iii) Propiedades físicas, inherentes al material que se seca o al aire de secado, las cuales se requieren para la solución del modelo y deben de ser identificadas de forma experimental o estimadas mediante modelos predictivos (Váquiro, 2009).

\subsection{Modelos empíricos}

Dada la complejidad de la modelización de los fenómenos de transporte en el proceso de secado, se hace uso de los modelos empíricos que no se basan en ningún fundamento físico, pero establecen una directa relación entre el contenido medio de humedad del producto y el tiempo de secado.

Las ecuaciones propuestas por estos modelos no consideran normalmente los fundamentos del proceso de secado y suelen incluir parámetros cuyo sentido físico no es fácil de establecer, por lo que no ofrecen una visión precisa de los fenómenos que tienen lugar, aunque pueden describir las curvas de secado obtenidas bajo ciertas condiciones de secado con bastante rigurosidad. Uno de los modelos más simples es el conocido como modelo exponencial descrito por la Ec.1.1, en la que $\mathrm{K}$ es una constante de velocidad (Kajuna et al., 2001; Simal et al., 2005), $\tau_{e q}$ es el contenido humedad en equilibrio; $\tau_{0}$ contenido de humedad inicial; $\tau$ es el contenido de humedad; $\omega$ es el contenido de humedad adimensional y t es el tiempo.

$$
\omega=\frac{\tau-\tau_{e q}}{\tau_{0}-\tau_{e q}}=\exp (-\mathrm{Kt})
$$

Este modelo asume que la resistencia externa es despreciable. Usualmente, este modelo no permite una simulación precisa de las curvas de secado de muchos alimentos, ya que subestima el comienzo de la curva de secado y sobrestima las etapas posteriores (Simal et al., 2005).

Varias investigaciones se han realizado para analizar la cinética de secado de diversos productos agrícolas con el fin de determinar los mejores modelos matemáticos que describan el secado de alimentos considerando que se comportan como una capa fina. Entre las diferentes investigaciones se puede destacar: Ozcan et al., (2005); Roberts et al., (2008); Ghodake et al., (2006); Karathanos (1999); Xanthopoulos et al., (2007); Wang et al., (2007); Yaldiz \& Ertekin (2001); Akpinar (2006); Demir et al., (2007); Arslan \& Ozcan (2008); Sharma \& Prasad (2004); Doymaz (2011). En la tabla 1.1 se resumen los modelos 
empíricos utilizados ampliamente para describir las cinéticas del proceso de secado de alimentos.

Otra alternativa para la modelización de procesos de secado es el uso de modelos de redes neuronales. Este tipo de modelos son considerados como modelos empíricos, ya que pueden relacionar matemáticamente variables independientes con las variables dependientes sin identificar una relación causal.

Tabla 1.1. Modelos empíricos.

\begin{tabular}{ll}
\hline Nombre del modelo & Expresión \\
\hline Newton & $\omega=\exp (-b t)$ \\
\hline Henderson and Pabis & $\omega=a \exp \left(-b_{H} t\right)$ \\
\hline Page & $\omega=\exp \left(-b_{P} t^{c}\right)$ \\
\hline Logarithmic & $\omega=a_{L} \exp \left(-b_{L} t\right)+c_{L}$ \\
\hline Two-term exponential & $\omega=a_{T e} \exp \left(-b_{T e} t\right)+\left(1-a_{T e}\right) \exp \left(-b_{T e} a_{T e} t\right)$ \\
\hline Wang and Singh & $\omega=1+a_{W} t+b_{W} t^{2}$ \\
\hline Parabolic & $\omega=a_{P b}+b_{P b} t+c_{P b} t^{2}$ \\
\hline
\end{tabular}

\subsection{Modelo de redes neuronales (ANN)}

Las redes neuronales son una generación de paradigmas para el procesamiento de la información, están diseñadas para imitar algunos de los comportamientos del cerebro humano (Baş \& Boyaci, 2007), y cuya principal ventaja es el hecho que pueden simular la relación no lineal entre las variables de entrada y salida, a través de un proceso de aprendizaje, sin la necesidad de modelos teóricos y empíricos.

El secado de alimentos es un sistema complejo, debido a las interacciones que tienen lugar entre los distintos componentes. Esto hace más difícil desarrollar modelos matemáticos que describan estos procesos, ya que en principio, es necesario comprender los principales mecanismos implicados en el proceso. Adicionalmente, los modelos matemáticos desarrollados resultan de una elevada complejidad y requieren de un largo tiempo de cálculo para su solución.

Pese a las crítica de que las ANN no se basan en fundamentos y/o leyes particulares, son una herramienta eficaz para el desarrollo de modelos matemáticos de procesos relativamente complejos, principalmente debido a su capacidad de aprendizaje (Zhou \& Therdthai, 2010). Son técnicas no paramétricas muy utilizadas en diversos ámbitos de la ciencia e ingeniería, porque permiten resolver problemas complejos, que muchas veces no son fáciles de resolver utilizando técnicas tradicionales. 
Las redes neuronales permiten obtener un modelo no explícito que relaciona un conjunto de variables salida con un conjunto de variables entrada. Así, estos modelos permiten predecir cuál es el valor de salida, dados unos valores de entrada del modelo. Para estimar el modelo es necesario disponer de un conjunto de observaciones de las variables. Estas observaciones son usadas como patrones de entrenamiento para que la red aprenda y sea capaz de predecir una salida del modelo, ante nuevas observaciones. Por tanto, las capacidades de la red van a depender en gran medida de esta fase de entrenamiento. En la fase de entrenamiento es necesario controlar muchos parámetros y distintos algoritmos de optimización, por lo que el usuario de una red neuronal debe tener conocimiento suficiente de cuáles son estos parámetros y cómo funcionan. Por otro lado, una vez entrenada la red, es muy importante también evaluar la robustez del modelo creado, comprobando que es adecuado para nuevos datos.

En las últimas cuatro décadas se han reportado una serie de estudios de ANN, y en la última década las redes neuronales han sido mejoradas y ampliamente utilizadas por los investigadores, lo que ha permitido el desarrollo de diferentes aplicaciones (Fang et al., 2007; Parlak, et al., 2006). Entre ellos se pueden encontrar varias aplicaciones para el procesamiento de alimentos, tales como: control de calidad (Bucinski et al., 2004.), secado (Tripathy, et al., 2009; Erenturk \& Erenturk, 2007) y tratamientos térmicos (Lu et al., 2010).

\section{Principios de una ANN}

Una red neuronal artificial (ANN) es un modelo matemático computacional inspirado en una estructura de sistemas biológicos neuronales. La Figura 1.2 muestra una red neuronal típica formada por la interconexión de los nodos (cada nodo constituye una neurona). Esta red neuronal tiene una capa de entrada (Input), dos capa oculta (Hidden layers, normalmente de 1 a 3 ), y una capa de salida (Output). La ANN tiene la capacidad de relacionar todas las variables de entrada con las variables de salida

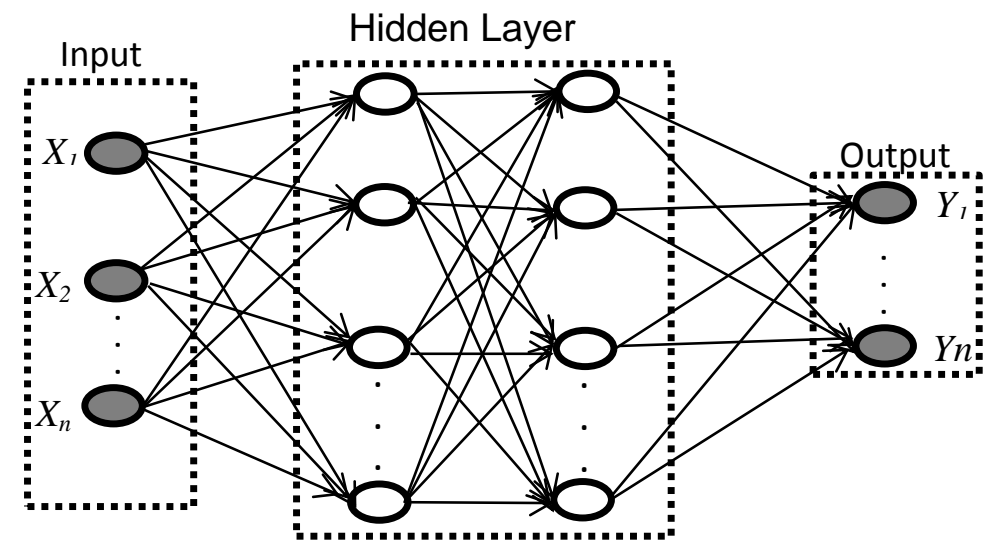

Figura 1.2. Esquema de la arquitectura de una ANN 
La salida de cada neurona se propaga por igual por estas conexiones hasta las neuronas de destino. Cada conexión tiene un peso asociado que pondera el valor numérico de la señal que viaja por ésta. Así pues, una red de neuronas artificial puede verse como un grafo cuyos nodos tienen funcionamiento similar, los cuales propagan la información a través de las distintas conexiones.

El funcionamiento de una neurona se puede describir en la figura 1.3. La neurona $j$ recibe una serie de entradas $\left(X_{1}, X_{2}, X_{3} \ldots, X_{n}\right)$. Cada señal se multiplica por el peso asociado a su conexión, $\left(W_{l}, W_{2}, \ldots, W_{n}\right)$. Se suman estas entradas ponderadas y se les aplica la función de transferencia para generar la señal de salida de la neurona $j$. Los valores de los pesos y las bias (valores de los umbrales de cada una de las neuronas) son ajustados durante la fase de aprendizaje.

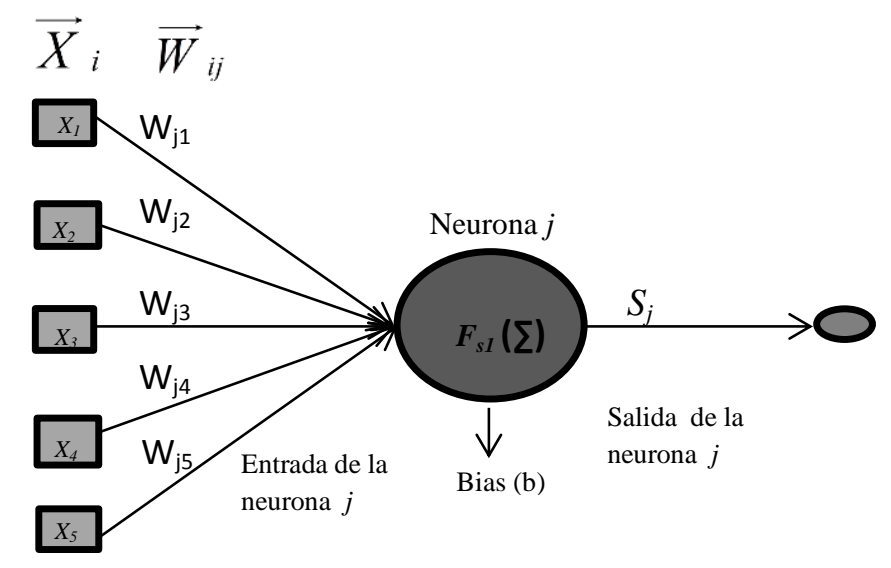

Figura 1.3. Esquema de funcionamiento de una neurona

En la figura $1.3 \overrightarrow{X_{l}}$ es el vector de entradas a la capa oculta y $\overrightarrow{W_{j l}}$ el vector de pesos correspondientes a las conexiones que van de todas las neuronas de la capa de entrada a la neurona $j$. La función $F_{s l}$ es la función de transferencia de la neurona $j$. Estas salidas $\left(S_{j}\right)$ son propagadas a las neuronas de la capa de salida las cuales generan las salidas de la red $\left(S_{i}\right) . b$ es el vector de los valores de las bias.

$$
\overrightarrow{S_{j}}=F_{s 1}\left(\overrightarrow{W_{j i}} \overrightarrow{X_{i}}\right)+\vec{b}
$$

Por último, cabría destacar el aspecto más importante y delicado de las ANN, que es el aprendizaje. Las ANN son sistemas de aprendizaje basadas en datos que son utilizados como patrones. Por ello la capacidad de una red de resolver un problema está muy ligada a los patrones utilizados durante su fase de aprendizaje.

El aprendizaje de una red neuronal consiste en hallar los valores precisos de los pesos de sus conexiones y bias, para que se minimicen los errores entre los valores experimentales y los calculados de las variables de salida. El proceso general consiste en ir introduciendo una serie de datos patrón y ajustar los pesos y bias siguiendo un determinado criterio. Unos de los criterios utilizados se 
fundamentan en el error cometido por la red, lo que obliga a conocer la salida que se debería obtener para cada uno de ellos. Es lo que se conoce como entrenamiento supervisado. De esta manera, primero se introducen los patrones, se reajustan los pesos y las bias, y posteriormente se comprueba si se ha cumplido un determinado criterio de convergencia; de no ser así se repite todo el proceso.

\section{Arquitectura de ANN}

\section{Redes perceptron multicapa}

La arquitectura del Perceptron, llamada mapeo de patrones (pattern-mapping), aprende a clasificar modelos mediante un aprendizaje supervisado. Los modelos que clasifica suelen ser generalmente vectores con valores binarios $(0,1)$ y las categorías de la clasificación se expresan mediante vectores binarios. El perceptron multicapa con conexiones hacia adelante es una generalización del perceptron simple. De hecho, algunos autores han demostrado que el perceptron multicapa es un aproximador universal de cualquier función continua en el espacio $R^{n}$

Las conexiones del perceptron multicapa son hacia adelante. Generalmente todas las neuronas de un nivel se conectan con todas las neuronas de la capa inmediatamente posterior. A veces, dependiendo de la red, se encuentran conexiones de neuronas que no están en niveles consecutivos, o alguna de las conexiones entre dos neuronas de niveles consecutivos no existe, es decir, el peso asociado a dicha conexión es constante e igual a cero.

Las funciones de transferencia que se suelen utilizar son la función identidad, la función sigmoidal y la función tangente hiperbólica. A continuación se muestran sus respectivas expresiones.

Función identidad

$$
F_{1}(x)=x
$$

Funcion sigmoidal

$$
F_{2}(x)=\frac{1}{1+\mathrm{e}^{\mathrm{x}}}
$$

Funcion tangente hiperbolica

$$
F_{3}(x)=\frac{1-\mathrm{e}^{\mathrm{x}}}{1+\mathrm{e}^{\mathrm{x}}}
$$

Algoritmo de retropropagación

Este algoritmo es el algoritmo básico de aprendizaje que usan las redes perceptron multicapa, mediante el cual se van adaptando todos los parámetros de la red. El tipo de entrenamiento que sigue este tipo de red es supervisado.

El aprendizaje de la red se plantea como un problema de minimización de una determinada función de error. En general se usa como función del error, el error medio cuadrático (Ec. 1.6), es decir: 


$$
\begin{aligned}
& E=\frac{1}{\mathrm{~N}} \sum_{\mathrm{n}=1}^{\mathrm{N}} e(n) \\
& e(n)=\frac{1}{2} \sum_{n=1}^{t}(s(n)-y(n))^{2}
\end{aligned}
$$

donde $s(n)$ es la salida patrón, $y(n)$ la salida obtenida de la red, $t$ el número de neuronas de salida y $\mathrm{N}$ el número de patrones. El problema es no lineal y como tal, el problema de minimización de la función error se resuelve por técnicas de optimización no lineales que se basan en ajustar los parámetros siguiendo una determinada dirección. Como podría ser la dirección negativa del gradiente de la función error.

\subsection{Modelo teórico difusional}

Diferentes mecanismos de transferencia de materia y calor tienen lugar en el secado de alimentos, pero considerar unicamente la difusión líquida ha mostrado ser una suposición adecuada para describir el movimiento de agua en el interior del sólido (Sanjuán et al., 2001; Saravacos \& Maroulis, 2001). Los modelos difusionales son fáciles de formular y normalmente proporcionan resultados razonables. La formulación y complejidad de la resolución del modelo depende de las suposiciones que se tienen en cuenta. Generalmente, se asume una difusividad efectiva que incluye todos los efectos relacionados con la cinética, tanto los conocidos como los fenómenos desconocidos.

Al considerar que el fenómeno difusivo es predominante en la transferencia de humedad durante el secado, muchos autores han mostrado que el comportamiento del producto durante el proceso puede ser descrito adecuadamente mediante la aplicación de la ley particular de Fick (García-Pascual et al., 2006; Reyes et al., 2002; Váquiro, 2009).

A partir de la ley de Fick, y realizando un balance microscópico de materia en un volumen control, se obtiene la ecuación de gobierno del problema de transferencia de materia (Simal et al., 2006). La ecuación de gobierno para una muestra que se comporta como lamina infinita (Ec. 1.8), y suponiendo que el material es homogéneo e isótropo y que la difusividad efectiva $(D)$ es constante, es:

$$
\frac{\partial \tau_{t}(\mathrm{x}, \mathrm{t})}{\partial \mathrm{t}}=D\left(\frac{\partial^{2} \tau_{t}(\mathrm{x}, \mathrm{t})}{\partial \mathrm{x}^{2}}\right)
$$

donde $\mathrm{x}$ representa la dirección de movimiento del agua.

La difusividad efectiva es una propiedad de transporte, característico del material. Se puede considerar como la inversa de la resistencia interna a la transferencia de materia, es un parámetro de la primera ley de Fick, según la Ec 1.9. 


$$
m_{x}=-D \frac{\partial C}{\partial x}
$$

donde $m_{x}$ es el flujo másico por unidad de área en la dirección $x$ y $C$ es la concentración puntual del agua.

Se han propuesto diferentes correlaciones empíricas para la estimación de la difusividad efectiva en función de la temperatura y la humedad. La Ec. 1.10 es una de las más empleadas, donde la dependencia de la difusividad efectiva con la temperatura es estimada a partir de una ecuación tipo Arrhenius,

$$
D=D_{0} \exp \left(\frac{-E_{a}}{R T}\right)
$$

donde el factor preexponencial $D_{0}$ es denominado difusividad efectiva de referencia y $E_{a}$ es la energía de activación. Adicionalmente, en la bibliografía se ha encontrado diferentes funciones que relacionan la dependencia de $D$ con la humedad (Marinos-Kouris \& Maroulis, 2006; Simal et al., 2006).

\subsubsection{Resolución del modelo}

Tal como se ha expuesto, dependiendo del tipo de modelo aplicado, se decidirá el modo de resolución para ajustar los parámetros del modelo. Los modelos empíricos suelen estar definidos por ecuaciones algebraicas, de fácil resolución. En los modelos teóricos se representan las ecuaciones de gobierno por ecuaciones en derivas parciales. Dependiendo del tipo de ecuación de gobierno y de las condiciones iniciales y de contorno, el modelo podrá ser resuelto analíticamente mediante separación de variables, o recurrir a métodos de resolución numéricos tales como el de diferencias finitas (Bon \& Kudra, 2007; Mulet et al., 2005) o elementos finitos (Bon et al., 2007; Váquiro, 2009).

La resolución del modelo puede presentar una complejidad considerable si en su formulación se considera una geometría irregular del producto, propiedades de transporte dependientes de la humedad y la temperatura, resistencia externa a los fenómenos de transferencia y el efecto de la contracción. En tal caso, los sistemas de ecuaciones en derivadas parciales correspondientes a los balances de materia y energía no pueden resolverse de forma analítica, siendo necesaria la utilización de métodos numéricos como son el de diferencias finitas o elementos finitos (Váquiro, 2009).

Una vez resuelto el modelo es necesario, con el propósito de representar adecuadamente el proceso, identificar sus parámetros. Los parámetros a estimar están relacionados con propiedades del material desconocidas o difíciles de medir experimentalmente, y que tienen una gran influencia sobre la dinámica del proceso (Mikleš \& Fikar, 2007). 


\subsection{Identificación paramétrica}

La identificación de los parámetros se realiza a partir de la minimización de la diferencia entre estimaciones del modelo y datos experimentales del proceso. Este ajuste del modelo a la información experimental es frecuentemente realizado a partir de las curvas de secado, con el objetivo de obtener un modelo que represente el proceso como la pérdida de humedad promedio del producto en función del tiempo (Molnár, 2006).

\subsection{Validación del modelo}

Una vez ajustado el modelo, es necesaria su validación con el propósito de determinar su fiabilidad en la representación del proceso. La validación se lleva a cabo a partir de información experimental. Una manera de validar el modelo es comparar los resultados obtenidos a otras condiciones experimentales y ver la capacidad de predicción del modelo en dichas condiciones (García-Pérez, 2007a).

\subsubsection{Propiedades físicas de interés}

Las propiedades físicas cuyo conocimiento es necesario en el secado de los alimentos se pueden clasificar en dos tipos: las que están relacionadas con las propiedades de los alimentos y las que lo están con las características del medio. Las relacionadas con el material son: actividad de agua, difusividad, conductividad, calor específico e isoterma de sorción. En cuanto a las relacionadas con las condiciones externas, son especialmente importantes los coeficientes de transferencia de materia y calor interfaciales y las propiedades del aire húmedo.

El conocimiento de las propiedades físicas es esencial para el desarrollo y resolución de modelos matemáticos fundamentados en los principios de transferencia de materia y calor que gobiernan el proceso de secado. Sin embargo, es preciso resaltar que son las consideraciones específicas del modelo respecto al producto y el proceso las que determinan las propiedades físicas requeridas (Váquiro, 2009).

A continuación se describen de forma general las propiedades físicas más relevantes consideradas en el desarrolló del modelo matemático del presente estudio.

\section{Actividad de agua}

La actividad del agua $\left(a_{w}\right)$ es considerada la propiedad más importante en un sistema alimenticio, y se encuentra estrechamente relacionado con las propiedades físicas del material y con la actividad microbiana, química y enzimática.

Cuando un alimento se encuentra en equilibrio con la atmósfera que lo rodea, la actividad de agua en el alimento es igual a la humedad relativa de la atmósfera 
circundante, razón por la cual la actividad de agua de un alimento puede ser considerada como su humedad relativa de equilibrio (Basu et al., 2006; Figura \& Teixeira, 2007; Sahin \& Sumnu, 2006; Walstra, 2003).

La actividad de agua se define como la relación que existe entre la presión de vapor de un alimento dado en relación con la presión de vapor del agua pura a la misma temperatura (Ec. 1.11).

$$
a_{\mathrm{w}}=\frac{P_{v}}{P_{s}}
$$

Existen diversas técnicas de medida de la actividad de agua en alimentos, aunque lo más habitual es emplear higrómetros de punto de rocío, higrómetros eléctricos o métodos gravimétricos.

\section{Isotermas de sorción}

En todos los alimentos existe una relación característica, a una temperatura determinada, entre el contenido de humedad del producto y su actividad de agua cuando se alcanza el equilibrio termodinámico en el sistema (Mulet et al., 2002).

Su conocimiento suministra información sobre el estado del agua dentro del producto y los requerimientos de energía en los procesos de secado (Basu et al., 2006; Figura \& Teixeira, 2007; Sahin \& Sumnu, 2006;).

Varios investigadores han estudiado la relación entre el contenido de humedad de equilibrio y la humedad relativa de equilibrio para describir matemáticamente el proceso de sorción. Más de 200 ecuaciones se han desarrollado teóricamente, semi-teóricamente o empíricamente, para determinar la relación entre el contenido de humedad de equilibrio de los alimentos y la humedad relativa del aire (Van den Berg \& Bruin, 1981; Sun \& Woods, 1993; Marinos-Kouris \& Maroulis, 1995; Sun \& Woods, 1994). Sin embargo, ninguna de estas ecuaciones puede describir matemáticamente el proceso de sorción para todos los valores de actividad de agua.

Dentro del gran número de modelos disponibles en la literatura, Soysal \& Oztekin (2001a) investigaron el contenido en humedad de equilibrio de algunas plantas medicinales, utilizando 7 ecuaciones empíricas (Henderson modificada, ChungPfost, Halsey modificada, Henderson, Chen-Clayton, Iglesias-Chirife y Oswin modificada) y concluyeron que la ecuación de Halsey modificada (Ec.1.12) puede servir como un excelente modelo para el cálculo de la humedad de equilibrio del tomillo, donde $T_{a}$ es la temperatura del aire $\left({ }^{\circ} \mathrm{C}\right)$ y $\tau_{e q}$ el contenido de humedad de equilibrio.

$$
a_{w}=\exp \left[-\exp \left(2.97977-0.00258492 T_{a}^{1.37743}\right) \tau_{e q}^{-1.44139}\right] \quad 1.12
$$




\section{Conductividad térmica}

La conductividad térmica de los materiales alimenticios es una de las propiedades importantes utilizadas para estimar la velocidad de transferencia de calor en los procesos térmicos. Es definida a través de la ley particular de Fourier, donde la velocidad de transferencia de calor por conducción se expresa matemáticamente según la Ec. 1.13,

$$
q_{c}=-\kappa \frac{\partial T}{\partial x}
$$

donde $q_{c}$ es el flujo de calor por conducción por unidad de área en la dirección $x ;$ y $\kappa$ es la conductividad térmica.

El contenido de agua tiene un papel importante en la conductividad térmica en los alimentos (Cuevas \& Cheryan, 1978). Los factores a tener encuentra en el momento de estimar la conductividad térmica son: estructurales (porosidad, distribución), de composición (diferentes fases, tales como aire, agua, y sólidos) y condiciones de proceso.

Las diferentes ecuaciones para la predicción de la conductividad térmica en alimentos se describen en Figura \& Teixeira (2007), Marinos-Kouris \& Maroulis (2006) y Sahin \& Sumnu (2006). Los métodos más usuales para la determinación experimental de la conductividad térmica en alimentos han sido descritos en Marinos- Kouris \& Maroulis (2006), Ramaswamy \& Marcotte (2005) y Sahin \& Sumnu (2006).

La ecuacion 1.14 ha sido empleado para calcular la conductividad térmica de frutas y vegetales (Singh \& Heldman, 2001).

$$
\kappa=1.41810^{-1}+\frac{4.9310^{-1} \tau}{(1+\tau)}
$$

\section{Calor especifico}

A presión constante, el calor específico $C_{p}$ es definido por la Ec. 1.15, donde $\theta$ es la entalpía específica y $T\left({ }^{\circ} \mathrm{C}\right)$ la temperatura del material.

$$
C p=\frac{d \theta}{d T}
$$

Al igual que la conductividad térmica, el calor específico depende significativamente de la composición. En aquellos alimentos con un alto contenido en humedad, el calor específico del agua representa la principal contribución por su elevado valor en comparación con los demás componentes del alimento. 
Como sucede con la conductividad térmica, existen diferentes modelos para predecir el calor específico de los alimentos a partir de sus compuestos principales, los cuales se describen en Figura \& Teixeira (2007), Krokida (2001), Rahman, (1995), Ramaswamy \& Marcotte (2005) y Sahin \& Sumnu (2006).

Dentro de las técnicas más usuales para la medición del calor específico (Lozano, 2006; Ramaswamy \& Marcotte, 2005; Sahin \& Sumnu, 2006), la calorimetría diferencial de barrido (DSC) es una de las más convenientes, porque con una muestra pequeña se pueden alcanzar resultados rápidos y precisos en productos homogéneos.

\section{Coeficientes de transferencias interfaciales}

En el secado convectivo, los fenómenos que ocurren son entre otros el transporte de líquido dentro del material hacia la superficie externa, la vaporización del contenido de humedad, la transferencia convectiva del vapor desde la superficie a la corriente de aire circundante, la transferencia de calor por conducción dentro del material y la transferencia de calor por convección desde el aire a la superficie del material.

Para cada uno de los fenómenos nombrados hay un mecanismo que se podría considerar predomínate. Cada mecanismo está, generalmente descrito mediante una fuerza impulsora y una resistencia al transporte. En el fenómeno de transporte de vapor de agua desde la superficie al aire en contacto con el material se utiliza el coeficiente de transferencia de materia (externo) para describir la resistencia. La resistencia es función de las condiciones del aire (densidad, viscosidad, difusividad, conductividad térmica y calor específico), geometría del sólido y de las condiciones de flujo (Baehr \& Stephan, 2006).

La fuerza impulsora se expresa como una diferencia de propiedad. El gradiente de propiedad se establece en la capa límite y este gradiente y por tanto también el espesor de la capa limite quienes definirán la resistencia (Baehr \& Stephan, 2006; Hottel et al., 2008; Saravacos \& Maroulis, 2001).

La transferencia de calor en la interfase sólido-fluido puede ser definida mediante la Ley de enfriamiento de Newton (Ec. 1.16)

$$
q_{s}=h\left(T_{s}-T_{\alpha}\right)
$$

donde $q_{s}$ (es el flujo de calor por unidad de área entre la superficie del sólido y el aire, $h$ es el coeficiente promedio de transferencia de calor por convección; $T_{s}$ es la temperatura en la superficie del sólido, y $T_{\alpha}$ es la temperatura del aire fuera de la capa límite. 
De manera similar se define la transferencia de humedad en la interfase sólidofluido (Ec.1.17), en la cual la fuerza impulsora es expresada mediante la diferencia de concentraciones,

$$
m_{w}=h_{m v}\left(C_{s}-C_{\alpha}\right)
$$

siendo $m_{w}$ el flujo de materia por unidad de área en la superficie del sólido, $h_{m v}$ el coeficiente promedio de transferencia de materia por convección, $C_{s}$ la concentración de vapor de agua en el aire en contacto con la superficie del sólido, y $C_{\alpha}$ la concentración de vapor de agua en el aire fuera de la capa límite.

La determinación experimental de los coeficientes de transferencia por convección ha sido estudiada por diversos autores (Marinos-Kouris \& Maroulis, 2006; Saravacos \& Maroulis, 2001), pero sólo pueden ser aplicadas en situaciones muy controladas.

Existen también ecuaciones empíricas que correlacionan las medidas de transferencia de materia y calor por convección mediante números adimensionales (Herman et al., 2001). Los coeficientes de transferencia de materia y calor (Ec. 1.18) dependen de las propiedades del aire y pueden ser expresados en términos de los números adimensionales de Nusselt $(\mathrm{Nu})$ y Sherwood $(\mathrm{Sh})$,

$$
h_{m v}=\frac{S h D_{A B}}{L_{c}}, \quad h=\frac{N u k_{a}}{L_{c}}
$$

donde $h_{m v}$ y $h$ son los coeficientes de transferencia de materia y de calor respectivamente; $k_{a}$ es la conductividad térmica del aire húmedo; $L_{c}$ es la dimensión característica del cuerpo; y $D_{A B}$ es la difusividad del vapor de agua en el aire.

Treybal (1980) describe unas correlaciones (Ec. 1.19) para el cálculo de los números adimensionales de $\mathrm{Nu}$ y $\mathrm{Sh}$ en lechos porosos (Herman et al., 2001) en función de números adimensionales.

$$
N u=\frac{a}{\varepsilon} \operatorname{Re}^{b} \operatorname{Pr}^{1 / 3}, \quad S h=\frac{a}{\varepsilon} \operatorname{Re}^{b} S c^{1 / 3}
$$

donde $\varepsilon$ es la porosidad del lecho, Re (Ec. 1.20) numero adimensional de Reynolds, $\operatorname{Pr}$ (Ec.1.21) el número adimensional de Prandlt y $S c$ (Ec. 1.22) el número adimensional de Schmidt. 


$$
\begin{aligned}
& \operatorname{Re}=\frac{v L_{c} \rho_{a}}{\mu} \\
& \operatorname{Pr}=\frac{C p_{d a} \mu}{\kappa_{a}} \\
& S c=\frac{\mu}{\rho_{a} D_{A B}}
\end{aligned}
$$

En las ecuaciones anteriores $v$ es la velocidad media del aire, $\rho_{a}$ es la densidad del aire, $\mu$ es la viscosidad del aire y $C p_{a}$ el calor específico del aire.

La difusividad del vapor de agua en el aire $\left(D_{A B}\right)$ puede ser estimada, a partir de la ecuación 1.23 (Perry et al. 1997), donde $T_{p p}$ es la temperatura de la interface airesuperficie de la muestra.

$$
D_{A B}=1.473810^{-4} \exp \left(\frac{-523.78}{T_{p p}}\right)
$$

\section{Propiedades del aire húmedo}

La velocidad con que se produce la vaporización de líquido dependerá de la concentración de vapor en la atmósfera circundante. Dicho fenómeno hace necesario efectuar cálculos que se basan en las propiedades de mezclas de vapor de agua y aire. Para estos cálculos se requiere conocer la concentración del vapor de agua en el aire en diversas condiciones de temperatura y presión, las propiedades térmicas de estas mezclas y los cambios que ocurren cuando la mezcla se pone en contacto con agua o con sólidos.

Suponiendo que el aire se comporta como un gas ideal, puede deducirse la ecuación que relaciona la humedad del aire en base seca con su humedad relativa $(X)$, y la ecuación que permite estimar la densidad del aire siendo $\left(\rho_{a}\right)$ (Ec.1.24),

$$
\rho_{a}=\frac{P(X+1)}{R T_{a b s}(0.035+0.055 X)}
$$

donde la humedad (X) (Ec.1.25).

$$
X=0.622 \frac{a_{w} P_{s}}{P-a_{w} P_{s}}
$$


El calor específico del aire húmedo (base seca) se puede estimar con la Ec.1.26, donde $C p_{d a}$ es el calor específico del aire seco y $C p_{v}$ es el calor específico del vapor de agua.

$$
C p_{a}=C p_{d a}+C p_{v} X
$$

Para el cálculo de la viscosidad del aire húmedo se aplicó el método Wilke (Ec. 1.27) para una mezcla binaria de aire-vapor de agua,

$$
\mu_{a}=\frac{\left(1-y_{v}\right) \mu_{d a}}{1-y_{v}+y_{v}+\psi_{d a, v}}+\frac{y_{v} \mu_{v}}{y_{v}\left(1-y_{v}\right)+\psi_{v . d a}}
$$

donde $\mu_{a}, \mu_{d a}$ y $\mu_{v}$ son las viscosidades del aire húmedo, aire seco y vapor de agua, respectivamente y $y_{v}$ es la fracción molar del vapor de agua en la mezcla (Ec.1.28).

$$
y_{v}=\frac{X}{0.622+X}
$$

$\Psi_{d a, v}$ y $\Psi_{v, d a}$ son parámetros definidos por las Ecs. (1.29) y (1.30), respectivamente

$$
\begin{aligned}
& \psi_{d a, v}=\left[0.468+0.527\left(\frac{\mu_{d a}}{\mu_{v}}\right)^{0.5}\right]^{2} \\
& \psi_{v, d a}=1.606 \frac{\mu_{v}}{\mu_{d a}} \psi_{d a, v}
\end{aligned}
$$

De manera similar (Poling et al., 2000) se puede determinar la conductividad térmica del aire húmedo puede ser estimada a partir de la Ec. 1.31, siendo $\kappa_{a}, \kappa_{a d}$ y $\kappa_{v}$ las conductividades térmicas del aire húmedo, aire seco y vapor de agua, respectivamente.

$$
\kappa_{a}=\frac{\left(1-y_{v}\right) \kappa_{d a}}{1-y_{v}+y_{v} \psi_{d a, v}}+\frac{y_{v} \kappa_{v}}{y_{v}+\left(1-y_{v}\right) \psi_{v, d a}}
$$




\subsection{NUEVAS TECNOLOGIAS APLICADAS AL SECADO CONVECTIVO}

El procesamiento de alimentos está en constante evolución en respuesta a diferentes desafíos y cambios en los gustos y necesidades de los consumidores. Estos cambios se deben a la necesidad de producir alimentos sanos, seguros y de mejor calidad, lo cual hace que los directamente afectados por estas demandas sean los procesos a los que son sometidos los alimentos (Cárcel, et al., 2012 y Chou \& Chua, 2001). Otro aspecto importante que se debe tener en cuenta es la reducción de las necesidades de energía de los procesos, lo que conlleva una disminución de los costos ambientales y financieros.

En este sentido, la introducción de nuevas tecnologías podría conducir a una reducción del tiempo de procesamiento o a una mejora de las condiciones de operación.

El secado es una operación que supone un uso intensivo de energía, lo que hace necesario examinar los diferentes métodos para mejorar la eficiencia energética (Chou \& Chua., 2001).

Los secaderos convencionales tienen varias limitaciones, como que la calidad del producto seco puede no ser uniforme debido al secado no uniforme y a la exposición larga o insuficiente al medio de secado, endurecimiento del producto debido al encostramiento en la superficie que es causada por un exceso en la velocidad de secado superficial (López et al., 2010), cambio significativo del color del producto con respecto al color original que es causado por reacciones de pardeamiento y reacción redox, etc. (Arabhosseini et al., 2010 ; Falade \&Omojola 2010; Aversa et al., 2010). Muchos estudios se han llevado a cabo a lo largo del tiempo para superar los problemas operativos y las dificultades de los secaderos convencionales, así como para mejorar la calidad de los productos secos (Fernández et al., 2010; Law et al., 2008).

Los nuevos desarrollos y las tecnologías emergentes se pueden clasificar en las siguientes categorías: aquellas que pretenden mejorar tecnologías ya existentes, y aquellas relacionadas con el desarrollo de tecnologías de secado rentables que disminuyan el impacto ambiental (Mujumdar, 2007).

Algunas de las principales tecnologías aplicadas para la intensificación de procesos son las microondas, la radiofrecuencia, la radiación infrarroja y los ultrasonidos de potencia. También cabe citar el secado intermitente para mejorar la calidad del producto y disminuir el consumo energético. 


\subsubsection{Microondas}

Las microondas son ondas electromagnéticas con una longitud de onda entre 1 $\mathrm{mm}$ a $1 \mathrm{~m}$. La frecuencia de estas microondas se encuentra entre 0,3 y $3 \mathrm{GHz}$ (Cohen \& Yang, 1995).

Las microondas causan un movimiento del agua y las moléculas con carga eléctrica en el interior de los alimentos. Esto se debe a que las moléculas son dipolos eléctricos y giran en su intento de alinearse con el campo eléctrico alterno inducido por el haz de microondas. Este movimiento molecular genera calor debido a la fricción generada por las moléculas en rotación. El movimiento inducido es función de la temperatura y características de material.

Este fenómeno provoca una diferencia de presión de vapor entre el interior y la superficie del producto, permitiendo una rápida transferencia de humedad en los alimentos (Sutar \& Prasad 2008). Los métodos de secado que aplican sólo microondas tienen importantes limitaciones (Zhang et al., 2006), entre las que se puede mencionar el calentamiento no uniforme, posibles daños en la textura por sobrecalentamiento en algunas zonas, limitada penetración de la radiación en el producto y baja eficiencia energética.

El secado por microondas produce daños al producto causados por un calentamiento excesivo debido al mal control de la transferencia calor y de materia (Datta, 1990; Ramaswamy et al., 1991).

A pesar de las ventajas que a priori aporta el secado asistido por microondas, actualmente las aplicaciones industriales son escasas (Zhang et al., 2006). Frecuentemente presenta interés para acelerar las últimas etapas de secado cuando el contenido de humedad es relativamente bajo.

Al igual que las microondas, las radiofrecuencias se han utilizado en combinación con métodos de secado convectivo, y su aplicación se puede realizar durante todo el proceso o en momentos concretos (Jumah, 2005a).

\subsubsection{Ultrasonidos de potencia}

Los ultrasonidos son ondas acústicas de frecuencia superior a $20 \mathrm{kHz}$, valor que representa el límite de audición humano (Raj et al., 2004). Esta clasificación no está basada en ningún tipo de fundamento físico, ya que las leyes de generación y propagación del sonido son las mismas en todo el espectro de frecuencia.

En los últimos años la tecnología de los ultrasonidos se ha considerado como una herramienta valiosa en los procesos de ingeniería de alimentos (Bhaskaracharya et al., 2009).

La aplicación de los ultrasonidos se basa en dos enfoques muy diferentes: 
- Ultrasonidos de baja intensidad con alta frecuencia. Se utilizan para obtener información sobre el medio en el que se propagan (ultrasonidos de señal), centrado específicamente en el control de calidad de los productos o procesos. Las aplicaciones están relacionadas principalmente con la medición de la velocidad de los ultrasonidos, la atenuación de la señal o el análisis de espectros de frecuencia.

- Ultrasonidos de alta intensidad y baja frecuencia (ultrasonidos de potencia). Aquellos en los que el objetivo es producir efectos en el medio en el que se propagan, siendo una puerta para aplicaciones industriales. Este tipo es por tanto el que resulta de interés en el secado.

A diferencia de otras tecnologías como microondas, radiofrecuencia o radiación infrarroja, los ultrasonidos de potencia no producen un calentamiento significativo del material, lo que favorece su aplicación en el secado de materiales sensibles al calor (Fairbanks, 1975,) incrementando la velocidad de secado. Este efecto está asociado a que los ultrasonidos de potencia en sólidos causan una rápida serie de compresiones y expansiones alternativas, de manera similar a una esponja cuando se aprieta y se libera varias veces (efecto esponja) (Gallego-Juárez et al., 1999). Las fuerzas implicadas por el presente mecanismo pueden ser mayores que la tensión superficial (Tarleton, 1992) que mantiene la humedad dentro de los capilares del material, llegando a crear canales microscópicos que pueden servir para la eliminación de la humedad. Además, el ultrasonido puede llegar a producir cavitación que puede ser beneficiosa para la eliminación de la humedad adherida firmemente (Tarleton, 1998).

Como anteriormente se ha indicado, los ultrasonidos de potencia pueden causar cambios en el material o en los procesos en los que son aplicados. Durante el proceso de secado ocurren dos tipos de resistencia al transporte de agua: resistencia interna al movimiento del agua dentro del material y resistencia externa entre la superficie del sólido y el aire (Rosselló et al., 1997; Simal et al., 2001; Ozuna, et al., 2011).

La resistencia interna es una característica del material, mientras que la resistencia externa depende del espesor de la capa límite de difusión. Los ultrasonidos de potencia producen variaciones de presión en las interfases sólidogas que pueden influir en la velocidad de evaporación del agua (Mulet et al., 2003; Pugin \& Turner, 1990). Durante la fase negativa del ciclo de presión, disminuye la presión parcial del agua en la superficie y, por tanto, se acelera la pérdida de humedad en la superficie del sólido. Este fenómeno puede resultar más importante durante el periodo de secado constante, ya que la superficie del material está completamente saturada de agua (Garcia-Pérez. 2007b). El uso de ultrasonidos de alta intensidad puede constituir una técnica para acelerar la transferencia de materia en sistemas líquido-sólido (Cárcel et al., 2007a) y sólido-gas (GarcíaPérez et al., 2006a). 
La aplicación de ultrasonidos de alta intensidad en los procesos de secado con aire ha sido utilizada durante más de cinco décadas. Sin embargo, su desarrolló ha sido muy lento debido a los problemas técnicos en el diseño de un eficiente y potente generador acústico de transmisión en aire (Mason et al., 2005). Muchos de estos problemas han sido resueltos en los últimos años, y ha permitido investigar la influencia de los ultrasonidos en el secado por aire caliente de algunos productos alimentarios.

Los ultrasonidos se han utilizado para afectar a la transferencia de materia en los sistemas sólido-líquido en procesos tales como la deshidratación osmótica de manzanas (Cárcel et al., 2007b; Liang, 1993; Simal et al., 1998) y el salado de la carne (Cárcel et al., 2007c; Sajas \& Gorbatow, 1978).

A continuación se comentan algunos de los estudios donde se han utilizado ultrasonidos en el secado convectivo de algunos alimentos.

Fernández \& Rodrigues (2007) aplicaron ultrasonidos de alta intensidad en sistemas sólido-líquido usando un baño ultrasónico, como un pre-tratamiento al secado por aire caliente de plátanos. Se observó un aumento en la difusión de la humedad después de la aplicación de ultrasonidos y una disminución en el tiempo total del proceso, en comparación con el tratamiento previo en una solución hipertónica seguido por secado con aire caliente.

Da-Mota \& Palau (1999) utilizaron un sistema de ultrasonidos tipo sirena para el secado acústico de cebolla. La velocidad de la pérdida de agua fue más rápida en las experiencias donde se aplicaron los ultrasonidos que las muestras secadas tradicionalmente con métodos convectivos.

Gallego- Juárez et al., (1999) aplicaron ultrasonidos de alta intensidad para la deshidratación de hortalizas aplicando vibraciones ultrasónicas en contacto directo con el producto y bajo una cierta presión estática, y su efecto fue comparado con resultados de secado convectivo asistidos por radiación ultrasónica y un secado convencional. Los resultados muestran que mediante el uso de vibraciones ultrasónicas en contacto directo con el producto, es posible reducir drásticamente el tiempo de tratamiento siendo relativamente fácil llegar a un contenido de humedad final en las muestras de menos de $1 \%$. Además, las cualidades de los productos se conservaron mejor que en el secado puramente convectivo y la rehidratación de la muestra fue superior al $70 \%$.

García-Pérez et al., (2006b) realizaron cinéticas de secado de cubos de zanahoria secados a una velocidad del aire de $1 \mathrm{~m} / \mathrm{s}$ a diferentes temperaturas de secado (30, 40, 50, 60 y $70 \pm 0,1^{\circ} \mathrm{C}$ ), usando un cilindro vibrante que produce un campo acústico estacionario. Observaron que la aplicación de ultrasonidos incrementó la velocidad de secado, especialmente a bajas temperaturas.

Riera et al., (2002) estudiaron la aplicación de una placa de vibración ultrasónica de alta potencia en contacto directo con las muestras, con y sin presión estática. 
Confirmaron que es un procedimiento eficaz para la deshidratación de vegetales, sin afectar a las características principales del alimento y conservando su calidad. La mejora obtenida mediante la aplicación de ultrasonidos de alta intensidad transmitidas por aire en la deshidratación de vegetales fue menor que la aplicación de ultrasonidos en una placa de vibración por contacto.

Cárcel et al., (2007a) analizaron las cinéticas de secado de cilindros de caqui (30 $\mathrm{mm}$ de altura y $13 \mathrm{~mm}$ de diámetro), utilizando 8 velocidades del aire de secado $\left(0,5,1,2,4,6,8,10\right.$ y $\left.12 \mathrm{~m} \mathrm{~s}^{-1}\right)$ con y $\sin$ ultrasonidos $(21,8 \mathrm{kHz}$ y $154,3 \mathrm{~dB}$ ) usando un cilindro vibrante que genera un campo acústico. Pudieron observar que los ultrasonidos influyeron en el proceso de transferencia de materia durante el secado de caqui sobre todo en velocidades del aire menores a $4 \mathrm{~m} / \mathrm{s}$.

Ortuño et al., (2010) estudiaron la influencia de los ultrasonidos de potencia usando un cilindro vibrante, en cinéticas de secado a $40{ }^{\circ} \mathrm{C}$ y $1 \mathrm{~m} / \mathrm{s}$ y en la microestructura de cáscara de naranja; observando que la aplicación de los ultrasonidos aceleró el proceso de secado de manera significativa. Los efectos de los ultrasonidos sobre la transferencia de materia fueron confirmados por observaciones microestructurales. En la superficie de la cutícula, los poros se obstruyeron por la dispersión de los componentes, lo que evidencia los efectos de los ultrasonidos en las interfases. Las células del flavedo se comprimieron y se observaron grandes espacios intercelulares de aire generados por la salida del agua del albedo.

Ozuna, et al., (2011) investigaron la influencia de los ultrasonidos de potencia en la cinética de secado de patata usando un cilindro vibrante, donde pudieron observar que la velocidad de secado era directamente proporcional a la potencia ultrasónica aplicada. Por lo tanto, la aplicación de ultrasonidos influye en la resistencia interna y externa a la transferencia de materia.

Los trabajos realizados sobre la aplicación de ultrasonidos de potencia en procesos de secado, permitieron identificar las posibles variables que pueden afectar su aplicación. Entras las cuales podemos mencionar variables relacionadas con las condiciones de proceso como son la temperatura y velocidad del aire y las relacionadas con las características del material como la porosidad y dureza. Otro variable a considerar es la identificación del umbral de potencia, a partir del cual pueden empezar a observarse efectos asociados con la aplicación de ultrasonidos.

\subsubsection{Secado intermitente}

La mayoría de los secaderos convencionales utilizan aire caliente como medio de secado, siendo la convección el modo de transferencia de calor, y se opera a presión atmosférica bajo condiciones estacionarias de secado. El proceso de secado ha sufrido ciertas modificaciones o cambios debido a los emergentes problemas del cambio climático y del desarrollo sostenible. Se han propuesto diferentes técnicas para minimizar el consumo de energía, que a su vez sean 
favorables para la calidad del producto, y sin alterar significativamente la cinética de secado.

Una de las técnicas estudiadas para tal fin es el secado intermitente. El secado intermitente se fundamenta en la implementación y combinación de condiciones variables, tales como la temperatura y la velocidad del aire de secado (Bon \& Kudra, 2007a; Chua et al., 2003; Islam et al., 2003).

Los esquemas de intermitencia pueden ser aplicados al operar los equipos (como en el caso de los secaderos por lotes operados de forma discontinua) o ser inherentes a su diseño (como en el caso del secador rotatorio de lecho fluidizado). Una clasificación general de los diferentes tipos de intermitencia se muestra en la Figura 1.4.

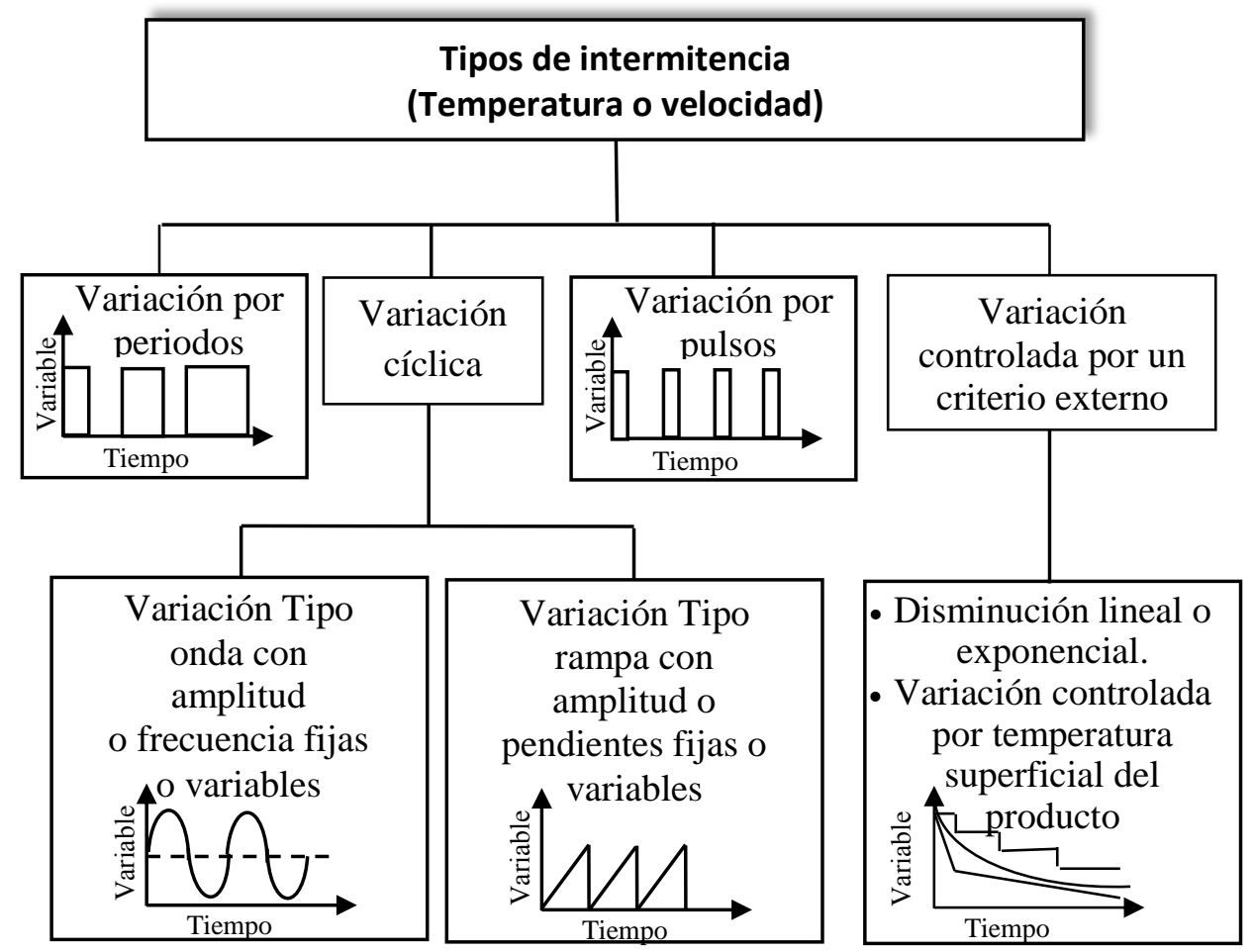

Figura. 1.4. Clasificación general de los esquemas de intermitencia aplicados al proceso de secado. Adaptado de Chua et al., (2003).

El objetivo es mejorar la eficiencia energética sin someter al producto más allá de su admisible límite de temperatura y límite de tiempo para la reducción de la humedad, cuando la cinética está controlada por los fenómenos de transferencia internos (Chua et al., 2003; Islam et al., 2003; Jumah \& Mujumdar, 2005; Mujumdar, 2004). La intermitencia permite reducir el consumo energético, y por ende, minimiza el impacto ambiental, mejorando la calidad final del producto. (Varnalis et al., 2001; Vaquiro, 2009). 
La técnica de secado intermitente se ha desarrollado principalmente en el campo de secado de granos y cereales, donde la mayor cantidad de los estudios se han enfocado en evaluar su viabilidad en cuanto a la eficiencia del proceso y a la reducción de problemas como la rotura, la fisura, y la pérdida de germinación de granos y semillas (Aquerreta et al., 2007; Do Carmo \& De Lima, 2008; Dong et al., 2009).

\subsubsection{Secado intermitente: variación controlada de la temperatura superficial del} producto.

Dentro de la definición de secado intermitente puede incluirse el secado en dos periodos (Fig. 1.5) aplicando diferente temperatura del aire en función de la evolución del producto. La variación de la temperatura superficial del producto representa una alternativa para establecer los periodos y mejorar la calidad final de los productos secos. Durante el primer periodo de calentamiento el producto es sometido a un secado convencional a alta temperatura hasta que la superficie del producto alcance una temperatura preestablecida. En este primer periodo de secado el flujo de aire caliente da lugar a procesos rápidos de transferencia de materia y calor por convección forzada, y reduce el tiempo necesario para que la superficie del producto alcance una temperatura preestablecida. En cambio, durante el segundo periodo de secado el producto se somete a temperaturas de secado más bajas, hasta alcanzar el contenido de humedad final deseado, lo cual permite que se reduzca el tratamiento térmico disminuyendo el impacto sobre la calidad del producto. Al tener efecto sobre la velocidad del proceso, la aplicación del primer periodo de secado a alta temperatura reduce el tiempo de proceso, pudiendo disminuir así los requerimientos de energía en comparación con procesos donde el suministro de calor es constante.

Tal y como sucede con otras tecnologías, el proceso de secado debe ser analizado con el propósito de determinar las mejores condiciones de operación, respecto a las características particulares del producto y del proceso. Dentro de las condiciones a controlar podría considerarse la duración del primer periodo de calentamiento, para asegurar que el producto llegue a una temperatura deseada en el menor tiempo posible, y asegurar una reducción del efecto tiempotemperatura sobre la calidad del producto. 


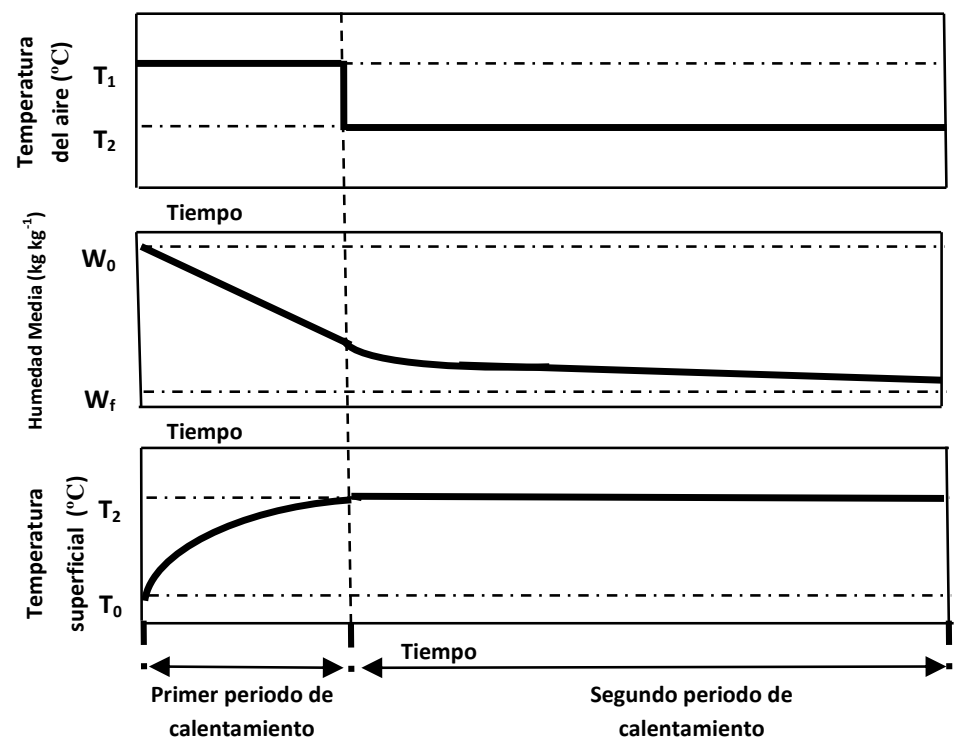

Figura 1.5. Evolución del contenido de humedad y la temperatura del producto en un proceso de secado intermitente. $\mathrm{T}_{1}$ y $\mathrm{T}_{2}\left({ }^{\circ} \mathrm{C}\right)$ son las temperaturas del aire en el primero y segundo periodo respectivamente, y $W_{0}$ y $W_{f}\left(\mathrm{~kg} \mathrm{~kg}^{-1}\right.$ b.s.) son los contenidos de humedad inicial y final del producto en base seca.

1.2.3.2. Influencia del secado intermitente sobre la eficiencia del proceso y sobre la calidad del producto.

Diferentes autores ha abordado el estudio de la intermitencia en el secado. A continuación se presentan algunos estudios de secado intermitente en los que se mejora la eficiencia del proceso y la calidad del producto.

Jumah et al., (1996) estudiaron el efecto del secado intermitente de granos, variando la temperatura del aire. Encontraron ventajas significativas en el consumo de energía y en la calidad del producto.

Chua et al., (2000a, b) demostraron que con una adecuada selección de la temperatura del aire en el secado intermitente, realizando una variación de temperatura se mejora la cantidad del contenido en ácido ascórbico de la guayaba (Psidium guajava) hasta en un $20 \%$ más que en los secados en condiciones isotérmicas. Chua et al., (2000b) demostraron también que el secado intermitente podría reducir el cambio de color de la patata, guayaba y banano en un $87 \%, 75$ $\%$ y $67 \%$, respectivamente. Chou et al., (2008), a través de un estudio de secado intermitente, revelaron un ahorro en el tiempo de secado efectivo de 25, 48 y 61 \%. Chou et al., (2008), Gunasekaran et al (1999), Li et al., (1999) y Pan et al., (1999a), demostraron que el secado intermitente (variando la temperatura) podría mejorar la calidad del producto. 
Pan et al., (1999b) establecieron un modelo que describía la cinética de degradación del $\beta$-caroteno. El modelo fue empleado para simular y predecir el efecto de las condiciones de operación sobre la calidad del producto. Los resultados obtenidos permitieron concluir que el secado intermitente variando la temperatura de secado reducía el tiempo de secado en un $40 \%$ en comparación con el secado continuo. Al comparar ambos esquemas de operación, en el secado intermitente se preservó el $87.2 \%$ del $\beta$-caroteno de las muestras de calabacín, mientras que en el secado continuo se preservó el $61.5 \%$.

En el estudio del secado intermitente de maíz en un secadero rotatorio de lecho fluidizado a chorro, Bon \& Kudra (2007) consiguieron disminuir tanto la entalpía promedio del producto como el consumo de energía, al optimizar, vía modelización y simulación, la duración de los periodos de calentamiento y reposo, y las temperaturas de los periodos de calentamiento.

\subsubsection{Modelización y simulación del proceso de del secado intermitente}

En el análisis de la aplicación de la intermitencia en el secado de alimentos resulta imprescindible, la modelización matemática y la simulación computacional. En la mayoría de estudios, incluso en aquellos más recientes, ha prevalecido el uso de modelos empíricos y teóricos (basados en principios físicos) de reducida complejidad, debido a la naturaleza del proceso (altamente no lineal, fuertemente interactivo, multivariante y transitorio). El disponer de modelos sencillos, de resolución rápidaL, es fundamental para aplicaciones a tiempo real.

A continuación se comentan algunos de los estudios donde han sido empleados modelos para describir el proceso de secado intermitente.

Baini \& Langrish (2007) utilizaron un modelo difusional para representar las cinéticas de secado continuo e intermitente en láminas de plátano, el cual predijo satisfactoriamente la información experimental en ambos modos de operación. La simulación del proceso se realizó a partir de la solución numérica, por elementos finitos, de un modelo difusional que describía la transferencia de materia y calor radial en un sistema de geometría cilíndrica. El modelo consideraba la difusividad efectiva dependiente de la temperatura, las propiedades termofísicas dependientes de la humedad, la resistencia externa a la transferencia de materia y calor, y la variación del volumen del producto en función del contenido de humedad promedio.

Váquiro, (2009) empleo un modelo difusivo para el secado continuo e intermitente de cubos de mango con un buen ajuste a los datos experimentales. El modelo difusivo describía la transferencia de materia y calor, considerando la difusividad efectiva dependiente de la temperatura y de la humedad puntual del producto y resistencia externa a la transferencia de materia y calor. El modelo desarrollado permitió realizar una optimización del proceso con el fin de reducir la ganancia entálpica de la muestra durante el proceso de secado, determinando los ciclos de secado y la duración de cada ciclo. 
Do Carmo \& De Lima (2008) simularon la transferencia de materia en el secado intermitente de lentejas usando el método de elementos finitos, empleando un modelo difusivo bidimensional para partículas de geometría elipsoidal, donde se asumió un difusividad efectiva constante y condiciones de equilibrio en la superficie.

Jumah \& Mujumdar (2005) aplicaron un sistema de inferencia neuro-borroso adaptativo (ANFIS) para la modelización empírica del secado intermitente de granos en un secadero en lecho fluidizado. El sistema ANFIS es una técnica que emplea las metodologías de la lógica borrosa y las redes neuronales para establecer un modelo empírico que representa un conjunto de datos determinado. En unas condiciones de operación dadas, este tipo de modelo representó adecuadamente el comportamiento periódico y las discontinuidades del proceso de secado intermitente en cuanto a humedad y temperatura promedio; sin embargo, dependió de un gran número de parámetros y no brindó información acerca de la distribución local de humedades y temperaturas.

\subsection{TOMILLO}

Las plantas medicinales forman parte de la creciente demanda de productos naturales con compuestos bioactivos (Badi et al., 2004), constituyendo un amplio grupo del cual se pueden destacar las plantas pertenecientes a la familia de las Lamiaceae. Este grupo de plantas son fuentes muy ricas en compuestos antioxidantes (Hossain et al., 2008; Shan, et al. 2005). Dentro de las plantas Lamiaceae se encuentran el romero, orégano, salvia, albahaca y tomillo, plantas aromáticas populares, que crecen en muchas regiones del mundo.

El tomillo (Thymus vulgaris L.) es un género con alrededor 350 especies de plantas aromáticas herbáceas y perennes, de la familia de las labiadas (Lamiaceae). Es nativa de los países de Mediterráneo, donde crece en amplias áreas de Francia, España, Portugal, Italia, Argelia, Marruecos, y de algunos países asiáticos y americanos.

El tomillo se considera un género bien definido; es un arbusto pequeño que alcanza los $60 \mathrm{~cm}$ de altura y de aspecto grisáceo. Tiene los tallos erguidos, cuadrangulares, leñosos y muy ramificados. Las hojas son pequeñas, ovales con los bordes enrollados, y tomentosas por el envés. Las flores son pequeñas de color rosa, tiene un penetrante olor aromático y florecen en primavera, a partir del mes de marzo.

Inmediatamente después de la cosecha, las hojas de tomillo son altamente perecederas y tienen que ser preservadas contra el deterioro y la descomposición. Por lo general contienen $75-80 \%$ de agua, y es necesario disminuir la humedad a valores inferiores al $18 \%$ para su conservación (Díaz-Maroto et al. 2002). 
El secado por aire caliente es ampliamente utilizado en el secado de hierbas, para inhibir el crecimiento microbiano y prevenir ciertos cambios bioquímicos. Al mismo tiempo se pueden dar alteraciones que afectan a la calidad, tales como cambios en apariencia y en el aroma causado por las pérdidas de volátiles o la formación de nuevas sustancias volátiles como resultado de reacciones de oxidación o esterificación (Hossain et al., 2010).

Las hojas del tomillo se pueden usar frescas o secas, como especia o en infusiones, y sus hojas secas se utilizan para la extracción de aceite esencial. En la industria alimentaria, algunos países del mediterráneo y del suroeste asiático usan el tomillo como un ingrediente alimentario importante. Es un componente común del ramillete de hierbas de Provenza (hierbas provenzales). Las hojas pueden ser separadas de los tallos de diferentes modos.

\subsubsection{Secado de tomillo}

La creciente importancia económica de plantas medicinales, ha permitido desarrollar diversas investigaciones que se encuentran referenciadas en la literatura, las cuales se pueden clasificar en dos grupos: i). Modelización de cinéticas de secado, ii). Influencia del proceso de secado sobre la calidad del aceite esencial.

Han sido pocos los estudios reportado en la literatura sobre la modelización de cinéticas de secado de tomillo. Dentro de estos estudios destaca el uso de los modelos matemáticos empíricos y la solución analítica de la Ley particular de Fick que describe la difusión de humedad a través de una lámina infinita.

A continuación se comentan algunas características particulares de la metodología empleada para la modelización de las cinéticas de secado.

Doymaz, (2011) estudió cinéticas de secado de tomillo a diferentes temperaturas $\left(40,50\right.$ y $\left.60^{\circ} \mathrm{C}\right)$ y a una velocidad de aire de $2 \mathrm{~m} / \mathrm{s}$. El tiempo de secado a $60^{\circ} \mathrm{C}$ fue menor en 1.5 y 4.12 veces en comparación con muestras secadas a $50{ }^{\circ} \mathrm{C}$ y $40 \stackrel{\circ}{ } \mathrm{C}$, respectivamente. Para representar las cinéticas del proceso empleó diferentes modelos empíricos, dentro de los cuales el modelo de Midilli arrojó mejores resultado. Empleó un modelo teórico para el transporte de materia de lámina infinita en una hoja de tomillo despreciando la resistencia externa, obteniendo valores de difusividad en un intervalo de 1.097 y $5.991 \times 10^{-9} \mathrm{~m}^{2} / \mathrm{s}$ en el rango de temperaturas ensayadas.

Rocha (2012) utilizó diferentes modelos empíricos para estudiar la cinética del secado de tomillo a temperaturas de $30,40,50,60$ y $70 \stackrel{\circ}{\circ}$ a una velocidad de $1 \mathrm{~m} / \mathrm{s}$. Para el cálculo de la difusividad efectiva uso un modelo de lámina infinita en una hoja obteniendo valores entre $3.69 \times 10^{-12}$ y $1.19 \times 10^{-10} \mathrm{~m}^{2} / \mathrm{s}$. De los modelos empíricos utilizados para describir las cinéticas de secado, el modelo de Page fue el que tuvo mejor ajuste. 
Existen otras investigaciones sobre la modelación matemática y sobre el estudio de las cinéticas de secado para diversas hortalizas y plantas medicinales, como la albahaca (Ozcan et al. 2005), plantas aromáticas (Akpinar 2006), hojas de acelga (Alibas 2006), hojas de té (Ghodake et al. 2006), Rehmannia (Rhim et al., 2007), hojas de romero (Arslan \& Ozcan 2008), cebolla (Lee \& Kim 2008) y Berberis (Aghbashlo et al. 2009).

La influencia del proceso de secado sobre la calidad del aceite esencial se ha estudiado centrando el esfuerzo en determinar el efecto de las condiciones de operación sobre la composición en volátiles de diversas plantas aromáticas. Se ha observado que ciertos componentes (normalmente presentes) aumentan en diferentes hierbas después del secado: por ejemplo, eugenol en la hoja de laurel (Díaz-Maroto et al., 2002), timol en el tomillo (Venskutonis, 1997).

Venskurtonis (1997), estudió compuestos volátiles en tomillo fresco, liofilizado y secado en horno a 30 y $60{ }^{\circ} \mathrm{C}$, identificó un total de 68 compuestos y observó que el contenido de compuestos aromáticos aumentó cuando la muestra se secó a $60{ }^{\circ} \mathrm{C}$.

Hossain et al., (2010), investigó el cambio en la capacidad antioxidante de 6 plantas aromáticas entre ellas el tomillo después de tres métodos de secado; comparándolos con muestras frescas, Encontró que de los métodos de secado, el secado por aire caliente fue el mejor para todas las muestras. Concluyendo que el secado es una técnica muy útil para aumentar la capacidad antioxidante de los extractos.

Rahimmalek \& Hossein-Golib (2013), estudió el efecto de 6 tratamientos diferentes de secado sobre el aceite esencial de tomillo y determino que la mejor temperatura de secado que conducen a incrementar el thymol/carvacrol fue $70^{\circ} \mathrm{C}$. Este efecto lo relaciono con la temperatura óptima de actividad enzimática donde se produce la converción $p$-cymene a thymol.

Calín-Sánchez et al., (2013), investigó el efecto de 3 métodos de secado sobre la composición del aceite esencial, identificando 33 compuestos, lo cuales se vieron afectados de forma diferente por cada método usado, concluyendo que un método combinado de $40 \stackrel{\circ}{\circ}$ y $240 \mathrm{~W}$ (Microondas) sobre $60 \mathrm{gr}$ de muestra fue la mejor opción de los métodos analizados.

\subsubsection{Aceite esencial}

Uno de los mayores intereses por las hojas de tomillo es su aceite esencial, son productos de gran demanda en la fabricación de perfumes y cosméticos, y también se utilizan con fines medicinales, en aditivos para alimentos, en productos farmacéuticos y cosméticos (Hanci et al., 2003; Lee et al., 2005).

En las Lamiaceae, el aceite esencial se almacena en tricomas glandulares peltadas. Están situados en la superficie epidérmica en ambos lados de las hojas, 
y muestran una anatomía muy típica (Figura 1.6). Bruni \& Modenesi (1983) estudiaron intensamente los tricomas en Thymus vulgaris L. por microscopía convencional, fluorescente y microscopia electrónica de barrido. Los tricomas glandulares peltados se componen de una célula del tallo basal, una célula endodérmica que impide el reflujo de sustancias secretadas por el apoplasto, y una glándula superior formada por 10-14 células secretoras, cuya característica destacada es un núcleo relativamente grande y un gran número de pequeñas vacuolas osmiófilas. El aceite esencial extraído de sus hojas, está compuesto por dos clases principales de productos secundarios, aceites esenciales volátiles y polifenoles, especialmente flavonoides. Ambos, aceites esenciales y flavonoides, son los principales responsables de las actividades farmacológicas de las plantas (Simeon de Bouchberg et al., 1976, Van den Broucke, 1983). Dado que el aceite esencial se encuentra en la superfice de las hojas resulta de gran interés la temperatura de la superficie durante el secado.

El aceite esencial del tomillo posee propiedades antisépticas, antiespasmódicas, carminativas, diaforéticas, desinfectantes, desodorantes, diuréticas, expectorantes, sedantes, tónicas y antihelmínticas. Estas propiedades se deben a sus componentes principales, thymol (2-isopropyl-5-methylphenol) del 20-54 \% y carvacrol (5-isopropyl-2-methylphenol) del 5-75\%. Adicionalmente posee diferentes quimiotipos (geraniol, linalool, $\alpha$-terpineol, thymol, carvacrol, $p$-cymene, trans-sabinene hydrate, terpinene-4-ol, borneol \&1, 8-cineole) (Muñoz, 1993), la mayoría de ellos con actividad antimicrobiana (Kaloustian et al., 2005, Shati \& Elsaid, 2009).
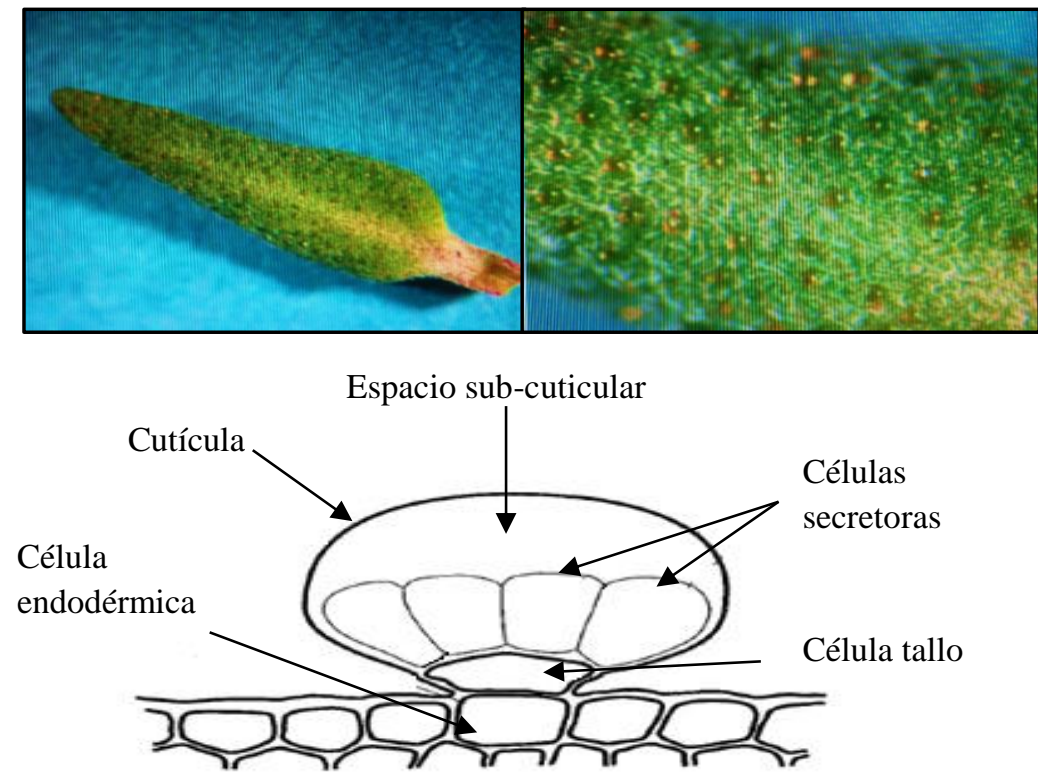

Figura 1.6. Anatomía glandular del tricoma del Thymus vulgaris $\mathrm{L}$. 
El timol se caracteriza por su poder desinfectante y fungicida. Por su sabor agradable está presente en la formulación de diversos enjuagues bucales (Pierce, 1999), pastas de dientes etc. Una disolución del $5 \%$ de timol en etanol se utiliza para la desinfección dermal y contra infecciones de hongos (Ramsewak, 2003). En veterinaria se aplica igualmente contra infecciones dermales y para estimular la digestión.

\subsubsection{Métodos de extracción}

Para la extracción de aceite esencial se pueden usar una serie técnicas, entre las que cabe mencionar hidrodestilación, destilación por vapor, extracción Soxhlet, destilación-extracción simultánea (SDE), extracción con fluidos supercríticos (SFE), maceración, digestión, infusión, decocción, percolación, extracción en contra-corriente, extracción asistida por microondas y extracción asistida por ultrasonidos (Handa et al., 2008). Únicamente la hidrodestilación, destilación por vapor, y SFE se utilizan industrialmente para la extracción de aceites esenciales (Diaz-Maroto et al. 2005). La principal diferencia entre estas técnicas está relacionada con el diseño de los reactores y equipos, los disolventes utilizados, el tiempo y temperatura de los procesos, o el uso de las nuevas tecnologías (microondas, ultrasonidos, SFE, o el uso de enzimas) (Esclapez et al, 2011).

Actualmente la tendencia en las técnicas de extracción es el uso de disolventes más ecológicos tales como la mezcla alcohol-agua, lo que conlleva tener costos elevados y bajo rendimiento de extracción. Por ello, existe un gran interés en el desarrollo de métodos de extracción más eficientes, como es el caso del método de extracción de con fluidos supercríticos.

\subsubsection{Extracción con fluidos supercríticos (SFE)}

La extracción de aceites esenciales de material vegetal representa una aplicación de los SFE, utilizando dióxido de carbono supercrítico $\left(\mathrm{SC}-\mathrm{CO}_{2}\right)$. Esta técnica de extracción se compara favorablemente con los procesos convencionales tales como hidrodestilación, destilación por vapor, extracción por disolvente. Permite altos rendimientos y al mismo tiempo reduce el tiempo de proceso. Además evita la degradación térmica e hidrolítica de compuestos lábiles y la existencia de residuos de disolventes tóxicos en el producto (Aarus, 2009). La mejora de la calidad de la extracción por SFE de aceites esenciales de algunas plantas, en comparación con métodos de extracción convencionales ha sido revisada exhaustivamente por Stahl et al., (1988), Moyler (1993), Reverchon (1997), Mukhopadhyay (2000), Reverchon \& De Marco (2006), Kutta et al., (2007) y DiazMaroto et al., (2005).

La SFE consiste en someter a un disolvente $\left(\mathrm{CO}_{2}\right)$ a un aumento de presión y temperatura, alcanzando la fase supercrítica (Figura 1.7). Es un estado de agregación donde no se distingue la diferencia entre el gas y el líquido (Dick et al., 1996). La densidad de los fluidos supercríticos es intermedia entre gas y líquido; por tanto, su poder solubilizante es similar al de los disolventes líquidos, mientras, 
que sus propiedades de transporte, como viscosidad y difusividad, son similares a las de los gases, lo que permite que el proceso de extracción tenga un mayor rendimiento por penetrar en materiales sólidos porosos más eficazmente que los disolventes líquidos (Riera et al., 2004).

El solvente más comúnmente utilizado para SFE es el $\mathrm{CO}_{2}$, por su bajo punto crítico (temperatura y presión críticas de $31,1 \stackrel{\circ}{\circ}$ y 73.8 bar, respectivamente), su cuasi carácter inerte (Sahena, 2009) y la fácil separación del $\mathrm{CO}_{2}$ del material extraído, ya que a presión atmosférica el $\mathrm{CO}_{2}$ es un gas y puede ser reciclado.

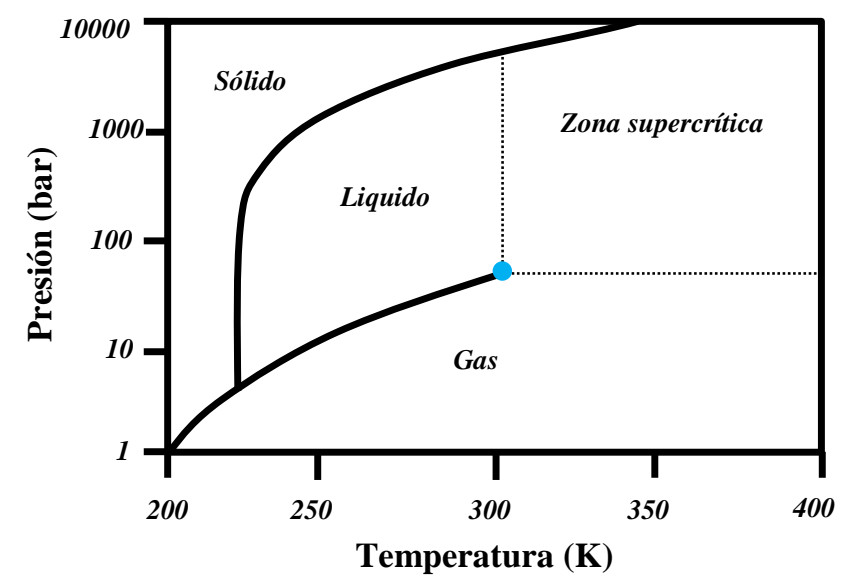

Figura 1.7. Diagrama de fases de $\mathrm{CO}_{2}$

\subsection{CONSIDERACIONES FINALES}

De la revisión bibliográfica realizada se pueden extraer las siguientes conclusiones:

- El secado convectivo por aire caliente es una de las operaciones más usadas en el procesado de alimentos, favoreciendo su uso otros procesos tales como extracción, manipulación, almacenamiento y transporte.

- $\quad$ El secado es una de las actividades industriales que genera mayor consumo energético $\mathrm{y}$, por ende, un impacto ambiental considerable, al mismo tiempo que influye sobre importantes parámetros de aceptación comercial, como son la calidad organoléptica y nutricional de los productos. 
- El secado convectivo presenta actualmente algunas limitaciones, entre las que se encuentran principalmente la baja velocidad del proceso y la pérdida de calidad del producto durante el secado.

- La aplicación de nuevas tecnologías de manera complementaria al secado convectivo puede contribuir a resolver alguna de las limitaciones del mismo. Entre estas tecnologías cabe destacar microondas, radiofrecuencia, radiación infrarroja, ultrasonidos de potencia y el secado intermitente.

- Los efectos que producen los ultrasonidos de potencia sobre los medios en que se aplican pueden influir en los procesos de transferencia calor y materia facilitando el proceso de secado, permitiendo realizar el secado a temperaturas bajas en materiales sensibles al calor.

- Diferentes investigaciones coinciden en que algunas variables del proceso, tales como temperatura, velocidad del aire de secado, intensidad ultrasónica y estructura del material, pueden afectar el secado asistido por ultrasonidos.

- El secado intermitente reduce el tiempo de calentamiento necesario para alcanzar el contenido de humedad deseado, disminuyendo los requerimientos de energía y el tiempo de exposición del producto al efecto de la temperatura, en comparación con procesos donde el suministro de calor es isotérmico.

- La modelización, simulación y optimización del proceso de secado, junto con la experimentación a escala de laboratorio y plantas piloto, son necesarias para estudiar en profundidad el proceso de secado, así como para el desarrollo de nuevos equipos y aplicaciones, y la mejora de los existentes.

- Existen diferentes teorías que intentan explicar el movimiento del agua en el interior del sólido. Entre ellas, la teoría difusional es la más frecuentemente utilizada para la modelización teórica del proceso de secado, con buenos resultados en diferentes productos y procesos.

- $\quad$ El proceso de secado es un sistema complejo, debido a las interacciones que tienen lugar entre los distintos componentes y la forma irregular de algunos materiales. Esto hace más difícil desarrollar modelos matemáticos que describan estos procesos, ya que, en principio, es necesario comprender los principales mecanismos implicados en el proceso. Los modelos matemáticos pueden resultar de una elevada complejidad y requerir de un largo tiempo de cálculo para su resolución.

- En función del objetivo de la modelización se pueden plantear modelos difusionales con diferentes grados de complejidad en su resolución. Esto permite evaluar la relación entre el esfuerzo requerido en la modelización y los resultados obtenidos para, de esta manera, realizar la selección del modelo más oportuno. 
- Los modelos empíricos pueden describir satisfactoriamente la tendencia de la evolución del contenido en humedad a través del tiempo, pero este tipo de modelos no contribuyen al estudio de los fenómenos de transferencialocal de materia y calor. Los modelos empíricos pueden ser muy útiles para aplicaciones industriales o para describir de manera sencilla fenómenos complejos.

- La modelización, además de considerarse como una herramienta para predecir el comportamiento de los procesos de secado, es muy útil de cara a la optimización y/o el control de procesos, constituyendo una herramienta poderosa para evaluar la introducción de una nueva tecnología en un proceso de secado.

- Las redes neuronales (ANN) son una generación de paradigmas para el procesamiento de la información. La principal ventaja es el hecho que pueden simular la relación no lineal entre las variables de entrada y salida sin describir una relación causal, a través de un proceso de aprendizaje.

- El conocimiento de las propiedades físicas es necesario para el desarrollo y resolución de modelos matemáticos fundamentados en los principios físicos que gobiernan el proceso de secado.

- Resulta interesante la utilización de procedimientos de optimización computacional que permitan establecer condiciones de operación adecuadas para la mejora de la eficiencia del proceso y la calidad del producto.

- Muchos compuestos volátiles con capacidad antioxidante normalmente presentes en el tomillo, después del secado incrementan su contenido, lo cual ha hecho que sean objeto de numerosos estudios para demostrar que el cambio en las concentraciones de los compuestos volátiles con capacidad antioxidante durante el secado depende de dos factores cruciales, tiempo y temperatura.

En base a estas consideraciones, resulta interesante realizar un estudio sobre la intensificación de las cinéticas de secado y la capacidad antioxidante de hojas de tomillo. Para disminuir el consumo energético, el impacto ambiental, y la influencia negativa sobre la calidad del producto, sería adecuado investigar la aplicación de tecnologías híbridas, como el secado convectivo asistidos por ultrasonidos de potencia, o aplicando la intermitencia del proceso de secado convectivo tradicional. 


\section{OBJETIVOS Y ESTRUCTURA DE LA TESIS DOCTORAL}



En base a la información obtenida de la revisión bibliográfica, se deduce que el secado convectivo, a pesar de ser unos de los procesos más utilizados, presenta algunas limitaciones de calidad y consumo energético que pueden ser considerados como desafíos para la mejora del proceso.

El principal el objetivo de este trabajo fue contribuir al estudio de la intensificación del secado convectivo mediante la aplicación de ultrasonidos de potencia y secado intermitente, con el fin de reducir el tiempo de proceso y preservar la calidad final del producto seco.

Para alcanzar este objetivo se establecieron los siguientes objetivos parciales:

- Estudiar el efecto de la temperatura y de la velocidad del aire sobre la cinética de secado de tomillo y evaluar la capacidad de diferentes modelos para predecir la evolución del contenido de humedad de las muestras.

- Evaluar el efecto de la temperatura y de la velocidad del aire de secado sobre la capacidad antioxidante de los extractos de tomillo seco, determinando las condiciones óptimas de operación a partir del desarrolló de una herramienta de gestión

- Evaluar y modelizar el efecto del secado convectivo asistido por ultrasonidos de potencia sobre las cinéticas de secado de tomillo, cuantificando la influencia de los ultrasonidos sobre los proceso de transferencia de calor y materia.

- Estudiar y modelizar el efecto de las condiciones de operación del secado convectivo asistido por ultrasonidos de potencia sobre la capacidad de los extractos de tomillo seco, determinando las condiciones óptimas de operación en función de las características de la muestra, y de las condiciones ambientales y operacionales

- Evaluar y modelizar el efecto de intensificación del secado intermitente, gestionando el proceso mediante una estrategia de secado que permita mejorar las cinéticas e incrementar la capacidad antioxidante de los extractos de tomillo seco. 

3. METODOLOGÍA 

La metodología propuesta para dar cumplimiento a los objetivos planteados se describe en la figura 3.1; dando lugar a cada uno de los artículos presentados en el capítulo de resultados

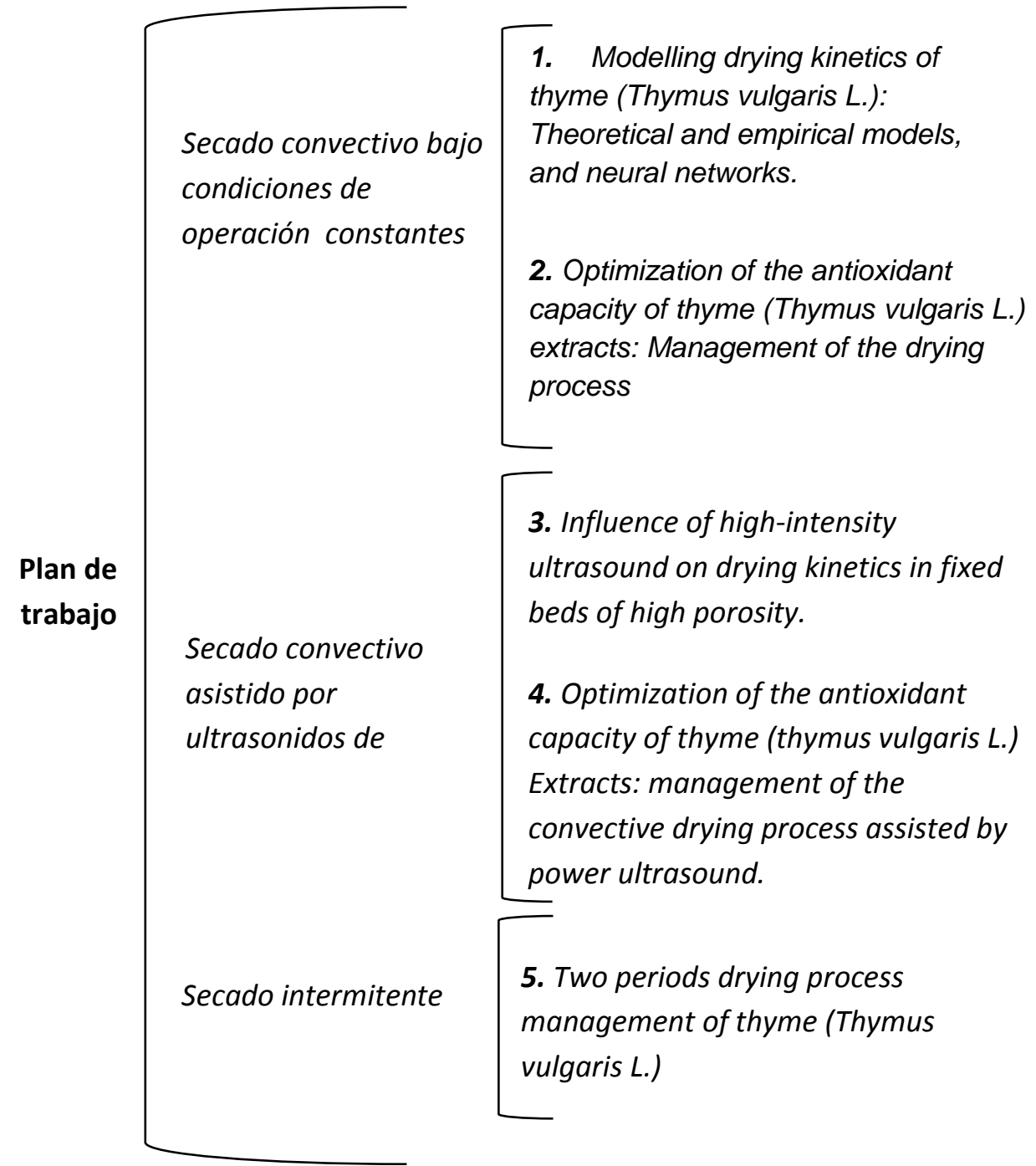

A continuación se describen los procedimientos, equipos comunes y modelos matemáticos desarrollados en cada trabajo de investigación. 


\subsection{MATERIA PRIMA}

Las plantas de tomillo fueron adquiridas en un cultivador local. Las hojas de tomillo fueron retiradas manualmente de los tallos de la planta, posteriormente fueron colocadas en bolsas de polietileno y almacenadas a $4 \pm 2{ }^{\circ} \mathrm{C}$ (Figura 3.1) hasta su procesado antes de 2 días.

\section{Determinación de la humedad}

La metodología seguida para determinar de forma experimental el contenido inicial de humedad de las hojas de tomillo, fue el procedimiento de la AOAC número 934.06 (AOAC, 1997). Se tomaron 3 y $5 \mathrm{~g}$ de la muestra en un pesasustancias. La muestra se distribuyó uniformemente en el fondo del pesasustancias. A continuación, los pesasustancias se introdujeron en una estufa a vacío a $70 \stackrel{\circ}{ } \mathrm{C}$ hasta peso constante (24 horas). Finalmente, los pesasustancias se enfriaron en un desecador y se pesaron. A partir de la variación de peso se calculó el valor del contenido de humedad. La determinación de la humedad experimental de las muestras se realizó en todos los casos por triplicado.

\section{Determinación de la densidad del tomillo}

La densidad del tomillo $\left(\rho_{d s}\right)$ se determinó a partir de la relación de masa de la muestra para el volumen real de la misma mediante el desplazamiento de tolueno (Konak et al., 2002; Nimkar \& Chattopadhyay, 2001). Se obtuvo el volumen de tolueno desplazado en un picnometro al sumergir 2-3 g de muestra.

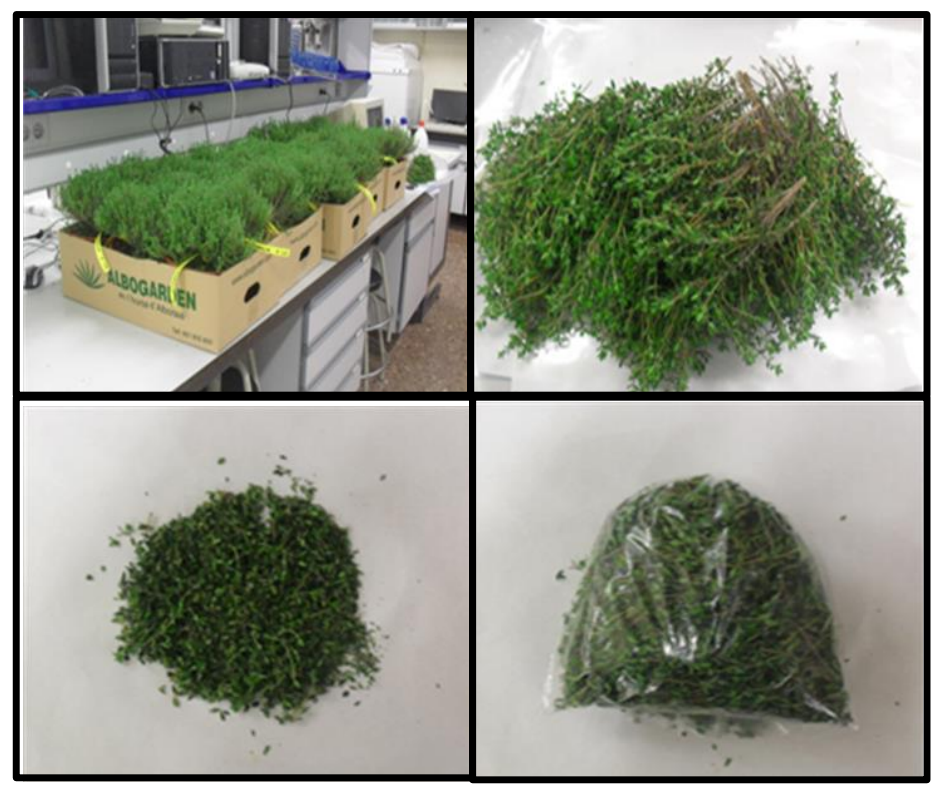

Figura 3.1. Preparación de las muestras para las experiencias de secado. 


\subsection{EXPERIENCIAS DE SECADO}

Para la realización de las experiencias de secado fue empleado un secadero convectivo a escala de laboratorio con control automático de la temperatura y velocidad del aire. El equipo se esquematiza en la Figura 3.2 y se describe a continuación:

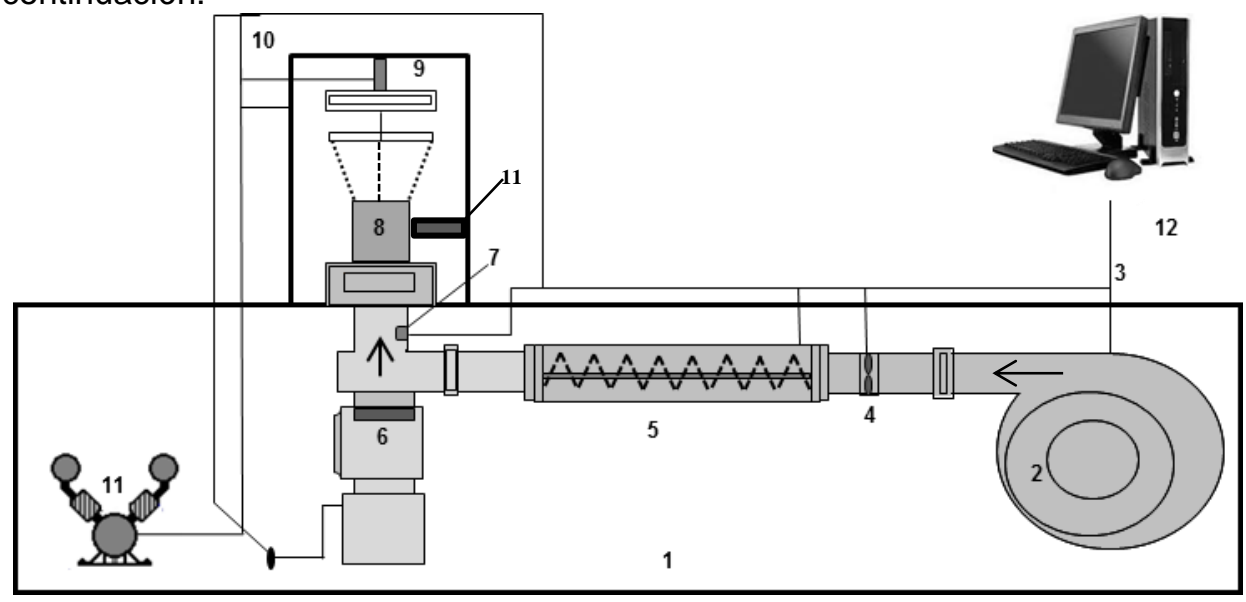

Figura 3.2. Esquema del secadero convectivo a escala de laboratorio empleado en las experiencias de secado. 1. Soporte; 2 . Soplante; 3 . Control de flujo; 4.

Anemómetro; 5 . Resistencia calefactora; 6 . Válvula neumática; 7. Sensor de temperatura (PT-100); 8. Cámara de secado con portamuestras; 9. Balanza de pesada rápida; 10. Elevador; 11. Compresor de aire; 12. Ordenador de adquisición de datos y control; 11. Transductor ultrasónico tipo sándwich.

Sistema de ventilación

El sistema de ventilación está compuesto por un soplante centrífugo de media presión (Fig. 3.2-2) (COT-100, Soler \& Palau, Barcelona, España), que impulsa el aire de secado, a través de las resistencias de calefacción, hacia la cámara de secado. La velocidad del aire impulsado es controlada por medio de un ordenador (Fig. 3.2-12) que actúa sobre un variador de frecuencia (Inverter DV-551, Panasonic, EEUU). La velocidad del aire se mide mediante un anemómetro de rueda alada (Fig. 3.2-4) (Wilh, Lambrecht $\mathrm{GmbH}$, Göttingen, Alemania), con una precisión de $\pm 0.1 \mathrm{~m} \mathrm{~s}^{-1}$, el cual se encuentra conectado a un instrumento indicador/convertidor (TTM-104, Red Lion, Cork, PA, EEUU) que digitaliza el valor de la velocidad del aire.

\section{Sistema de calefacción}

El sistema de calefacción del aire de secado está constituido por resistencias eléctricas (Fig. 3.2-5), con una potencia total de 3000 W. Un sensor PT 100 está conectado a un indicador/convertidor (TM-109, Toho Electronics Inc., Kanagawa, 
Japón), utilizado para digitalizar el valor de la temperatura del aire. El sistema calefactor está controlado por el ordenador, que actúa sobre un variador de intensidad (80 A, Nixa, Valencia, España).

\section{Cámara de secado y sistema de pesada}

La cámara de secado (Fig. 3.2-8) está constituida por un cilindro portamuestras, donde se coloca el material a secar. El portamuestras es pesado de forma periódica mediante una balanza (Fig. 3.2-9) (PM4000, Mettler Toledo, Greifensee, Suiza) conectada al ordenador. Al comienzo de la experiencia de secado la balanza se tara de forma automática, y durante el procesamiento se registra la evolución del peso de la muestra con el tiempo. Durante la pesada, y para mantener la estabilidad de la balanza, una válvula neumática de tres vías (Fig. 3.2-6) desvía momentáneamente la salida del aire.

\section{Sistema de medición de condiciones ambientales}

La temperatura y la humedad relativa ambiental fueron registradas utilizando un sensor (TG 120, Galltec, Bondorf, Alemania) conectado a dos instrumentos indicadores/convertidores (TM-109, Toho Electronics Inc., Kanagawa, Japón).

\section{Sistema de control y adquisición de datos}

El sistema de control lo constituye un ordenador en el que se alojan diferentes programas a ese efecto. El control del secadero se realiza mediante una aplicación informática desarrollada en Microsoft Visual Basic. El programa permite operar el equipo para realizar tanto experiencias de secado continuo como experiencias de secado intermitente. El programa permite seleccionar los valores de consignas de las variables de secado (temperatura y velocidad del aire), el intervalo de tiempo entre pesadas y los criterios de finalización de la operación o de cada periodo (tiempo trascurrido o porcentaje de peso perdido). Además, el programa genera un archivo de datos con toda la información relativa al proceso de secado, es decir, la evolución del peso de las muestras, la temperatura y la velocidad del aire de secado, y la temperatura y la humedad relativa ambiental. El ordenador está conectado al cuadro de control del secadero y a los distintos instrumentos indicadores/convertidores mediante una tarjeta de adquisición de datos (PCL812PG, UCS, Wolverhampton, Reino Unido). A través de un puerto RS232 el ordenador se comunica con la balanza. El programa compara los valores instantáneos de temperatura y velocidad del aire de secado con los valores de consigna, y en función de la diferencia entre ambos, envía, utilizando un algoritmo de control PID, una señal a los actuadores del control (variador de frecuencia y variador de potencia).

Sistema de aplicación de ultrasonidos de potencia

En la figura 3.3 se detalla el montaje del sistema ultrasónico de potencia en el secadero convectivo. 


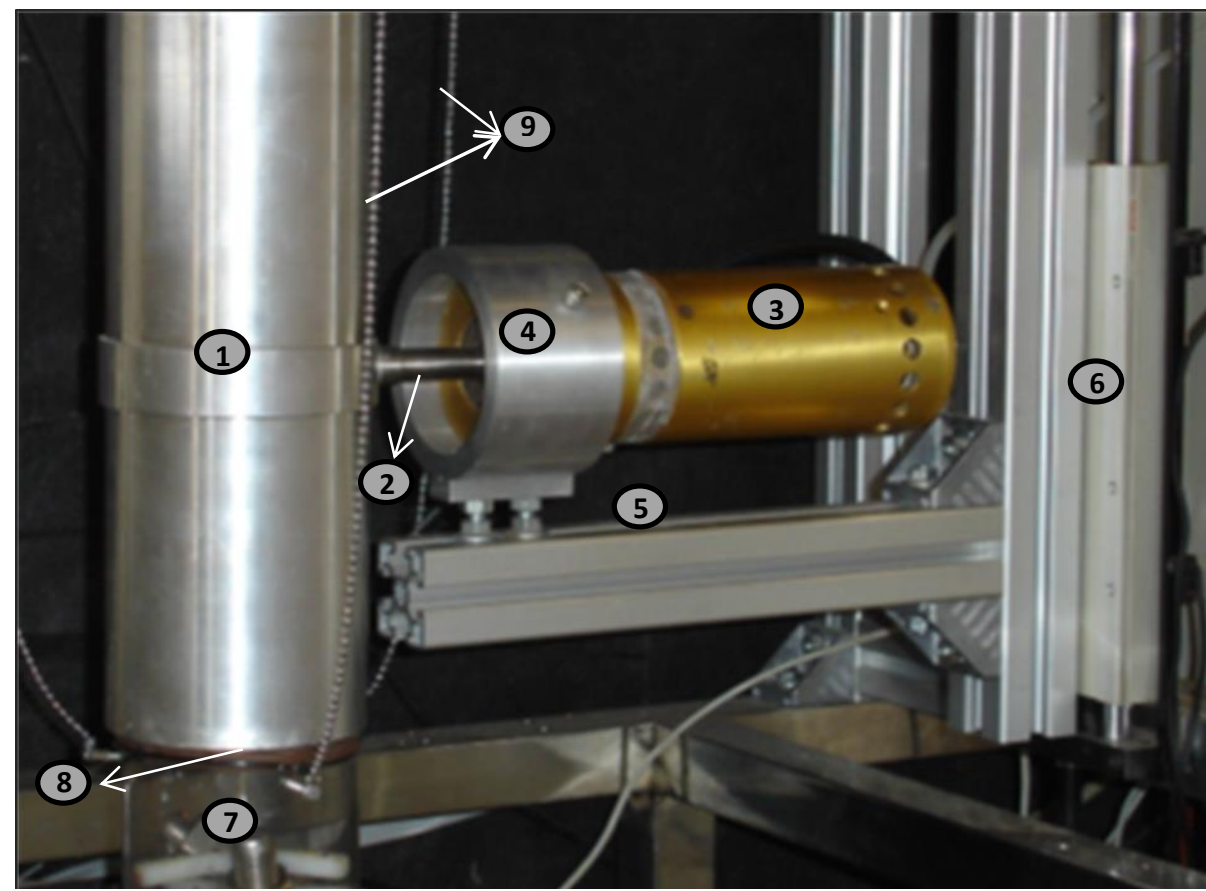

Figura 3.3. Sistema ultrasónico de potencia en el secadero convectivo. 1. Cilindro vibrante; 2 Amplificador mecánico; 3. Transductor ultrasónico tipo sándwich; 4. Brida de anclaje; 5 . Soporte metálico; 6 . Elemento neumático de subida del sistema ultrasónico; 7. Cámara portamuestras; 8 . Junta; 9. Sistema de sujeción para el anclaje de la cámara portamuestras a la balanza.

El sistema de aplicación ultrasónico consistente en un cilindro, vibrando a flexión, excitado por un vibrador compuesto por un transductor tipo sándwich y un amplificador mecánico descrito por García-Pérez (2007a).

En la Figura 3.4 se muestra un esquema que recoge los principales componentes del sistema ultrasónico instalados en el secadero convectivo. El generador ultrasónico de potencia (Instituto de acústica, CSIC, España) se encarga de generar la señal eléctrica a la frecuencia de trabajo y de amplificarla. El adaptador de impedancias (Instituto de Acústica, CSIC, España) permite la optimización eléctrica del sistema. Este adaptador consta de un transformador con una impedancia de entrada de $50 \Omega$ e impedancia variable entre 200 y $500 \Omega$, además de una inductancia con salida variable entre 5 y $9 \mathrm{mH}$ para compensar la capacidad interelectródica del prototipo ultrasónico. La inclusión del vatímetro en el sistema ultrasónico permite excitar al transductor a la frecuencia correcta, que corresponde con el modo de las 12 líneas nodales. 


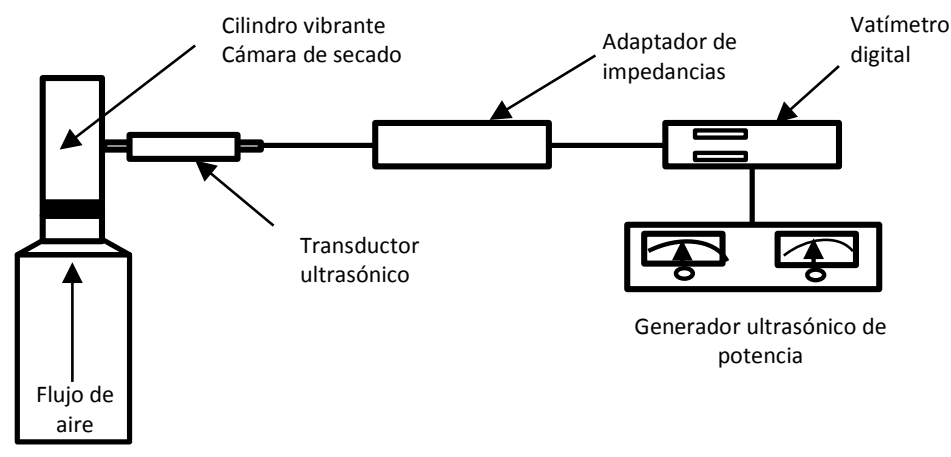

Figura 3.4 Principales elementos del sistema ultrasónico de potencia

Las muestras fueron secadas mediante procesos de secado continuo, secado asistido por ultrasonidos de potencia y secado intermitente. Las hojas de tomillo $(20 \mathrm{~g})$ se distribuyeron uniformemente en el porta muestra, formando un lecho con un espesor de $3 \pm 0.3 \mathrm{~cm}$.

En la Tabla 3.1 se reseñan las condiciones experimentales utilizadas en las diferentes experiencias de secado. Las experiencias se realizaron por triplicado para cada una de las distintas condiciones experimentales.

Tabla 3.1. Condiciones experimentales utilizadas en las experiencias de secado.

\begin{tabular}{|c|c|c|}
\hline $\begin{array}{l}\text { Esquema de } \\
\text { operación }\end{array}$ & Condiciones & Valores \\
\hline \multirow{3}{*}{ Secado continuo } & Temperaturas de secado & $40,50,60$ y $70 \stackrel{\circ}{ } \mathrm{C}$ \\
\hline & Velocidad del aire de secado & $1 \mathrm{~m} \mathrm{~s}^{-1}$ \\
\hline & Contenido final de humedad & Menor o igual $19 \%$ d.b. \\
\hline \multirow{4}{*}{$\begin{array}{l}\text { Secado asistido } \\
\text { por ultrasonidos } \\
\text { de potencia }\end{array}$} & Temperaturas de secado & $40,50,60,70$ y $80^{\circ} \mathrm{C}$ \\
\hline & Velocidad del aire de secado & 1,2 y $3 \mathrm{~m} \mathrm{~s}^{-1}$ \\
\hline & Potencia ultrasónica & $0,6.2,12.3$ y $18.5 \mathrm{~kW} \mathrm{~m}^{-3}$ \\
\hline & Contenido final de humedad & Menor o igual $19 \%$ d.b. \\
\hline \multirow{4}{*}{$\begin{array}{l}\text { Secado } \\
\text { Intermitente }\end{array}$} & Temperatura primer periodo de secado & $80^{\circ} \mathrm{C}$ \\
\hline & Temperatura segundo periodo de secado & $40,50,60$ y $70 \stackrel{\circ}{ } \mathrm{C}$ \\
\hline & Velocidad del aire de secado & 1 y $2 \mathrm{~s}^{-1}$ \\
\hline & Contenido final de humedad & Menor o igual $10 \%$ d.b. \\
\hline
\end{tabular}




\subsection{EXTRACCIÓN DEL ACEITE ESENCIAL DE TOMILLO Y DETERMINACIÓN DE LA CAPACIDAD ANTIOXIDANTE}

Para la obtención del aceite esencial de las hojas secas de tomillo fue empleado el método de extracción de fluidos supercríticos (SFE) en un quipo escala laboratorio (Fig.3.5.).

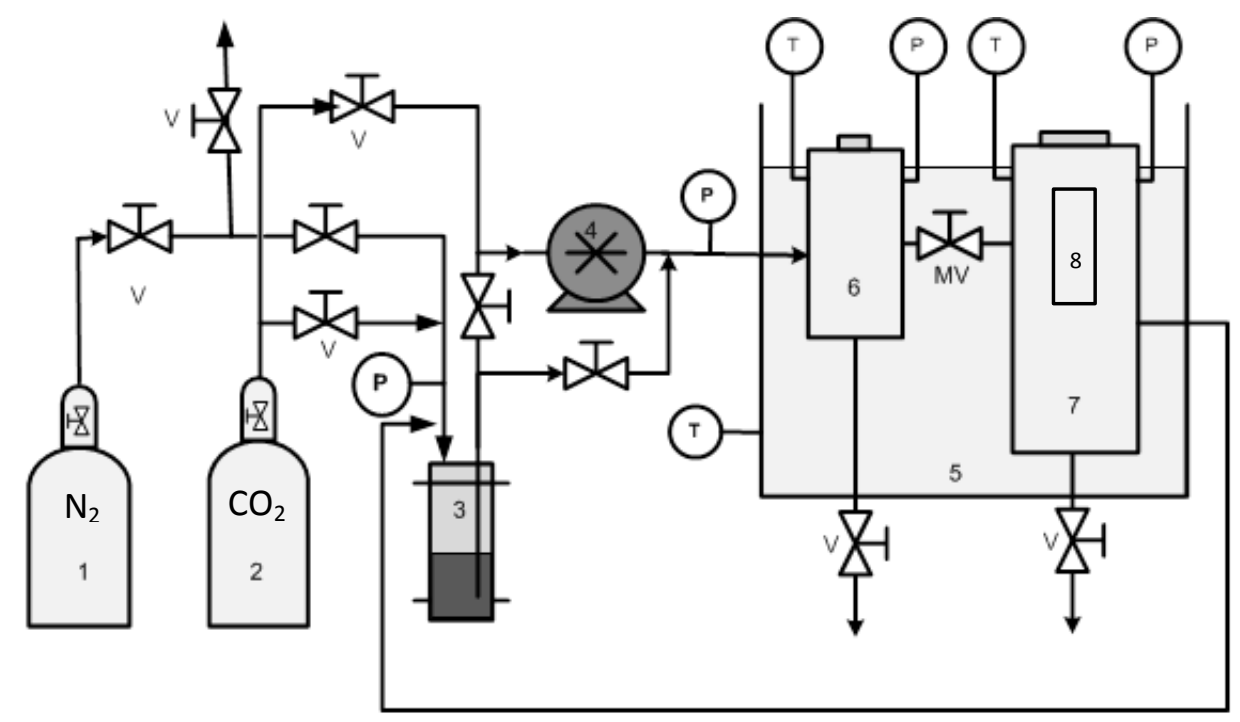

Figura 3.5. Planta escala laboratorio de extracción por $\mathrm{CO}_{2}$ en condiciones supercríticas. 1). Tanque de $\mathrm{N}_{2} ; 2$ ). Tanque de $\left.\mathrm{CO}_{2} ; 3\right)$. Tanque pulmón de $\mathrm{CO}_{2}$ a -18 ํ; 4). Bomba; 5). Baño termostático; 6). Extractor; 7). Tanque separador;

8) Cartucho porta muestra; MV). Microvalvula.

El equipo está diseñado para alcanzar 700 bar. La planta incluye un tanque de $\mathrm{N}_{2}$ (1, Fig. 3.5) y un tanque de $\mathrm{CO}_{2}$ (2, Fig. 3.5), que se mantienen a temperatura ambiente; un depósito de almacenamiento a $-18^{\circ} \mathrm{C}$ (3, Fig. 3.5), una bomba (4, Fig. 3.5) y un baño termostático (5, Fig. 3.5) para mantener el extractor (6, Fig. 3.5) y un tanque separador (7, Fig. 3.5) a la temperatura de proceso.

$\mathrm{CO}_{2}$ líquido se suministra desde el tanque hasta el depósito $\left(-18^{\circ} \mathrm{C}\right)$ en el que se comprime a 200 bar por medio de la inyección de $\mathrm{N}_{2}$ gaseoso. $\mathrm{El} \mathrm{CO}_{2}$ líquido se suministra desde el fondo del depósito de enfriamiento, que por medio de la bomba se comprime a la presión deseada antes de ser inyectado al recipiente extractor, a un flujo constante de $\mathrm{CO}_{2}$ de $6,5 \mathrm{~mL} / \mathrm{min}$. La presión en el recipiente separador se mantuvo constante en $60 \pm 5$ bar, ajustada de forma manual por

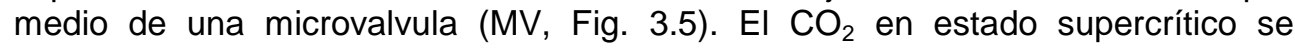
devuelve al depósito de enfriamiento para completar el ciclo de extracción. El extractor, el separador el depósito pulmón y los distintos elementos auxiliares en contacto con $\mathrm{CO}_{2}$ supercrítico son de acero inoxidable tipo 316. Los medidores de 
presión y temperatura están instalados en el recipiente de extracción para monitorizar las condiciones supercríticas.

En un cartucho porta muestra (capacidad de $200 \mathrm{~mL}$ ) se colocaron $3.5 \mathrm{~g}$ de muestra seca y se mezcló con $7 \mathrm{~mL}$ de etanol. El proceso de extracción se llevó a

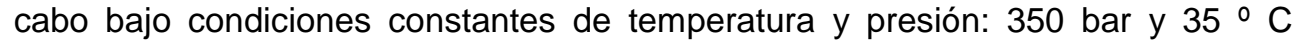
durante $1 \mathrm{~h}$. El extracto $(3-5 \mathrm{~mL})$ se recogió en la parte inferior del separador y se mantuvo refrigerado a $4 \stackrel{\circ}{\mathrm{C}}$ en frascos opacos hasta determinar la capacidad antioxidante antes de 2 días.

-La capacidad antioxidante (AC) de los extractos se midió siguiendo el método FRAP (Saura-Calixto \& Goñi, 2006; Benzie \& Strain, 1996). Con este método, se determina la capacidad de reducción férrica $\left(\right.$ de $\mathrm{Fe}^{3+}$ a $\mathrm{Fe}^{2+}$ ) que tiene una muestra a pH bajo. En presencia de un reductor (antioxidante) el complejo que se forma de hierro $\left(\mathrm{Fe}^{3+}\right)$ con tripiridiltriazina (TPTZ) se reduce a la forma ferrosa $\left(\mathrm{Fe}^{2+}\right)$ dando lugar a una coloración azul intensa con una absorción máxima a $595 \mathrm{~nm}$. Los valores del FRAP se obtienen comparando la absorción de las muestras con la que tiene el TROLOX, un antioxidante sintético. En el procedimiento experimental, se preparó el reactivo FRAP a partir de tampón acetato sódico anhidro $0.3 \mathrm{M} \mathrm{a} \mathrm{pH}$ 3.6, $\mathrm{FeCl}_{3} \cdot 3 \mathrm{H}_{2} \mathrm{O} 20$ milimolar y TPTZ (2, 4,6- tri (2- piridil)-s-triazina) $10 \mathrm{mM}$ en $\mathrm{HCl} 40 \mathrm{mM}$, siendo la proporción utilizada de estos compuestos 1:1:1. En una cubeta de $1.5 \mathrm{~mL}$, se mezclan $30 \mu \mathrm{L}$ de agua destilada, $30 \mu \mathrm{L}$ de muestra y $900 \mu \mathrm{L}$ de reactivo FRAP, en este orden. Tras la mezcla, los reactivos se incubaron durante 30 min en un baño termostático (Tecton 200, P-Selecta) a $37^{\circ} \mathrm{C}$. Tras este tiempo, se midió la absorbancia de las muestras en un espectrofotómetro (He入ios Gamma, Thermo Electro Corporation) a $595 \mathrm{~nm}$. Para cada muestra, se realizaron 3 repeticiones.

Es necesaria la realización de una curva de calibrado de TROLOX para poder interpretar las absorbancias medidas, por lo que los resultados se expresan en $\mathrm{mmol}$ de TROLOX/g de muestra. Para ello se realizaron disoluciones de concentración conocida de TROLOX y se midió la absorbancia a $595 \mathrm{~nm}$, a $37 \stackrel{\circ}{\circ} \mathrm{C}$ a los $30 \mathrm{~min}$. Las disoluciones se realizaron con el mismo disolvente en el que están las muestras, en este caso, etanol 96으 (Panreac).

\subsection{ANALISIS DE LA CINÉTICA DE SECADO. MODELIZACION DEL PROCESO DE SECADO}

Para analizar el proceso de secado se consideraron modelos empíricos, redes neuronales, un modelo teórico sin resistencia externa y un modelo difusivo con resistencia externa.

Para analizar la capacidad de los modelos para describir la evolución del contenido de humedad con cada temperatura de secado ensayada, se realizó una comparación de la bondad del ajustes de los modelos, a partir del análisis de los 
errores relativos (ER) ecuación 3.1 y la la varianza explicada (VAR) ecuación 3.2, del ajuste de los datos experimentales y los valores estimados por cada modelo (Bon et al., 2010). Valores del ER inferiores al $10 \%$ indican un ajuste adecuado para la mayoría de los casos prácticos.

$$
\begin{aligned}
& \mathrm{ER}=\frac{100}{\mathrm{~N}} \sum_{\mathrm{i}=1}^{\mathrm{N}} \frac{\left|\mathrm{Z}_{\exp _{\mathrm{i}}}-\mathrm{Z}_{\mathrm{cal}_{\mathrm{i}}}\right|}{\mathrm{Z}_{\exp _{\mathrm{i}}}} \\
& \mathrm{VAR}=\left[1-\frac{\mathrm{S}_{\mathrm{xy}}^{2}}{\mathrm{~S}_{\mathrm{y}}^{2}}\right]-100
\end{aligned}
$$

Adicionalmente para probar la bondad de cada modelo, se realizó el test de hipótesis nula con un nivel de significación del $5 \%$, para demostrar que los datos del vector residual son aleatorios y tiene una distribución normal con media 0 y varianza desconocida.

\subsubsection{Desarrollo de ANNs}

Los ANNs fueron desarrollados utilizando el lenguaje de programación de Matlab considerando la arquitectura más común de alimentación hacia adelante (feedforward) (Figura 3.6), con varias capas ocultas aplicando el algoritmo de entrenamiento "back-propagation", el cual permitió calcular el valor de los pesos y las bias de la ANN.

Una de las propiedades más común de las ANNs desarrolladas es el uso de funciones de transferencia. Para establecer la función de transferencia adecuada, diferentes funciones de transferencia fueron probadas (tansig, logsig y purelin). Este es un tipo de ANNs tienen un aprendizaje supervisado, basado un algoritmo de gradientes descendente (algoritmo Levenberg-Marquardt), con el fin de minimizar el error. Para el diseño de las redes neuronales fue necesario corregir el problema que surge en el enteramiento de sobre ajuste "over fitting", usando el método de regularización bayesiana o realizando un división de los datos de entrada a la red para cada una de la etapas del análisis (enteramiento, validación y prueba).

Al no existir una regla fija para determinar el número de capas ocultas que debe tener una ANN, el número de capas ocultas se fija en uno, pero estas pueden ser aumentadas si el ajuste no es adecuado. Para seleccionar un número suficiente de neuronas (1-10 neuronas) por capa oculta con las cuales se obtienen el número más bajo de los pesos y bias, se consideraron los valores de los errores cuadráticos medios (MSE) y los coeficientes de correlación en cada etapa del análisis de la ANN.

Para determinar las variables consideradas como input y output, se realizó un análisis de la varianza (ANOVA), para determinar el efecto significativo de las variables consideras input sobre las variables output. 


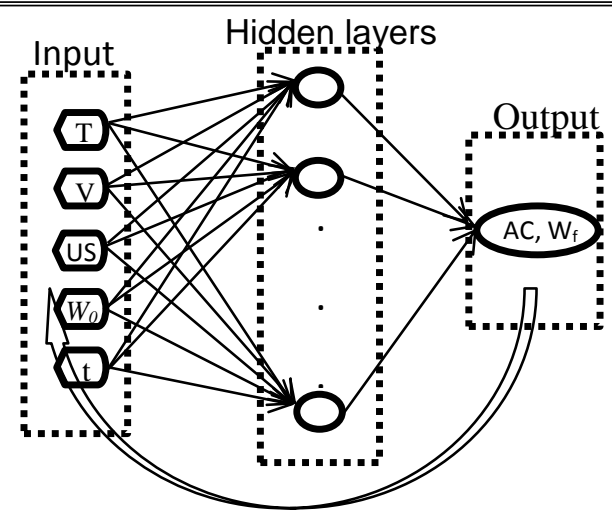

La figura 3.6. Modelo una ANN

Para cada una de las ANN, fue necesario establecer las variables consideras como indendientes (Input) que tenían un efecto significativo sobre la variable dependiente (Target).

Cada conjunto de variables input se establecio en función de las condiciones de operación de cada metodología de secado aplicada.

\subsubsection{Modelo difusional de transferencia de materia y calor en una hoja y en el lecho considerando resistencia externa}

Para modelizar el proceso de secado en el lecho se consideró fenómenos de transferencia de materia y calor en un sistema con lecho poroso y en una hoja de tomillo suponiendo que se comporta como una lámina infinita. La formulación de las ecuaciones de gobierno fue realizada teniendo en cuenta, como simplificaciones, que el material era homogéneo e isótropo, y que el efecto de la contracción sobre los procesos de transferencia era despreciable, y asumiendo que las propiedades de transporte (difusividad efectiva y conductividad térmica) dependían de los valores de temperatura.

Para resolver el modelo, las condiciones iniciales y de contorno fueron establecidas considerando que la distribución de la humedad y la temperatura dentro del sólido al inicio del proceso eran uniformes, que la resistencia externa a la transferencia de materia y de calor no eran despreciables, y que las propiedades del aire alrededor del sólido eran uniformes.

Para completar la formulación del modelo, fueron consideradas las ecuaciones para la estimación de las propiedades térmicas del producto, las isotermas de sorción, los coeficientes de transferencia de calor y de materia por convección, datos psicrométricos (ASAE, 1999; Genskow et al., 2008) y las propiedades físicas del aire húmedo. 


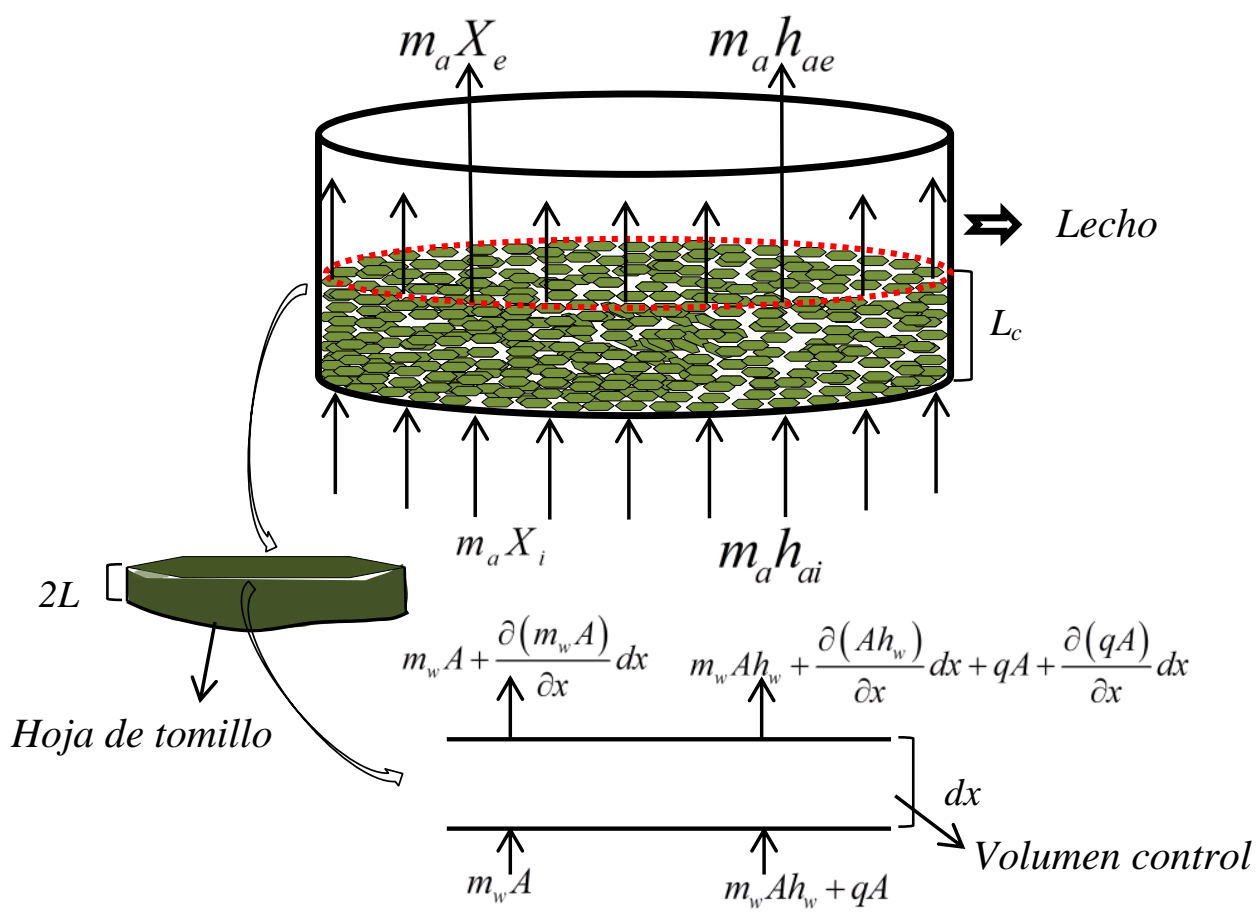

Figura. 3.7. Flujos de calor y de materia entrante y saliente en un lecho y en una hoja de tomillo

A partir de los balances de materia y energía tanto en lecho como en las hojas de tomillo se desarrollaron los modelos para predecir los cambios producidos. Los balances para establecer los modelos se presentan en el anexo 1.

Para la transferencia de calor en el lecho la ecuación de gobierno (Ec 3.3) y condiciones iniciales (Ec. 3.4) fueron:

Ecuación de gobierno

$$
\begin{aligned}
& m_{a} \int_{T_{a}}^{T_{a e}}\left(C p_{a s}+X_{i} C p_{v}\right) d T+\left[m_{a}\left(X_{i}-X_{e}\right)-\varepsilon \rho_{a s} V \frac{d \bar{X}}{d t}\right] \int_{T(1, t)}^{T_{a}} C p_{v} d T \\
& =-(1-\varepsilon) V \frac{h}{L}\left[T(1, t)-T_{a}\right]+\varepsilon \rho_{a s} V\left[C p_{a s}\left(T_{a}\right)+\bar{X} C p_{v}\left(T_{a}\right)\right] \frac{d T_{a}}{d t}
\end{aligned}
$$

Condiciones iniciales

$$
\begin{aligned}
& T(t=0)=T_{0} \\
& T_{a}(t=0)=T_{a 0}
\end{aligned}
$$


Para la transferencia de materia en el lecho la ecuación de gobierno (Ec 3.5) y las condiciones iniciales (Ec. 3.6) fueron:

Ecuación de gobierno

$m_{a}\left(X_{i}-X_{e}\right)=\rho_{d a}\left(T_{a}, X\right) \varepsilon V \frac{d \bar{X}}{d t}+M_{d s} \frac{d \bar{\tau}}{d t}$

Condiciones iniciales

$$
\begin{aligned}
& \bar{X}(t=0)=X_{0} \\
& \bar{\tau}(t=0)=\tau_{0}
\end{aligned}
$$

Para la transferencia de calor en la hoja, la ecuación de gobierno (Ec 3.7), condición de inicial (Ec. 3.8) y condiciones de contorno (Ec. 3.9 y 3.10) fueron:

Ecuación de gobierno

$$
\begin{aligned}
\frac{D}{L^{2}} \rho_{d s} \frac{\partial \tau}{\partial z} C p_{w}(T) \frac{\partial T}{\partial z}= & -\frac{\partial}{\partial z}\left(\frac{\kappa}{L^{2}} \frac{\partial T}{\partial z}\right)+ \\
& \rho_{d s}\left[C p_{d s}(T)+C p_{w} \tau(T)\right] \frac{\partial T}{\partial t}
\end{aligned}
$$

Condición inicial

$$
\bar{T}(z, 0)=T_{0}
$$

Condiciones de contorno

$$
\begin{aligned}
& \frac{\partial T}{\partial z}(0, t)=0 \\
& -\frac{h}{L}\left[T(1, t)-T_{a}\right]=\frac{\kappa(\tau)}{L^{2}} \frac{\partial T}{\partial z}(1, t)-\frac{D}{L^{2}} \rho_{d s} \frac{\partial \tau}{\partial z}(1, t) \lambda(T(1, t))
\end{aligned}
$$

Para la transferencia de materia en la hoja, la ecuación de gobierno (Ec 3.11), condición de inicial (Ec. 3.12) y condiciones de contorno (Ec. 3.13 y 3.14) fueron:

Ecuación de gobierno

$$
0=\frac{\partial}{\partial x}\left(D \rho_{d s} \frac{\partial \tau}{\partial t}\right)+\rho_{d s} \frac{\partial \tau}{\partial t}
$$


Condición inicial

$$
\begin{aligned}
& \tau(z, 0)=\tau_{0} \\
& \text { Condiciones de contorno } \\
& \frac{\partial \tau}{\partial z}(0, t)=0 \\
& -\frac{D}{L^{2}} \rho_{d s} \frac{\partial \tau}{\partial z}(1, t)=\frac{h_{m v}}{L}\left[\rho_{d a i} X_{e q}-\rho_{d a} \bar{X}\right]
\end{aligned}
$$

\subsection{ANALISIS DEL EFECTO DE LAS CONDICIONES DE OPERACIÓN SOBRE LA CAPACIDAD ANTIOXIDANTE DE LOS EXTRACTOS DE TOMILLO SECO}

Para determinar el efecto de las condiciones de operación sobre la capacidad antioxidante de los extractos de tomillo, se realizaron análisis de la varianza (ANOVA) multivariable, obtenido en las experiencias de secado, con el fin de establecer que condiciones de operación tenían un efecto significativo sobre la capacidad antioxidante.

Para gestionar el proceso de secado en función de la capacidad antioxidante (AC) se formuló un problema de optimización que permitiera maximizar $A C$ en función de las condiciones de operación (variables decisorias).

Las condiciones de operación dependen del tipo de secado aplicado, es decir, secado convectivo o secado convectivo asistidos por ultrasonidos de potencia.

Para poder calcular la función objetivo del problema de optimización (AC) fue necesario desarrollar un modelo matemático, que permitiera describir la evolución de $A C$ en función de las condiciones de operación. Debido a la complejidad que envuelve el desarrollo de modelos teóricos que predigan la evolución del AC en función de las condiciones de operación del proceso, se desarrollaron redes neuronales. 


\subsection{NOMENCLATURA}

\begin{tabular}{|c|c|c|}
\hline$A$ & Área de la hoja & $m^{2}$ \\
\hline ANN & Red neuronal artificial & \\
\hline$a_{w}$ & Actividad de agua & \\
\hline $\mathrm{a}, \mathrm{a}_{1}, \mathrm{a}_{\mathrm{Te}}, \mathrm{a}_{\mathrm{Pb}}$ & $\begin{array}{l}\text { Parámetros adimensionales de los modelos empíricos } \\
\text { (Tabla 1.1) }\end{array}$ & \\
\hline $\begin{array}{l}b, b_{H}, b_{L}, b_{T e} \\
b_{P b}, b_{p}, b_{w}\end{array}$ & Parámetros de los modelos empíricos (Tabla 1.1) & $s^{-1}$ \\
\hline $\mathrm{C}, \mathrm{C}_{\mathrm{L}}, \mathrm{C}_{\mathrm{Pb}}$ & Parámetros de los modelos empíricos (Tabla 1.1) & $\mathrm{s}^{-1}$ \\
\hline$C$ & Concentración puntual de humedad & $\mathrm{kg} \mathrm{m}^{-3}$ \\
\hline$C_{p}$ & Calor específico & $\mathrm{kJ} \mathrm{kg}^{-1} \mathrm{~K}^{-1}$ \\
\hline$C p_{a}$ & Calor específico del aire & $\mathrm{kJ} \mathrm{kg}^{-1} \mathrm{~K}^{-1}$ \\
\hline$C p_{d a}$ & Calor específico del aire seco & $\mathrm{kJ} \mathrm{kg}^{-1} \mathrm{~K}^{-1}$ \\
\hline$C p_{d s}$ & Calor específico del sólido seco & $\mathrm{kJ} \mathrm{kg}^{-1} \mathrm{~K}^{-1}$ \\
\hline$C p_{v}$ & Calor específico del vapor de agua & $\mathrm{kJ} \mathrm{kg}^{-1} \mathrm{~K}^{-1}$ \\
\hline$C p_{w}$ & Calor específico del agua & $\mathrm{kJ} \mathrm{kg}^{-1} \mathrm{~K}^{-1}$ \\
\hline$C_{s}$ & Concentración de vapor de agua en la interfase & $\mathrm{kg} \mathrm{m}^{-3}$ \\
\hline$C_{\alpha}$ & Concentración de vapor de agua en el aire & $\mathrm{kg} \mathrm{m}^{-3}$ \\
\hline$D$ & Difusividad efectiva & $\mathrm{m}^{2} \mathrm{~s}^{-1}$ \\
\hline$D_{0}$ & Factor preexponencial de la ecuación Arrhenius & $\mathrm{m}^{2} \mathrm{~s}^{-1}$ \\
\hline$D_{A B}$ & Difusividad del vapor de agua en el aire & $m^{2} s^{-1}$ \\
\hline$E_{a}$ & Energía de activación & $\mathrm{kJ} \mathrm{kmol}^{-1}$ \\
\hline ER & Error relativo & $\%$ \\
\hline$H$ & Entalpía del volumen control & $\mathrm{kJ} \mathrm{kg}^{-1}$ \\
\hline$h$ & $\begin{array}{l}\text { Coeficiente promedio de transferencia de calor por } \\
\text { convección }\end{array}$ & $\mathrm{kW} \mathrm{m} \mathrm{m}^{-2} \mathrm{~K}^{-1}$ \\
\hline$H_{a}$ & Entalpía total del aire en el lecho & $\mathrm{kJ} \mathrm{kg}^{-1}$ \\
\hline$h_{a}$ & Entalpía del aire & $\mathrm{kJ} \mathrm{kg}^{-1}$ \\
\hline$h_{a e}$ & Entalpía del aire a la salida del lecho & $\mathrm{kJ} \mathrm{kg}^{-1}$ \\
\hline$h_{a i}$ & Entalpía del aire a la entrada del lecho & $\mathrm{kJ} \mathrm{kg}^{-1}$ \\
\hline$H_{b}$ & Entalpía de todo el lecho & $\mathrm{kJ} \mathrm{kg}^{-1}$ \\
\hline$h_{d a}$ & Entalpía del aire seco & $\mathrm{kJ} \mathrm{kg}^{-1}$ \\
\hline$h_{d a e}$ & Entalpía del aire seco a la salida del lecho & $\mathrm{kJ} \mathrm{kg}^{-1}$ \\
\hline$h_{d a i}$ & Entalpía del aire seco en la entrada del lecho & $\mathrm{kJ} \mathrm{kg}^{-1}$ \\
\hline$H_{d s}$ & Entalpía del sólido seco en del lecho & $\mathrm{kJ} \mathrm{kg}^{-1}$ \\
\hline$h_{d s}$ & Entalpía del sólido seco & $\mathrm{kJ} \mathrm{kg}^{-1}$ \\
\hline$h_{m v}$ & Coeficiente promedio de transferencia de materia & $\mathrm{m} \mathrm{s}^{-1}$ \\
\hline$H_{s}$ & Entalpía del sólido del lecho & $\mathrm{kJ} \mathrm{kg}^{-1}$ \\
\hline$H_{s u}$ & Entalpía de cada hoja en el lecho & $\mathrm{kJ} \mathrm{kg}^{-1}$ \\
\hline$h_{v}$ & Entalpía especifica del vapor de agua & $\mathrm{kJ} \mathrm{kg}^{-1}$ \\
\hline$H_{w}$ & Entalpía del agua en el lecho & $\mathrm{kJ} \mathrm{kg}^{-1}$ \\
\hline
\end{tabular}




\begin{tabular}{|c|c|c|}
\hline $\begin{array}{l}h_{w} \\
\mathrm{~K}\end{array}$ & $\begin{array}{l}\text { Entalpía especifica de agua liquida } \\
\text { Constante de velocidad modelo emperico }\end{array}$ & $\mathrm{kJ} \mathrm{kg}^{-1}$ \\
\hline$L$ & Longitud características de la hoja & $\mathrm{m}$ \\
\hline$L_{c}$ & Altura del lecho & $\mathrm{m}$ \\
\hline$m_{a}$ & Flujo de másico de aire a través del lecho & $\mathrm{kg} \mathrm{s}^{-1}$ \\
\hline$M_{d a}$ & Masa del aire seco & $\mathrm{kg}$ \\
\hline$M_{d s}$ & Masa del sólido seco & $\mathrm{kg}$ \\
\hline$m_{v}$ & Flujo convectivo de vapor de agua por unidad de área & $\mathrm{kg} \mathrm{m}^{-2} \mathrm{~s}^{-1}$ \\
\hline$M_{v a}$ & Masa de agua en el aire & $\mathrm{kg}$ \\
\hline$m_{w}$ & Flujo de agua por unidad de área en el solido & $\mathrm{kg} \mathrm{m}^{-2} \mathrm{~s}^{-1}$ \\
\hline$M_{w}$ & Masa de agua en la hoja & $\mathrm{kg}$ \\
\hline$m_{x}$ & Flujo másico por unidad de área en la dirección $x$ & $\mathrm{~kg} \mathrm{~m}^{-2} \mathrm{~s}^{-1}$ \\
\hline$N$ & Numero de observaciones & \\
\hline$P$ & Presión total & $\mathrm{kPa}$ \\
\hline$P M_{v}$ & Peso molecular del agua & $\mathrm{kg} \mathrm{kmol}^{-1}$ \\
\hline Ps & Presión de saturación del agua & $\mathrm{kPa}$ \\
\hline$P v$ & Presión de vapor del producto humedo & $\mathrm{kPa}$ \\
\hline$q$ & Flujo de calor por unidad de área & $\mathrm{kW} \mathrm{m} \mathrm{m}^{-2}$ \\
\hline$q_{c}$ & Flujo de calor por conducción por unidad área & $\mathrm{kW} \mathrm{m} \mathrm{m}^{-2}$ \\
\hline$q_{s}$ & Flujo de calor por convección por unidad área & $\mathrm{kW} \mathrm{m} \mathrm{m}^{-2}$ \\
\hline$q_{v}$ & Flujo de calor para evaporar el agua & $\mathrm{kW} \mathrm{m} \mathrm{m}^{-2}$ \\
\hline$R$ & constante de los gases perfectos & $\mathrm{kJ} \mathrm{kmol}^{-1} \mathrm{~K}^{-}$ \\
\hline SFE & Extracción con fluidos supercríticos & \\
\hline$S_{y}$ & Desviación estándar total & \\
\hline$S_{y x}$ & Desviación estándar de la estimación & \\
\hline$t$ & Tiempo & s \\
\hline$T$ & Temperatura de la muestra & $\stackrel{\circ}{\mathrm{C}}$ \\
\hline$T_{0}$ & Temperatura inicial de la muestra & $\stackrel{\circ}{\mathrm{C}}$ \\
\hline$T_{a}$ & Temperatura del aire & $\stackrel{\circ}{\mathrm{C}}$ \\
\hline$T_{a b s}$ & Temperatura absoluta. & $\mathrm{K}$ \\
\hline$T_{a o}$ & Temperatura inicial del aire & $\stackrel{\circ}{\mathrm{C}}$ \\
\hline$T_{p p}$ & Temperatura de la interface solido-aire & $\stackrel{\circ}{\mathrm{C}}$ \\
\hline$T_{s}$ & Temperatura en la superficie del sólido & $\stackrel{\circ}{\mathrm{C}}$ \\
\hline$T_{\alpha}$ & Temperatura del aire fuera de la capa límite & $\stackrel{\circ}{ } \mathrm{C}$ \\
\hline$v$ & Velocidad del aire & $\mathrm{m} \mathrm{s}^{-1}$ \\
\hline$V$ & Volumen del lecho & $m^{3}$ \\
\hline$V_{a}$ & Volumen del aire en el lecho & $\mathrm{m}^{3}$ \\
\hline VAR & Varianza explicada & $\%$ \\
\hline$V_{p}$ & Volumen del solido en todo el lecho & $\mathrm{m}^{3}$ \\
\hline$V_{u}$ & Volumen de la hoja & $\mathrm{m}^{3}$ \\
\hline$x$ & Coordenada espacial & $\mathrm{m}$ \\
\hline $\bar{X}$ & Contenido de humedad media del aire & $\mathrm{kg} \mathrm{kg}^{-1} \mathrm{~b} . \mathrm{s}$ \\
\hline$X$ & Contenido de humedad puntual del aire & $\mathrm{kg} \mathrm{kg}^{-1} \mathrm{~b} . \mathrm{s}$ \\
\hline
\end{tabular}




\begin{tabular}{ll}
\hline \hline$X_{e}$ & Contenido de humedad del aire a la salida del lecho \\
$X_{i}$ & Contenido de humedad del aire a la entrada del lecho \\
$X_{0}$ & Contenido de humedad inicial del aire \\
$X_{e q}$ & Humedad de equilibrio del aire con la humedad de la \\
$y_{v}$ & superficie del sólido \\
$z$ & Fracción molar del vapor de agua \\
$Z_{\text {cal }}$ & Distancia adimensional \\
$Z_{\text {exp }}$ & Valor calculado \\
\hline
\end{tabular}

$\mathrm{kg} \mathrm{kg}^{-1}$ b.s $\mathrm{kg} \mathrm{kg}^{-1}$ b.s $\mathrm{kg} \mathrm{kg}^{-1}$ b.s $\mathrm{kg} \mathrm{kg}^{-1}$ b.s $\mathrm{kmol} \mathrm{kmol}^{-1}$

\section{Símbolos griegos}

$\begin{array}{lll}\mu & \text { Viscosidad del aire } & \mathrm{kg} \mathrm{m}^{-1} \mathrm{~s}^{-1} \\ \mu_{a}, & \text { Viscosidad del aire húmedo } & \mathrm{kg} \mathrm{m}^{-1} \mathrm{~s}^{-1} \\ \mu_{d a} & \text { Viscosidad del aire seco } & \mathrm{kg} \mathrm{m}^{-1} \mathrm{~s}^{-1} \\ \mu_{v} & \text { Viscosidad del vapor de agua } & \mathrm{kg} \mathrm{m}^{-1} \mathrm{~s}^{-1} \\ \varepsilon & \text { Porosidad del lecho } & \\ \theta & \text { Entalpía específica } & \mathrm{kJ} \mathrm{kg}^{-1} \\ \kappa & \text { Conductividad térmica } & \mathrm{W} \mathrm{m}^{-1} \mathrm{k}^{-1} \\ \kappa_{a} & \text { Conductividad térmica del aire húmedo } & \mathrm{kW} \mathrm{m}^{-1} \mathrm{~K}^{-1} \\ \kappa_{d a} & \text { Conductividad térmica del aire seco } & \mathrm{kW} \mathrm{m}^{-1} \mathrm{~K}^{-1} \\ \kappa & \text { Conductividad térmica en el sólido } & \mathrm{kW} \mathrm{m}^{-1} \mathrm{~K}^{-1} \\ \kappa_{v} & \text { Conductividad térmica del vapor de agua } & \mathrm{kW} \mathrm{m}^{-1} \mathrm{~K}^{-1} \\ \lambda & \text { Calor latente de vaporización del agua pura } & \mathrm{kJ} \mathrm{kmol}^{-1} \\ \rho_{a} & \text { Densidad del aire húmedo } & \mathrm{kg} \mathrm{m}^{-3} \\ \rho_{d a} & \text { Densidad del aire seco } & \mathrm{kg} \mathrm{m}^{-3} \\ \rho_{a e q} & \text { Densidad del aire en equilibrio } & \mathrm{kg} \mathrm{m}^{-3} \\ \rho_{d s} & \text { Densidad del sólido seco } & \mathrm{kg} \mathrm{m}^{-3} \\ \tau & \text { Contenido de humedad puntual de la hoja } & \mathrm{kg} \mathrm{kg}^{-1} \mathrm{~b} . S \\ \tau_{0} & \text { Contenido de humedad inicial de la hoja } & \mathrm{kg} \mathrm{kg}^{-1} \mathrm{~b} . \mathrm{s} \\ \tau_{e q} & \text { Contenido de humedad de equilibrio del producto } & \mathrm{kg} \mathrm{kg}^{-1} \mathrm{~b} . S \\ \bar{\tau} & \text { Contenido de humedad promedio en la hoja } & \mathrm{kg} \mathrm{kg}^{-1} \mathrm{~b} . S \\ \omega & \text { Contenido de humedad adimensional } & \end{array}$


4. RESULTADOS 



\title{
4.1. MODELLING DRYING KINETICS OF THYME (Thymus Vulgaris L.): THEORETICAL AND EMPIRICAL MODELS, AND NEURAL NETWORKS
}

J. Rodríguez, G. Clemente, N. Sanjuán and J. Bon

FOOD SCIENCE AND TECHNOLOGY INTERNATIONAL

DOI: $10.1177 / 1082013212469614$

\begin{abstract}
The drying kinetics of thyme was analyzed by considering different conditions: air temperature of between $40{ }^{\circ} \mathrm{C}$ and $70{ }^{\circ} \mathrm{C}$, and air velocity of $1 \mathrm{~m} / \mathrm{s}$. A theoretical diffusion model and eight different empirical models were fitted to the experimental data. From the theoretical model application, the effective diffusivity per unit area of the thyme was estimated (between $3.6810^{-5}$ and $2.1210^{-4} \mathrm{~s}^{-1}$ ). The temperature dependence of the effective diffusivity was described by the Arrhenius relationship with activation energy of $49.42 \mathrm{~kJ} / \mathrm{mol}$. Eight different empirical models were fitted to the experimental data. Additionally, the dependence of the parameters of each model on the drying temperature was determined, obtaining equations that allow estimating the evolution of the moisture content at any temperature in the established range. Furthermore, artificial neural networks were developed and compared with the theoretical and empirical models using the percentage of the relative errors and the explained variance. The artificial neural networks were found to be more accurate predictors of moisture evolution with VAR $>99.3 \%$ and $\mathrm{ER}<$ $8.7 \%$.
\end{abstract}

Keywords: Mathematical models, fitting models, model comparisons 


\section{INTRODUCTION}

The food industry is becoming increasingly interested in aromatic herbs, mainly of the Lamiaceae family, for its medicinal properties and for possessing a wide variety of antioxidant components such as phenolic compounds.

Thyme (Thymus vulgaris L.) is a member of the Lamiaceae family, native to Mediterranean countries. It is very important for the horticultural industry and can be used in herbal teas or as a condiment and the essential oils extracted from its fresh leaves and flowers are known for their different beneficial properties: antiseptic, carminative, antimicrobial and antioxidative (Shati and Elsaid, 2009). However, thyme is perishable, which requires the use of preservation methods in order to lengthen its useful life for further use (Doymaz, 2009).

Hot air drying is one of the oldest food preservation processes. However, the exposure to thermal energy can affect important food properties, such as the chemical composition, texture, color and flavor. Therefore, the selection of a suitable drying method, developing an appropriate mathematical model, and the determination of the optimum operating parameters, are essential to achieve high quality, minimum cost products with a maximum yield (Clemente et al., 2011).

Many mathematical models have been proposed to describe the drying process. These models can be categorized as theoretical, semi-theoretical and empirical (McMinn, 2006; Ozdemir and Devres, 1999). A great deal of research has been carried out into the mathematical modeling and experimental drying processes of different agro-based products, such as kiwifruits (Maskan, 2001), red pepper (Akpinar et al., 2003), aromatic plants (Akpinar, 2006), tea leaves (Ghodake et al., 2006), rosemary leaves (Arslan and Ozcan, 2008), onion (Lee and Kim, 2008), and spinach leaves (Doymaz, 2009).

Food processing is a complex system due to the complicated interactions that take place between various components. This makes it more difficult to develop mathematical models, since, in principle, it is necessary to understand the major mechanisms involved in the process. Despite the criticism that it is not based on fundamental and/or individuals laws, an artificial neural network is an effective tool for developing mathematical models of relatively complex processes, mainly due to its ability to learn (Zhou and Therdthai, 2010). ANNs are being applied in agri-food processes including drying, baking, osmotic dehydration and high-pressure processes as well as in the estimation of food properties and quality indicators (Sablani and Rahman, 2003; Chegini, 2008). Recently, modeling the drying of food products using ANN has gained momentum for irregular geometries (Erenturk and Erenturk, 2007); however, there is no reference in literature to the modeling of thyme drying using ANN. 
The objectives of this study were to apply and compare a theoretical model, different empirical models, and ANNs to predict the evolution of thyme moisture content during the convective drying at different temperatures.

\section{MATERIALS AND METHODS}

\section{Sample preparation}

Fresh thyme samples (Thymus vulgaris L.) were acquired from a grower/producer in Valencia, Spain, and kept in refrigeration $\left(4^{\circ} \mathrm{C}\right)$ for their later use. The initial moisture content was determined according to the AOAC standards (1997), obtaining the following results: $78.42 \%$ (w.b.) \pm 3.26 .

\section{Drying experiments}

Several drying experiments were carried out in triplicate, at constant temperatures of $40,50,60$ and $70{ }^{\circ} \mathrm{C}$, and an air velocity of $1.0 \mathrm{~m} / \mathrm{s}$; the relative humidity of the hot air was between $3.7-18 \%$. In every experiment, the sample's initial weight was $50 \mathrm{~g}( \pm 0.5 \mathrm{~g})$, and the drying process was performed until the final moisture content was about $10 \%$ (w.b.). The thyme samples were distributed uniformly into de drying chamber, forming a bed with a thickness of $2.99 \pm 0.2 \mathrm{~cm}$, and the air flow passed through the bed.

A completely automatic, laboratory scale convective drier (Sanjuán, et al., 2003), with control of air temperature and velocity was used (Figure 1). The drying chamber was formed by a cylindrical sample holder which was periodically weighed (at 5 min intervals), and the weight was measured and registered using a balance connected to a computer.

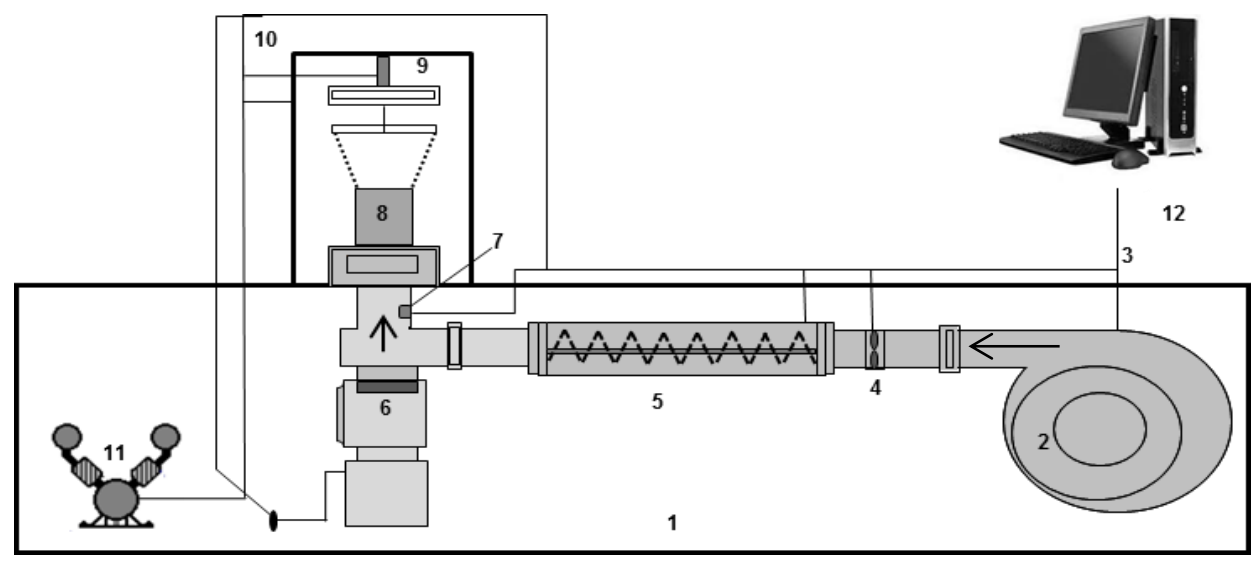

Figure 1. Schema of an automatic convective drier on a laboratory scale: (1) support; (2) fan; (3) flow control; (4) anemometer; (5) electrical resistance; (6) pneumatic valve;

(7) temperature sensor; (8) drying chamber; (9) balance; (10) elevator; (11) air compressor; and (12) control and data acquisition. 


\section{Mathematical modeling}

\section{Theoretical model}

Considering that the product behaves like an infinite slab, a theoretical model (Eqs. (1) to (2)) based on Fick's particular law was applied, taking the following simplifications into account: (i) negligible external resistance to mass transfer; (ii) isotropic and homogenous material; (iii) negligible material shrinkage.

$$
\begin{aligned}
& \frac{\tau_{(t)}-\tau_{e}}{\tau_{O}-\tau_{e}}=2 \sum_{\mathrm{n}=0}^{\infty} \frac{\mathrm{e}^{-D \beta_{\mathrm{n}}^{2} \mathrm{t}}}{\beta_{\mathrm{n}}^{2} \mathrm{~L}^{2}} \\
& \beta_{\mathrm{n}}=(2 \mathrm{n}+1) \frac{\pi}{2 \mathrm{~L}}
\end{aligned}
$$

The equilibrium moisture values were estimated using the Modified Halsey equation (Eq. (3)) obtained from literature (Soysal, 2001).

$$
a_{w}=\exp \left[-\exp \left(2.97977-0.00258492 T^{1.37743}\right) \tau_{e}^{-1.44139}\right]
$$

To estimate the equilibrium moisture content from equation (3) the relative humidity is needed. The relative humidity of the hot air was calculated from the hot air temperature and the relative humidity and the temperature of the environment, considering that the wet air behaves like a perfect gas.

The saturation pressure of water vapor in the wet air was estimated using an equation obtained from literature (ASAE, 1999).

The experimental results were applied to fit the mathematical model obtaining the value of the effective diffusivity $(D)$. Later, the dependence of the parameters on the air temperature was analyzed applying the Arrhenius equation (Eq. (4))

$$
D=D_{0} \exp \left(-\frac{E_{a}}{R(T+273.16)}\right)
$$

\section{Empirical models}

A search was performed to find mathematical models of the convective drying of irregular shaped products, like thyme. Table 1 shows 7 widely used semitheoretical drying models (Doymaz, 2011), where $\omega$ is the dimensionless moisture content (Eq. (5)) and $t$ is the time. 
$\omega(t)=\frac{\tau_{(t)}-\tau_{e}}{\tau_{0}-\tau_{e}}$

Tabla 1. Empirical models selected

\begin{tabular}{ll}
\hline Model name & Model \\
\hline 1. Newton & $\omega=\exp (-b t)$ \\
\hline 2. Henderson and Pabis & $\omega=a \exp \left(-b_{H} t\right)$ \\
\hline 3. Page & $\omega=\exp \left(-b_{P} t^{c}\right)$ \\
\hline 4. Logarithmic & $\omega=a_{L} \exp \left(-b_{L} t\right)+c_{L}$ \\
\hline 5. Two-term exponential & $\omega=a_{T e} \exp \left(-b_{T e} t\right)+\left(1-a_{T e}\right) \exp \left(-b_{T e} a_{T e} t\right)$ \\
\hline 6. Wang and Singh & $\omega=1+a_{W} t+b_{W} t^{2}$ \\
\hline 7. Parabolic & $\omega=a_{P b}+b_{P b} t+C_{P b} t^{2}$ \\
\hline
\end{tabular}

The equilibrium moisture content values $\left(\tau_{e}\right)$ were determined using equation (3), from the experimental values of the hot air temperature, and the relative humidity and temperature of the environment, considering that the wet air behaves like a perfect gas.

The experimental drying kinetics was used to fit mathematical models in order to obtain the values of the model parameters. Subsequently, the dependence of the parameters on the air temperature was analyzed, searching for polynomial relations in order to obtain, in each case, a generic model that could predict the evolution of the dimensionless moisture content in function of the time and temperature.

\section{Artificial Neural networks}

ANNs, a new generation of information processing paradigms designed to mimic some of the behaviors of the human brain (Bas, and Boyaci, 2007), has as main advantage the fact that ANNs can simulate the nonlinear relationship between input and output variables through a learning process, and generalize the knowledge among homologous series without need for theoretical and empirical models.

ANNs were applied to predict the average moisture content evolution and dimensionless moisture content: (a) one ANN to predict the dimensionless moisture content evolution $\left(\mathrm{ANN}_{\mathrm{r}}\right)$ and (b) a second $\mathrm{ANN}$ to predict the average moisture content evolution $\left(\mathrm{ANN}_{\mathrm{t}}\right)$.

The ANNs were developed considering the most common architecture, based on a multilayer feed-forward structure with the back-propagation training algorithm used for computing the ANN weights and biases. This architecture is the result of a 
'universal approximation' (Hornik et al., 1989; Siegelman and Sontag, 1991) computing model based on Kolmogorov's theorem (Kolmogorov, 1957) and the more comprehensive observation done by Hecht-Nielsen (1990). There are two

main ideas behind a feed-forward neural network: (a) the first idea is a full connection architecture, as the outputs of neurons from the previous layer are connected with the corresponding inputs of all neurons of the following layer and (b) the second idea is a back-propagation learning algorithm, when the errors of the neurons from the output layer are being sequentially back-propagated through all the layers from the 'right hand' side to the 'left hand' side, in order to calculate the errors of all other neurons. One more common property of a major part of the feedforward networks is the use of sigmoid activation functions for its neurons. This is a type of network of supervised learning that is based on an algorithm of descending gradients (Levenberg-Marquardt algorithm) (Levenberg, 1944; Marquardt, 1963), in order to minimize the error. One of the problems that occur during neural network training is called overfitting. The error on the training set is driven to a very small value, but when new data is presented to the network, the error is large. The network has memorized the training examples, but it has not learned to generalize to new situations (Lertworasirikul and Saetan, 2010). To improve the generalization, the method called regularization was applied, which updates the weight and bias values according to the Levenberg-Marquardt optimization. It minimizes a combination of squared errors and weights, and then determines the correct combination so as to produce a network that generalizes well. The process is called Bayesian regularization (Aggarwal et al., 2005; MacKay, 1992).

There is no fixed rule for determining the required hidden layers and nodes. In general, one hidden layer has been found to be adequate, and only in some cases, may a slight advantage be gained using two hidden layers (Lertworasirikul and Saetan, 2010). Therefore, although the number of hidden layers was fixed at one, this could be increased if the fit was not adequate, while the number of neurons in the hidden layer, and transference functions between layers (tansig, logsig and purelin) were investigated. To fit each ANN, a total of 273 data from 15 drying experiments were used. In the ANN developed to predict the evolution of the dimensionless moisture content $\left(\mathrm{ANN}_{\mathrm{r}}\right)$, two independent variables were considered: drying temperature $(\mathrm{T})$ and time $(\mathrm{t})$; as target matrix, the dimensionless moisture content was applied. In the ANN developed to predict the evolution of the average moisture content $\left(\mathrm{ANN}_{\mathrm{t}}\right)$, four inputs were considered: drying temperature $(T)$, relative air humidity ( $h r)$, initial sample moisture $\left(\mathrm{W}_{0}\right)$ and time $(\mathrm{t})$. With this ANN, the evolution of the average moisture content would be evaluated. The evolution of the value of the average moisture content depends both on the air conditions $(\mathrm{T}, \mathrm{hr})$ and the initial moisture content $\left(\mathrm{W}_{0}\right)$, for which reason the variables $\mathrm{hr}$ and $\mathrm{W}_{0}$ were added as inputs. In this case, the average moisture content was considered as target matrix.

The proposed neural networks possessed a common structure: an input vector, with two components $(T, t)$ (Figure 2(a)) or four components $\left(T, t, h_{r}, W_{0}\right)$ (Figure 
2(b)), one or two hidden layers with a number of neurons to be estimated, an output layer with one neuron, and one output (dimensionless moisture content or average moisture content). In the hidden layers, the transfer function was studied, and the linear transfer function was applied in the output layer.

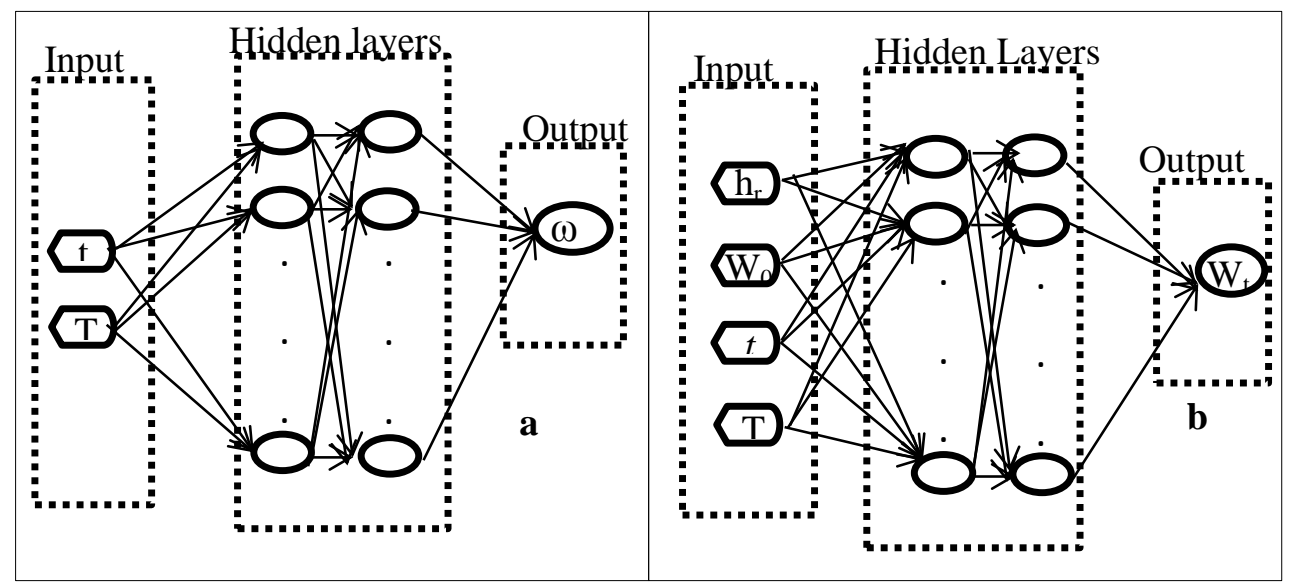

Figure 2. Neural network schemes. a) Inputs vector with two components; b) Inputs vector with four components.

\section{Statistical analysis}

The average value of the percentage of the relative errors (ER) (equation (6)) and the explained variance (VAR) statistics were used to evaluate the accuracy of fit (Bon et al., 2010). The average value of the relative errors is a measure of the random component in the estimation. VAR indicates the proportion of variance that is accounted for by the model.

$\mathrm{ER}=\frac{100}{\mathrm{~N}} \sum_{\mathrm{i}=1}^{\mathrm{N}} \frac{\left|\mathrm{Z}_{\exp _{\mathrm{i}}}-\mathrm{Z}_{\mathrm{cal}_{\mathrm{i}}}\right|}{\mathrm{Z}_{\exp _{\mathrm{i}}}}$

\section{Computional tools}

To fit the theoretical model, obtaining the value of the parameter $D$, and to analyze the dependence of the $D$ fitting the Arrhenius equation, algorithms were developed using MatlabßR2009a (The MathWorks, 2009) as the computational tool. The 'nlinfit' function was applied to estimate the parameter values, by means of nonlinear regression, and the 'nlparci' function to estimate the confidence intervals for the parameters. 
To fit the empirical models the Curve Fitting Toolbox of Matlab®R2009a was applied. To develop the ANN, the Neural Network Toolbox ${ }^{\text {TM }}$ of Matlab®R2009a was used. Using the Matlab languages, a function was developed to create, by applying the function 'newff', and to train, by applying the function 'train', a feedforward backpropagation network. This function looked for the number of neurons in the hidden layers.

\section{RESULTS AND DISCUSSION}

\section{Drying kinetic}

Figure 3 shows the drying kinetics of thyme for different air temperatures; predictably, the drying rate increases as the air temperature rises. At the beginning of the drying process, when the moisture content of the product is high, the drying rate is relatively high; in the same way it can be observed that when the product moisture content decreases, the drying rate drops. As can be observed from Figure 5.1 .3 , at drying temperatures of $60{ }^{\circ} \mathrm{C}$ and $70{ }^{\circ} \mathrm{C}$, the drying time is reduced considerably by $76 \%$ and $85 \%$, compared to the drying total time at $40{ }^{\circ} \mathrm{C}$.

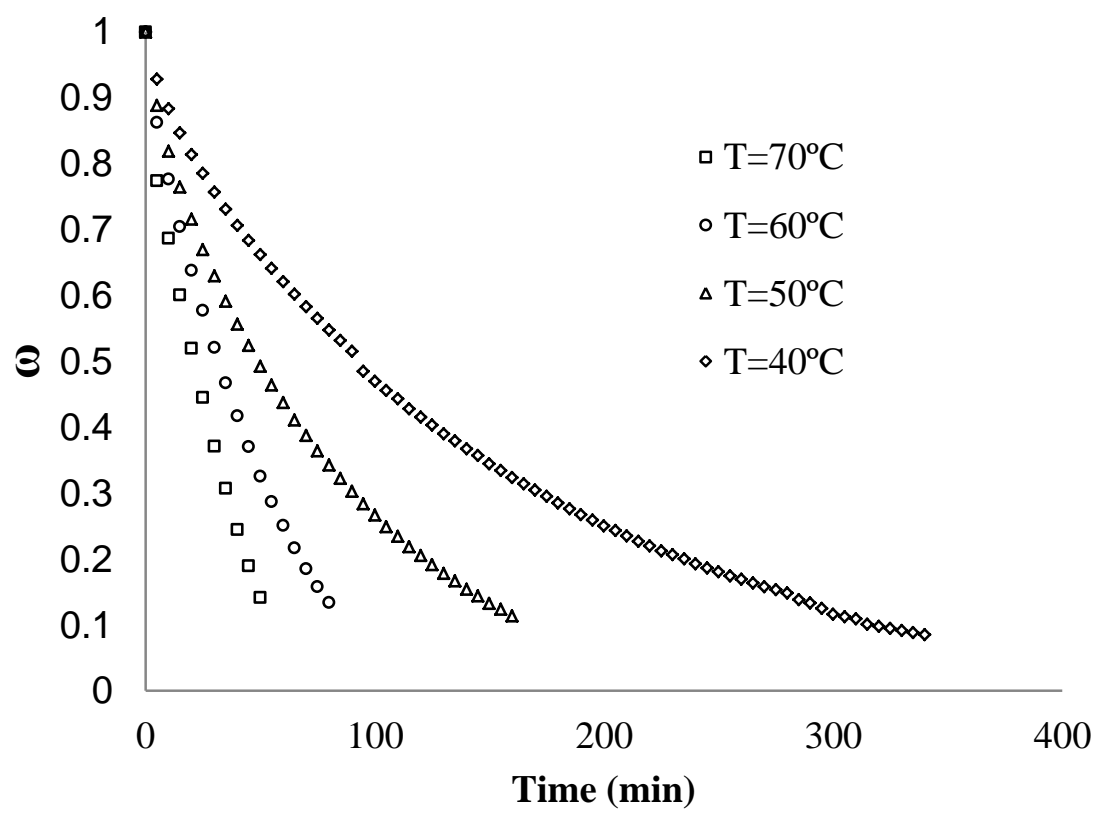

Figure 3. Thyme drying at different air temperatures 


\section{Theoretical model}

The theoretical model was defined by considering several assumptions according equation (1), as the external resistance to mass transfer was negligible. A way to assess the relative importance of external resistance is by means of equation (7) (Mulet, 1994).

$$
\frac{d[\operatorname{Ln}(\omega)]}{d t}=\frac{(q+m \omega)^{0.5}}{\omega}
$$

Plotting $\left(\omega d[\operatorname{Ln}(\omega] / d t)^{2}\right.$ versus $\omega$ allows the prevailing resistance to be assessed. When external resistance predominates, the plot is a straight line. Otherwise, it is a parabola; as can be observed from Figure 4, the internal resistance governs mass transfer during the drying process.

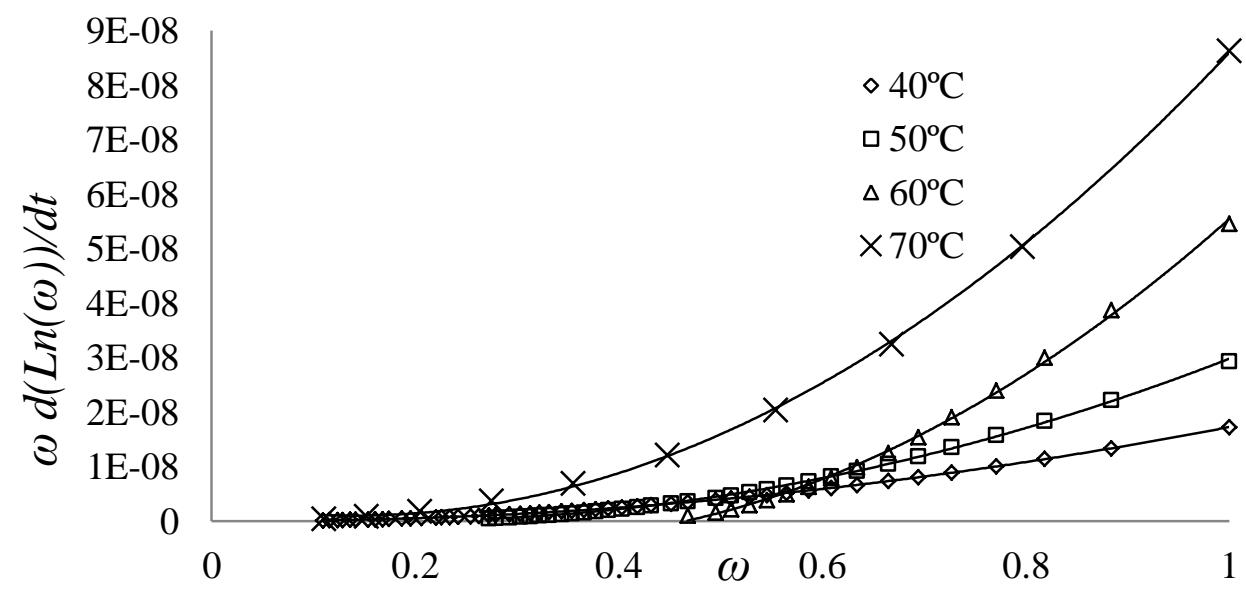

Figure 4. Influence of external resistance on drying kinetics of thyme.

The estimated values of $D$ for all the drying conditions are presented in Table 2, obtaining values between $3.6810^{-5}$ and $2.1210^{-4} \mathrm{~s}^{-1}$. As expected, the values increased greatly in-line with the increase in drying temperature. The results show a good fit between the experimental and estimated values (VAR > 95.7\%; ER < $20.8 \%$ ). To fit the dependence of $D$ on the temperature (equation (4)) by means of a nonlinear regression the initial values of the parameters were estimated by fitting equation (4) linearized. Table 3 presents the parameter values obtained using the nonlinear regression, obtaining activation energy with a value of $49.42 \mathrm{~kJ} / \mathrm{mol}$. 
Table 2. Values of effective diffusivity per unit area at different hot air temperatures ( $D$ \pm standard deviation) $10^{-9}\left(\mathrm{~s}^{-1}\right)(95 \%$ confidence intervals $)$.

\begin{tabular}{|c|c|c|c|c|c|}
\hline \multirow{2}{*}{$\begin{array}{c}T \\
\left({ }^{\circ} \mathrm{C}\right)\end{array}$} & \multirow{2}{*}{$D\left(\mathrm{~s}^{-1}\right)$} & \multicolumn{2}{|c|}{ Confidence bounds } & \multirow{2}{*}{ ER (\%) } & \multirow{2}{*}{ VAR (\%) } \\
\hline & & Lower & higher & & \\
\hline 40 & $7.7 \pm 1.1$ & 7.4 & 8.0 & $20.8 \pm 3.8$ & $95.7 \pm 1.3$ \\
\hline 50 & $15.2 \pm 1.2$ & 14.7 & 15.7 & $11.0 \pm 1.2$ & $98.5 \pm 0.9$ \\
\hline 60 & $27.6 \pm 2.5$ & 25.7 & 29.6 & $17.4 \pm 2.5$ & $97.5 \pm 1.4$ \\
\hline 70 & $44.5 \pm 1.4$ & 44.4 & 48.6 & $18.4 \pm 3.2$ & $98.3 \pm 1.6$ \\
\hline
\end{tabular}

Relative error (ER) considering the dimensionless moisture content.

Table 3. Results of the fit of the Arrhenius equation (95\% confidence intervals)

\begin{tabular}{|c|c|c|c|c|c|}
\hline \multirow{2}{*}{ Parameter } & \multirow{2}{*}{ Value } & \multicolumn{2}{|c|}{ Confidence bounds } & \multirow{2}{*}{ ER (\%) } & \multirow{2}{*}{ VAR (\%) } \\
\hline & & Lower & higher & & \\
\hline$D_{0}\left(\mathrm{~m}^{2} / \mathrm{s}\right)$ & 7855 & -1879 & 34500 & \multirow{2}{*}{3.6} & \multirow{2}{*}{99.8} \\
\hline$E_{a}(\mathrm{~kJ} / \mathrm{mol})$ & 49.42 & 40.05 & 58.80 & & \\
\hline
\end{tabular}

\section{Empiricals models}

Dimensionless moisture content data versus drying time were fitted with the different models listed in Table 1. Tables 4 to 7 present the results of nonlinear regression analysis performed to fit the empirical models for each drying temperature. The results show a good fit between the experimental and estimated values of every model (VAR $>97.6 \%$; $E R<16.7 \%$ ). To analyze the dependence of the parameters of the models with the temperature, polynomial equations were fitted, because previously it was checked that the Arrhenius equation did not estimate properly the relationship between the parameters and the temperature.

Table 8 presents the polynomial relations between parameters and temperature, and the statistical results of the fit of the polynomial equations. When these equations are considered in the corresponding model, generic models are obtained to be used in the temperature interval under consideration $\left(40-70^{\circ} \mathrm{C}\right)$. 
Table 4. Results of the fitting of empirical models using experimental results obtained by air drying at $40{ }^{\circ} \mathrm{C}$

\begin{tabular}{|l|l|r|r|r|r|r|r|r|}
\hline Models & & & Models parameters & VAR (\%) & ER (\%) \\
\hline 1. & $\mathrm{~b}$ & $0.00014 \pm 2.610^{-5}$ & & & $99.2 \pm 0.01$ & $7.2 \pm 1.3$ \\
\hline 2. & $\mathrm{a}$ & $0.91300 \pm 0.0$ & $\mathrm{~b}_{\mathrm{H}}$ & $0.00014 \pm 0.0$ & $99.4 \pm 0.03$ & $16.7 \pm 3.2$ \\
\hline 3. & $\mathrm{~b}_{\mathrm{P}}$ & $0.00040 \pm 2.110^{-5}$ & $\mathrm{C}$ & $0.89675 \pm 0.05$ & $99.8 \pm 0.01$ & $3.5 \pm 0.9$ \\
\hline 4. & $\mathrm{a}_{\mathrm{L}}$ & $0.88070 \pm 0.0$ & $\mathrm{~b}_{\mathrm{L}}$ & $0.00017 \pm 0.0$ & $\mathrm{C}_{\mathrm{L}}$ & $0.05746 \pm 0.0$ & $99.7 \pm 0.02$ & $12.2 \pm 2.4$ \\
\hline 5. & $\mathrm{a}_{\mathrm{Te}}$ & $0.28265 \pm 0.02$ & $\mathrm{~b}_{\mathrm{Te}}$ & $0.00021 \pm 2.110^{-5}$ & $99.6 \pm 0.05$ & $4.3 \pm 1.1$ \\
\hline 6. & $\mathrm{a}_{\mathrm{W}}$ & $-0.00011 \pm 1.610^{-5}$ & $\mathrm{~b}_{\mathrm{W}}$ & $3.7410^{-9} \pm 1.010^{-9}$ & & $99.9 \pm 0.00$ & $12.7 \pm 3.4$ \\
\hline 7. & $\mathrm{a}_{\mathrm{Pb}}$ & $0.890600 \pm 0.07$ & $\mathrm{~b}_{\mathrm{Pb}}$ & $-0.000090 \pm 1.210^{-5}$ & $\mathrm{C}_{\mathrm{Pb}}$ & $2.7010^{-9} \pm 7.510^{-10}$ & $99.2 \pm 0.06$ & $5.9 \pm 1.8$ \\
\hline
\end{tabular}

Table 5. Results of the fitting of empirical models using experimental results obtained by air drying at $50 \stackrel{\circ}{C}$

\begin{tabular}{|c|c|c|c|c|c|c|c|c|}
\hline \multicolumn{2}{|c|}{ Models } & \multicolumn{5}{|c|}{ Models parameters } & \multirow{2}{*}{$\frac{\text { VAR (\%) }}{99.2 \pm 0.03}$} & \multirow{2}{*}{$\frac{\text { ER (\%) }}{8.3 \pm 1.3}$} \\
\hline 2. & $\mathrm{~b}$ & $0.00023 \pm 1.310^{-5}$ & & & & & & \\
\hline 2. & a & $0.96680 \pm 0.02$ & $b_{H}$ & $0.00023 \pm 3.0210^{-5}$ & & & $99.7 \pm 0.01$ & $3.7 \pm 0.9$ \\
\hline 3. & $b_{p}$ & $0.00028 \pm 1.010^{-4}$ & C & $0.98983 \pm 0.04$ & & & $99.8 \pm 0.01$ & $4.5 \pm 1.2$ \\
\hline 4. & $a_{L}$ & $1.10853 \pm 0.23$ & $b_{L}$ & $0.00023 \pm 4.0810^{-6}$ & $C_{L}$ & $0.018580 \pm 0.110^{-3}$ & $99.7 \pm 0.02$ & $7.1 \pm 0.6$ \\
\hline 5. & $\mathrm{a}_{\mathrm{Te}}$ & $1.01350 \pm 0.02$ & $\mathrm{~b}_{\mathrm{Te}}$ & $0.00025 \pm 2.0610^{-5}$ & & & $99.1 \pm 0.02$ & $4.2 \pm 2.3$ \\
\hline 6. & $a_{w}$ & $-0.00019 \pm 1.910^{-5}$ & $b_{W}$ & $1.3610^{-8} \pm 2.4610^{-9}$ & & & $99.9 \pm 0.00$ & $10.0 \pm 2.4$ \\
\hline 7. & $\mathrm{a}_{\mathrm{Pb}}$ & $0.92746 \pm 0.013$ & $\mathrm{~b}_{\mathrm{Pb}}$ & $-0.00017 \pm 2.0210^{-5}$ & $\mathrm{C}_{\mathrm{Pb}}$ & $9.32012^{-9} \pm 1.0510^{-9}$ & $99.2 \pm 0.02$ & $5.1 \pm 0.7$ \\
\hline
\end{tabular}


Table 6 Results of the fitting of empirical models using experimental results obtained by air drying at $60{ }^{\circ} \mathrm{C}$

\begin{tabular}{|c|c|c|c|c|c|c|c|c|}
\hline \multicolumn{2}{|c|}{ Models } & \multicolumn{5}{|c|}{ Models parameters } & \multirow{2}{*}{$\frac{\text { VAR (\%) }}{97.6 \pm 0.10}$} & \multirow{2}{*}{$\frac{\text { ER }(\%)}{8.7 \pm 1.3}$} \\
\hline 3. & $\mathrm{~b}$ & $0.00039 \pm 1.310^{-5}$ & & & & & & \\
\hline 2. & a & $1.01310 \pm 0.02$ & $b_{H}$ & $0.00039 \pm 2.7410^{-5}$ & & & $98.1 \pm 0.50$ & $9.0 \pm 1.5$ \\
\hline 3. & $b_{p}$ & $0.00018 \pm 3.110^{-5}$ & C & $1.09400 \pm 0.15$ & & & $99.8 \pm 0.60$ & $8.2 \pm 2.3$ \\
\hline 4. & $a_{L}$ & $1.13300 \pm 0.66$ & $b_{L}$ & $0.00029 \pm 8.1910^{-}$ & $C_{L}$ & $-0.15505 \pm 6.6310^{-2}$ & $99.2 \pm 0.30$ & $3.1 \pm 0.8$ \\
\hline 5. & $\mathrm{a}_{\mathrm{Te}}$ & $1.56800 \pm 0.13$ & $\mathrm{~b}_{\mathrm{Te}}$ & $0.00045 \pm 2.5710^{-4}$ & & & $99.2 \pm 0.40$ & $4.1 \pm 1.2$ \\
\hline 6. & $a_{w}$ & $-0.00031 \pm 1.110^{-5}$ & $b_{w}$ & $2.4810^{-8} \pm 6.0510^{-9}$ & & & $98.8 \pm 0.80$ & $4.3 \pm 0.5$ \\
\hline 7. & $a_{\mathrm{Pb}}$ & $0.971700 \pm 8.10^{-3}$ & $\mathrm{~b}_{\mathrm{Pb}}$ & $-0.000280 \pm 7.310^{-6}$ & $\mathrm{C}_{\mathrm{Pb}}$ & $2.0510^{-9} \pm 5.5710^{-10}$ & $99.5 \pm 0.30$ & $3.4 \pm 0.8$ \\
\hline
\end{tabular}

Table 7. Results of the fitting of empirical models using experimental results obtained by air drying at $70 \stackrel{\circ}{ } \mathrm{C}$

\begin{tabular}{|c|c|c|c|c|c|c|c|c|}
\hline \multicolumn{2}{|c|}{ Models } & \multicolumn{5}{|c|}{ Models parameters } & \multirow{2}{*}{$\frac{\text { VAR (\%) }}{99.2 \pm 0.12}$} & \multirow{2}{*}{$\frac{\text { ER (\%) }}{11.9 \pm 1.3}$} \\
\hline 1. & $b$ & $0.00054 \pm 4.110^{-5}$ & & & & & & \\
\hline 2. & a & $1.02936 \pm 0.04$ & $b_{H}$ & $0.00055 \pm 4.0710^{-5}$ & & & $99.4 \pm 0.13$ & $10.8 \pm 1.8$ \\
\hline 3. & $b_{p}$ & $0.00012 \pm 2.110^{-5}$ & C & $1.26433 \pm 0.16$ & & & $99.8 \pm 0.23$ & $9.1 \pm 0.9$ \\
\hline 4. & $a_{L}$ & $1.25743 \pm 0.28$ & $b_{L}$ & $0.00040 \pm 1.1910^{-4}$ & $C_{L}$ & $-0.27942 \pm 2.1310^{-2}$ & $99.7 \pm 0.16$ & $6.2 \pm 1.3$ \\
\hline 5. & $\mathrm{a}_{\mathrm{Te}}$ & $1.01350 \pm 0.16$ & $\mathrm{~b}_{\mathrm{Te}}$ & $0.00025 \pm 2.3710^{-4}$ & & & $99.6 \pm 0.12$ & $5.8 \pm 1.1$ \\
\hline 6. & $a_{w}$ & $-0.00038 \pm 4.610^{-5}$ & $b_{W}$ & $3.3110^{-8} \pm 1.6610^{-8}$ & & & $99.9 \pm 0.01$ & $3.3 \pm 0.3$ \\
\hline 7. & $a_{\mathrm{Pb}}$ & $0.98566 \pm 0.02$ & $b_{\mathrm{Pb}}$ & $-0.00040 \pm 2.4810^{-5}$ & $\mathrm{C}_{\mathrm{Pb}}$ & $4.0910^{-9} \pm 3.1210^{-10}$ & $99.2 \pm 1.1$ & $2.6 \pm 0.8$ \\
\hline
\end{tabular}


Table 8. Empirical relations between parameters and temperature, and statistical results.

\begin{tabular}{ccrcc}
\hline Model & Polynomial equation & VAR (\%) & ER (\%) \\
\hline $\mathbf{1}$ & $\mathrm{b}$ & $1.33810^{-5} \mathrm{~T}-0.00041$ & 99.3 & 6.5 \\
\hline $\mathbf{2}$ & $\mathrm{a}$ & $0.991 \pm 0.051$ & & \\
& $\mathrm{~b}_{\mathrm{H}}$ & $1.41310^{-5} \mathrm{~T}-4.43210^{-4}$ & 99.3 & 7.1 \\
\hline $\mathbf{3}$ & $\mathrm{b}_{\mathrm{P}}$ & $-8.53110^{-6} \mathrm{~T}+7.19610^{-4}$ & 97.5 & 15.8 \\
& $\mathrm{c}$ & $1.13410^{-2} \mathrm{~T}+4.33710^{-1}$ & 98.3 & 1.7 \\
\hline \multirow{2}{*}{$\mathbf{4}$} & $\mathrm{a}_{\mathrm{L}}$ & $1.39410^{-2} \mathrm{~T}+2.88010^{-1}$ & 94.6 & 4.1 \\
& $\mathrm{~b}_{\mathrm{L}}$ & $6.81310^{-6} \mathrm{~T}-1.06010^{-4}$ & 96.7 & 4.2 \\
& $\mathrm{C}_{\mathrm{L}}$ & $-2.48410^{-4} \mathrm{~T}^{2}+1.53410^{-2} \mathrm{~T}-1.51710^{-1}$ & 98.6 & 13.1 \\
\hline \multirow{2}{*}{$\mathbf{5}$} & $\mathrm{a}_{\mathrm{Te}}$ & $-1.14810^{-3} \mathrm{~T}^{2}+1.75710^{-1} \mathrm{~T}-4.9017$ & 99.3 & 2.9 \\
& $\mathrm{~b}_{\mathrm{Te}}$ & $3.16310^{-7} \mathrm{~T}^{2}-1.96510^{-5} \mathrm{~T}+4.76310^{-4}$ & 99.3 & 7.2 \\
\hline \multirow{2}{\mathbf{6}}{} & $\mathrm{a}_{\mathrm{W}}$ & $-9.04210^{-6} \mathrm{~T}+2.49410^{-4}$ & 99.3 & 3.6 \\
& $\mathrm{~b}_{\mathrm{W}}$ & $1.14810^{-9} \mathrm{~T}-4.35710^{-8}$ & 97.8 & 13.2 \\
\hline \multirow{2}{*}{$\mathbf{7}$} & $\mathrm{a}_{\mathrm{Pb}}$ & $-4.61910^{-5} \mathrm{~T}^{2}+8.41910^{-3} \mathrm{~T}+6.26510^{-1}$ & 99.1 & 4.1 \\
& $\mathrm{~b}_{\mathrm{Pb}}$ & $-1.06010^{-5} \mathrm{~T}+3.44510^{-4}$ & 99.6 & 5.7 \\
& $\mathrm{C}_{\mathrm{Pb}}$ & $2.82610^{-11} \mathrm{~T}^{2}-1.87410^{-9} \mathrm{~T}+3.23210^{-8}$ & 99.8 & 3.6 \\
\hline
\end{tabular}

\section{Artificial neural network}

The number of hidden layers (between 1 and 3 ) and the number of neurons of each hidden layer (between 2 and 10), and the corresponding bias and weights numbers, was looked for, selecting the number hidden layers and the number of neurons for which the 'best' values of the objective function applied in the training of the ANN was obtained. For that, the function created using the Matlab language was applied. Table 9 presents both the number of hidden layers, the number of neurons in the hidden layers and also the transfer function used in each ANN.

The correlation between the experimental and estimated values by neural networks can be observed from Table 10. 
Tabla 9. Number of hidden layers and number of neurons

in the hidden layers

\begin{tabular}{|cccccc|}
\cline { 2 - 6 } \multicolumn{1}{c}{} & Transfers & Number of & Number of & VAR (\%) & ER (\%) \\
\hline \multirow{2}{*}{ ANN $_{\mathbf{r}}$} & Tansig & 1 & 10 & 97.8 & 10.1 \\
& Logsig & 1 & 10 & 96.9 & 9.2 \\
& Purelin & 1 & 10 & 78.9 & 24.3 \\
\hline \multirow{2}{*}{ ANN $_{\mathbf{t}}$} & Tansig & 1 & 10 & 98.7 & 8.9 \\
& Logsig & 1 & 10 & 98.8 & 7.6 \\
& Purelin & 1 & 10 & 79.9 & 18.9 \\
\hline \multirow{2}{*}{ ANN $_{\mathbf{r}}$} & Tansig & 2 & $6 / 4$ & 99.7 & 3.7 \\
& Logsig & 2 & $5 / 5$ & 98.7 & 2.8 \\
& Purelin & 2 & $4 / 4$ & 78.9 & 18.9 \\
\hline \multirow{2}{*}{ ANN $_{\mathbf{t}}$} & Tansig & 2 & $5 / 5$ & 99.9 & 1.6 \\
& Logsig & 2 & $5 / 6$ & 99.9 & 3.4 \\
& Purelin & 2 & $4 / 2$ & 84.4 & 24.3 \\
\hline \multirow{2}{*}{ ANN $_{\mathbf{r}}$} & Tansig & 3 & $4 / 2 / 4$ & 99.3 & 2.4 \\
& Logsig & 3 & $5 / 2 / 3$ & 98.9 & 3.2 \\
& Purelin & 3 & $4 / 3 / 2$ & 82.1 & 8.9 \\
\hline \multirow{2}{*}{ ANN $_{\mathbf{t}}$} & Tansig & 3 & $5 / 3 / 2$ & 99.2 & 1.6 \\
& Logsig & 3 & $4 / 2 / 4$ & 99.1 & 2.4 \\
& Purelin & 3 & $3 / 4 / 2$ & 85.6 & 13.5 \\
\hline
\end{tabular}

\section{Models comparison}

Table 10 presents the statistical results of the application of the generic models, considering the experimental results for each temperature and considering all the experimental results. In every case, the designed neural networks show the best agreement for the drying curves of thyme, with VAR $>99.3 \%$ and $\mathrm{ER}<2.9 \%$ for $A N N_{r}$, and with VAR $>99.7 \%$ and $E R<8.7 \%$ for $\mathrm{ANN}_{\mathrm{t}}$. 
Tabla 10. Statistical results of the fit (for all experimental results) and of the application $\left(40{ }^{\circ} \mathrm{C}, 50 \stackrel{\circ}{\circ}, 60{ }^{\circ} \mathrm{C}\right.$ and $\left.70 \stackrel{\circ}{\circ}\right)$ of the generic models.

\begin{tabular}{|c|c|c|c|c|c|c|c|c|c|c|c|}
\hline & & \multicolumn{2}{|c|}{$40^{\circ} \mathrm{C}$} & \multicolumn{2}{|c|}{$50^{\circ} \mathrm{C}$} & \multicolumn{2}{|c|}{$60^{\circ} \mathrm{C}$} & \multicolumn{2}{|c|}{$70^{\circ} \mathrm{C}$} & \multicolumn{2}{|c|}{ All experimental } \\
\hline & & VAR (\%) & ER (\%) & VAR (\%) & ER (\%) & VAR (\%) & ER (\%) & VAR (\%) & ER (\%) & VAR (\%) & ER (\%) \\
\hline Theoretical model & & 99.5 & 5.6 & 99.7 & 5.5 & 98.4 & 3.7 & 97.1 & 19.5 & 93.4 & 17.8 \\
\hline \multirow{7}{*}{ Empirical models } & 1. & 99.3 & 14.7 & 99.6 & 12.7 & 99.2 & 8.5 & 98.6 & 14.0 & 97.1 & 13.0 \\
\hline & 2. & 99.3 & 14.4 & 99.5 & 13.8 & 99.2 & 8.7 & 98.4 & 12.4 & 96.9 & 13.2 \\
\hline & 3. & 99.5 & 13.3 & 99.1 & 23.5 & 98.7 & 23.2 & 98.3 & 21.1 & 96.7 & 18.5 \\
\hline & 4. & 99.1 & 12.2 & 99.7 & 8.9 & 99.6 & 8.2 & 99.4 & 13.9 & 97.5 & 10.4 \\
\hline & 5. & 99.1 & 68.6 & 99.3 & 19.0 & 99.5 & 12.7 & 99.3 & 20.5 & 87.3 & 39.6 \\
\hline & 6. & 93.4 & 50.8 & 91.4 & 56.2 & 99.6 & 8.1 & 99.4 & 45.1 & 92.1 & 40.4 \\
\hline & 7. & 97.2 & 52.2 & 99.2 & 31.2 & 99.5 & 13.7 & 99.4 & 8.7 & 89.6 & 35.5 \\
\hline \multirow{2}{*}{ ANNs } & $\mathrm{ANN}_{\mathrm{r}}$ & 99.9 & 0.6 & 99.8 & 1.4 & 99.7 & 1.4 & 99.3 & 2.9 & 99.7 & 3.7 \\
\hline & $\mathbf{A N N}_{\mathrm{t}}$ & 99.9 & 0.8 & 99.9 & 0.7 & 99.9 & 3.3 & 99.7 & 8.7 & 99.9 & 1.6 \\
\hline
\end{tabular}

Relative error (ER) was calculated considering the dimensionless moisture content, except for $\mathrm{ANN}_{\mathrm{t}}$, where the ER is calculated considering the average moisture content, in $\mathrm{db}$. 


\section{CONCLUSIONS}

Analyzing the influence of the temperature on the parameters of the models studied, generic models to estimate the evolution of dimensionless moisture content in function of the hot air temperature and drying time were obtained.

For the global application of the theoretical and empirical generic models analyzed, the logarithmic model showed the best statistical results of the fit. The fit of the theoretical diffusive model allowed estimating the effective diffusivity per unit area and the activation energy for the thyme variety used. Both for individual cases (for each air hot temperature) to general cases (global application), the ANNs application showed the best statistical results of the fit.

Therefore, the ANNs developed constitute an adequate model to predict the moisture content, representing the evolution of thyme drying better than either the theoretical model or the empirical models proposed. The models developed through ANNs would be of special interest in the formulation and optimization problems on line, and in the predictive control of process.

\section{FUNDING}

The authors acknowledge the financial support from the 'Ministerio de Educación y Ciencia' in Spain, CONSOLIDER INGENIO 2010 (CSD2007-00016).

\section{NOMENCLATURE}

$\mathrm{a}, \mathrm{a}_{1}, \mathrm{a}_{\mathrm{Te}}, \mathrm{a}_{\mathrm{Pb}}$ Dimensionless parameters of empirical models

$a_{w}$ Water activity

$a_{w} \quad$ Parameters of empirical model $\left(s^{-1}\right)$

ANN Artificial neural network

$\mathrm{ANN}_{\mathrm{r}}$ ANN developed to predict the evolution of the dimensionless moisture content

ANN $_{t}$ ANN developed to predict evolution of the average moisture content

$b, b_{H}, b_{L}, b_{T e}, b_{P b} \quad$ Parameters of empirical models $\left(s^{-1}\right)$

$b_{P} \quad$ Parameter of empirical model $\left(s^{-1}\right)$

$b_{W}$ Parameter of empirical model $\left(s^{-2}\right)$

C, $C_{L}$ Dimensionless parameters of empirical models

$\mathrm{C}_{\mathrm{Pb}}$ Parameter of empirical model $\left(\mathrm{s}^{-2}\right)$

D Effective diffusivity $\left(\mathrm{s}^{-1}\right)$ 


$$
\begin{aligned}
\mathrm{D}_{o} & \text { Parameter of the Arrhenius equation }\left(\mathrm{m}^{2} / \mathrm{s}\right) \\
E_{a} & \text { Activation energy }(\mathrm{kJ} / \mathrm{mol}) \\
\mathrm{ER} & \text { Average value of the relative errors }(\%) \\
\mathrm{h}_{\mathrm{r}} & \text { Relative humidity } \\
\mathrm{L} & \text { Semi-thickness of the bed }(\mathrm{m}) \\
\mathrm{m} & \text { Parameter of equation } 5.1 .7 \\
\mathrm{~N} & \text { Number of observations } \\
\mathrm{q} & \text { Parameter of equation } 5.1 .7 \\
\mathrm{R} & \text { Constant of perfect gas }(\mathrm{kJ} / \mathrm{mol} \mathrm{K}) \\
\mathrm{T} & \text { Air temperature }\left({ }^{\circ} \mathrm{C}\right) \\
\mathrm{t} & \text { Drying time (s, min) } \\
\mathrm{VAR} & \text { Explained variance }(\%) \\
\mathrm{Z}_{\mathrm{cal}} & \text { Calculated value of a property } \\
\tau & \text { Average moisture content, in dry basis }(\mathrm{kg} / \mathrm{kg}) \\
\tau_{0} & \text { Initial moisture content, in dry basis }(\mathrm{kg} / \mathrm{kg}) \\
\tau_{e} & \text { Equilibrium moisture content, in dry basis }(\mathrm{kg} / \mathrm{kg})
\end{aligned}
$$

\section{REFERENCES}

Aggarwal, K. K., Singh, Y., Chandra, P., Puri, M. (2005). Bayesian Regularization in a Neural Network Model to Estimate Lines of Code Using Function Points. Journal of Computer Sciences, 1, (4):505-509.

Akpinar, E.K. ( 2006). Mathematical modelling of thin layer drying process under open sun of some aromatic plants. Journal of Food Engineering, 77: 864-870.

Akpinar, E. K., Bicer, Y., Yildiz, C. (2003). Thin layer drying of red pepper. Journal of Food Engineering, 59: 99-104.

AOAC. (1997). Official methods of analysis of AOAC International, 16th edn, (Association of Official Analytical Chemist International AOAC, Gaithersburg, USA).

Arslan, D., Ozcan, M.M. (2008). Evaluation of drying methods with respect to drying kinetics, mineral content and color characteristics of rosemary leaves. Energy Conversion and Management, 49, 1258-1264. 
ASAE. (1999). Psychrometric data, D271.2 DEC99. American Society of Agricultural Engineers ASAE, USA.

Baş, D., Boyaci IH. (2007). Modeling and optimization II: comparison of estimation capabilities of response surface methodology with artificial neural networks in a biochemical reaction. Journal of Food Engineering 78: 846-854.

Bon, J.,Váquiro, H., Benedito, J., Telis-Romero, J. (2010). Thermophysical properties of mango pulp (Mangifera indica L. cv. Tommy Atkins). Journal of Food Engineering, 97, 563-568.

Chegini, G.R. (2008). Prediction of process and product parameters in an orange juice spray drying using artificial neural network. Journal of Food Engineering, $84: 534,543$.

Clemente, G., Bon, J., Sanjuán, N., Mulet, A. (2011). Drying modelling of defrosted pork meat under forced convection conditions. Meat Science, 88: 374-378.

Doymaz, I. (2011). Drying of Thyme (Thymus Vulgaris L.) and selection of a suitable thin-layer drying model. Journal of Food Processing and Preservation. doi: 10.1111/j.1745-4549.2010.00488.x.

Doymaz, I. (2009). Thin-layer drying of spinach leaves in a convective dryer. Journal of Food Process Engineering, 32: 112-125.

Erenturk S. and Erenturk K., (2007). Comparison of genetic algorithm and neural network approaches for the drying process of carrot. Journal of Food Process Engineering, 78(3): 905-912.

Ghodake, H.M., Goswami, T.K., Chakraverty, A. (2006). Mathematical modeling of withering characteristics of tea leaves. Drying Technology, 24: 159-164.

Hecht-Nielsen R. (1990). Neurocomputing. New York: Addison Wesley.

Hornik, K. Stinchcombe M and White H. (1989). Multilayer feedforward neural networks are universal approximators. Neural Network 2: 259-366.

Kolmogorov AN. (1957). On the representation of continuous functions of many variables by superposition of continuous functions and addition (in Russian). The Reports of the Academy of Sciences of the USSR, Vol. 114. Doklady, Akademii Nauk, SSSR, pp. 953-956.

Lee, J.H., Kim, H.J. (2008). Drying kinetics of onion slices in a hot-air dryer. Journal of Food Science \& Nutrition, 13: 225-230. 
Lertworasirikul, S., Saetan, S. (2010). Artificial neural network modeling of mass transfer during osmotic dehydration of kaffir lime peel. Journal of Food Engineering, 98(2): 214-223.

Levenberg K A. (1944). Method for the solution of certain non-linear problems in least squares. Quarterly of Applied Mathematics. 2 (2): 164-168.

MacKay, D.J.C. (1992). A Practical Bayesian Framework for Backpropagation Networks. Neural Computation, 4(3), 448-472.

Marquardt DW. (1963). An algorithm for least-squares estimation of nonlinear parameters. .Journal of the Institute of Mathi-matics and its Application. 2 (2): 431441.

Maskan, M. (2001). Kinetics of color change of kiwifruits during hot air and microwave drying. Journal of Food Engineering, 48: 169-175.

Mcminn, W.A.M. (2006). Thin-layermodeling of the convective, microwave, microwave-convective and microwave-vacuum drying of lactose powder. Journal of Food Engeneering, 72: 113-123.

Mulet, A. (1994). Drying modelling and water diffusivity in carrots and potatoes. Journal of Food Engineering, 22: 329-348.

Ozdemir, M. and Devres, Y.O. (1999). The thin layer drying characteristics of hazelnuts during roasting. Journal of Food Engineering, 42: 225-233.

Sablani, S.S. and Rahman, M.S. (2003). Using neural networks to predict thermal conductivity of food as a function of moisture content, temperature and apparent porosity. Food Research International, 36: 617-623.

Sanjuán, N., Lozano, M., Garcia-Pascual, P., and Mulet, A. (2003). Dehydration kinetics of red pepper (Capsicum annuum $L$ var Jaranda). Journal of the Science of Food and Agriculture, 83(7): 697-701.

Shati, A.A. Elsaid, F.G. (2009). Effects of water extracts of thyme (Thymus vulgaris) and ginger (Zingiber officinale Roscoe) on alcohol abuse. Food Chemical and Toxicology, 47: 1945-1949.

Soysal Y. Oztekin S. (2001). Comparison of seven equilibrium moisture content equations for some medicinal and Aromatic. Journal of Agricultural Engineering Research, 78(1): 57-63.

The MathWorks. (2009). MATLAB user's guide. The MathWorks Inc., SouthNatick, MA, USA. 
Zhou, W., Therdthai, N. (2010). Special topics in Food Engineering: Artificial neural networks in food processing,, In D. Sun (Ed), Mathematical Modeling of Food Processing (pp. 901-920). Boca Raton: CRC Press. 


\title{
4.2. OPTIMIZATION OF THE ANTIOXIDANT CAPACITY OF THYME (Thymus Vulgaris L.) EXTRACTS: MANAGEMENT OF THE DRYING PROCESS
}

\author{
J.Rodríguez, C. Ortuño, J. Benedito, J. Bon
}

INDUSTRIAL CROPS AND PRODUCTS

46 (2013) $258-263$

\begin{abstract}
The antioxidant properties of medicinal plants have been at the center of research for their use as preservatives or nutraceuticals by the food industry; additionally, to obtain quality products at a minimum cost and maximum yield, through optimal operating parameters, is a challenge for the food industry. The aims of this work was to effect operating conditions drying process on antioxidant capacity of the thyme and optimize the drying process creating a process management system to formulate and solve an optimization problem. The thyme drying process was analyzed under different drying air temperatures $(\mathrm{T})\left(40-80{ }^{\circ} \mathrm{C}\right)$ and drying air velocity $(\mathrm{V})(1-2 \mathrm{~m} / \mathrm{s})$. The essential oil was extracted by applying a supercritical fluid extraction method ( $35{ }^{\circ} \mathrm{C}, 35 \times 10^{3} \mathrm{kPa}$ ). To formulate and solve the optimization problem, artificial neural networks were developed. The optimum value of the optimization problem depend of the constraints established, shorting the drying time to research the final moisture content fixed.
\end{abstract}

Keywords: Antioxidant capacity, process management, optimization, neural networks. 


\section{Introduction}

Due to a growing consumer demand for healthy foods of natural origin, the food industry is becoming increasingly interested in aromatic herbs, mainly those belonging to the Lamiaceae family (Thyme, oregano, etc.). These herbs are very rich sources of antioxidant compounds (Hossain et al. 2008; Shan, et al. 2005) which could be used in food preservation to protect them from oxidative damage. However, thyme is perishable due to its high water content ( $65-68 \%$, in w.b.), thereby requiring the use of preservation methods for its further use. Hot air drying is one of the oldest food preservation processes.

The effect of drying on the antioxidant capacity (AC) of various aromatic plants and vegetables has been the subject of numerous studies, some study reported show an increase in antioxidant capacity of the extracts; this change depends on several factors, such as the drying method and the operating conditions, like temperature, and air velocity (Venskutonis, 1997; Hossain et al. 2010).

Nowadays, obtaining high quality products at minimum cost, but with a maximum yield, is a challenge in the chemical, petrochemical, food and pharmaceutical industry. For that purpose, in order to obtain the optimum operating parameters, appropriate mathematical models are needed (Clemente et al. 2011).

For optimize the thyme drying process, it is necessary to apply an appropriate model that allow modeling evolution $A C$ as function of the drying operations conditions. To develop theoretical models that describing the effect of the drying operations conditions on the $A C$, it is necessary to understand the major mechanisms involved in the process. Another way, the neural networks (ANN) can simulate the non-linear relationship between input and output variables through a learning process, without the need for theoretical and empirical models.

A number of neural network paradigms have been reported in the last four decades and, in the last decade, the neural networks have been refined and widely used by researchers, developing different applications (Fang et al. 2007; Parlak et al. 2006). Among these may be found several food-processing ones, such as quality control (Bucinski et al. 2004), drying applications (Tripathy et al. 2009; Erenturk and Erenturk, 2007), thermal processing (Lu et al. 2010) and food freezing (Goñi et al. 2008). However, there is no reference in literature either to the thyme drying modeling using ANN, or to the estimation of the effect of the drying operating conditions on the antioxidant capacity (AC) of thyme.

The aim of this work was to optimize the operating conditions of the convective drying process of thyme to maximize the $\mathrm{AC}$ of the extracts of the dried product. 


\section{Materials and methods}

\subsection{Sample preparation}

Fresh thyme samples (Thymus vulgaris L.) were acquired from Vivarium Albogarden in Valencia, Spain. The leaves of the plant were plucked manually, and kept in refrigeration $\left(4^{\circ} \mathrm{C}\right)$ for their later use. The initial moisture content was 68 $75 \%$ (w.b), determined according to the AOAC standards (1997).

\subsection{Drying experiments}

A completely automatic laboratory scale convective drier (Sanjuán, et al. 2003), with both air temperature and velocity control, was used. The samples were weighed (at $5 \mathrm{~min}$ intervals), and the weight was registered using a balance connected to a computer.

Drying experiments were carried out in triplicate, at constant temperatures of 40 , $50,60,70$ and $80^{\circ} \mathrm{C}$. The air velocities, measured at room temperature, of 1 and 2 $\mathrm{m} / \mathrm{s}$ was considered, because to velocities upper a $2 \mathrm{~m} / \mathrm{s}$ the samples could blow, and in industrials applications the air velocity used for drying is lower to $2 \mathrm{~m} / \mathrm{s}$. In

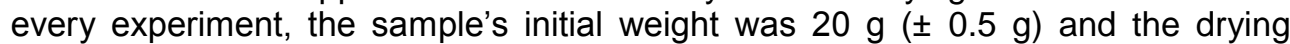
process was carried out until the final moisture content was less than 18\% (DiazMaroto et al. 2002). The leaves thyme were distributed uniformly in the drying chamber, forming a bed $2.99 \pm 0.2 \mathrm{~cm}$ thick, and the air flow passed through the bed.

\subsection{Extraction of thyme essential oil}

The thyme essential oil has been extracted by applying the Supercritical Fluid Extraction method (SFE) (Aarus et al. 2009; Brunner, 2005; Velasco et al. 2007); in other studies SFE, has been analyzed and compared favorably with convectional extraction process (Reverchon, 1997; Mukhopadhyay, 2000; and Reverchon and De Marco, 2006).

For each extraction, $3.5 \mathrm{~g}$ of dried leaves of the sample was mixed with $7 \mathrm{~mL}$ of ethanol as cosolvent, and placed in the extraction cartridge (capacity of $200 \mathrm{~mL}$ ). The extraction process was carried out under constant conditions of pressure and temperature: $3510^{3} \mathrm{kPa}$ and $35^{\circ} \mathrm{C}$ for $1 \mathrm{~h}$ (previously studied). After of extraction process the essential oil mixed with $\mathrm{CO}_{2}$ in supercritical conditions passed to a separator vessel under atmospheric pressure, where the essential oil of thyme was easily separated. The extract $(3-5 \mathrm{~mL})$ was collected from the bottom and was kept refrigerated at $4 \stackrel{\circ}{\circ} \mathrm{C}$ in opaque flasks until the analyses were carried out.

\subsection{Determination of antioxidant capacity}

The FRAP (ferric reducing activity power) is a commonly used method with which to measure the antioxidant activity of plant extracts (Hossain et al., 2010; Stratil et al., 2006). 


\subsection{Optimization problem}

An optimization problem was formulated to determine the drying operating conditions that maximize the antioxidant capacity of the extracts of dried thyme:

- The following operating conditions of thyme drying were established as decision variables: drying air temperature $(\mathrm{T})$, drying air velocity $(\mathrm{V})$ and drying time (t).

- The $A C$ of the dried thyme extracts was defined as the objective function (FO) to maximize; to quantify the $A C$, a model was set up to estimate the effect of the drying operating conditions on the AC of the extracts. Due to the complexity involved in the development of theoretical models, and there are not reference of empirical models to predict the evolution of the $A C$ of the product extract in function of the operating conditions, an artificial neural network (ANN), which could be consider as an empirical model, was developed.

- The constraints that limit the search region of the decision variables were determined from the drying experimental values of the operating conditions and from the drying experimental results (Table1). Different possible values of the final moisture content $\left(\mathrm{W}_{\mathrm{f}}\right)$ were established to study the effect of the $W_{f}$ on the AC. The AC depends of the operating conditions, among which are the decision variables $(T, V, t)$. The limits of the $\mathrm{V}$ and $\mathrm{T}$ can be established directly, and the constraint of the drying time ( $\mathrm{t}$ ) was fixed indirectly by the values of the other operating conditions and of the desired $\mathrm{W}_{\mathrm{f}}$. Therefore, a mathematical model was developed to estimate the final moisture content as a function of the values of the operating conditions of the drying process. Due to the irregular shape of the raw material (Thyme), to the complexity to develop a theoretical model to estimate the moisture content evolution in the bed, and the relatively long time necessary for its solution, an ANN model was developed.

Table 1. Range of drying operating conditions.

\begin{tabular}{|l|c|c|}
\hline & Minimum & Maximum \\
\hline Drying Temperature $\left({ }^{\circ} \mathrm{C}\right)$ & 39.9 & 79.9 \\
\hline Drying velocity $(\mathrm{m} / \mathrm{s})$ & 1.1 & 2.4 \\
\hline Time $(\mathrm{s})$ & 1200 & 26700 \\
\hline Initial moisture content $\left(\mathrm{kg} \mathrm{H}{ }_{2} \mathrm{O} / \mathrm{kg}\right.$, in d.b) & 2.19 & 3.04 \\
\hline Air humidity $\left(\mathrm{kg} \mathrm{H}_{2} \mathrm{O} / \mathrm{kg}\right.$, in d.b) & 0.007 & 0.017 \\
\hline Final moisture content $\left(\mathrm{kg} \mathrm{H}_{2} \mathrm{O} / \mathrm{kg}\right.$, in d.b) & 0.14 & 0.51 \\
\hline
\end{tabular}

This optimization problem has to be solved before the process drying beginning to apply the optimal values of the decision variables to maximize the $A C$ of the 
extracts of the final product. To select the method with which to solve the optimization problem, the problem's characteristics were analyzed: the formulated optimization problem was multivariable (three decision variables), non-linear (FO and several constraints), and the FO was derivable with respect to decision variables. Therefore, to solve the formulated non-linear optimization problem, the function "fmincon" of Matlab $\AA$ R2011a was used (The Mathworks, 2011). This function optimizes constrained, non-linear, and multivariable optimization problems, using the Sequential Quadratic Programming method.

\subsection{Design of the ANN}

Two ANNs (Figure 1) were developed to predict the antioxidant capacity $\left(\mathrm{ANN}_{\mathrm{AC}} .1\right.$, Figure 1) and the final moisture content ( $A N N_{\text {wf. }} 2$, Figure 1) of the dried product.

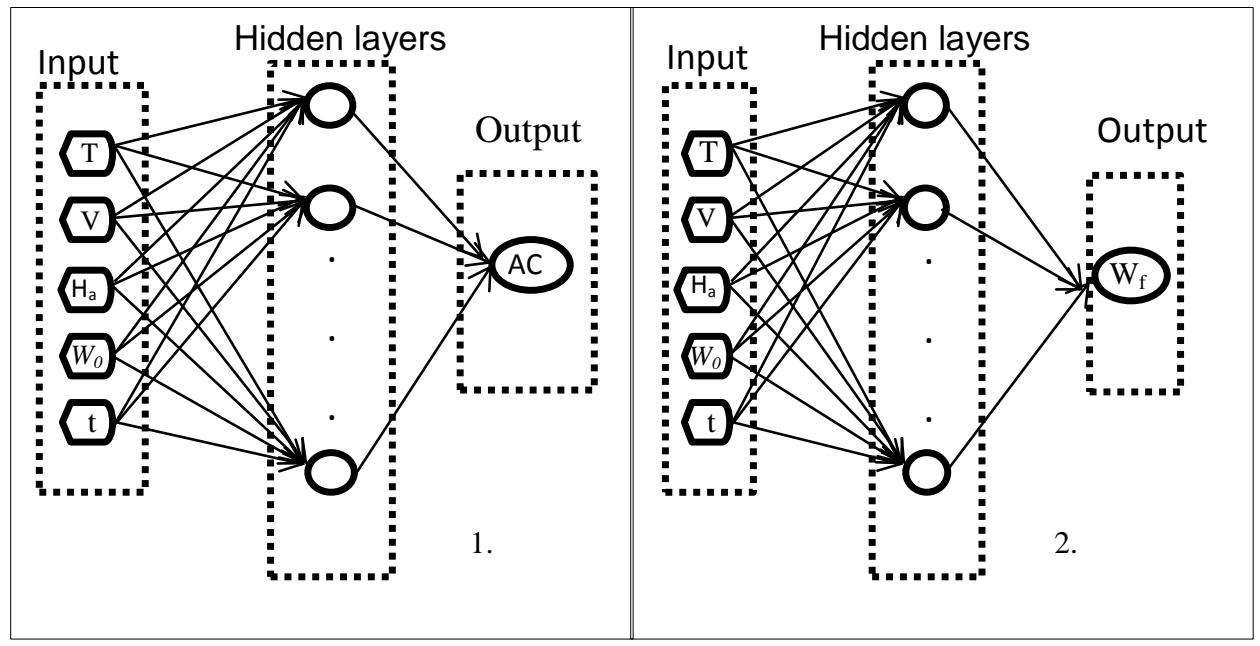

Figure 1. Neural network structure. 1. $A \mathrm{ANN}_{\mathrm{AC}}$; 2. $A \mathrm{ANN}_{\mathrm{WF}}$

The design of the ANNs took into account the most common architecture, based on a multilayer feed-forward structure with the back-propagation training algorithm used for computing the ANN weights and biases. There is no fixed rule for determining the required hidden layers and nodes (Lertworasirikul and Saetan, 2010). In general, one hidden layer has been found to be adequate, and only in some cases, may a slight advantage be gained by using two hidden layers (HechtNielsen, 1989). Therefore, the number of hidden layers was analyzed between one and two, and the number of neurons in the hidden layer and the transfer functions (tansig, logsig, purelin) in the hidden layer and in the output layer were investigated.

To develop the ANN, the Neural Network Toolbox ${ }^{\mathrm{TM}}$ of Matlab ${ }^{\circledR}$ R2011a was used (The Mathworks, 2011). Using the Matlab languages, a feed-forward backpropagation network was developed applying the "newff" function, and the ANN was trained, to look for the number of neurons in the hidden layers, by 
applying the "train" function. The parameter values were updated through a training procedure, with the aim of minimizing the mean square errors (MSE) between the network's outputs and the experimental values. The minimization of MSE was accomplished using the Levenberg- Marquardt algorithm (Levenberg, 1944; Marquardt, 1963). To avoid the problem of over-fitting during neural network training, the input vectors and target vectors of each ANN were randomly divided, with $70 \%$ used for training, $15 \%$ for validation and $15 \%$ for testing.

To select an adequate number of neurons to obtain the lowest number of weights and biases, the overall (considering all the experimental and calculated data) correlation coefficient value, the overall mean square errors (MSE) value, the MSE and correlation coefficients estimated in each part of the ANN analysis (training, validation and testing) were considered.To fit each ANN, the results of 30 drying experiments and the results of 30 SFE extractions were used (Table 2).

\subsection{Statistical analysis}

An ANOVA study was carried out to determine the significant influence of the operating conditions on the AC. For that, the function "anovan" of Matlab $\otimes$ R2011a (The Mathworks, 2011) was used; this function performs a multi-way analysis of variance to test the effects of multiple factors on the mean of the dependent vector. The average value of the relative errors (ER) (Eq. (1)) and the correlation coefficient (R) statistics were used to evaluate the accuracy of fit (Bon et al. 2010). The ER is a measure of the random component in the estimation; $R$ indicates the proportion of variance of the data that is accounted for by the model.

$$
\mathrm{ER}=\frac{100}{\mathrm{~N}} \sum_{\mathrm{i}=1}^{\mathrm{N}} \frac{\left|\mathrm{Z}_{\exp _{\mathrm{i}}}-\mathrm{Z}_{\mathrm{cal}_{\mathrm{i}}}\right|}{\mathrm{Z}_{\exp _{\mathrm{i}}}}
$$

To test the goodness of each model, additionally a t-test of the null hypothesis was performed at the $5 \%$ significance level, to prove that data in the residual vector are random and have a normal distribution with mean 0 and unknown variance, against the alternative that the mean is not 0 . To test the assumption that the residual vector comes from normal distributions, a Lilliefors test, at the $5 \%$ significance level, was used.

The "ttest" function of Matlab® R2011a (The Mathworks, 2011) was used to perform the statistical t-test. The "lillietest" function of Matlab® R2011a was used to perform the Lilliefors test. 
Table 2. Operating conditions of the thyme drying process, final moisture content and AC of the essential oil extracted.

\begin{tabular}{|c|c|c|c|c|c|c|c|}
\hline $\mathbf{N}$ & $\mathbf{T}\left({ }^{\circ} \mathbf{C}\right)$ & $\mathrm{V}(\mathrm{m} / \mathrm{s})$ & $\mathrm{H}_{\mathrm{a}}$ & $\mathbf{w}_{0}$ & $t(s)$ & $\mathbf{W}_{\mathrm{f}}$ & AC \\
\hline 1 & 79.9 & 2.3 & 0.015 & 2.75 & 1200 & 0.147 & 94.1 \\
\hline 2 & 79.9 & 2.4 & 0.016 & 2.75 & 1200 & 0.153 & 95.7 \\
\hline 3 & 79.8 & 2.3 & 0.016 & 2.75 & 1200 & 0.141 & 94.2 \\
\hline 4 & 69.9 & 2.1 & 0.010 & 2.82 & 2100 & 0.278 & 101.4 \\
\hline 5 & 69.8 & 2.3 & 0.010 & 2.53 & 1800 & 0.358 & 107.2 \\
\hline 6 & 69.6 & 2.3 & 0.010 & 2.59 & 1800 & 0.322 & 105.5 \\
\hline 7 & 59.8 & 2.2 & 0.012 & 2.61 & 4200 & 0.476 & 84.2 \\
\hline 8 & 59.9 & 2.2 & 0.012 & 2.81 & 3900 & 0.489 & 85.1 \\
\hline 9 & 59.8 & 2.3 & 0.011 & 2.88 & 3900 & 0.508 & 84.3 \\
\hline 10 & 49.9 & 2.2 & 0.010 & 2.81 & 7500 & 0.494 & 65.1 \\
\hline 11 & 49.9 & 2.2 & 0.011 & 2.97 & 6900 & 0.503 & 67.7 \\
\hline 12 & 49.9 & 2.1 & 0.012 & 2.96 & 7500 & 0.498 & 66.5 \\
\hline 13 & 39.9 & 2.1 & 0.011 & 2.90 & 28800 & 0.515 & 46.8 \\
\hline 14 & 39.9 & 2.1 & 0.012 & 2.80 & 28800 & 0.515 & 47.7 \\
\hline 15 & 39.9 & 2.1 & 0.011 & 2.90 & 28800 & 0.504 & 47.8 \\
\hline 16 & 79.9 & 1.3 & 0.017 & 3.04 & 1500 & 0.326 & 66.4 \\
\hline 17 & 79.9 & 1.3 & 0.017 & 3.04 & 2100 & 0.251 & 60.6 \\
\hline 18 & 79.9 & 1.3 & 0.017 & 3.04 & 1500 & 0.304 & 67.1 \\
\hline 19 & 70.0 & 1.2 & 0.007 & 2.45 & 2400 & 0.261 & 54.4 \\
\hline 20 & 69.9 & 1.2 & 0.008 & 2.45 & 2400 & 0.303 & 55.1 \\
\hline 21 & 69.8 & 1.1 & 0.008 & 2.45 & 2700 & 0.243 & 52.4 \\
\hline 22 & 59.9 & 1.1 & 0.009 & 2.36 & 4500 & 0.301 & 42.4 \\
\hline 23 & 59.9 & 1.1 & 0.007 & 2.37 & 4500 & 0.340 & 43.3 \\
\hline 24 & 59.9 & 1.1 & 0.008 & 2.36 & 4200 & 0.322 & 41.9 \\
\hline 25 & 49.9 & 1.1 & 0.007 & 2.19 & 9600 & 0.329 & 29.4 \\
\hline 26 & 50.0 & 1.1 & 0.008 & 2.19 & 9000 & 0.340 & 28.8 \\
\hline 27 & 49.9 & 1.1 & 0.007 & 2.19 & 9600 & 0.329 & 27.1 \\
\hline 28 & 39.9 & 1.1 & 0.009 & 2.45 & 20100 & 0.348 & 27.8 \\
\hline 29 & 39.9 & 1.1 & 0.001 & 2.45 & 22200 & 0.334 & 21.6 \\
\hline 30 & 39.9 & 1.1 & 0.008 & 2.45 & 22200 & 0.333 & 21.0 \\
\hline
\end{tabular}

$\mathrm{H}_{\mathrm{a}}, \mathrm{W}_{0}$ and $\mathrm{W}_{\mathrm{f}}$ in $\left(\mathrm{kg} \mathrm{H} \mathrm{H}_{2} \mathrm{O} / \mathrm{kg}\right.$, in d.b)

\section{Results}

\subsection{Drying}

Table 2 shows the experimental conditions and the results of the drying experiments and of the AC. The drying air temperature measured varies between 39.9 and $79.9{ }^{\circ} \mathrm{C}$. Considering that the air velocity was measured at room temperature, the hot air velocity was estimated considering that the air behaves as an ideal gas (Eq. (2)). 


$$
\mathrm{V}_{\mathrm{H}}=\mathrm{V}_{\infty} \frac{\mathrm{T}_{\mathrm{H}}}{\mathrm{T}_{\infty}}
$$

Predictably, the drying velocity increases as the air temperature and velocity rise, and therefore the drying time is reduced to obtain established final moisture content.

\subsection{Antioxidant capacity}

The AC content of the dried product extracts ranged between 21.0 and 107.2 [Trolox] mmol/L equivalents (Table 5.2.2). Figure 5.2.2 shows the influence of both the temperature and velocity of the air drying on the AC content of the dried product extracts. AC significantly increases when the drying air velocity and temperature rise, although a decrease is observed at $80{ }^{\circ} \mathrm{C}$ and $2 \mathrm{~m} / \mathrm{s}$ (Figure 5.2.2). This behavior was observed for Hossain et al. (2010) and Venskutonis, (1997). Nevertheless, at temperatures above $70 \stackrel{\circ}{ } \mathrm{C}$ (at $2 \mathrm{~m} / \mathrm{s}$ ), the AC decreases, which could be due to the degradation of the essential oil and/or an increase in oil loss (Fletcher et al., 2005).

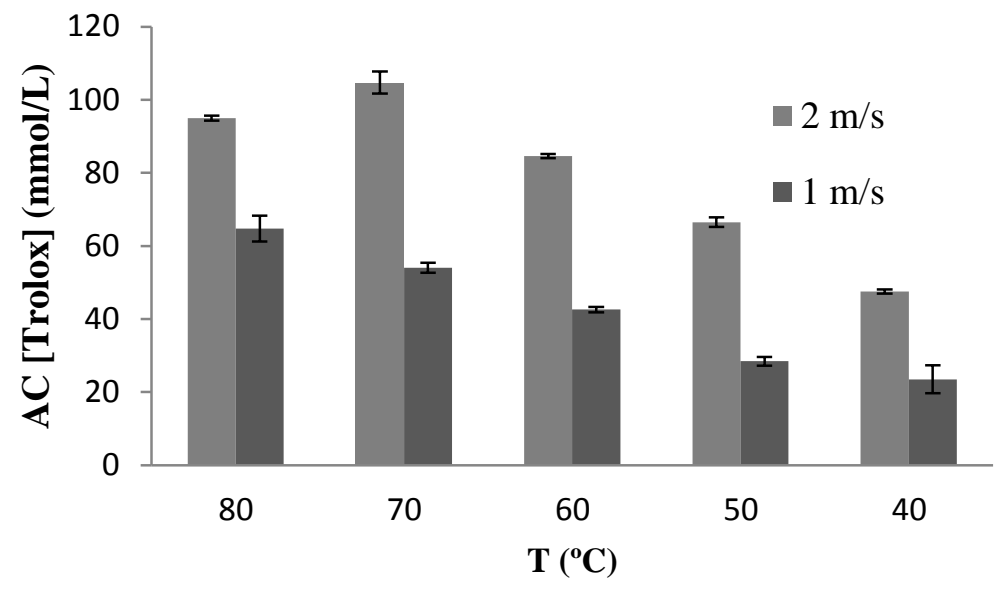

Figure 2. Antioxidant capacity of dried thyme at different air velocities and different air temperatures.

\subsection{ANN models}

Table 3 shows the results of the ANOVA study carried out to analyze the influence of the operating conditions $\left(\mathrm{T}, \mathrm{V}, \mathrm{Ha}, \mathrm{W}_{0}, \mathrm{t}\right)$ on $\mathrm{AC}$. According to the results, all the operating conditions have a significant influence on $A C(p<0.05)$ and, therefore, were considered as input variables for the $A N N_{A C}$ model. 
Table 3. Results of analysis of variance.

\begin{tabular}{|c|c|c|c|c|c|}
\hline Source & SS & df & MS & $\mathbf{F}$ & $\mathbf{p}$ \\
\hline $\mathbf{T}$ & $1.65 \mathrm{E}+09$ & 4 & $4.12 \mathrm{E}+08$ & 30.48 & 0 \\
\hline $\mathbf{V}$ & $4.07 \mathrm{E}+09$ & 1 & $4.06 \mathrm{E}+09$ & 300.63 & 0 \\
\hline $\mathbf{H}_{\mathbf{a}}$ & $1.20 \mathrm{E}+08$ & 1 & $1.20 \mathrm{E}+08$ & 8.9 & 0.0071 \\
\hline $\mathbf{W}_{\mathbf{0}}$ & $6.18 \mathrm{E}+07$ & 1 & $6.18 \mathrm{E}+07$ & 4.57 & 0.0044 \\
\hline $\mathbf{t}$ & $3.43 \mathrm{E}+08$ & 1 & $3.43 \mathrm{E}+08$ & 25.38 & 0.0001 \\
\hline Error & $2.84 \mathrm{E}+08$ & 21 & $1.35 \mathrm{E}+07$ & & \\
\hline Total & $2.02 \mathrm{E}+09$ & 29 & & & \\
\hline
\end{tabular}

To develop an ANN model of the thyme drying process, as the drying velocity and the final moisture content depend on both the drying air conditions (humidity, temperature, velocity) and on the initial moisture content of the thyme, the drying operating conditions were also considered as input variables of $A N N_{W f}$. To fit the $A N N_{A C}$ model, the experimental values of the $A C$ were considered as the target matrix, and the experimental $W_{f}$ values were considered as the target matrix to fit the $\mathrm{ANN}_{\mathrm{Wf}}$ model. In the hidden layers, the hyperbolic tangent was used as the transfer function, and the linear transfer function was applied in the output layer.

After fitting, both models had a good agreement between the simulated and experimental results with a correlation coefficient of 0.999 for $\mathrm{ANN}_{\mathrm{AC}}$, and 0.993 for ANN $\mathrm{WF}_{\mathrm{F}}$

Table 4 shows the goodness of the ANNs. For both cases, the t-test fails to reject the null hypothesis (residual vector with mean 0 ) at the default 0.05 significance level. Under the null hypothesis, as indicated by the $p$ value, the probability of the residual vector mean being in the confidence interval (ci) is high, and ci contains 0 .

In the Lilliefors test of composite normality, the 'lillietest'function, uses a table of critical values computed using Monte Carlo simulation for sample sizes less than 1000 and significance levels of between 0.001 and 0.50 . Critical values for a test are computed by interpolating in the table. If the test statistic is bigger than the critical value, the null hypothesis of normality can be rejected at a significance level. For both cases, the statistical values are less than the critical values; then the Lilliefors test fails to reject the corresponding null hypothesis at the default 0.05 significance level. As a consequence, the normality of the residuals is established.

Thus, from these results, it could be concluded that the designed ANNs were properly capable of simulating the relationships between the input and output variables.

\subsection{Optimization problem}

To test the optimization procedure, different cases were figured out. Table 5 shows the results of the optimization problem for different and experimental cases. In the 
first 8 cases of table 5 , the decision variables were constrained to the limits shown in table 1 . In the following cases (9 to 11), the upper value of the air velocity was modified $(1.5,2$ and $1.2 \mathrm{~m} / \mathrm{s})$ in order to test the behavior of drying air temperature and drying time. In these cases, the optimum value of the air velocity is the maximum allowed.

The optimum values of the decision variables depend on the constraints of the decision variables, the values of the uncontrollable variables $\left(\mathrm{H}_{\mathrm{a}}, \mathrm{W}_{0}\right)$, and the established limits for the $W_{f}$. From the results (Table 5), the optimum value of the air temperature was near $70{ }^{\circ} \mathrm{C}$, the optimum value of the air velocity was higher than $2 \mathrm{~m} / \mathrm{s}$, and the optimum value of the heating time coincided with the lowest value of the corresponding constraint. Also, the moisture content of the dried product coincided with the lowest limit established for the $\mathrm{W}_{\mathrm{f}}$.

The cases 12 to 20 of table 5 , optimum values of the decision variables for problems whose values of both uncontrolled variables and $W_{f}$ are analogous to the corresponding values of the experimental samples 1-4-8-11-15-17-22-27-29 (Table 2 ), respectively. The FO value has increased in every case (between $4.9 \%$ and $360.4 \%)$. As expected, the increase of the FO was greater in the cases corresponding to samples with lower experimental values of $T$ and $V$, because the optimum values of the decision variables were near $70 \stackrel{\circ}{ } \mathrm{C}$ for the hot air temperature, and near or over $2 \mathrm{~m} / \mathrm{s}$ for the hot air velocity. As in all cases, the optimum value of the heating time is the lowest established limit, and the optimum value of the drying air velocity is near its upper one. To validate the $A N N_{s}$ and the optimization problem, three experiments were carried out; the experimental data and results are shown in table 6 . To optimize each case, it was necessary to know the $W_{0}$ of the sample, to fix the desired $W_{f}$ (constraint of the optimization problem) and to know the values of the input variables of the ANNs. From the temperature and relative humidity of the ambient air, the absolute humidity $(\mathrm{Ha})$ was estimated by considering that the air behaves like an ideal gas. The optimization problem was formulated and solved, and the optimum values of the decision variables were applied in the dried sample. The experimental drying and AC results were compared with the calculated results, obtaining a difference of between 2 and $7 \%$ for the $A C$ and between 1.3 and $7.6 \%$ for the $W_{f}$, both with respect to the experimental value.

According to the results obtained, the ANNs could be a powerful tool with which to model the influence of the operating conditions of the thyme drying process on the $A C$ and the $W_{f}$ and to optimize the conditions of the thyme drying process in order to maximize the AC of the essential oil extracted from thyme. The developed ANNs can be applied by considering the experimental conditions and results of the thyme drying process. To extend the application of the ANNs, they should be trained using experimental results obtained by considering wider ranges of the uncontrolled variables $\left(\mathrm{Ha}, \mathrm{W}_{0}\right)$ and/or of the established final moisture content $\left(\mathrm{W}_{\mathrm{f}}\right)$ for each experimental value of the controllable variables $(T, V, t)$. 
Table 4. Results of the goodness of each ANN

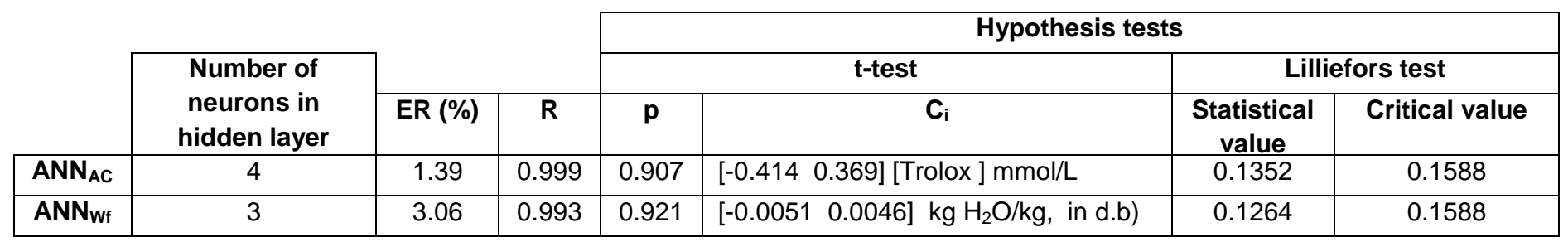

Table 5. Solution of the optimization problem to possible and experimental cases

\begin{tabular}{|c|c|c|c|c|c|c|c|c|c|}
\hline \multirow[t]{2}{*}{ Cases } & \multirow{2}{*}{$\begin{array}{c}\mathrm{Ha} \\
\left(\begin{array}{c}\mathrm{kg} \mathrm{H} \mathrm{H}_{2} \mathrm{O} / \mathrm{kg} \\
\text { in d.b) }\end{array}\right.\end{array}$} & \multirow{2}{*}{$\begin{array}{c}\mathrm{W}_{0} \\
(\underset{\text { in d.b }}{\mathrm{H}} \mathrm{O} \mathrm{O} / \mathrm{kg}\end{array}$} & \multicolumn{2}{|c|}{$\begin{array}{c}W_{f} \\
\left(\mathrm{~kg} \mathrm{H}_{2} \mathrm{O} / \mathbf{k g} \text {, in d.b) }\right.\end{array}$} & \multicolumn{3}{|c|}{$\begin{array}{c}\text { Decision variables } \\
\text { (optimal values) }\end{array}$} & \multirow{2}{*}{$\begin{array}{c}\text { FO } \\
\text { [Trolox] } \\
\text { mmol/L }\end{array}$} & \multirow{2}{*}{$\begin{array}{c}W_{f} \\
\left(\mathrm{~kg} \mathrm{H}_{2} \mathrm{O} / \mathrm{kg} \text {, in }\right. \\
\text { d.b) }\end{array}$} \\
\hline & & & Min. & Max. & $\mathbf{T}\left({ }^{\circ} \mathbf{C}\right)$ & $\mathrm{V}(\mathrm{m} / \mathrm{s})$ & $t(s)$ & & \\
\hline 2 & 0.010 & 2.75 & 0.253 & 0.305 & 71.5 & 2.3 & 1200 & 107.7 & 0.253 \\
\hline 3 & 0.014 & 2.19 & 0.253 & 0.305 & 71.9 & 2.2 & 1200 & 99.5 & 0.253 \\
\hline 4 & 0.014 & 2.75 & 0.253 & 0.305 & 72.4 & 2.1 & 1200 & 106.1 & 0.253 \\
\hline 6 & 0.010 & 2.47 & 0.344 & 0.464 & 70.7 & 2.3 & 1200 & 105.3 & 0.344 \\
\hline 7 & 0.010 & 3.04 & 0.344 & 0.464 & 69.4 & 2.2 & 1200 & 108.1 & 0.344 \\
\hline 8 & 0.014 & 2.47 & 0.357 & 0.370 & 70.5 & 2.1 & 1200 & 103.2 & 0.357 \\
\hline 9 & 0.016 & 2.80 & 0.140 & 0.510 & 80.0 & 1.5 & 1200 & 73.3 & 0.232 \\
\hline 10 & 0.016 & 2.80 & 0.240 & 0.510 & 71.9 & 2.0 & 1200 & 98.6 & 0.240 \\
\hline 11 & 0.016 & 2.80 & 0.240 & 0.510 & 80.0 & 1.2 & 1200 & 67.5 & 0.302 \\
\hline
\end{tabular}




\begin{tabular}{|c|c|c|c|c|c|c|c|c|}
\hline \multirow[t]{2}{*}{ Cases } & \multirow{2}{*}{$\begin{array}{c}\mathrm{Ha} \\
\left(\mathrm{kg} \mathrm{H}_{2} \mathrm{O} / \mathrm{kg}\right. \\
\text { in } \mathrm{d} . \mathrm{b})\end{array}$} & \multirow{2}{*}{$\begin{array}{c}\mathrm{W}_{0} \\
\left(\mathrm{~kg} \mathrm{H}_{2} \mathrm{O} / \mathrm{kg}\right. \\
\text { in d.b) }\end{array}$} & \multirow[t]{2}{*}{$\begin{array}{c}W_{f} \\
\left(\mathrm{~kg} \mathrm{H}_{2} \mathrm{O} / \mathrm{kg} \text {, in d.b) }\right.\end{array}$} & \multicolumn{3}{|c|}{$\begin{array}{c}\text { Decision variables (optimal } \\
\text { values) }\end{array}$} & \multirow{2}{*}{$\begin{array}{c}\text { FO } \\
\text { [Trolox] } \\
\text { mmol/L }\end{array}$} & \multirow[t]{2}{*}{$\begin{array}{l}\Delta \mathrm{FO} \\
(\%)\end{array}$} \\
\hline & & & & $T\left({ }^{\circ} \mathrm{C}\right)$ & $V(m / s)$ & t (s) & & \\
\hline $12 / 1$ & 0.016 & 2.74 & 0.147 & 74.8 & 2.1 & 1200 & 101.1 & 6.4 \\
\hline $13 / 4$ & 0.010 & 2.81 & 0.278 & 69.8 & 2.3 & 1200 & 106.4 & 4.9 \\
\hline $14 / 8$ & 0.012 & 2.81 & 0.489 & 62.2 & 2.27 & 1200 & 103.4 & 21.3 \\
\hline $15 / 11$ & 0.011 & 2.97 & 0.503 & 60.6 & 2.34 & 1200 & 103.7 & 53.1 \\
\hline $16 / 15$ & 0.011 & 2.90 & 0.504 & 60.3 & 1.93 & 1200 & 102.1 & 114.9 \\
\hline $17 / 17$ & 0.017 & 3.04 & 0.251 & 70.5 & 1.93 & 1200 & 93.9 & 55.8 \\
\hline $18 / 22$ & 0.009 & 2.35 & 0.301 & 71.7 & 2.38 & 1200 & 95.5 & 125.1 \\
\hline $19 / 27$ & 0.007 & 2.19 & 0.329 & 72.2 & 2.38 & 1200 & 81.0 & 198.9 \\
\hline $20 / 29$ & 0.009 & 2.44 & 0.334 & 69.9 & 2.38 & 1200 & 99.8 & 360.4 \\
\hline
\end{tabular}

Table 6. Validation of the $\mathrm{ANN}_{\mathrm{s}}$ and of the optimization problem

\begin{tabular}{|c|c|c|c|c|c|c|c|c|c|c|c|c|}
\hline \multirow{3}{*}{ Cases } & \multirow{3}{*}{$\begin{array}{c}\mathrm{W}_{0} \\
\left(\mathbf{k g ~ \mathrm { H } _ { 2 } \mathrm { O } / \mathrm { kg }} \text {, }\right. \\
\text { in d.b) }\end{array}$} & \multirow{3}{*}{ 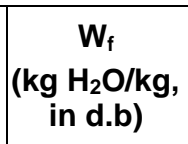 } & \multirow{3}{*}{$\mathrm{T}_{\infty}\left({ }^{\circ} \mathrm{C}\right)$} & \multirow{3}{*}{$h_{r}(\%)$} & \multirow{3}{*}{$\begin{array}{c}\mathrm{Ha} \\
\left(\begin{array}{c}\mathrm{kg} \mathrm{H} \mathrm{H}_{2} \mathrm{O} / \mathrm{kg} \\
\text { in } \mathrm{d} . \mathrm{b})\end{array}\right.\end{array}$} & \multicolumn{5}{|c|}{ Optimum values } & \multirow{3}{*}{$\begin{array}{c}\Delta \mathrm{FO} \\
(\%)\end{array}$} & \multirow{3}{*}{$\begin{array}{l}\Delta W \\
(\%)\end{array}$} \\
\hline & & & & & & \multicolumn{3}{|c|}{ Decision variables } & \multicolumn{2}{|c|}{ FO } & & \\
\hline & & & & & & $\mathrm{T}\left({ }^{\circ} \mathrm{C}\right)$ & $V(\mathrm{~m} / \mathrm{s})$ & $t(s)$ & Cal. & Exp. & & \\
\hline 1 & 2.82 & 0.17 & 26.8 & 47.8 & 0.010 & 76.8 & 2 & 1200 & 107.5 & 101.9 & 2 & 5.5 \\
\hline 2 & 2.82 & 0.25 & 23.9 & 51.3 & 0.009 & 75.9 & 2 & 1200 & 102.5 & 95.3 & 7 & 7.6 \\
\hline 3 & 2.82 & 0.33 & 24.4 & 50.6 & 0.009 & 74.7 & 2 & 1200 & 103.4 & 97.8 & 5.6 & 1.3 \\
\hline
\end{tabular}




\section{Conclusions}

To optimize the AC of the dried thyme, it appears that it is very important to carry out an optimal management of the drying process. To that end, formulating and solving an adequate optimization problem is a powerful method.

According to the results obtained, the ANNs could be a powerful tool to model the influence of the operating conditions of the thyme drying process on the $A C$ and the $\mathrm{Wf}$ and to optimize the conditions of the thyme drying process in order to maximize the AC of the essential oil extracted from thyme. The ANNs, additionally, enable the application of an optimal management system in situ because the ANNs shorten the time of calculate in comparison with theoretical models.

From most of the results of the optimization problem, the optimum values of the decision variables depend both on the values of the uncontrolled variables $(\mathrm{Ha}$, $\mathrm{W}_{0}$ ) and on the established $\mathrm{W}_{\mathrm{f}}$.

It appears necessary to shorten the heating time to maximize the AC; therefore, the drying time, which depends on air velocity and temperature, is a significant point to consider.

\section{Acknowledgements}

The authors would like to acknowledge the financial support of the Government of Spain through the MICINN (DPI2009-14549-C04), from CARNISENUSA project (CSD2007-00016) included in the program CONSOLIDER-INGENIO-2010.

\section{Notation}

AC Antioxidant capacity content

[Trolox ]mmol/L

ANN Artificial neural network

ANN $_{A C} \quad$ ANN developed to predict the AC

ANN $N_{W F}$ ANN developed to predict the $W_{f}$

$\mathrm{Ci} \quad$ Confidence interval

df Degrees of freedom

ER Relative errors

$\%$

$\mathrm{F} \quad$ Ratio of the mean squares

FO Objective function

$\mathrm{Ha}$ Absolute humidity

$\mathrm{kg} \mathrm{H}_{2} \mathrm{O} / \mathrm{kg}$, in d.b 


\begin{tabular}{|c|c|c|}
\hline MS & $\begin{array}{l}\text { Mean squares for each source, which is the ratio } \\
\text { SS/df }\end{array}$ & \\
\hline MSE & Mean square errors & \\
\hline $\mathrm{N}$ & Number of observations & \\
\hline $\mathrm{p}$ & Probability & \\
\hline $\mathrm{R}$ & Correlation coefficent & \\
\hline SFE & Supercritical Fluid Extraction & \\
\hline SS & Sum of residual squares & \\
\hline $\mathrm{T}$ & Temperature & $\stackrel{\circ}{ } \mathrm{C}$ \\
\hline $\mathrm{t}$ & Time & s \\
\hline$T_{\infty}$ & Room temperature & $\mathrm{K}$ \\
\hline $\mathrm{T}_{\mathrm{H}}$ & Hot air temperature & K \\
\hline $\mathrm{V}_{\infty}$ & Air velocity at room temperature & $\mathrm{m} / \mathrm{s}$ \\
\hline $\mathrm{V}_{\mathrm{H}}$ & Hot air velocity & $\mathrm{m} / \mathrm{s}$ \\
\hline $\mathrm{W}_{0}$ & Initial moisture content & $\mathrm{kg} \mathrm{H}_{2} \mathrm{O} / \mathrm{kg}$, in d.b \\
\hline$W_{f}$ & Final moisture content & $\mathrm{kg} \mathrm{H} 20 / \mathrm{kg}$, in d.b \\
\hline$Z_{\text {cal }}$ & Calculated value & \\
\hline$Z_{\text {exp }}$ & Experimental value & \\
\hline$\Delta \mathrm{FO}$ & Variation of the objective function & $\%$ \\
\hline$\Delta \mathrm{Wf}$ & Variation of the $W_{f}$ & $\%$ \\
\hline
\end{tabular}

\section{References}

Aarus, K., Uquihe, E., Del Valle, J.M. 2009. Matrix effects in supercritical CO2 extraction of essential oils from plant material. J. Food Eng. 92, 438-447.

AOAC. (1997). Official methods of analysis of AOAC International, 16th edn, (Association of Official Analytical Chemist International AOAC, Gaithersburg, USA).

Bon, J., Váquiro, H., Benedito, J., Telis-Romero, J. 2010. Thermophysical properties of mango pulp (Mangifera indica L. cv. Tommy Atkins). J. Food Eng. 97, 563-568. 
Brunner, G. 2005. Supercritical fluids: Technol. and application to food processing. J. Food Eng. 67, 21-33.

Bucinski, A., Zielinski, H., Kozzowska, H. 2004. Artificial neural networks for prediction of antioxidant capacity of cruciferous sprouts. Trends Food Sci. Technol. $15,161-169$.

Clemente, G., Bon, J., Sanjuán., Mulet, A. 2011. Drying modelling of defrosted pork meat under forced convection conditions. Meat Sci. 88, 374-378.

Diaz-Maroto, M.C., Perez Coello, M. S., Cabezudo, M. D. 2002. Effect of different drying methods on the volatile components of parsley (Petroselinum crispum L.). Eur. Food Res. Technol. 215, 227-230.

Erenturk, S., Erenturk, K. 2007.Comparison of genetic algorithm and neural network approaches for the drying process of carrot. J. Food Process. Eng. 78(3), 905-912.

Fang, Y. C., Wu, B.W. 2007. Neural network application for thermal image recognition on flow-resolution objects. J. Opt. A: Pure and Applied Optics, 9 (2), 134-144.

Fletcher, R.S., Slimmon, T., McAuley, C.Y., Kott, L.S. 2005. Heat stress reduces the accumulation of rosmarinic acid and the total antioxidant capacity in spearmint (Mentha spicata L). J. Sci. Food Agr., 85,2429-2436.

Goñi, S.M., Oddone, S., Segura, J.A., Mascheroni, R.H., Salvadori, V.O. 2008. Prediction of foods freezing and thawing times: Artificial neural networks and genetic algorithm approach. J. Food Eng. 84, 164-178.

Hecht-Nielsen, R. 1989. Theory of the backpropagation neural network. In Proceedings of International Joint Conference on Neural Networks, Washington, DC: 593-605.

Hossain, M.B., Barry-Ryan. C., Martin-Diana, A.B., Brunton, N.P. 2010. Effect of drying method on the antioxidant capacity of six Lamiaceae herbs. Food Chem. 123, 85-91.

Hossain, M.B., Brunton, N.P., Barry-Ryan, C., Martin-Diana, A.B., and Wilkinson, M. 2008. Antioxidant activity of spice extracts and phenolics in comparison to synthetic antioxidants. Rasayan. J. Chem. 1(4), 751-756.

Lertworasirikul S and Saetan S. (2010). Artificial neural network modeling of mass transfer during osmotic dehydration of kaffir lime peel. Journal of Food Engineering 98(2): 214-223. 
Levenberg, K.A. 1944. Method for the solution of certain non-linear problems in least squares. J. Appl. Math. 2 (2), 164-168.

Lu, H.F., Zheng, H., Lou, H.Q., Jiang, L.L,, Chen, Y., Fang, S.S. 2010. Using neural networks to estimate the losses of ascorbic acid, total phenols, flavonoid, and antioxidant activity in asparagus during thermal treatments. J. Agr. Food Chem. 58, 2995-3001.

Marquardt, D.W. 1963. An algorithm for least-squares estimation of nonlinear parameters. J. Soc. for Ind. App. Math. 2 (2), 431-441.

Mukhopadhyay, M., 2000. Natural Extracts Using Supercritical Carbon Dioxide. CRC Press, Boca Raton, FL

Parlak, A., Islamoglu, Y., Yasar, H., Egrisogut, A. 2006. Application of artificial neural network to predict specific fuel consumption and exhaust temperature for a diesel engine. App. Therm. Eng., 26, 824-828.

Reverchon, E., De Marco, I., 2006. Supercritical fluid extraction and fractionation of natural matter. J. Supercrit. Fluids. 38 (2), 146-166.

Reverchon, E. 1997. Supercritical fluid extraction and fractionation of essential oils and related products. J. Supercrit. Fluids. 10 (1), 1-37.

Sanjuán, N., Lozano, M., Garcia-Pascual, P., Mulet, A. 2003. Dehydration kinetics of red pepper (Capsicum annuum L var Jaranda). J. Sci. Food Agr., 83(7), 697701.

Shan, B., Cai, Y.Z., Sun, M., Corke, H. 2005. Antioxidant capacity of 26 spice extracts and characterization of their phenolic constituents. J. Food Chem. 53, 7749-7759.

Stratil, P., Klejdus, B., Kuban, V. 2006. Determination of total content of phenolic compounds and their antioxidant activity in vegetables-evaluation of spectrophotometric methods. J. Agr. Food Chem. 54, 607-616.

The Mathworks. 2011. Matlab user's guide. The MathWorks Inc, SouthNatick, MA, USA.

Tripathy, P.P., Kumar, S. 2009. Neural network approach for food temperature prediction during solar drying. International J. Therm. Sci. 48, 1452-1459.

Velasco, R.J., Villada, H.S., Carrera, J.E. 2007. Application of supercritical fluis in agribusiness. Inf. Tecn. 18(1), 53-65.

Venskutonis, R. 1997. Effect of drying on the volatile constituents of thyme (Thymus vulgaris L.) and sage (Salvia officinalis L.). Food Chem. 59, 219-227. 


\title{
4.3. INFLUENCE OF HIGH-INTENSITY ULTRASOUND ON DRYING KINETICS IN FIXED BEDS OF HIGH POROSITY
}

\author{
J. Rodríguez. A, Mulet and J. Bon.
}

Submited: DRYING TECHNOLOGY

\begin{abstract}
Hot air drying is an energy intensive process and can affect bioactive components. A common method of food drying is in a fixed bed. The application of high-intensity ultrasound could constitute a way of improving traditional convective drying systems. Therefore, the main aim of this work was to assess the influence of highintensity ultrasound on transfer phenomena during the convective drying in a highporosity bed of non-porous materials, like thyme leaves. For this purpose, drying kinetics of thyme leaves were carried out at 1,2 and $3 \mathrm{~m} \mathrm{~s}^{-1}$ air velocity at different air temperatures $(40,50,60,70$, and $80 \pm 1.2 \stackrel{\circ}{\circ}$ ), and different levels of acoustic power density $\left(0,6.2,12.3,18.5 \mathrm{~kW} \mathrm{~m}^{-3}\right)$. The time was taken into consideration when modeling the drying kinetics by varying the boundary conditions for heat and mass transfer between the air and the product. External resistance was where the process intensification was mainly identified. Nevertheless, any influence of the application of ultrasound on transport phenomena was only observed at air temperatures and air velocities of below $70 \stackrel{\circ}{\circ}$ and $3 \mathrm{~m} \mathrm{~s}^{-1}$ respectively.
\end{abstract}

Keywords: Food drying, Heat and mass transfer, Mathematical modeling, Ultrasound assisted drying 


\section{INTRODUCTION}

Drying, a process in which heat and mass transfer processes are present, is one of the oldest and most important methods of food preservation known to man ${ }^{[1]}$. Despite the fact that hot air drying is a widely used method, it does present some quality and energy limitations which may be considered as challenges if the process is to be improved. These limitations can be found in the changes in the biochemical properties of foodstuffs, causing the deterioration of aroma compounds ${ }^{[2]}$, the degradation of nutritional substances ${ }^{[3]}$, browning and color loss ${ }^{[4]}$, among other things.

The introduction of new drying technologies could lead to a shortening of the processing time, thus improving both the energy efficiency of drying operations and the quality of the dried products ${ }^{[5]}$. High-intensity airborne sonic and ultrasonic waves have been used to intensify the drying rate of materials. The acoustically assisted hot air drying process permits the use of lower temperatures and may be useful for drying heat-sensitive materials ${ }^{[6]}$.

It could be of importance for the industry to improve the drying process in order to preserve the bioactive components of foods. Those ingredients that can be obtained from thyme leaves appear to be an interesting ingredient for food formulation.

The use of ultrasonic energy is very promising because it can act without affecting the main characteristics and quality of the products. Ultrasound introduces pressure variations, oscillating velocities and microstreaming at the interfaces, which may modify the diffusion boundary layer. As a consequence, ultrasound may affect both external and internal resistance to mass transfer ${ }^{[7]}$. It is known that ultrasound effects are product-dependent and are related to product porosity ${ }^{[8,9]}$. As a consequence, it is of interest to analyze ultrasound-intensifying effects in porous beds of non-porous materials, like leaves.

The convective drying of foods in fixed beds of high porosity is an important application. The complexity of the process arises from the simultaneous heat and mass transfer between the air and the product. In order to address this complexity, it is necessary to model the process adequately. Several models have been formulated to describe the heat and mass transfer processes during fixed bed drying. These models include either simplified or rigorous models. The simplified models are mainly based on the assumption of a dominant mechanism for heat and mass transfer. Thompson et al ${ }^{[10]}$, Berbert et al ${ }^{[11]}$ and Sun and Woods ${ }^{[12]}$ proposed deep-bed drying models based on heat and mass balances taken over a thin layer of grain, while Barre et al ${ }^{[13]}$ used algebraic expressions in order to simulate the product moisture content and air temperature during the deep-bed drying of grains. 
Rigorous mathematical representations have been developed for the batch drying of foodstuffs from the non-steady state heat and mass balances in a differential element of the fixed bed ${ }^{[14,15,16,17,18]}$.

Although it has been acknowledged that the phenomena involved during drying are complex and that no simple model can account for real behavior, the diffusion theory based on Fick's laws is the most common one with which to describe drying processes during the falling rate period ${ }^{[19,20]}$. Diffusion models are built following some assumptions that establish the degree of complexity of the solution. The most common assumptions to consider are related to the effective moisture diffusivity ${ }^{[21]}$ and the external resistance to mass transfer ${ }^{[22]}$.

Several empirical and simple theoretical drying models have been proposed to describe the drying process of thyme ${ }^{[23,24]}$. However, there is no information in the literature about a time varying boundary conditions model, permitting the description of the high-intensity ultrasound intensifying effects during the convective drying of a bed of thyme leaves.

The aim of this work is to address the transport mechanisms involved in the ultrasonic drying of a porous bed. For that purpose, how the temperature, air velocity and the application of high power ultrasound influenced the hot air drying kinetics of a bed of thyme leaves was analyzed.

\section{MATERIALS AND METHODS}

\section{Sample preparation}

Fresh thyme samples (Thymus vulgaris L.) were obtained (Vivarium Albogarden in Valencia, Spain). The leaves of the plant were plucked manually, and kept in refrigeration $\left(4^{\circ} \mathrm{C}\right)$ in a closed container for their later use. The initial moisture content was $68-70 \%$ (w.b), determined according to the AOAC standards ${ }^{[25]}$. The density of the dry solid was determined using the toluene displacement method.

The physical properties of thyme, dry air and water vapor used in fitting the model are summarized in Table 1.

\section{Drying experiments}

A power-ultrasound assisted convective drier was used, as already described in previous works ${ }^{[26]}$. The thyme leaves were distributed uniformly inside the drying chamber, forming a bed with a thickness of $3 \pm 0.3 \mathrm{~cm}$, with through air flow. For each condition tested, the drying experiments were carried out in triplicate. The experiments were conducted at different air temperatures $\left(T_{a}\right)(40,50,60,70$ and $\left.80 \pm 1.2^{\circ} \mathrm{C}\right)$ and different air velocities $(v)\left(1,2\right.$ and $\left.3 \mathrm{~m} \mathrm{~s}^{-1}\right)$ applying 4 ultrasonic power (US) levels $\left(0,6.2,12.3,18 \mathrm{~kW} \mathrm{~m}^{-3}\right)$. In every experiment, the sample's initial weight was $20 \mathrm{~g}( \pm 0.5 \mathrm{~g})$, and the drying process was carried out until the final moisture content was less than $18 \%$ (w.b) ${ }^{[27]}$. 
Table 1. Physical properties used in the model solution

\begin{tabular}{|c|}
\hline $\begin{array}{l}\text { Specific heat of dry air }\left(\mathrm{kJ} \mathrm{kg}^{-1} \mathrm{~K}^{-1}\right)^{[38]} \\
C p_{d a}=2.927510^{-7} T_{a}^{3}+4.704710^{-4} T_{a}^{2}+1.78210^{-2} T_{a}+1005.3\end{array}$ \\
\hline $\begin{array}{l}\text { Specific heat of water vapor }\left(\mathrm{kJ} \mathrm{kg}^{-1} \mathrm{~K}^{-1}\right)^{[38]} \\
C p_{v}=10384.59-50.37 T_{a}+7.410^{-2} T_{a}^{2}\end{array}$ \\
\hline $\begin{array}{l}\text { Water activity }{ }^{[39]} \\
a_{w}=\exp \left[-\exp \left(2.97977-0.00258492 T_{a}^{1.37743}\right) \tau_{e q}^{-1.44139}\right]\end{array}$ \\
\hline $\begin{array}{l}\text { Diffusivity of water in the air phase }\left(\mathrm{m}^{2} \mathrm{~s}^{-1}\right)^{[29]} \\
D_{A B}=1.473810^{-4} \exp \left(\frac{-523.78}{T_{p p}}\right)\end{array}$ \\
\hline $\begin{array}{l}\text { Thermal conductivity }\left(\mathrm{kJ} \mathrm{m}^{-1} \mathrm{~s}^{-1} \mathrm{~K}^{-1}\right) \text { for fruits and vegetables }{ }^{[40]} \\
\kappa=1.41810^{-1}+\frac{4.9310^{-1} \tau}{(1+\tau)}\end{array}$ \\
\hline $\begin{array}{l}\text { Porosity of the bed } \\
\varepsilon=\frac{V_{a}}{V}\end{array}$ \\
\hline
\end{tabular}

\section{Modeling}

To address the effect of US on the drying kinetics, a mathematical model was developed considering simultaneous heat and mass transfer phenomena in both the bed and the thyme leaves. The following assumptions were considered for the purposes of obtaining the mathematical model.

- The bed was initially homogeneous and isotropic

- The leaves were considered as behaving like an infinite slab 
- The shrinkage effect on transfer processes was negligible, and the transport properties in the leaves (effective diffusivity and thermal conductivity) were temperature dependent.

- The air in the bed was well-mixed.

A dimensionless distance was considered (equation (1)) for the leaves, and the following governing equations (2) - (5) were obtained from the mass and energy balance in the bed and leaves.

$$
z=\frac{x}{L} \wedge z \in[0,1]
$$

Equation (2) represents the unsteady-state heat balances describing the evolution of the air temperature $\left(T_{a}\right)$ in the bed.

$$
\begin{aligned}
& m_{a} \int_{T_{a e}}^{T_{a i}}\left(C p_{d a}\left(T_{a}\right)+X_{e} C p_{v}\left(T_{a}\right)\right) d T_{a}+\left[\left(X_{e}-X_{a}\right) m_{a}-\varepsilon \rho_{d a} V \frac{d X_{a}}{d t}\right] \int_{T(1, t)}^{T_{a e}} C p_{v}\left(T_{a}\right) d T_{a} \\
& =-(1-\varepsilon) V \frac{h}{L}\left[T(1, t)-T_{a}\right]+\varepsilon \rho_{d a} V\left[C p_{d a}\left(T_{a}\right)+X_{a} C p_{v}\left(T_{a}\right)\right] \frac{d T_{a}}{d t}
\end{aligned}
$$

Equation (3) represents the unsteady-state mass balances for describing the evolution of the air moisture content $\left(X_{a}\right)$ in the bed,

$$
m_{a}\left(X_{e}-X_{a}\right)=\rho_{d a}\left(T_{a i}, X_{a}\right) \varepsilon V \frac{d X_{a}}{d t}+M_{d s} \frac{d \bar{\tau}}{d t}
$$

Equation (4) describes the evolution of the local moisture content $(\tau)$ in the leaves,

$$
\frac{\partial}{\partial z}\left(\frac{D}{L^{2}} \rho_{d s} \frac{\partial \tau}{\partial z}\right)=\rho_{d s} \frac{\partial \tau}{\partial t}
$$

and equation (5) represents the evolution of temperature $(T)$ in the leaves.

$$
\frac{D}{L^{2}} \rho_{d s} \frac{\partial \tau}{\partial z} C p_{w}(T) \frac{\partial T}{\partial z}=\frac{\partial}{\partial z}\left(\frac{\kappa(\tau)}{L^{2}} \frac{\partial T}{\partial z}\right)+\rho_{d s}\left[C p_{d s}(T)+\tau C p_{w}(T)\right] \frac{\partial T}{\partial t}
$$

To complete the drying model, both the initial and boundary conditions were considered. The initial moisture content distribution and temperature in the bed and 
leaves are assumed to be uniform. As boundary conditions, the distribution of the moisture content and temperature in the leaves are assumed were symmetrical.

Equation 6 was applied to calculate the average moisture content in the leaves.

$$
\bar{\tau}=\int_{0}^{1} \tau(z, t) d z
$$

In order to evaluate the mass transfer boundary conditions on the leaf's surface, it is assumed that liquid water that diffuses into the surface per unit area evaporates at the same rate (dynamic equilibrium) and is transported by convection into the air (equation (7)).

$$
-\frac{D}{L^{2}} \rho_{d s} \frac{\partial \tau}{\partial z}(1, t)=\frac{h_{m v}}{L}\left[\rho_{d a i} X_{e q}-\rho_{d a} X_{a}\right]
$$

The equilibrium moisture content of the air $\left(X_{e q}\right)$ was estimated using isotherms (Table 1) and considering that air behaves as an ideal gas.

The heat boundary conditions assume that the heat transmitted by convection from the air to the leaf's surface increases the temperature of the leaf and evaporates the water reaching the surface (equation (8)).

$$
-\frac{h}{L}\left[T(1, t)-T_{a}\right]=\frac{\kappa(\tau)}{L^{2}} \frac{\partial T}{\partial z}(1, t)-\frac{D}{L^{2}} \rho_{d s} \frac{\partial \tau}{\partial z}(1, t) \lambda(T(1, t))
$$

The effect of temperature on the diffusivity is described by an Arrhenius type equation.

\section{Heat and mass transfer coefficient}

When using non-constant boundary conditions, the main problem is obtaining an adequate estimation of the heat and mass transfer coefficient ${ }^{[28]}$.

The values of the heat and mass transfer coefficients ( $h$ and $h_{m v}$ ) (equation $\left.(9)\right)$ can be calculated from empirical equations involving dimensionless numbers ${ }^{[29]}$.

$$
h_{m v}=\frac{S h D_{A B}}{L_{c}}, \quad h=\frac{N u \kappa_{a}}{L_{c}}
$$


In early works, the ${ }^{[30]}$ mathematical expression was established as one of the best methods for calculating those dimensionless numbers for particle beds [15] (equation (10)).

$$
N u=\frac{a}{\varepsilon} \operatorname{Re}^{b} \operatorname{Pr}^{1 / 3}, \quad S h=\frac{a}{\varepsilon} \operatorname{Re}^{b} S c^{1 / 3}
$$

To identify $D / L^{2}$ and the parameters $a$ and $b$ (equation (10)), an optimization problem was formulated. In the optimization problem, the parameters were considered as the decision variable, and the objective function was the mean relative error calculated through the comparison of experimental and calculated average moisture contents.

A dimensionless average moisture content for the leaves in the bed was considered (equation (11)) for the purpose of analyzing the results.

$$
\omega=\frac{\bar{\tau}-\tau_{e q}}{\tau_{0}-\tau_{e q}}
$$

\section{Computational tools}

To solve the optimization problem, the "fmincon" function of Matlab $\otimes$ R2011a was used ${ }^{[31]}$, obtaining the value of parameters $D / L^{2}, a$ and $b$.

To calculate the objective function, it was necessary to solve the mathematical model for the drying process, which was carried out by using a numerical method to solve the governing equations and calculate the objective function. For this purpose, the COMSOL Multiphysics ${ }^{\circledR} 3.4^{[32]}$ tool was employed using the finite element method. The "nlinfit' function was applied to estimate the parameter values of the Arrhenius equation by means of non-linear regression.

\section{Statistical analysis}

The average value of the relative errors $(E R)$ and the explained variance (VAR) statistics were used to evaluate the accuracy of fit ${ }^{[33]}$. The average value of the relative errors is a measure of the random component in the estimation. VAR indicates the proportion of variance that is accounted for by the model.

To test the goodness of the fit, both the t-test and Lilliefors test were carried out. The "ttest" function was used to perform the statistical t-test and "lillietest" function was used to perform the Lilliefors test ${ }^{[31]}$. 


\section{RESULTS}

\section{Drying kinetics}

Figures 1, 2 and 3 show the drying kinetics of thyme at different velocities $(1,2$, and $\left.3 \mathrm{~m} \mathrm{~s}^{-1}\right)$ of ultrasound application $\left(0,18.5 \mathrm{~kW} \mathrm{~m}^{-3}\right)$ at different $T_{a}$. As expected, the increase in air velocity, air temperature and US applications increased the drying kinetics. From Figures 1 and 2, it may be seen that the drying rate was increased when US was applied, especially at air temperatures less than $70 \stackrel{\circ}{ } \mathrm{C}$, whereas when the air temperatures were higher $\left(T_{a}>60^{\circ} \mathrm{C}\right)$, the reduction in the drying time brought about by US application was lower. The intensifying effect of ultrasound on drying kinetics was influenced by air velocity: the higher the air velocity, the milder the effect (Figs 3 and 5). As can be observed in figure 1, the drying time reduction obtained at an air velocity of $1 \mathrm{~m} \mathrm{~s}^{-1}$ at 40 or $50 \stackrel{\circ}{\circ} \mathrm{C}$ was around $30 \%$ when US was applied. The effects of US on the transport mechanisms will be better understood if addressed from the perspective of modeling.

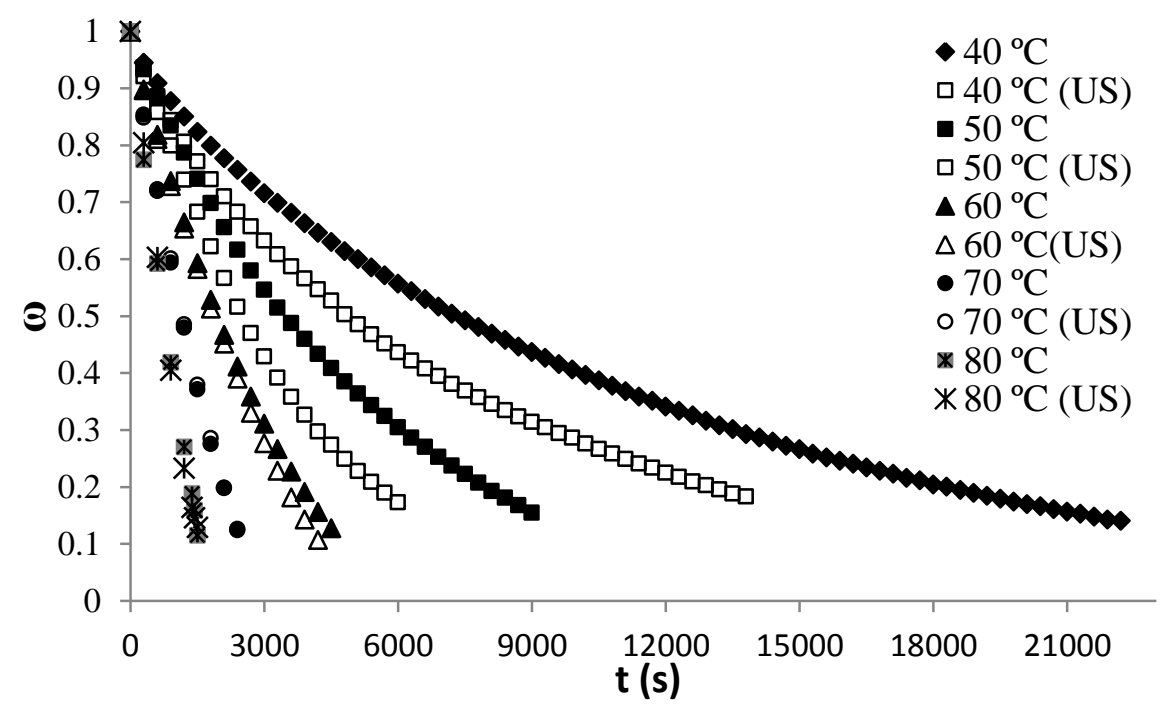

Figure 1. Convective drying kinetics of thyme at $v=1 \mathrm{~m} / \mathrm{s}$, different air temperatures, and US $18.5 \mathrm{~kW} \mathrm{~m}^{-3}$. 


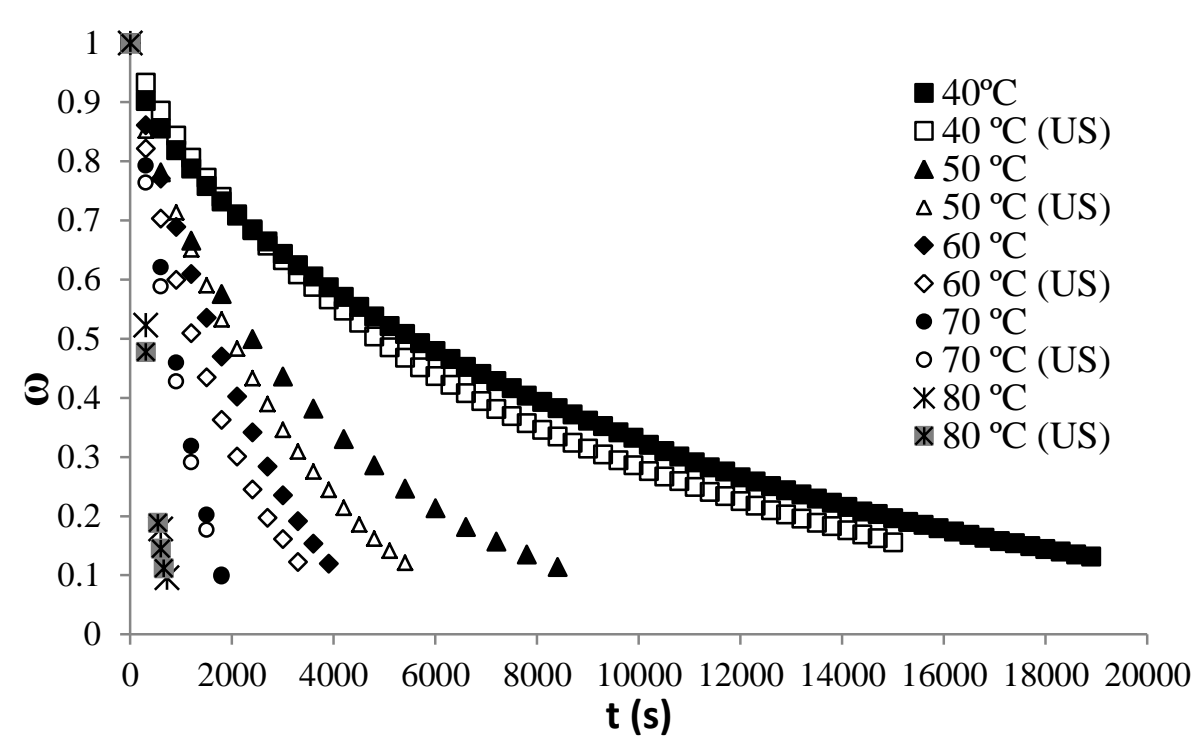

Figure 2. Convective drying kinetics of thyme at $v=2 \mathrm{~m} / \mathrm{s}$, different air temperatures, and US $18.5 \mathrm{~kW} \mathrm{~m}^{-3}$.

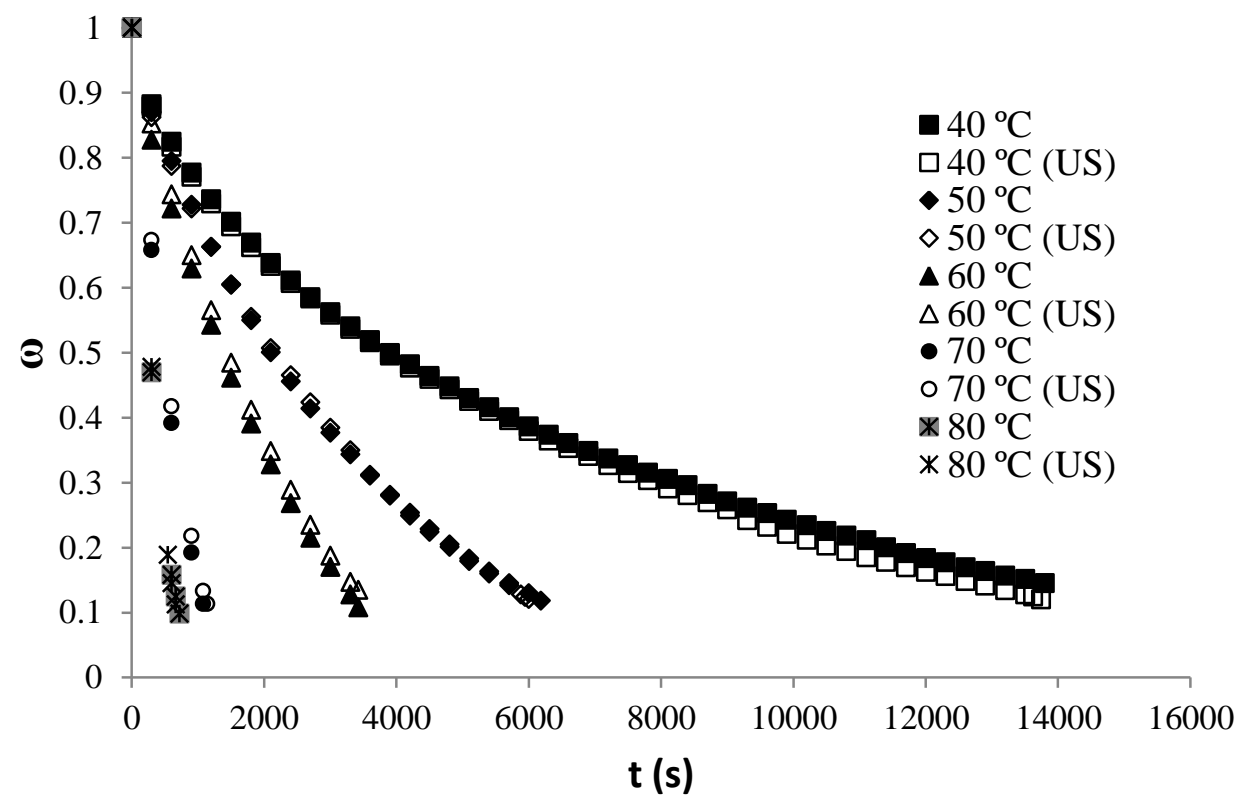

Figure 3. Convective drying kinetics of thyme at $v=3 \mathrm{~m} / \mathrm{s}$, different air temperatures, and US $18.5 \mathrm{~kW} \mathrm{~m}^{-3}$. 


\section{Modeling}

The model allows a good fit between the experimental and estimated values (VAR $\geq 99.4 \%$; $E R \leq 4.9 \%$ ) as seen in Figure 4 . In every case, the t-test fails to reject the null hypothesis (residual vector with mean 0 ) at the default 0.05 significance level. In the Lilliefors tests, the statistical values are less than the critical values in both cases; therefore, the Lilliefors test fails to reject the corresponding null hypothesis, at the 0.05 significance level. As a consequence, the normality of the residuals was checked.

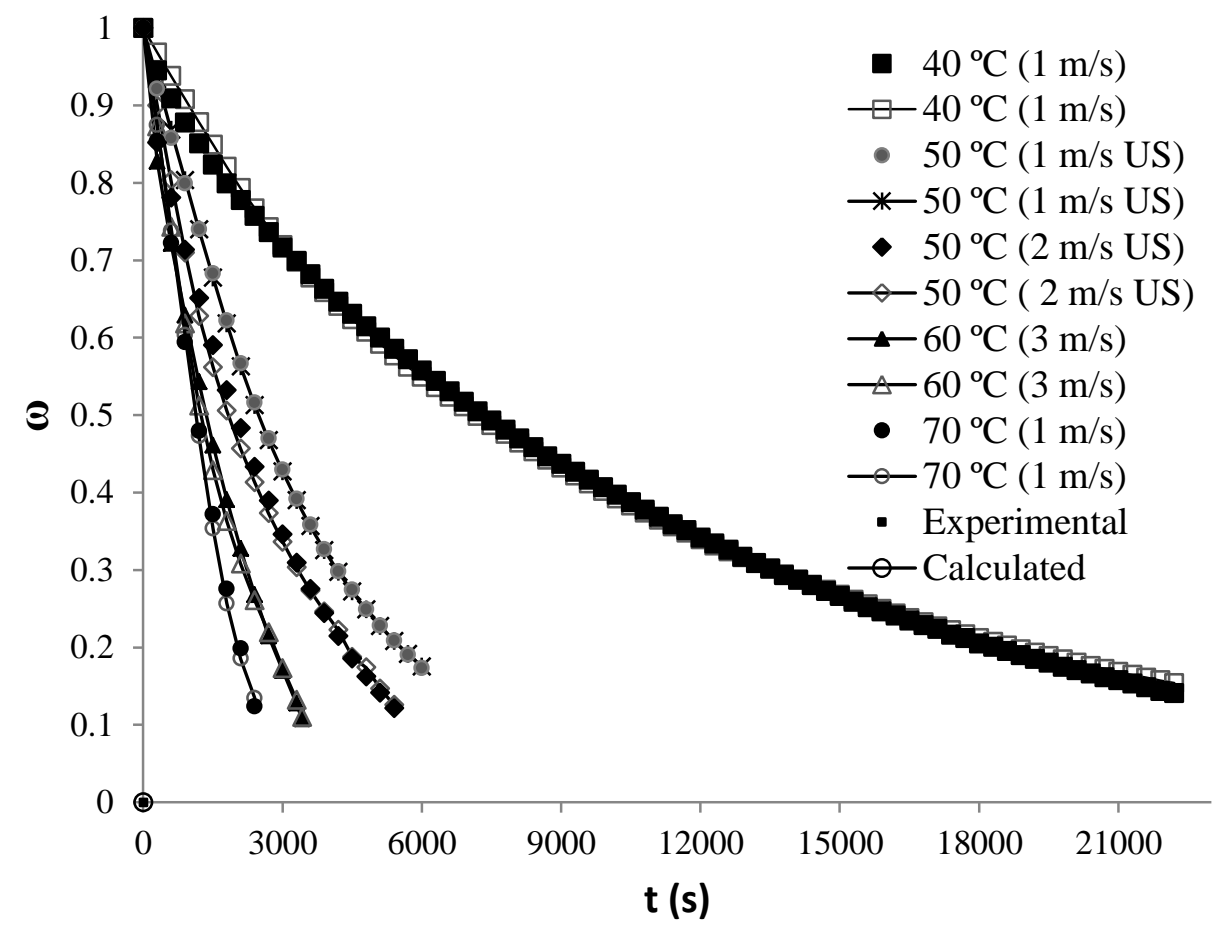

Figure 4. Experimental and calculated drying kinetics for different air velocities and temperatures, and US of $18.5 \mathrm{~kW} \mathrm{~m}^{-3}$.

\section{Ultrasonic effects on transport phenomena}

Tables.2, 3, and 4 show the parameters identified $\left(D / L^{2}, h_{m v}\right.$ and $\left.h\right)$ from modeling. It can be observed that the parameters identified were affected by air temperature, air velocity and US application.

Figure 5 shows the effect US and air velocity have on $D / L^{2}$. The influence of air velocity on drying kinetics is mainly linked to external resistance ${ }^{[19]}$. As the velocity 
increases; there is a reduction in the thickness of the boundary layer around the body.

Table 2. Parameters identified by the model at an air velocity of $1 \mathrm{~m} \mathrm{~s}^{-1}$, relative error and explained variance.

\begin{tabular}{|c|c|c|c|c|c|c|}
\hline $\begin{array}{c}\text { US } \\
\left(\mathrm{kW} \mathrm{m}^{-3}\right)\end{array}$ & $\mathbf{T}\left({ }^{\circ} \mathbf{C}\right)$ & $D / L^{2}\left[10^{4}\right] .\left(\mathrm{s}^{-1}\right)$ & $\begin{array}{c}h_{m v}\left[10^{4}\right] \\
\left(\mathrm{kWm}^{-2} \mathrm{~K}^{-1}\right)\end{array}$ & $\begin{array}{c}h\left[10^{I}\right] \\
\left(\mathrm{kWm}^{-2} \mathbf{K}^{-1}\right)\end{array}$ & $\operatorname{ER}(\%)$ & $\operatorname{VAR}(\%)$ \\
\hline \multirow{5}{*}{0} & 40 & $0.56 \pm 0.06$ & $1.37 \pm 0.08$ & $1.45 \pm 0.13$ & 3.3 & 99.8 \\
\hline & 50 & $1.08 \pm 0.06$ & $1.75 \pm 0.13$ & $1.79 \pm 0.16$ & 1.5 & 99.9 \\
\hline & 60 & $2.02 \pm 0.08$ & $2.03 \pm 0.02$ & $2.11 \pm 0.05$ & 2.4 & 99.8 \\
\hline & 70 & $4.98 \pm 0.13$ & $2.53 \pm 0.07$ & $2.51 \pm 0.14$ & 2.4 & 99.9 \\
\hline & 80 & $8.50 \pm 0.16$ & $2.96 \pm 0.08$ & $2.66 \pm 0.08$ & 3.8 & 99.8 \\
\hline \multirow{5}{*}{6.2} & 40 & $0.69 \pm 0.03$ & $1.68 \pm 0.04$ & $1.63 \pm 0.12$ & 1.8 & 99.9 \\
\hline & 50 & $1.21 \pm 0.07$ & $2.08 \pm 0.11$ & $2.07 \pm 0.17$ & 1.9 & 99.9 \\
\hline & 60 & $2.12 \pm 0.12$ & $2.29 \pm 0.02$ & $2.21 \pm 0.03$ & 2.7 & 99.8 \\
\hline & 70 & $5.02 \pm 0.18$ & $2.56 \pm 0.03$ & $2.56 \pm 0.01$ & 2.1 & 99.9 \\
\hline & 80 & $8.46 \pm 0.22$ & $2.93 \pm 0.02$ & $2.66 \pm 0.08$ & 3.5 & 99.8 \\
\hline \multirow{5}{*}{12.3} & 40 & $0.77 \pm 0.05$ & $1.99 \pm 0.04$ & $2.02 \pm 0.18$ & 3.6 & 99.4 \\
\hline & 50 & $1.31 \pm 0.06$ & $2.26 \pm 0.02$ & $2.27 \pm 0.02$ & 0.3 & 99.9 \\
\hline & 60 & $2.24 \pm 0.08$ & $2.37 \pm 0.01$ & $2.36 \pm 0.03$ & 2.8 & 99.8 \\
\hline & 70 & $4.98 \pm 0.15$ & $2.55 \pm 0.08$ & $2.57 \pm 0.08$ & 1.8 & 99.9 \\
\hline & 80 & $8.48 \pm 0.08$ & $2.93 \pm 0.09$ & $2.64 \pm 0.23$ & 3.7 & 99.8 \\
\hline \multirow{5}{*}{18.5} & 40 & $0.85 \pm 0.02$ & $2.15 \pm 0.02$ & $2.14 \pm 0.06$ & 0.7 & 99.9 \\
\hline & 50 & $1.45 \pm 0.02$ & $2.38 \pm 0.02$ & $2.36 \pm 0.02$ & 0.6 & 99.9 \\
\hline & 60 & $2.52 \pm 0.08$ & $2.48 \pm 0.02$ & $2.57 \pm 0.01$ & 3.1 & 99.8 \\
\hline & 70 & $4.96 \pm 0.09$ & $2.55 \pm 0.04$ & $2.52 \pm 0.02$ & 2.7 & 99.8 \\
\hline & 80 & $8.52 \pm 0.18$ & $2.89 \pm 0.05$ & $2.62 \pm 0.03$ & 3.5 & 99.8 \\
\hline
\end{tabular}


Resultados

Table 3. Parameters identified by the model at an air velocity of $2 \mathrm{~m} \mathrm{~s}^{-1}$, relative error and explained variance.

\begin{tabular}{|c|c|c|c|c|c|c|}
\hline 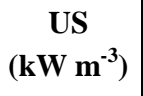 & $\mathrm{T}\left({ }^{\circ} \mathrm{C}\right)$ & $D / L^{2}\left[10^{4}\right] \cdot\left(\mathrm{s}^{-1}\right)$ & $\begin{array}{c}h_{m v}\left[10^{4}\right] . \\
\left(\mathbf{k W m}^{-2} \mathbf{K}^{-1}\right)\end{array}$ & $\begin{array}{c}h\left[10^{1}\right] \\
\left(\mathrm{kWm}^{-2} \mathrm{~K}^{-1}\right)\end{array}$ & $\operatorname{ER}(\%)$ & VAR (\%) \\
\hline \multirow{5}{*}{0} & 40 & $0.62 \pm 0.03$ & $2.58 \pm 0.02$ & $1.97 \pm 0.06$ & 2.2 & 99.8 \\
\hline & 50 & $1.10 \pm 0.03$ & $3.06 \pm 0.03$ & $2.19 \pm 0.02$ & 3.8 & 99.7 \\
\hline & 60 & $2.08 \pm 0.04$ & $3.41 \pm 0.01$ & $3.19 \pm 0.03$ & 3.8 & 99.7 \\
\hline & 70 & $5.01 \pm 0.06$ & $4.11 \pm 0.09$ & $3.88 \pm 0.09$ & 3.1 & 99.8 \\
\hline & 80 & $8.30 \pm 0.09$ & $4.12 \pm 0.04$ & $4.04 \pm 0.03$ & 3.9 & 99.6 \\
\hline \multirow{5}{*}{6.2} & 40 & $0.68 \pm 0.02$ & $2.96 \pm 0.03$ & $2.17 \pm 0.08$ & 1.8 & 99.9 \\
\hline & 50 & $1.24 \pm 0.06$ & $3.22 \pm 0.06$ & $2.43 \pm 0.03$ & 4.1 & 99.6 \\
\hline & 60 & $2.15 \pm 0.03$ & $3.56 \pm 0.05$ & $3.50 \pm 0.09$ & 4.3 & 99.6 \\
\hline & 70 & $4.96 \pm 0.11$ & $4.04 \pm 0.05$ & $3.93 \pm 0.01$ & 4.7 & 99.6 \\
\hline & 80 & $8.45 \pm 0.09$ & $4.14 \pm 0.04$ & $4.01 \pm 0.09$ & 3.7 & 99.6 \\
\hline \multirow{5}{*}{12.3} & 40 & $0.76 \pm 0.04$ & $3.34 \pm 0.04$ & $2.44 \pm 0.06$ & 1.5 & 99.9 \\
\hline & 50 & $1.32 \pm 0.03$ & $3.48 \pm 0.05$ & $2.69 \pm 0.09$ & 3.6 & 99.7 \\
\hline & 60 & $2.24 \pm 0.02$ & $3.76 \pm 0.03$ & $3.68 \pm 0.03$ & 3.5 & 99.7 \\
\hline & 70 & $5.06 \pm 0.09$ & $4.06 \pm 0.06$ & $3.92 \pm 0.09$ & 3.9 & 99.7 \\
\hline & 80 & $8.44 \pm 0.07$ & $4.15 \pm 0.06$ & $4.03 \pm 0.11$ & 4.1 & 99.6 \\
\hline \multirow{5}{*}{18.5} & 40 & $0.84 \pm 0.07$ & $3.53 \pm 0.09$ & $2.58 \pm 0.03$ & 1.9 & 99.8 \\
\hline & 50 & $1.42 \pm 0.06$ & $3.77 \pm 0.08$ & $2.89 \pm 0.07$ & 3.9 & 99.6 \\
\hline & 60 & $2.53 \pm 0.07$ & $3.93 \pm 0.03$ & $3.81 \pm 0.09$ & 3.1 & 99.8 \\
\hline & 70 & $5.04 \pm 0.08$ & $4.06 \pm 0.08$ & $3.89 \pm 0.13$ & 3.2 & 99.8 \\
\hline & 80 & $8.48 \pm 0.09$ & $4.17 \pm 0.05$ & $4.00 \pm 0.08$ & 2.2 & 99.9 \\
\hline
\end{tabular}


Resultados

Table 4. Parameters identified by the model at an air velocity of $3 \mathrm{~m} \mathrm{~s}^{-1}$, relative error and explained variance.

\begin{tabular}{|c|c|c|c|c|c|c|}
\hline 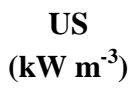 & $\mathrm{T}\left({ }^{\circ} \mathrm{C}\right)$ & $D / L^{2}\left[10^{4}\right] \cdot\left(\mathrm{s}^{-1}\right)$ & $\begin{array}{c}h_{m v}\left[10^{4}\right] \\
\left(\mathbf{k W m}^{-2} \mathbf{K}^{-1}\right)\end{array}$ & $\begin{array}{c}h\left[10^{1}\right] \\
\left(\mathrm{kWm}^{-2} \mathrm{~K}^{-1}\right)\end{array}$ & $\operatorname{ER}(\%)$ & VAR (\%) \\
\hline \multirow{5}{*}{0} & 40 & $0.66 \pm 0.08$ & $3.27 \pm 0.04$ & $2.35 \pm 0.03$ & 0.9 & 99.9 \\
\hline & 50 & $1.11 \pm 0.07$ & $3.43 \pm 0.03$ & $2.46 \pm 0.02$ & 2.5 & 99.9 \\
\hline & 60 & $2.08 \pm 0.03$ & $3.78 \pm 0.05$ & $3.32 \pm 0.05$ & 4.9 & 99.6 \\
\hline & 70 & $4.87 \pm 0.16$ & $4.12 \pm 0.11$ & $4.04 \pm 0.16$ & 2.4 & 99.8 \\
\hline & 80 & $8.39 \pm 0.09$ & $4.51 \pm 0.09$ & $4.70 \pm 0.06$ & 0.3 & 99.9 \\
\hline \multirow{5}{*}{6.2} & 40 & $0.67 \pm 0.08$ & $3.33 \pm 0.03$ & $2.33 \pm 0.03$ & 3.1 & 99.9 \\
\hline & 50 & $1.12 \pm 0.12$ & $3.42 \pm 0.02$ & $2.49 \pm 0.04$ & 3.3 & 99.8 \\
\hline & 60 & $2.49 \pm 0.08$ & $3.80 \pm 0.06$ & $3.35 \pm 0.12$ & 3.1 & 99.8 \\
\hline & 70 & $4.98 \pm 0.11$ & $4.08 \pm 0.05$ & $4.02 \pm 0.08$ & 2.6 & 99.9 \\
\hline & 80 & $8.32 \pm 0.11$ & $4.54 \pm 0.15$ & $4.72 \pm 0.13$ & 1.9 & 99.9 \\
\hline \multirow{5}{*}{12.3} & 40 & $0.67 \pm 0.07$ & $3.28 \pm 0.05$ & $2.30 \pm 0.05$ & 1.5 & 99.9 \\
\hline & 50 & $1.07 \pm 0.08$ & $3.41 \pm 0.04$ & $2.46 \pm 0.08$ & 3.4 & 99.8 \\
\hline & 60 & $2.34 \pm 0.09$ & $3.84 \pm 0.08$ & $3.36 \pm 0.09$ & 3.7 & 99.7 \\
\hline & 70 & $4.95 \pm 0.12$ & $4.12 \pm 0.06$ & $4.04 \pm 0.11$ & 2.9 & 99.9 \\
\hline & 80 & $8.53 \pm 0.07$ & $4.50 \pm 0.18$ & $4.69 \pm 0.09$ & 0.4 & 99.9 \\
\hline \multirow{5}{*}{18.5} & 40 & $0.66 \pm 0.05$ & $3.30 \pm 0.15$ & $2.37 \pm 0.08$ & 1.5 & 99.9 \\
\hline & 50 & $1.13 \pm 0.08$ & $3.54 \pm 0.09$ & $2.50 \pm 0.03$ & 3.9 & 99.7 \\
\hline & 60 & $2.41 \pm 0.09$ & $3.79 \pm 0.09$ & $3.38 \pm 0.06$ & 3.6 & 99.7 \\
\hline & 70 & $4.83 \pm 0.09$ & $4.10 \pm 0.03$ & $3.99 \pm 0.08$ & 2.3 & 99.9 \\
\hline & 80 & $8.45 \pm 0.09$ & $4.53 \pm 0.03$ & $4.71 \pm 0.14$ & 0.4 & 99.9 \\
\hline
\end{tabular}




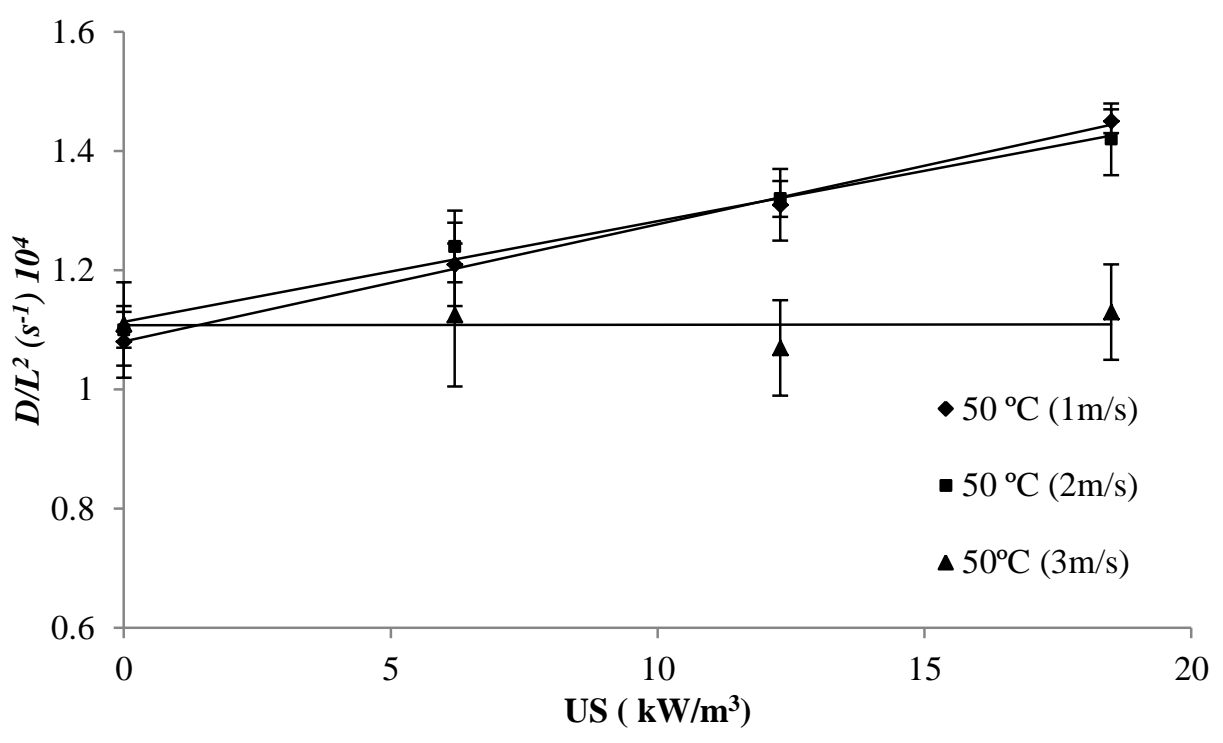

Figure 5. Influence of US on the average $D / L^{2}$ for drying thyme leaves at different air velocities

When the drying process is controlled by the sample's internal resistance to moisture diffusion, the increase in the air drying velocity does not affect the drying rate ${ }^{[34,35]}$; this behavior was observed at drying kinetics of $3 \mathrm{~m} \mathrm{~s}^{-1}$.

The internal resistance is linked to the identified $D / L^{2}$ parameter; in the fixed porous bed, US application directly affects the leaves. Figure 6 shows the effect of US application on $D / L^{2}$ at different air temperatures. $D / L^{2}$ increased as the temperature rose, which means that the internal resistance to mass transfer decreased as the temperature increased. $D / L^{2}$ only increases when US is applied in the experiments at $T_{a} \leq 60^{\circ} \mathrm{C}$. However, the influence of power ultrasound on $D / L^{2}$ values (at the US level tested) was milder when compared to how much it affected heat and mass transfer coefficient values (Tables 2 and 3 ). This behavior may be linked to the effects of the acoustic energy impinging the bed. It has been found ${ }^{[8,9]}$ that porosity should be considered as an important structural variable for the purposes of determining the acoustic intensification in food drying. The bed is highly porous, thus allowing ultrasound to penetrate and affect the external resistance. The small intercellular spaces, characteristic of low-porosity products such as thyme leaves, make this product less prone to the influence of ultrasound as previously reported ${ }^{[8]}$. Therefore, it would be necessary to apply higher levels of US intensity to obtain greater effects on the internal resistance. 


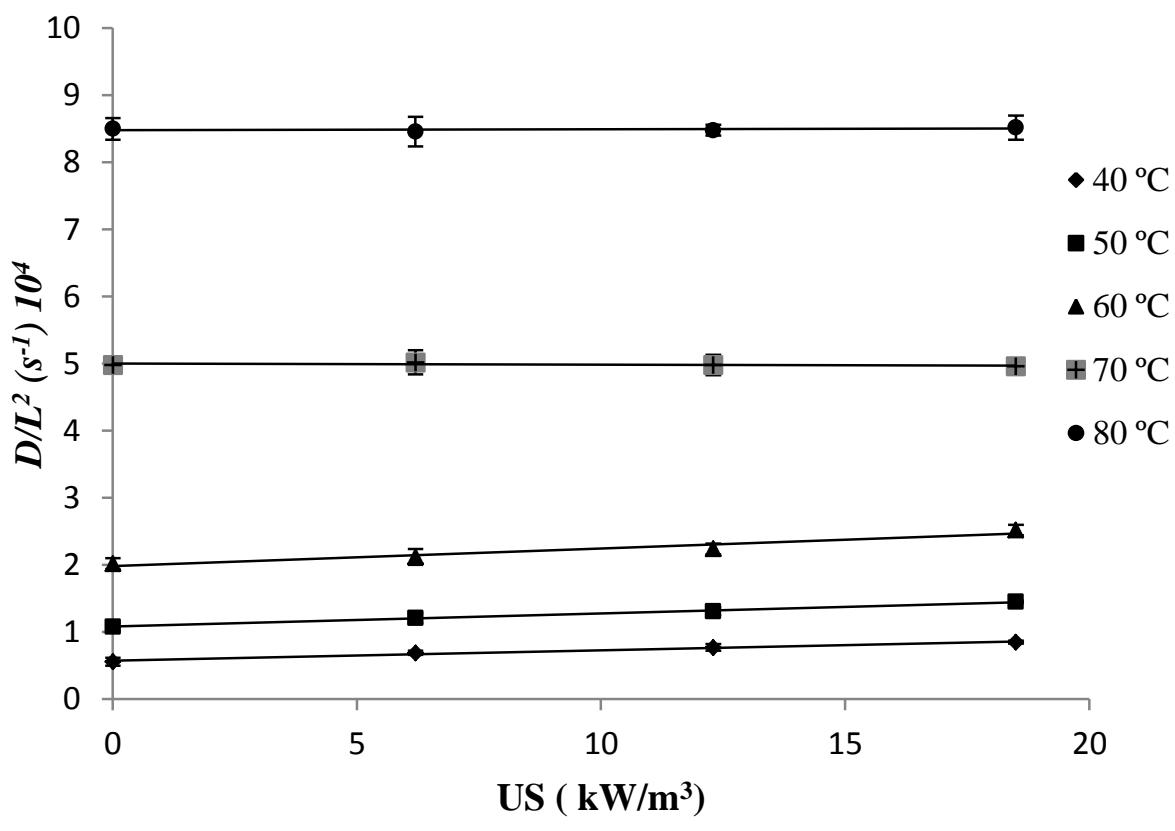

Figure 6. Influence of US on the average $D / L^{2}$ for drying thyme leaves at different air temperatures and an air velocity of $1 \mathrm{~m} / \mathrm{s}$.

The effect of US application on the external resistance to heat and mass transfer was observed (Tables 2 and 3). Figure 7 shows the effect of US application and air velocity on the mass transfer coefficient. The air velocity is mainly linked to the external resistance: the mass transfer coefficient increasing as the air velocity rose. As the applied US penetrated into the bed, the external resistance to mass transfers was affected $\left(v<3 \mathrm{~m} \mathrm{~s}^{-1}\right)$. Therefore, the mass transfer mechanisms involved in the drying of thyme leaves were significantly affected by ultrasonic energy application, due to the reduction of both external resistances. US has a greater influence at low air velocities $\left(1 \mathrm{~m} \mathrm{~s}^{-1}\right)$, being negligible at the highest velocity tested $\left(3 \mathrm{~m} \mathrm{~s}^{-1}\right)$. This will suggest that the external resistance is more seriously influenced at low air velocities, this being linked not only to the larger boundary layer at low air velocities but also to the sonic filed disruption at high air velocities ${ }^{[36.37]}$. Figure 8 shows the effect US application has on the mass transfer coefficient at different air temperatures; it may be observed that the external resistance to mass transfer decreased as the temperature rose. The mass transfer coefficient increased in line with US intensity at $T_{a}<70^{\circ} \mathrm{C}$; the influence of ultrasound decreased as the temperature rose. This could be linked to the fact that the effect of ultrasound is related to the supply of ultrasonic energy, which is constant, whilst the temperature effect increases in line with temperature ${ }^{[37]}$. For the heat transfer coefficient, behavior similar to that observed for the mass transfer coefficient could be drawn. 


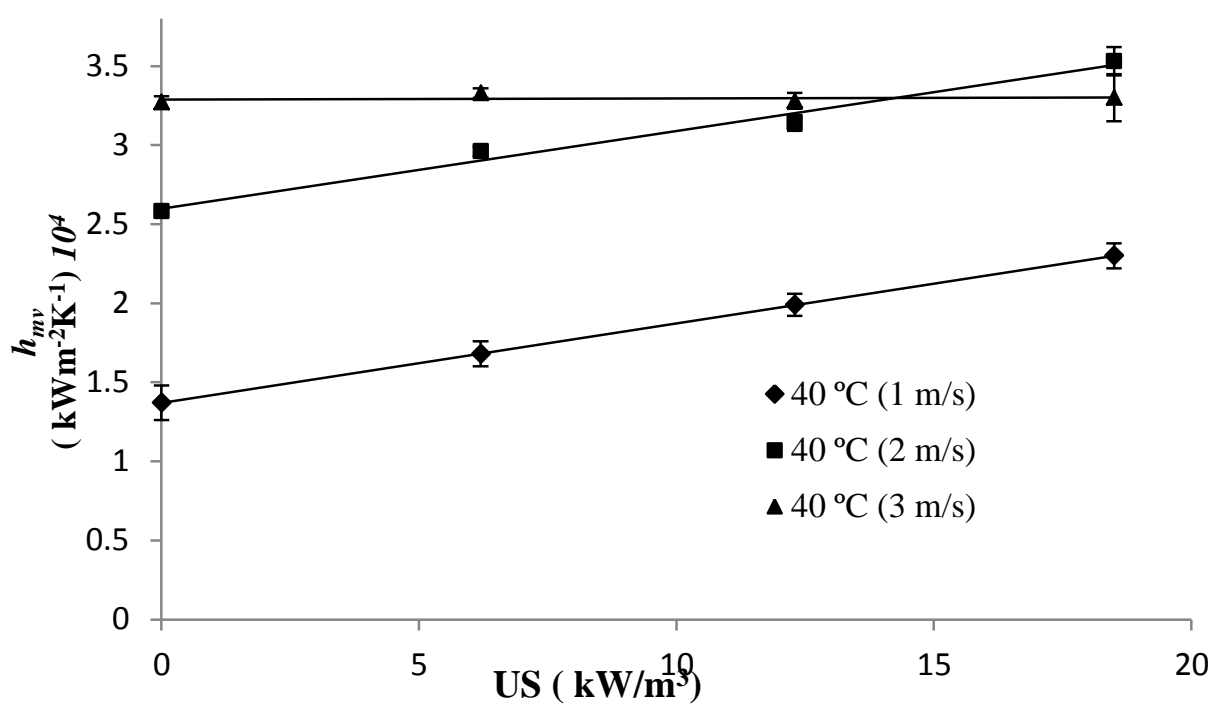

Figure 7. Influence of US on the average $h_{m v}$ for drying thyme leaves at different air velocities.

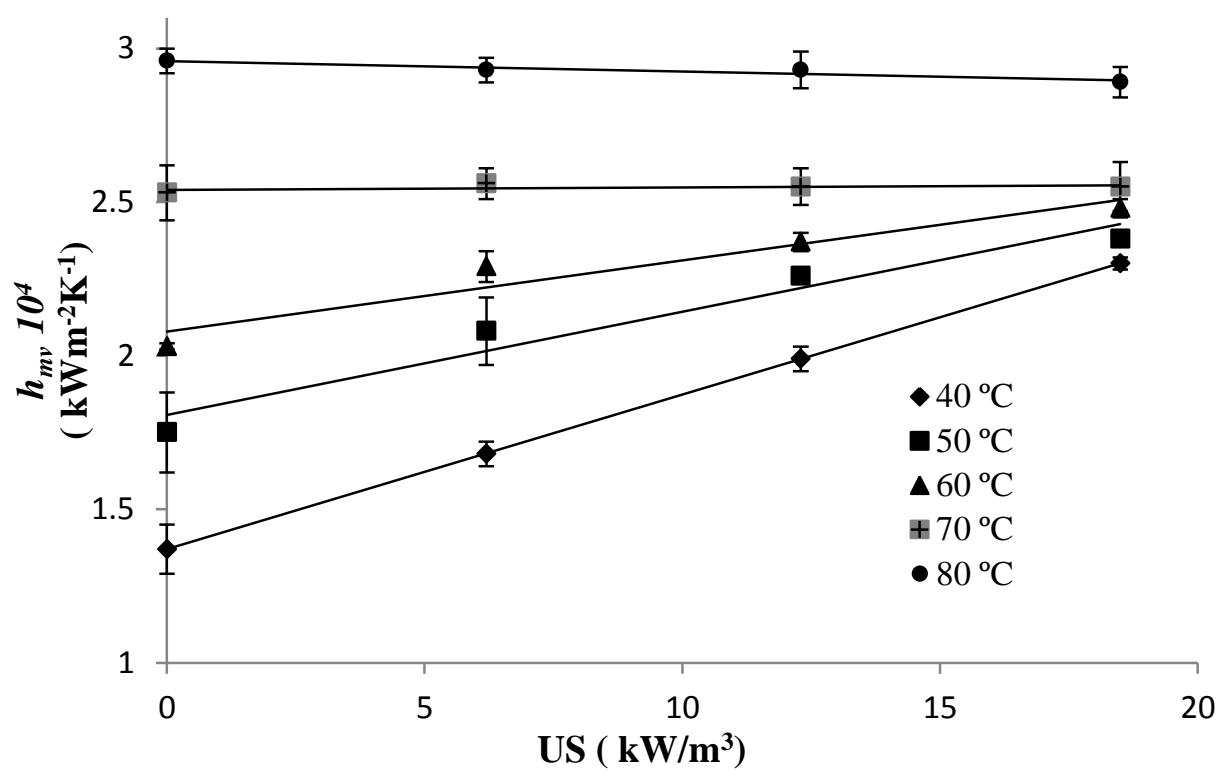

Figure 8. Influence of US on the average $h_{m v}$ for drying thyme leaves at different air temperatures and an air velocity of $1 \mathrm{~m} / \mathrm{s}$. 


\section{CONCLUSIONS}

The drying kinetics of the fixed bed of thyme leaves could be intensified by US application. In some instances, reductions in the drying time of about $30 \%$ could be obtained. To describe the bed behavior, a time varying boundary conditions model was found to be necessary. Through modeling, it was found that the main effects observed were those on external resistance. This confirms a previous finding that showed a relationship between US intensification and porosity. Since the bed was highly porous and not the leaves, there was a milder influence on the internal resistance than the external one. It was also found that a high drying air velocity or temperature will hide US effects, corroborating the findings in single layer drying.

\section{Acknowledgements}

The authors of this work acknowledge the financial support from the "Ministerio de Educación y Ciencia" in Spain, CONSOLIDER INGENIO 2010 (CSD2007-00016).

\section{References}

1. Akpinar, E.K. Mathematical modelling of thin layer drying process under open sun of some aromatic plants. Journal of Food Engineering 2006, 77, 864-870.

2. Timoumi, S.; Mihoubi, D.; Zagrouba, F. Shrinkage, vitamin C degradation and aroma losses during infra-red drying of apple slices. Swiss Society of Food Science and Technology 2007, 40, 1648-1654.

3. Santos, P.H.S.; Silva, M.A. Kinetics of L-ascorbic degradation in pineapple drying under ethanolic atmosphere. Drying Technology 2009, 27, 947-954.

4. Suvarnakuta, P.; Devahastin, S.; Mujumdar, A.S. Drying kinetics and b-carotene degradation in carrot undergoing different drying processes. Journal of Food Science 2005 70(8), s520-s526.

5. Chou, S.K.; Chua, K.J. New hybrid drying technologies for heat sensitive foodstuff. Trends in Food Science \& Technology 2001, 12, 359-369.

6. Gallego-Juarez, J. A.; Riera, E.; de la Fuente Blanco, S.; Rodríguez-Corral, G.; Acosta-Aparicio, V. M.; Blanco, A. Application of High-Power Ultrasound for Dehydration of Vegetables: Processes and Devices. Drying Technology 2007, 25, 1893-901.

7. García-Pérez, J.V., Cárcel, J.A., De la Fuente, S. and Riera, E., (2006). Ultrasonic drying of foodstuff in a fluidized bed: parametric study, Ultrasonics 44: e539-e543. 
8. García-Pérez, J.V.; Cárcel, J.A.; Riera, E.; Mulet, A. Influence of applied acoustic energy on the drying of carrots and lemon peel. Drying Technology 2009, 27, 281-287.

9. García-Pérez, J.V.; Ozuna, C.; Ortuño, C.; Cárcel, J.A.; Mulet, A. Modeling Ultrasonically Assisted Convective Drying of Eggplant . Drying Technology 2011, 29, 1499-1509.

10. Thompson, T.L.; Peart, R.M.; Foster, G.H. Mathematical simulation of corn Drying - A new model. Transactions of the ASAE 1968, 11 (4), 582-586.

11. Berbert, P.A.; Queiroz, D.M.; Silva, J.S.; Pinheiro, J.B. Simulation of coffee drying in a fixed bed with periodic airflow reversal. Journal of Agricultural Engineering Research 1995, 60, 167-173.

12. Sun, D.W.; Woods, J.L. Simulation of the heat and mass transfer process during drying in deep grain beds. Drying Technology 1997, 15 (10), 24792508 .

13. Barre, H.J.; Baughman, G.R.; Hamdy, M.Y. Application of the logarithmic model to cross-flow deep-bed grain drying. Transactions of the ASAE 1971, 13 (8), 1061-1064.

14. Ratti, C.; Mujumdar, A.S. Simulation of packed bed drying of foodstuffs with airflow reversal. Journal of Food Engineering 1995, 26 (3), 259-271.

15. Herman, E.; Rodríguez, G. C.; García, M. A. Mathematical modelling for fixedbed drying considering heat and mass transfer and interfacial phenomena. Drying Technology 2001, 9 (1), 137-154.

16. Sitompul, J.P.; Istadi, Widiasa, I.N. Modeling and simulation of deep-bed grain dryers. Drying Technology 2001, 19 (2), 269-280.

17. Istadi, I.; Sitompul, J.P. A comprehensive mathematical and numerical modeling of deep-bed grain drying. Drying Technology 2002, 20 (6), 11231142.

18. Herman-Lara, E.; Salgado-Cervantes, M.A.; García-Alvarado, M.A. Mathematical simulation of convection food batch drying with assumptions of plug flow and complete mixing of air. Journal of Food Engineering 2005, 68 (3), 321-327.

19. Mulet, A. Drying modelling and water diffusivity in carrots and potatoes. Journal of Food Engineering 1994, 22, 329-348. 
20. Crank, J. The Mathematics of Diffusion; Oxford University Press: London, 1975.

21. Maroulis, Z.B.; Saravacos, G.D.; Panagiotou, N.M.; Krokida, M.K. Moisture diffusivity data compilation for foodstuffs: effect of material moisture content and temperature. International Journal of Food Properties 2001, 4, 225-237.

22. Simal, S.; Femenía, A.; García-Pascual, P.; Rosselló , C. Simulation of the drying curves of a meat-based product: Effect of the external resistance to mass transfer. Journal of Food Engineering 2003, 58, 193-199.

23. Rodríguez, J.; Clemente, G.; Sanjuán, N.; Bon, J. (). Modeling drying kinetics of thyme (Thymus vulgaris L.): Theoretical and empirical models, and neural networks. Food Science and Technology International 2012, DOI: $10.1177 / 1082013212469614$.

24. Doymaz, I. Drying of Thyme (Thymus Vulgaris L.) and selection of a suitable thin-layer drying model. Journal of Food Processing and Preservation 2011, doi: 10.1111/j.1745-4549.2010.00488.x.

25. AOAC. Official methods of analysis of AOAC International, 16th edn, (Association of Official Analytical Chemist International AOAC, Gaithersburg, USA), 1997

26. Cárcel, J. A.; Garcia-Perez, J. V.; Riera, E.; Mulet A. Improvement of convective Drying of Carrot by Applying Power Ultrasound-Influence of Mass Load Density. Drying Technology 2011, 29, 174-182.

27. Diaz-Maroto, M. C.; Perez Coello, M. S.; Cabezudo, M. D. Effect of different drying methods on the volatile components of parsley (Petroselinum crispum L.). European Food Research and Technology 2002, 215, 227-230.

28. Bon, J.; Rosello, C.; Femenia, A.; Eim, V.; Simal, S. Mathematical Modeling of Drying Kinetics for Apricots: Influence of the External Resistance to Mass Transfer. Drying Technology 2007, 25, 1829-1835.

29. Perry, R.H.; Green, D.W.; Maloney, J.O. Perry's Chemical Engineers Handbook; seventh ed. McGraw-Hill: USA, 1997

30. Treybal, R. E. Mass-transfer operations; McGraw-Hill (2nd ed.): USA, 1980

31. The Mathworks. . Matlab user's guide. The MathWorks Inc., SouthNatick, MA, USA, 2011

32. COMSOL AB. COMSOL multiphysics user's guide version 3.5, (COMSOL AB., Stockholm, Sweden), 2007 
33. Bon, J.;Váquiro, H.; Benedito, J.; Telis-Romero, J. Thermophysical properties of mango pulp (Mangifera indica L. cv. Tommy Atkins). Journal of Food Engineering 2010, 97, 563-568.

34. Mulet, A.; Sanjuán, N.; Bon, J.; Simal, S. Drying model for highly porous hemispherical bodies. European Food Research and Technologyv1999, 210 (2), 80-83.

35. Erriguible, A.; Bernada, P.;vCouture, F.; Roques, M.A. Modelling of heat and mass transfer at the boundary between a porous medium and its surroundings. Drying Technology 2005, 23, 455-472.

36. Cárcel, J. A.; García-Pérez, J. V.; Riera, E.; Mulet, A. Influence of High Intensity Ultrasound on Drying Kinetics of Persimmon. Drying Technology 2007, 25, 185-193.

37. García-Pérez, J.V.; Rosselló, C.; Cárcel, J.A.; De la Fuente, S.; Mulet, A. (). Effect of Air Temperature on Convective Drying Assisted by High Power Ultrasound. Defect and Diffusion Forum 2006, 258-260, 563-574.

38. Pelegrina, A.H.; Echarte, R.E.; Crapiste, G.H. Calculo de las propiedades del aire húmedo y su aplicación en la simulación de procesos: VII taller de herramientas de cálculo en ingeniería de alimentos. Santiago de Chile 1999.

39. Soysal, Y.; Oztekin S. Comparison of seven equilibrium moisture content equations for some medicinal and Aromatic. Journal of Agricultural Engineering Research 2001, 78(1), 57-63.

40. Singh, R.P.; Heldman, D.R. Introduction to Food Engineering; third ed. Academic Press: Glasgow, Great Britain, 2001.

\section{NOMENCLATURE}

a Parameter equation 9

$a_{w} \quad$ Water activity

$b \quad$ Parameter equation 9

$C p_{d a} \quad$ Specific heat of dry air

$C p_{v} \quad$ Specific heat of vapor

$C p_{w} \quad$ Specific heat of water

$C p_{d s} \quad$ Specific heat of the dry solid

$D \quad$ Effective water diffusivity in the sample

$\mathrm{J} \mathrm{kg}^{-1} \mathrm{~K}^{-1}$

$D_{A B} \quad$ Diffusivity of water in air

$\mathrm{J} \mathrm{kg}^{-1} \mathrm{~K}^{-1}$

$\mathrm{J} \mathrm{kg}^{-1} \mathrm{~K}^{-1}$

$\mathrm{J} \mathrm{kg}^{-1} \mathrm{~K}^{-1}$

$\mathrm{m}^{2} \mathrm{~s}^{-1}$

$\mathrm{m}^{2} \mathrm{~s}^{-1}$ 
ER Relative error

$h \quad$ Heat transfer coefficient

$h_{m v} \quad$ Mass transfer coefficient

$L \quad$ Half thickness of the leaves

$L_{c} \quad$ Thickness of the bed

$M_{d s} \quad$ Mass of the dry solid

$m_{a} \quad$ Dry air mass flow

$P M_{\mathrm{v}} \quad$ Molecular weight of water vapor

$R \quad$ Ideal gases constant

$T \quad$ Temperature of the solid

$T(1, t)$ Temperature on the leaf surface

$T_{a} \quad$ Air temperature

$T_{a e} \quad$ Air temperature bed exit

$T_{a i} \quad$ Air temperature bed inlet

$T_{p p} \quad$ Temperature on the gas-solid interface

$t \quad$ Time

US Acoustic power density

$V \quad$ Volume of the bed

$V_{a} \quad$ Air volume in the bed

VAR Explained variance

$x \quad$ Coordinate

$X_{a} \quad$ Air moisture content

$X_{e} \quad$ Moisture content of hot air

$X_{e q} \quad$ Equilibrium moisture content of hot air

$z$ Dimensionless coordinate

Greeks

$\varepsilon \quad$ Bed porosity

$\kappa \quad$ Thermal conductivity thyme

$\kappa_{a} \quad$ Thermal conductivity air

$\lambda$ latent heat of vaporization

$v \quad$ Air velocity

$\rho_{d a} \quad$ Density of the dry air
$\%$

$\mathrm{kW} \mathrm{m}^{-2} \mathrm{~K}^{-1}$

$\mathrm{kW} \mathrm{m} \mathrm{m}^{-2} \mathrm{~K}^{-1}$

$\mathrm{m}$

m

$\mathrm{kg}^{-1}$

$\mathrm{kg} \mathrm{s}^{-1}$

$\mathrm{kg} \mathrm{mol}^{-1}$

$\mathrm{kJ} \mathrm{kmol}^{-1} \mathrm{~K}^{-1}$

$\stackrel{\circ}{\circ}$

${ }^{\circ} \mathrm{C}$

$\stackrel{\circ}{\circ}$

${ }^{\circ} \mathrm{C}$

$\stackrel{\circ}{ } \mathrm{C}$

${ }^{\circ} \mathrm{C}$

$\mathrm{s}$

$\mathrm{kW} \mathrm{m} \mathrm{m}^{-3}$

$\mathrm{m}^{-3}$

$\mathrm{m}^{-3}$

$\%$

m

$\mathrm{kg}$ water $(\mathrm{kgdB})^{-1}$

$\mathrm{kg}$ water $(\mathrm{kgdB})^{-1}$

$\mathrm{kg}$ water $(\mathrm{kgdB})^{-1}$ $k W m^{-1} K^{-1}$

$\mathrm{kWm}^{-1} \mathrm{~K}^{-1}$

$\mathrm{kJ} \mathrm{kg}^{-1}$

$\mathrm{m} \mathrm{s}^{-1}$

$\mathrm{kg} \mathrm{m}^{-3}$ 


\begin{tabular}{|c|c|c|}
\hline$\rho_{d a i}$ & Density of the dry air at surface temperature & $\mathrm{kg} \mathrm{m}^{-3}$ \\
\hline$\rho_{d s}$ & Density of the dry solid & $\mathrm{kg} \mathrm{m}^{-3}$ \\
\hline $\bar{\tau}$ & Average moisture content of the product & $\mathrm{kg}$ water (kgds) $)^{-1}$ \\
\hline$\tau$ & Moisture content of the product & $\mathrm{kg}$ water (kgds) \\
\hline$\tau_{e q}$ & Equilibrium moisture content & $\mathrm{kg}$ water(kgds) $)^{-1}$ \\
\hline$\tau_{0}$ & Initial moisture content of the product & $\mathrm{kg}$ water (kgds) ${ }^{-}$ \\
\hline$\omega$ & Dimensionless moisture content & \\
\hline \multicolumn{3}{|c|}{ Dimensionless numbers } \\
\hline$N u$ & Nusselt number & \\
\hline $\operatorname{Pr}$ & Prandtl number & \\
\hline $\operatorname{Re}$ & Reynolds number & \\
\hline$S c$ & Schmidt number & \\
\hline$S h$ & Sherwood number & \\
\hline
\end{tabular}




\title{
4.4. OPTIMIZATION OF THE ANTIOXIDANT CAPACITY OF THYME (Thymus Vulgaris L.) EXTRACTS: MANAGEMENT OF THE CONVECTIVE DRYING PROCESS ASSISTED BY POWER ULTRASOUND
}

\author{
J. Rodriguez, E.C. Melo, A. Mulet, J. Bon \\ Submited: JOURNAL OF FOOD ENGINEERING
}

\begin{abstract}
Food properties change during processing, altering the quality of the final product. Sometimes, the important causal relationships are not well known and thus process management is difficult. This is especially true when chemical changes can occur as in the case of the drying of bioactive materials. The aim of this work was to develop a management tool for the thyme drying process, assisted by power ultrasound, to allow the appropriate values of the operating conditions that maximize the antioxidant capacity $(A C)$ of the dried thyme extracts to be determined. For this proposal, the thyme drying process was analyzed at different drying air temperatures $(\mathrm{T})\left(40\right.$ to $\left.80{ }^{\circ} \mathrm{C}\right)$, drying air velocities $\left(\mathrm{v}_{\mathrm{a}}\right)(1$ to $3 \mathrm{~m} / \mathrm{s})$ and levels of power ultrasound (US) $\left(0,6.2,12.3,18.5 \mathrm{~kW} \mathrm{~m}^{-3}\right)$. The essential oil was extracted by means of a supercritical fluid extraction method, and its AC was measured by FRAP. The drying velocity and the AC of the dried thyme extracts were both influenced by the magnitude of the air velocity and temperature, and also by power ultrasound. Artificial neural networks were developed to formulate and solve the optimization problem. The developed management tool allowed the optimal conditions of the process to be established, thereby maximizing the AC values in function of the raw materials, process characteristics and room air conditions.
\end{abstract}

Keywords: drying, power ultrasound, process management, antioxidant capacity. 


\section{Introduction}

Bioactive compounds with antioxidant capacity are valuable components for food design. Many plants are an important source of these compounds, thyme (Thymus Vulgaris L.) being among those plants. The post-harvesting process of medicinal plants is of great importance in the production chain due to the fact that it has a direct influence on the quality and quantity of the active principles in the product (Khorshidi et al., 2009).

Thus, in order to avoid exposure to high temperatures and long processing times, the drying rate must be intensified.

Hot air drying is one of the oldest food preservation processes and a major operation employed in agro-food industries to reduce transportation costs and to facilitate product-use. The reduction in the water content and the increase in the temperature of the solid during drying can affect important food properties, such as flavour, colour, vitamin degradation, essential oil and texture, negatively affecting the quality of the final product. Additionally, drying processes are highly energy consuming. In many cases, the objective behind the use of an energy efficient process and the need to attain the highest possible product quality clash. Optimization allows the explicit formulation of both energy and quality objectives, and will therefore have a large potential in enhancing the drying process operation (Banga and Singh, 1994). For that purpose, in order to obtain the optimum operating parameters, appropriate mathematical models are needed (Clemente et al., 2011).

When drying thyme, the yield and quantitative composition of the essential oil content of certain compounds with antioxidant capacity (AC) can be influenced during drying (Venskutonis, 1997, Rodríguez et al., 2013). Compound degradation (Hamrouni-Sellami et al., 2011) is influenced by both drying air temperature and drying time. According to Hamrouni-Sellami et al. (2012), drying not only resulted in the disappearance of some compounds but also in the appearance of others which were absent in fresh leaves. Some compounds seem to have more affinity with the water fraction contained in thyme leaves and, thereby, they were lost with the water during the drying process. Therefore, the increase in drying velocity influences the formation or degradation of certain compounds. To avoid high temperature exposure and long processing times, the drying velocity must be intensified, and, consequently, the energy yield of the process will increase. The introduction of new technologies could lead to a reduction in the processing time or an improvement in operating conditions (Cárcel et al., 2012). Ultrasonic assisted drying has the ability to help remove moisture without significantly heating the product by accelerating the mass transfer processes (García-Pérez et al., 2006).

The Supercritical Fluids Extraction method (SFE) has been applied to extract the essential oils of medicinal plants, and its results compared favorably (better quality and greater quantity of essential oil) with other conventional extraction processes (Reverchon and De Marco, 2006). Prado et al. (2009) indicated that extraction 
methods, such as steam distillation, can degrade essential oil components, like thymol, as a result of their high operating temperature.

Several studies have been conducted to evaluate the effect of drying treatments compared with the effects they have on the main volatile compounds in thyme leaves (Rahimmalek and Hossein-Golib, 2013; Hossain et al., 2010; Calín-Sánchez et al., 2013). However, there is no information on the effects of high-intensity ultrasound assisted convective drying on the drying kinetics and antioxidant capacity (AC) of thyme leaves. As a consequence, it is interesting to study the effect of the intensified convective drying of foods in fixed beds by the application of power ultrasound on drying kinetics and AC, and develop a management tool to determine the optimal values of the operating conditions that maximize AC.

As the $\mathrm{AC}$ of the extracts of the dried product depends on the operating conditions of the drying process, it would be convenient to develop a mathematical model to predict the evolution of the $A C$ as a function of the values of the operating conditions. Due to the large number of variables involved, it is difficult to develop theoretical models to describe the moisture content evolution, in conjunction with $\mathrm{AC}$ behavior and linked to the operating conditions of the drying process. The length of time required for their resolution would represent a handicap for their use in real time; therefore, it could be of interest to develop empirical models, such as artificial neural networks (ANNs).

The main advantage of neural networks is their ability to represent complex input/output relationships; however, they do not have the ability to explicitly identify possible causal relationships. In the last decade, neural networks have been widely used for different food-processing applications, such as drying (Tripathy et al., 2009; Hernández-Pérez et al., 2004; Hernández, 2008 and 2009), thermal processing (Lu et al., 2010) and food freezing (Goñi et al., 2008) and also to predict both the antioxidant capacity (Bucinski et al., 2004) and the changes that take place in the different compounds during storage (Zheng et al., 2011).

The aim of this work was to develop an optimization tool that allows the power ultrasound-assisted drying process to be managed so as to maximize the $A C$ of the extracts. For that purpose, an analysis was carried out of the influences of the operating conditions on the drying process and their effects on the AC. 


\section{Material and methods}

\subsection{Sample preparation}

Fresh thyme samples (Thymus vulgaris L.) were obtained from a local supplier (Vivarium Albogarden in Valencia, Spain). The leaves of the plant were plucked manually, and kept in refrigeration $\left(4^{\circ} \mathrm{C}\right)$ for their later use. The initial moisture content was $68-86 \%$ (w.b), determined according to the AOAC standards (1997)

\subsection{Drying experiments}

The experimental set-up of the combined hot air-ultrasound system was described by Cárcel et al. (2011). An airborne ultrasonic device constitutes the drying chamber (volume $2.4 \mathrm{~L}$ ); it includes an aluminum vibrating cylinder (internal diameter $100 \mathrm{~mm}$, height $310 \mathrm{~mm}$ and thickness $10 \mathrm{~mm}$ ) driven by a piezoelectric composite transducer $(21.7 \mathrm{kHz})$. Drying experiments were carried out in triplicate, at constant temperatures $(\mathrm{T})$ of $40,50,60,70$ and $80^{\circ} \mathrm{C}$ and with air velocities $\left(\mathrm{v}_{\mathrm{a}}\right)$, measured at room temperature, of 1,2 and $3 \mathrm{~m} / \mathrm{s}$, combined with power ultrasound of $0,6.2,12.3,18.5 \mathrm{~kW} \mathrm{~m}^{-3}$. In all the experiments, the frequency was kept constant, at $21.7 \mathrm{kHz}$. In every experiment, the sample's initial weight was $20 \mathrm{~g} \mathrm{( \pm}$ $0.5 \mathrm{~g}$ ), and the drying process was performed until the final moisture content was $18 \%$ (d.b.). The thyme leaves were distributed uniformly inside the drying chamber, forming a bed with a thickness of $3 \pm 0.3 \mathrm{~cm}$, and the air flow passed through the bed. The maximum air velocity was chosen in order to avoid material losses brought about by fluidization entrainment.

\subsection{Influence of ultrasound on the drying process.}

To analyze the influence of US applications on the drying rate $\left(r_{d}\right)$, this variable must be computed (Eq. (1)). Equation (1) represents the drying rate of dimensionless moisture content $\left(\mathrm{s}^{-1}\right)$. To that end, the experimental values of the moisture content during sample drying were fitted by the "least-squares spline approximation" of order 4, using the "spap2" function of Matlab® R2011a (The Mathworks, 2011), and the derivatives obtained by using the "fnder" function. The effect of the ultrasound on the drying rate was addressed under different conditions: at varying air velocities ( $\mathrm{v}_{\mathrm{a}} 1,2$ and $3 \mathrm{~m} / \mathrm{s}$ ), temperatures ( $\mathrm{T} 40,50,60$ 70 and $\left.80{ }^{\circ} \mathrm{C}\right)$, and levels of applied ultrasonic power $\left(0,6.2,12.3,18.5 \mathrm{~kW} \mathrm{~m}^{-3}\right)$.

$$
\mathrm{r}_{\mathrm{d}}=\frac{1}{\mathrm{~W}_{0}} \frac{\mathrm{dW}}{\mathrm{dt}}
$$

As the drying kinetic is modified when US is applied in the drying process, the AC of the extracts could also be influenced. To determine how significantly US influences the AC, a statistical analysis (ANOVA) was carried out. 


\subsection{Extraction of thyme essential oil}

To analyze the influence of US drying on the AC, the essential oil of the dried thyme was extracted using the (SFE).

A sample of $3.5 \mathrm{~g}$ was taken from each dried batch, mixed with $7 \mathrm{~mL}$ of ethanol as co-solvent and placed in the extraction cartridge (capacity of $200 \mathrm{~mL}$ ). The extraction process was carried out under constant conditions of pressure and temperature: 350 bar and $35{ }^{\circ} \mathrm{C}$ for $1 \mathrm{~h}$ (previously established). After the extraction process, the mixture of essential oil and $\mathrm{CO}_{2}$ under supercritical conditions is sent to a separator vessel under atmospheric pressure, where the thyme essential oil was easily separated. The extract $(3-5 \mathrm{~mL})$ was collected from the bottom and was kept refrigerated at $4{ }^{\circ} \mathrm{C}$ in opaque flasks until the analyses were carried out.

\subsection{Determination of antioxidant capacity}

The FRAP (ferric reducing activity power) method was used to estimate the AC of the extracts. The FRAP is a method that is commonly used to measure the antioxidant activity of plant extracts (Saura-Calixto and Goñi, 2006).

\subsection{Management tool}

To establish a management tool an optimization problem was formulated to determine the drying operating conditions maximize the antioxidant capacity of the extracts:

- Objective function (OF) to be maximized: the $A C$ of the dried thyme extracts. To quantify the OF, a model was set up to estimate the effect of the drying operating conditions on the AC of the product extracts. Due to the complexity involved in the development of theoretical models with which to predict the evolution of the antioxidant capacity during the drying process of thyme, an artificial neural network ( $A N N_{A C}$ ) was developed to link $A C$ and moisture content evolution.

- Decision variables. The controllable operating conditions of thyme drying were established as decision variables: drying air temperature $(T)$, drying air velocity $\left(\mathrm{V}_{\mathrm{H}}\right)$, power ultrasound (US).

- Constraints. The upper and lower bounds of the decision variables were determined from the drying experimental values of the operating conditions (Table 1). The final moisture content $\left(\mathrm{W}_{\mathrm{f}}\right)$ was considered as a constraint. Therefore, a mathematical model must be developed to estimate the evolution of the moisture content $\left(\mathrm{W}_{\mathrm{t}}\right)$ as a function of the values of the operating conditions of the drying process. For optimization purposes, a simple model is preferred in order to avoid lengthy calculations for real-time management 
applications. An artificial neural network $\left(\mathrm{ANN}_{\mathrm{Wt}}\right)$ model was developed for that purpose.

Table 1. Range of drying operating conditions

\begin{tabular}{|c|c|c|}
\hline & $\begin{array}{c}\text { Minimum } \\
\text { value }\end{array}$ & $\begin{array}{c}\text { Maximum } \\
\text { value }\end{array}$ \\
\hline Drying temperature $\left({ }^{\circ} \mathrm{C}\right)$ & 39.9 & 79.9 \\
\hline Drying velocity $(\mathrm{m} / \mathrm{s})$ & 1.0 & 3.6 \\
\hline Power ultrasound $\left(\mathrm{kW} \mathrm{m}^{-3}\right)$ & 0 & 18.5 \\
\hline Initial moisture content $\left(\mathrm{kg} \mathrm{H}_{2} \mathrm{O} / \mathrm{kg} \mathrm{d.s}\right)$ & 2.18 & 5.96 \\
\hline Final moisture content $\left(\mathrm{kg} \mathrm{H}_{2} \mathrm{O} / \mathrm{kg} \mathrm{d}\right.$. s) & 0.22 & 0.88 \\
\hline
\end{tabular}

The most common architecture was considered for the design of the ANNs, based on a multilayer feed-forward structure with the back-propagation training algorithm for computing the weights and biases.

There is no fixed rule for determining the required hidden layers and nodes (Lertworasirikul and Saetan, 2010). In general, one hidden layer has been found to be adequate, and only in some cases may a slight advantage be gained by using two hidden layers. Therefore, the number of hidden layers analyzed was between one and two, and to select the adequate transfer functions for each hidden layer and for the output layer, the tansig, logsig and purelin functions were tested.

The Neural Network Toolbox TM of Matlab $®$ R2011a was used (The Mathworks, 2011) to develop the ANN. Using the Matlab languages, a feed-forward backpropagation network was developed, where the values of the input layer were normalized in the range of 0 to 1 . The parameter values were computed through a training procedure, with the aim of minimizing the mean square errors (MSE) between the network's outputs and the experimental values, using the LevenbergMarquardt algorithm. To avoid the problem of over-fitting during neural network training, the input and target vectors of each ANN were randomly divided, with $70 \%$ used for training, $15 \%$ for validation and $15 \%$ for testing. To select an adequate number of neurons with which to obtain the lowest number of weights and biases, the overall (considering all the experimental and calculated data) correlation coefficient value, the overall mean square errors (MSE) value and the MSE and correlation coefficients estimated in each part of the ANN analysis (training, validation and testing), were considered. 
The characteristics of the optimization problem formulated were analyzed so as to select the best method for solving the optimization problem: the formulated optimization problem was multivariable (three decision variables), non-linear (OF and several constraints), and the OF was derivable with respect to the decision variables. Therefore, the function "fmincon" of Matlab® R2011a was used (The Mathworks, 2011) to solve the formulated non-linear optimization problem. This function optimizes constrained, non-linear, and multivariable optimization problems, using the Sequential Quadratic Programming method.

\subsection{Statistical analysis}

ANOVA analyses were carried out to determine the significance of the influence of the operating conditions $\left(T, V_{H}, U S, W_{0}\right.$ and $\left.t\right)$ on the $A C, W_{t}$ and $r_{d}$. Additionally, the significance of the influence of the US on the AC and $r_{d}$ for each air temperature and air velocity was considered. For that purpose, the function "anovan" of Matlab® R2011a (The Mathworks, 2011) was applied; this function performs a multi-way analysis of variance to test the effects of multiple factors on the mean of the dependent variable. The average value of the relative errors (ER) (Eq. 2) and the correlation coefficient (R) statistics were used to evaluate the accuracy of fit (Bon et al. 2010). The ER is a measure of the random component in the estimation; $R^{2}$ indicates the proportion of variance of the data that is accounted for by the model.

$$
\mathrm{ER}=\frac{100}{\mathrm{~N}} \sum_{\mathrm{i}=1}^{\mathrm{N}} \frac{\left|\mathrm{Z}_{\exp _{\mathrm{i}}}-\mathrm{Z}_{\mathrm{cal}_{\mathrm{i}}}\right|}{\mathrm{Z}_{\exp _{\mathrm{i}}}}
$$

Additionally, a t-test of the null hypothesis was performed at the $5 \%$ significance level to test the goodness of fit of each model. This was carried out to test that the data in the residual vector are random and show a normal distribution with mean 0 and unknown variance, against the alternative that the mean is not 0 . To test the assumption that the residual vector comes from normal distributions, a Lilliefors test was used at the $5 \%$ significance level.

The "ttest" function of Matlab ${ }^{\circledR}$ R2011a (The Mathworks, 2011) was used to perform the statistical t-test. The "lillietest" function of Matlab $®$ R2011a was used to perform the Lilliefors test

\section{Results}

\subsection{Influence of US on the drying process}

Since the air velocity was measured at room temperature, the hot air velocity was estimated considering that the air behaves as an ideal gas (Eq. (3)). The drying air temperature measured ranged between 39.9 and $79.9{ }^{\circ} \mathrm{C}$, and the hot air velocity between 1.1 and $3.6 \mathrm{~m} / \mathrm{s}$. 


$$
\mathrm{v}_{\mathrm{H}}=\mathrm{v}_{\mathrm{a}} \frac{\mathrm{T}_{\mathrm{H}}}{\mathrm{T}_{\mathrm{a}}}
$$

The drying rate $\left(r_{d}\right)$ was estimated from the experimental values of the moisture content evolution. As expected, by raising the air temperature and air velocity, the drying rate increases and, therefore, the drying time is reduced to attain the desired final moisture content. The effect of the power of ultrasound on rd was observed at drying temperatures of between 40 and $60^{\circ} \mathrm{C}$, and an air velocity of between 1 and $2 \mathrm{~m} / \mathrm{s}$; the drying rate increases as the US power rises (Figures 1 and 2) (Cárcel et al., 2007; García-Pérez et al., 2009).

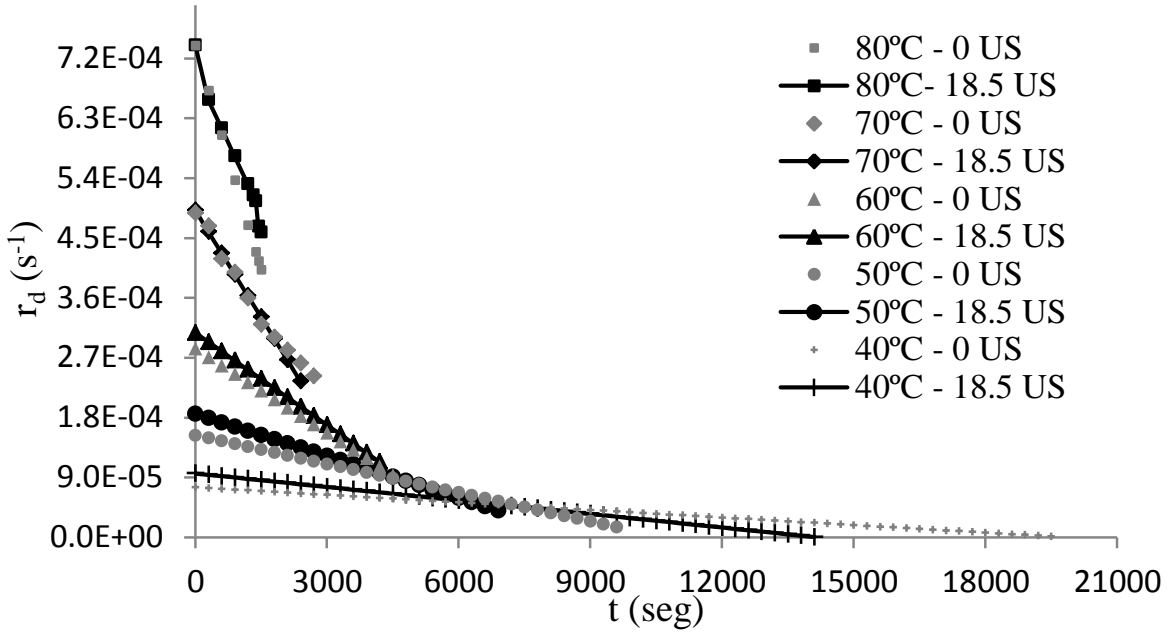

Figure 1. Drying velocity of thyme at $\mathrm{v}_{\mathrm{H}} \approx 1 \mathrm{~m} / \mathrm{s}$ and differentUS power ( 0 and $18.5 \mathrm{~kW} / \mathrm{m}^{3}$ ).

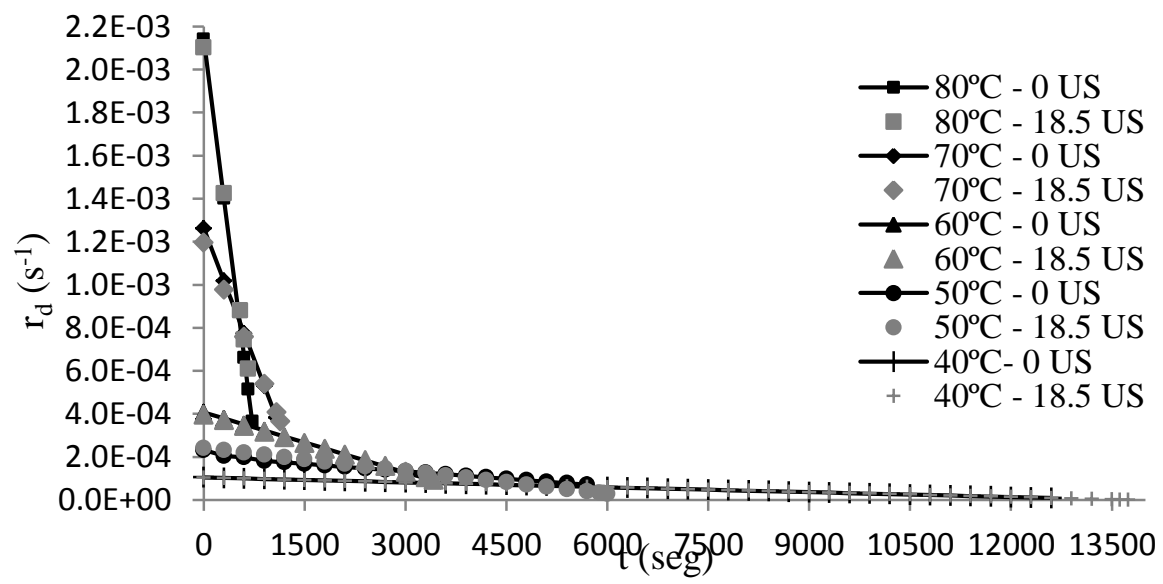

Figure 2. Drying velocity of thyme at $\mathrm{v}_{\mathrm{H}} \approx 3 \mathrm{~m} / \mathrm{s}$ and differentUS power $(0$ and $18.5 \mathrm{~kW} / \mathrm{m}^{3}$ ). 
For drying air temperatures over $60^{\circ} \mathrm{C}$ (Figures 1 and 2 ) and/or a drying air velocity of $3 \mathrm{~m} / \mathrm{s}$ (Figure 2), the application of US does not increase the drying velocity; therefore, the influence of US on these operating conditions is negligible under those conditions. The fact that US exert no influence on an air velocity of $3 \mathrm{~m} / \mathrm{s}$ is attributed to the disruption of the acoustic field caused by the air flow (Cárcel et al. 2007). Additionally, the ANOVA which was carried out corroborated what was observed in Figures 1 and 2, with $p<0.05$.

The AC significantly increased in function of the magnitude of the operating conditions applied in the drying process. Table 2 shows that, for a drying air velocity of $1 \mathrm{~m} / \mathrm{s}$, the $A C$ increased when T (between 40 and $70^{\circ} \mathrm{C}$ ) and US (when $\mathrm{T} \leq 60^{\circ} \mathrm{C}$ ) rose. For a drying air velocity of $2 \mathrm{~m} / \mathrm{s}$, the $A C$ increased in comparison with the values obtained at $1 \mathrm{~m} / \mathrm{s}$, and T and US were observed to have the same effect on AC. However, at temperatures above $70^{\circ} \mathrm{C}$ (at $2 \mathrm{~m} / \mathrm{s}$ ), the $A C$ decreased, which could be due to the degradation of the essential oil and/or an increase in oil loss (Hamrouni-Sellami et al., 2011) . For an air velocity of $3 \mathrm{~m} / \mathrm{s}$, the AC decreased in comparison with the values obtained at air velocities of $2 \mathrm{~m} / \mathrm{s}$, which would be due to the loss of compounds caused by the increased surface temperature of the leaf. The effect of the US application on the AC was negligible for this air velocity.

These effects on the AC (Table 2) can be explained from previous studies, where the importance of phenolic monoterpenes and aromatic volatile compounds contributed significantly to the total antioxidant capacity. Therefore, a correlation between the total phenolic content and antioxidant capacity assays has been reported (Zheng \& Wang, 2001).

The effect of the air temperature on the evolution of $A C$ could be due to a temperature-induced enzymatic reaction (monooxygenases), which leads to the conversion of $p$-cymene into thymol (Poulose and Croteau, 1978).

As the application of US increases the drying rate, some compounds with a greater affinity to the water fraction contained in thyme leaves, such as $\beta$ myrcene and $\gamma$ terpinene, disappear faster, leading to the appearance of some compounds (Hamrouni-Sellami et al., 2012). Therefore, the increased drying rate influences the formation or degradation of compounds because the surface temperature of thyme leaves rises; this could explain the fact that the AC value increases when the drying process is assisted by US, and that, in this case, the AC values at $2 \mathrm{~m} / \mathrm{s}$ were higher than at $1 \mathrm{~m} / \mathrm{s}$.

Therefore, the AC variation showed in this study can be mainly attributed not only to the effects of the temperature and the hot air velocity, but also to that of the application of US on the variation of the drying rate. 
Table 2. Antioxidant capacity of the essentials oils extracted for different operating conditions of the thyme drying process.

\begin{tabular}{|c|c|c|c|c|c|c|c|c|c|}
\hline \multirow[b]{2}{*}{ Sample } & \multicolumn{3}{|c|}{$\mathrm{v}_{\mathrm{H}} \approx 1 \mathrm{~m} / \mathrm{s}$} & \multicolumn{3}{|c|}{$\mathrm{v}_{\mathrm{H}} \approx 2 \mathrm{~m} / \mathrm{s}$} & \multicolumn{3}{|c|}{$\mathrm{v}_{\mathrm{H}} \approx 3 \mathrm{~m} / \mathrm{s}$} \\
\hline & $\overline{\mathrm{T}\left({ }^{\circ} \mathrm{C}\right)}$ & $\begin{array}{c}\text { US } \\
\left(k W / m^{3}\right)\end{array}$ & $\begin{array}{c}\text { AC } \\
{[\text { Trolox] }} \\
\text { (mmol/L) }\end{array}$ & $\mathrm{T}\left({ }^{\circ} \mathrm{C}\right)$ & $\begin{array}{c}\text { US } \\
\left(\mathrm{kW} / \mathrm{m}^{3}\right)\end{array}$ & $\begin{array}{c}\mathrm{AC} \\
{[\text { Trolox] }} \\
\text { (mmol/L) }\end{array}$ & $\bar{T}\left({ }^{\circ} \mathrm{C}\right)$ & $\begin{array}{c}\text { US } \\
\left(\mathrm{kW} / \mathrm{m}^{3}\right)\end{array}$ & $\begin{array}{c}\mathrm{AC} \\
\text { [Trolox] } \\
\text { (mmol/L) }\end{array}$ \\
\hline 1 & $79.8 \pm 0.03$ & 0 & $64.70 \pm 2.8$ & $79.8 \pm 0.2$ & 0 & $90.90 \pm 2.3$ & $79.8 \pm 0.1$ & 0 & $56.93 \pm 2.3$ \\
\hline 2 & $79.8 \pm 0.03$ & 6.2 & $65.52 \pm 2.1$ & $79.8 \pm 0.1$ & 6.2 & $90.01 \pm 1.8$ & $79.8 \pm 0.1$ & 6.2 & $56.84 \pm 1.8$ \\
\hline 3 & $79.9 \pm 0.03$ & 12.3 & $63.80 \pm 2.6$ & $79.8 \pm 0.1$ & 12.3 & $88.21 \pm 2.1$ & $79.6 \pm 0.1$ & 12.3 & $54.40 \pm 2.6$ \\
\hline 4 & $79.9 \pm 0.03$ & 18.5 & $64.47 \pm 2.3$ & $79.8 \pm 0.1$ & 18.5 & $89.36 \pm 1.6$ & $79.8 \pm 0.1$ & 18.5 & $57.02 \pm 1.4$ \\
\hline 5 & $69.9 \pm 0.10$ & 0 & $53.46 \pm 1.4$ & $69.8 \pm 0.2$ & 0 & $103.46 \pm 2.9$ & $69.8 \pm 0.1$ & 0 & $54.20 \pm 1.8$ \\
\hline 6 & $70.0 \pm 0.07$ & 6.2 & $65.33 \pm 2.7$ & $69.9 \pm 0.1$ & 6.2 & $107.89 \pm 3.1$ & $69.8 \pm 0.3$ & 6.2 & $54.70 \pm 2.3$ \\
\hline 7 & $70.0 \pm 0.05$ & 12.3 & $59.14 \pm 1.1$ & $69.9 \pm 0.1$ & 12.3 & $107.64 \pm 4.1$ & $69.8 \pm 0.2$ & 12.3 & $51.15 \pm 3.2$ \\
\hline 8 & $69.9 \pm 0.04$ & 18.5 & $65.14 \pm 2.5$ & $69.9 \pm 0.1$ & 18.5 & $108.48 \pm 2.1$ & $69.6 \pm 0.2$ & 18.5 & $54.70 \pm 2.6$ \\
\hline 9 & $59.9 \pm 0.03$ & 0 & $42.89 \pm 1.6$ & $59.9 \pm 0.1$ & 0 & $84.59 \pm 0.5$ & $59.8 \pm 0.1$ & 0 & $47.50 \pm 2.3$ \\
\hline 10 & $59.9 \pm 0.02$ & 6.2 & $46.16 \pm 3.9$ & $59.9 \pm 0.1$ & 6.2 & $89.42 \pm 1.3$ & $60.1 \pm 0.2$ & 6.2 & $46.87 \pm 1.9$ \\
\hline 11 & $60.2 \pm 0.50$ & 12.3 & $56.26 \pm 2.5$ & $59.9 \pm 0.1$ & 12.3 & $87.12 \pm 0.7$ & $59.8 \pm 0.1$ & 12.3 & $48.08 \pm 2.1$ \\
\hline 12 & $59.9 \pm 0.01$ & 18.5 & $62.23 \pm 1.2$ & $59.9 \pm 0.1$ & 18.5 & $92.63 \pm 0.9$ & $59.8 \pm 0.3$ & 18.5 & $46.62 \pm 1.3$ \\
\hline 13 & $50.0 \pm 0.06$ & 0 & $38.45 \pm 1.2$ & $49.9 \pm 0.1$ & 0 & $66.50 \pm 1.3$ & $49.9 \pm 0.3$ & 0 & $42.96 \pm 1.2$ \\
\hline 14 & $49.9 \pm 0.02$ & 6.2 & $40.14 \pm 0.2$ & $50.0 \pm 0.1$ & 6.2 & $69.85 \pm 0.2$ & $49.9 \pm 0.3$ & 6.2 & $41.17 \pm 1.8$ \\
\hline 15 & $49.9 \pm 0.01$ & 12.3 & $42.63 \pm 2.2$ & $49.9 \pm 0.1$ & 12.3 & $71.65 \pm 1.1$ & $49.9 \pm 0.3$ & 12.3 & $41.62 \pm 1.3$ \\
\hline 16 & $49.9 \pm 0.03$ & 18.5 & $44.25 \pm 1.1$ & $49.9 \pm 0.1$ & 18.5 & $80.34 \pm 1.1$ & $49.9 \pm 0.2$ & 18.5 & $40.96 \pm 1.7$ \\
\hline 17 & $39.9 \pm 0.04$ & 0 & $34.77 \pm 4.4$ & $40.0 \pm 0.1$ & 0 & $47.36 \pm 0.8$ & $39.9 \pm 0.2$ & 0 & $32.49 \pm 1.8$ \\
\hline 18 & $40.0 \pm 0.05$ & 6.2 & $40.18 \pm 1.2$ & $40.0 \pm 0.1$ & 6.2 & $50.39 \pm 1.3$ & $39.9 \pm 0.1$ & 6.2 & $33.86 \pm 2.2$ \\
\hline 19 & $40.0 \pm 0.06$ & 12.3 & $42.78 \pm 1.6$ & $40.0 \pm 0.1$ & 12.3 & $66.35 \pm 2.1$ & $39.9 \pm 0.1$ & 12.3 & $33.89 \pm 2.4$ \\
\hline 20 & $40.0 \pm 0.06$ & 18.5 & $45.20 \pm 1.1$ & $40.0 \pm 0.1$ & 18.5 & $71.66 \pm 3.6$ & $39.9 \pm 0.1$ & 18.5 & $34.07 \pm 3.1$ \\
\hline
\end{tabular}




\subsection{Management tool}

To fit the ANNAC, the results of 180 drying experiments and the corresponding results of 180 SFE extractions were applied, and to fit the ANNwt, 2483 values of the drying kinetics were used.

Different numbers of hidden layers were tested, and adequate fits were obtained when there were 2. It was found that, of the transfer functions tested in the hidden layers and output layer, the ones that exhibited the best fit were obtained with hyperbolic tangent and linear transfer functions. The ANNs developed showed a good agreement between the simulated and experimental results (Figure 3 and Table 3).

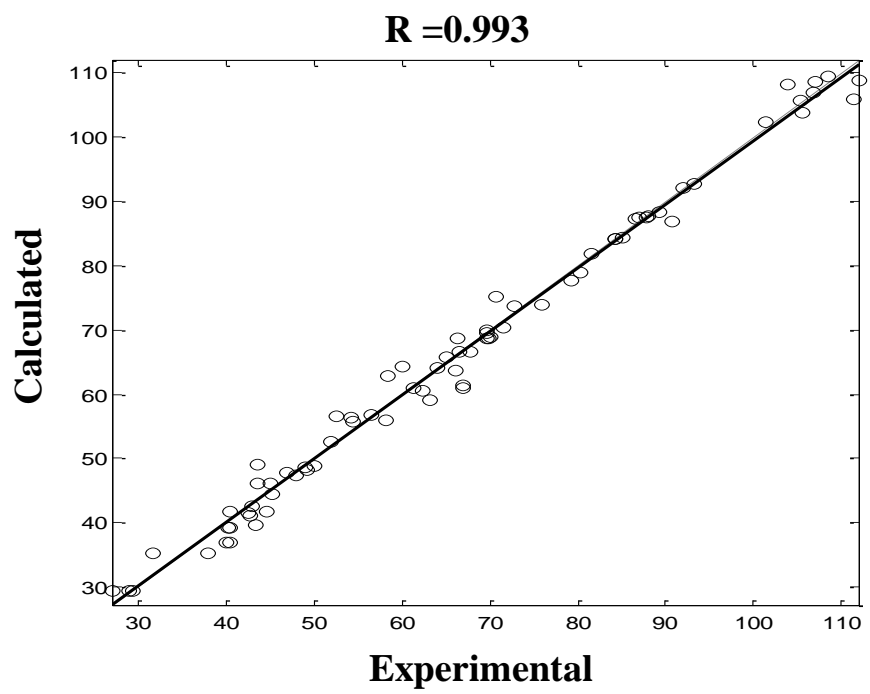

Figure 3. Experimental and ANNAC calculated AC for all the experiments 
Table 3. Results of the goodness of each ANN

\begin{tabular}{|c|c|c|c|c|c|c|c|c|}
\hline & \multirow[b]{3}{*}{$\begin{array}{c}\text { Hidden } \\
\text { layers }\end{array}$} & \multirow[b]{3}{*}{$\begin{array}{l}\text { Number of } \\
\text { neurons in } \\
\text { hidden layer }\end{array}$} & \multirow[b]{3}{*}{$\begin{array}{l}\text { ER } \\
(\%)\end{array}$} & \multirow[b]{3}{*}{$\mathbf{R}$} & \multicolumn{4}{|c|}{ Hypothesis tests } \\
\hline & & & & & \multicolumn{2}{|r|}{ t-test } & \multicolumn{2}{|c|}{ Lilliefors test } \\
\hline & & & & & $\mathbf{p}$ & $\mathbf{C}_{\mathbf{i}}$ & $\begin{array}{c}\text { Statistical } \\
\text { value }\end{array}$ & $\begin{array}{c}\text { Critical } \\
\text { value }\end{array}$ \\
\hline $\mathrm{ANN}_{\mathrm{AC}}$ & 2 & $4 \times 4$ & 3.46 & 0.993 & 0.971 & {$\left[\begin{array}{ll}-0.363 & 0.3775\end{array}\right]$ Trolox mmol/L } & 0.0615 & 0.0709 \\
\hline $\mathbf{A N N}_{\mathrm{Wt}}$ & 2 & $5 \times 6$ & 6.23 & 0.992 & 0.883 & [-0.0057 0.0049] $\mathrm{kg} \mathrm{H}_{2} \mathrm{O} / \mathrm{kg}$, d.s.) & 0.0166 & 0.0182 \\
\hline
\end{tabular}

Table 4. Solution of the optimization problem to different operating cases.

\begin{tabular}{|c|c|c|c|c|c|c|c|c|c|c|c|}
\hline \multirow[t]{3}{*}{ Non controlled } & \multicolumn{6}{|c|}{ Constraints of the decision variables } & \multicolumn{4}{|c|}{ Optimum values } & \multirow{3}{*}{$\begin{array}{c}\text { OF } \\
\text { [Trolox] } \\
\text { mmol/L }\end{array}$} \\
\hline & \multirow{2}{*}{$\begin{array}{c}W_{f} \\
\left(\mathrm{~kg} \mathrm{H}_{2} \mathrm{O} / \mathrm{kg}\right. \\
\text { d.s.) }\end{array}$} & \multicolumn{2}{|c|}{$\mathbf{T}\left({ }^{\circ} \mathrm{C}\right)$} & \multirow{2}{*}{$\begin{array}{c}V_{H} \\
(\mathrm{~m} / \mathrm{s})\end{array}$} & \multicolumn{2}{|c|}{ US $\left(\mathrm{kW} \mathrm{m}^{-3}\right)$} & \multirow{2}{*}{$\begin{array}{c}T \\
\left({ }^{\circ} \mathrm{C}\right)\end{array}$} & \multirow{2}{*}{$\begin{array}{c}V_{H} \\
(m / s)\end{array}$} & \multirow{2}{*}{$\begin{array}{l}\text { US } \\
\text { (W) }\end{array}$} & \multirow[t]{2}{*}{$t(s)$} & \\
\hline & & Min. & Max. & & Min. & Max. & & & & & \\
\hline 5.13 & $0.18-0.52$ & 40 & 80 & $1-3$ & 0 & 18.5 & 71 & 2.2 & 0 & 1997 & 110.87 \\
\hline 2.50 & $0.18-0.52$ & 40 & 60 & $1-2$ & 0 & 18.5 & 60 & 2 & 18.5 & 2200 & 91.68 \\
\hline 4.08 & $0.18-0.52$ & 40 & 80 & $1-3$ & 0 & 18.5 & 72 & 2.3 & 0 & 1800 & 112.33 \\
\hline 2.18 & $0.18-0.52$ & 40 & 50 & $1-3$ & 0 & 18.5 & 50 & 2.1 & 18.5 & 5800 & 83.25 \\
\hline 4.05 & $0.18-0.52$ & 40 & 60 & $1-3$ & 0 & 18.5 & 60 & 2.2 & 18.5 & 4191 & 91.27 \\
\hline 5.96 & $0.18-0.52$ & 40 & 60 & $1-3$ & 0 & 18.5 & 60 & 2.1 & 18.5 & 3600 & 75.01 \\
\hline 2.19 & $0.18-0.52$ & 40 & 80 & $1-3$ & 0 & 18.5 & 69 & 2.3 & 0 & 2394 & 112.33 \\
\hline 4.95 & $0.18-0.52$ & 40 & 80 & $1-3$ & 0 & 18.5 & 72 & 2.1 & 0 & 1900 & 108.85 \\
\hline 2.36 & $0.18-0.52$ & 40 & 80 & $1-3$ & 0 & 18.5 & 69 & 2.1 & 0 & 1200 & 112.33 \\
\hline
\end{tabular}


Table 5. Validation of the ANNs and of the optimization problem

\begin{tabular}{|c|c|c|c|c|c|c|c|c|c|c|c|c|c|}
\hline \multirow{3}{*}{$\begin{array}{c}W_{0} \\
\text { (kg H} \mathrm{H}_{2} \mathrm{O} / \mathrm{kg} \\
\text { d.s.) }\end{array}$} & \multirow{3}{*}{$\begin{array}{c}W_{f} \\
\left(\mathrm{~kg} \mathrm{H} \mathrm{H}_{2} \mathrm{O} / \mathrm{kg}\right. \\
\text { d.s. })\end{array}$} & \multirow{3}{*}{$\begin{array}{c}T_{a} \\
(\stackrel{\circ}{O})\end{array}$} & \multirow{3}{*}{$\begin{array}{l}h_{r} \\
(\%)\end{array}$} & \multirow{2}{*}{\multicolumn{3}{|c|}{$\begin{array}{c}\text { Constraints of the decision } \\
\text { variables }\end{array}$}} & \multicolumn{4}{|c|}{ Optimum values } & \multirow{2}{*}{\multicolumn{2}{|c|}{ OF }} & \multirow{3}{*}{$\begin{array}{l}\Delta \mathrm{FO} \\
(\%)\end{array}$} \\
\hline & & & & & & & \multirow{2}{*}{$\begin{array}{c}T \\
\left({ }^{\circ} \mathrm{C}\right)\end{array}$} & \multirow{2}{*}{$\begin{array}{c}V \\
(\mathrm{~m} / \mathrm{s})\end{array}$} & \multirow{2}{*}{$\begin{array}{l}\text { US } \\
\text { (W) }\end{array}$} & \multirow[b]{2}{*}{$t(s)$} & & & \\
\hline & & & & $\mathbf{T}\left({ }^{\circ} \mathrm{C}\right)$ & $\begin{array}{c}V_{H} \\
\left(\mathrm{~m} \mathrm{~s}^{-1}\right)\end{array}$ & $\frac{\mathrm{US}}{\left(\mathrm{kW} \mathrm{m}^{-3}\right)}$ & & & & & Cal. & Exp. & \\
\hline 4.26 & 0.28 & 26.2 & 65.1 & $40-80$ & $1-3$ & $0-18.5$ & 71 & 2.1 & 0 & 1823 & 101.9 & 106.5 & 4.5 \\
\hline 4.65 & 0.37 & 26.5 & 65.3 & $40-80$ & $1-3$ & $0-18.5$ & 67 & 2.3 & 18.5 & 2389 & 103.0 & 106.8 & 3.8 \\
\hline 3.86 & 0.22 & 26.3 & 65.4 & $40-60$ & $1-2$ & $0-18.5$ & 60 & 2 & 18.5 & 4328 & 98.39 & 95.1 & 3.3 \\
\hline
\end{tabular}


Table 4 shows the results for different thyme-drying operating processes with different initial moisture contents. The optimal value of the decision variables depends on the constraints considered, some of which are bounded (temperature, US power). This management tool allowed the thyme drying process to be better managed, in function of the bonds established under the process operating conditions. From the results of the optimization tool, it can be seen that to attain the maximum value of the $A C$ (OF), the processing time is the shortest possible (bounded at $60{ }^{\circ} \mathrm{C}$ and $18.5 \mathrm{~kW} \mathrm{~m}^{-3}$ ), and consequently also the energy consumption is minimized.

It is worth pointing out that when the temperature is allowed to go up to $80{ }^{\circ} \mathrm{C}$, the best $A C$ is obtained, from the management tool, when processing temperature is around $70^{\circ} \mathrm{C}$. This coincides with the results reported in the literature (Rahimmalek and Hossein-Golib, 2013).

Table 5 shows the experimental data and the results of three experiments performed to validate the management tool. The optimization problem was formulated by considering the constraints of the decision variables, and then the optimum values of the decision variables were applied in the corresponding drying process. The AC of the dried thyme extract was measured and compared with the calculated results, obtaining a difference of between 3.3 and $4.5 \%$ compared to the experimental results.

The results obtained show that it is very important to manage the samples and the operating conditions of the drying process in order to optimize the $A C$ of the dried thyme.

The objectives of an energy efficient process and the highest possible product quality could be established from the management tool, and will therefore be of great potential in the enhancement of the operation of power-ultrasound assisted drying processes.

The optimization tool developed illustrates the significance and feasibility of the ANN model for drying process management when a complex objective function is considered, mainly when causal effects are difficult to establish. Due to the fact that an ANN may be calculated quickly, its application in the models developed to estimate the OF and the drying time (Wf value established) allows it to be used in an on-line management tool.

\section{Conclusions}

At air velocities of 1 and $2 \mathrm{~m} / \mathrm{s}$ and air temperatures of under $60{ }^{\circ} \mathrm{C}$, the intensification of convective drying brought about by the application of US increases the drying velocity, shortening the process time and increasing the AC values of dried thyme extracts. 
Using the management tool developed, it was possible to establish the optimum value of the drying process conditions under which the $A C$ of the dried thyme extracts was at its maximum, considering the conditions present at the moment of drying. The general methodology employed to develop the management tool could be applied in the optimization of the operating conditions of the US-assisted drying process, thus maximizing the AC of the dried product extract. This could be important when the causal relationships are not known.

The results showed that optimization is an important tool for process management, maximizing product quality in the shortest time possible and having a significant impact on energy consumption and, hence, on the process costs.

\section{Acknowledgements}

The authors would like to acknowledge the financial support of the Government of Spain through the MICINN (DPI2009-14549-C04), from the CARNISENUSA project (CSD2007-00016) included in the program CONSOLIDER-INGENIO-2010.

\section{Notation}

$\begin{array}{lll}\text { AC } & \text { Antioxidant capacity content } & \text { [Trolox ]mmol/L } \\ \text { ANN } & \text { Artificial neural network } & \\ \text { ANN }_{\text {AC }} & \text { ANN developed to predict the AC } & \\ \text { ANN }_{W t} & \text { ANN developed to predict the } \mathrm{W}_{\mathrm{f}} & \\ \mathrm{C}_{\mathrm{i}} & \text { Confidence interval } & \% \\ \mathrm{ER} & \text { Relative errors } & \% \\ \mathrm{~h}_{\mathrm{r}} & \text { Relative humidity } & \\ \mathrm{MSE} & \text { Mean square errors } & \\ \mathrm{N} & \text { Number of observations } \\ \mathrm{p} & \text { Probability of observing a value as extreme or } \\ \mathrm{OF} & \text { more extreme of the test statistic } \\ \mathrm{R} & \text { Objective function } \\ \mathrm{R}^{2} & \text { Correlation coefficent } \\ \mathrm{r}_{\mathrm{d}} & \text { Square of correlation coefficent } \\ \mathrm{SFE} & \text { Drying rate }\end{array}$




\begin{tabular}{lll}
\hline \hline$T$ & Temperature & ${ }^{\circ} \mathrm{C}$ \\
$\mathrm{t}$ & Time & $\mathrm{s}$ \\
$\mathrm{T}_{\mathrm{a}}$ & Room temperature & $\mathrm{K}$ \\
$\mathrm{T}_{\mathrm{H}}$ & Hot air temperature & $\mathrm{K}$ \\
$\mathrm{US}$ & Power ultrasound & $\mathrm{W}$ \\
$\mathrm{V}_{\mathrm{a}}$ & Air velocity at room temperature & $\mathrm{m} / \mathrm{s}$ \\
$\mathrm{V}_{\mathrm{H}}$ & Hot air velocity & $\mathrm{m} / \mathrm{s}$ \\
$\mathrm{W}$ & Average moisture content. & $\mathrm{kg} \mathrm{H} \mathrm{H}_{2} \mathrm{O} / \mathrm{kg} \mathrm{d}$. s. \\
$\mathrm{W}_{0}$ & Initial moisture content & $\mathrm{kg} \mathrm{H} \mathrm{H}_{2} \mathrm{O} / \mathrm{kg} \mathrm{d} . \mathrm{s}$. \\
$\mathrm{W}_{\mathrm{f}}$ & Final moisture content & $\mathrm{kg} \mathrm{H} \mathrm{H}_{2} \mathrm{O} / \mathrm{kg} \mathrm{d} \mathrm{s}$. \\
$\mathrm{W}_{\mathrm{t}}$ & Moisture content evolution & $\mathrm{kg} \mathrm{H} \mathrm{H}_{2} \mathrm{O} / \mathrm{kg} \mathrm{d}$. s. \\
$\mathrm{Z}_{\text {cal }}$ & Calculated value & \\
$\mathrm{Z}_{\text {exp }}$ & Experimental value & \\
$\Delta \mathrm{FO}$ & Variation of the objective function & $\%$
\end{tabular}

\section{REFERENCES}

AOAC. 1997. Official methods of analysis of AOAC International, 16th edn, (Association of Official Analytical Chemist International AOAC, Gaithersburg, USA).

Banga, J.R. \& Singh, R.P. (1994). Optimization of air drying of foods. Journal of Food Engineering. 23, 189-211.

Bon, J., Váquiro, H., Benedito, J., \& Telis-Romero, J. (2010). Thermophysical properties of mango pulp (Mangifera indica L. cv. Tommy Atkins). Journal of Food Engineering, 97, 563-568.

Bucinski, A., Zielinski, H., \& Kozzowska, H. (2004). Artificial neural networks for prediction of antioxidant capacity of cruciferous sprouts. Trends in Food Science and Technology, 15, 161-169.

Calín-Sánchez, A., Figiel, A., Lech, Krzysztof., Szumny, A., \& CarbonellBarrachina, A. A. (2013). Effects of drying methods on the composition of thyme (Thymus vulgaris L.) essential oil. Drying Tecnhology, 31, 224-235. 
Cárcel, J. A., García-Pérez, J. V., Riera, E., \& Mulet, A. (2007). Influence of High Intensity Ultrasound on Drying Kinetics of Persimmon. Drying Technology, 25, 185193.

Cárcel, J. A., Garcia-Perez, J. V., Riera, E., \& Mulet A. (2011). Improvement of convective Drying of Carrot by Applying Power Ultrasound-Influence of Mass Load Density. Drying Technology, 29, 174-182.

Cárcel, J.A., García-Pérez, J.V., Benedito, J., \& Mulet, A. (2012). Food process innovation through new technologies: Use of ultrasound. Journal of Food Engineering, 110, 200-207.

Clemente, G., Bon, J., Sanjuán, N., \& Mulet, A. (2011). Drying modelling of defrosted pork meat under forced convection conditions. Meat Science. 88, 374378.

García-Pérez, J.V., Cárcel, J.A., Fuente-Blanco, S.E., \& Riera, E. (2006) Ultrasonic drying of foodstuff in a fluidized bed: Parametric study. Ultrasonics, 44, 539-543.

García-Perez, J.V., Cárcel, J.A., Riera, E., \& Mulet, A. (2009). Influence of the applied acoustic energy on the drying of carrots and lemon peel. Drying Technology, 27, 281-287.

Goñi, S.M., Oddone, S., Segura, J.A., Mascheroni, R.H., \& Salvadori, V.O. (2008). Prediction of foods freezing and thawing times: Artificial neural networks and genetic algorithm approach. Journal of Food Engineering, 84, 164-178.

Hamrouni-Sellami, I., Bettaieb Rebey, I., Sriti, J., Zohra Rahali, F., Limam, F., \& Marzouk, B. (2012). Drying sage (Salvia officinalis L.) plants and its effects on content, chemical composition, and radical scavenging activity of the essential oil. Food and Bioprocess Technology, 5, 2978-2989.

Hamrouni-Sellami, I., Wannes, W.A., Bettaieb, I., Berrima, S., Chahed, T., Marzouk, B., \& Limam, F. (2011). Qualitative and quantitative changes in the essential oil of Laurus nobilis L. leaves as affected by different drying methods. Food Chemestry, 126, 691-769.

Hernández, J.A. (2009). Optimum operating conditions for heat and mass transfer in foodstuffs drying by means of neural network inverse. Food Control, 20, 435438.

Hernández, J.A., Heyd, B., Trystram, G. (2008). Prediction of brightness and surface area kinetics during coffee roasting. Journal of Food Engineering, 89, 156 163 
Hernández-Pérez, J.A., García-Alvarado, M.A., Trystram, G., Heyd, B. (2004). Neural networks for the heat and mass transfer prediction during drying of cassava and mango. Innovative Food Science and Emerging Technologies, 5, 57-64.

Khorshidi, J., Mohammadi, R., Fakhr, T.M. \& Nourbakhsh, H. (2009). Influence of drying methods, extraction time, and organ type on essential oil content of rosemary (Rosmarinus officinalis L.). Natural Science. 7 (11), 42-44.

Lertworasirikul, S., \& Saetan, S. (2010). Artificial neural network modeling of mass transfer during osmotic dehydration of kaffir lime peel. Journal of Food Engineering 98(2), 214-223.

Lu, H.F., Zheng, H., Lou, H.Q., Jiang, L.L,, Chen, Y., \& Fang, S.S. (2010). Using neural networks to estimate the losses of ascorbic acid, total phenols, flavonoid, and antioxidant activity in asparagus during thermal treatments. Journal of Agricultural and Food Chemistry, 58, 2995-3001.

Poulose, A.J., \& Croteau, R. (1978). Biosynthesis of aromatic monoterpenes conversion of $y$-terpinene to $p$-cymene and thymol in Thymus vuigaris $L$. Archives of Biochemistry and Biophysics, 187 (2), 307-314.

Prado, J.M., Leal, P.F., Meireles, M.A.A. (2009). Comparison of manufacturing cost of thyme extract obtained by supercritical fluid extraction and steam distillation, in: 9th International Symposium on Supercritical Fluids, Arcachon- France, 135.

Rahimmalek, M., \& Hossein-Goli, S.A. (2013). Evaluation of six drying treatments with respect to essential oil yield, composition and color characteristics of Thymys daenensis subsp. daenensis. Celak leaves. Industrial Crops and Products, 42, 613-619.

Reverchon, E., \& De Marco, I. (2006). Supercritical fluid extraction and fractionation of natural matter. Journal Supercritical Fluids, 38 (2), 146-166.

Rodríguez, J., Ortuño, C., Benedito, J., Bon J. (2013). Optimization of the antioxidant capacity of thyme (Thymus vulgaris L.) extracts: Management of the drying process. Industrial Crops and Products, 46: 258- 263.

Saura-Calixto, F., \& Goñi, I. (2006). Antioxidant capacity of the Spanish Mediterranean diet. Food Chemistry, 94, 442-47.

The Mathworks. 2011. Matlab user's guide. The MathWorks Inc., SouthNatick, MA, USA.

Tripathy, P. P., \& Kumar, S. (2009). Neural network approach for food temperature prediction during solar drying. International Journal of Thermal Sciences, 48, 14521459. 
Venskutonis, R. (1997). Effect of drying on the volatile constituents of thyme (Thymus vulgaris L.) and sage (Salvia officinalis L.). Food Chemistry, 59, 219-227.

Zheng, H., Jiang. L., Lou, H., Hu., Y., Kong, X., , \& Lu, H., (2011). Application of Artificial Neural Network (ANN) and Partial Least-Squares Regression (PLSR) to Predict the Changes of Anthocyanins, Ascorbic Acid, Total Phenols, Flavonoids, and Antioxidant Activity during Storage of Red Bayberry Juice Based on Fractal Analysis and Red, Green, and Blue (RGB) Intensity Values. Journal of Agricultural and Food Chemistry, 59, 592-600.

Zheng, W., \& Wang, S. Y. (2001). Antioxidant activity and phenolic compounds in selected herbs. Journal of Agricultural and Food Chemistry, 49, 5165-5170. 



\title{
4.5. TWO PERIODS DRYING PROCESS MANAGEMENT OF THYME (Thymus Vulgaris L.)
}

\author{
J. Rodriguez, E.C. Melo, A. Mulet, J. Bon \\ Submited: JOURNAL OF FOOD ENGINEERING
}

\begin{abstract}
Drying effects in food processing and the preservation of the antioxidant activity are frequently the result of different events which can take place consecutively or simultaneously. From this consideration, the goal of this work was to establish a drying strategy that allowed the drying time to be decreased thus improving both energy efficiency and the antioxidant capacity of dried thyme leaves (AC). The drying strategy consisted of two consecutive periods of drying. The first drying period was carried out at $80^{\circ} \mathrm{C}$ and then immediately set to $70,60,50$ and $40{ }^{\circ} \mathrm{C}$ (second drying period $\left.\left(T_{a 2}\right)\right)$, at a different air velocity $(v)\left(1\right.$ or $\left.2 \mathrm{~m} \mathrm{~s}^{-1}\right)$ to avoid thyme deterioration. The essential oil was obtained by a supercritical fluid extraction and the antioxidant capacity was measured by ferric reducing activity power (FRAP). Two consecutive drying periods were found to improve the drying kinetics, reducing the drying time by between 7 and $39 \%$, while the AC increased from 4 to $27 \%$ compared with constant drying conditions. The use of two consecutive drying periods was found to be an interesting strategy and its application should be considered when drying other materials.
\end{abstract}

Keywords: Intermittent drying, energy efficiency, antioxidant capacity 


\section{Introduction}

For many years, aromatic plants have been used for a large number of purposes (medicine, nutrition, flavorings, beverages, cosmetics, and industrial uses). It has been acknowledged that many of them have medicinal properties and possess a variety of antioxidant effects. Lamiaceae herbs, like thyme, are very rich sources of phenolic compounds associated with their antioxidant activity (Hossain et al. 2008; Shan, et al. 2005).

Thyme has a high water content $(65-80 \%$, in w.b.) and, as such, that requires the use of a preservation method in order to lengthen its useful life for further use (Doymaz, 2011). Hot air drying, one of the oldest food preservation processes, is by far the most widely used treatment and is considered the first step in many food processes. It is recognized that drying is an energy-intensive process as heat needs to be supplied for water evaporation. Both the effect of the heat treatment on the quality of the product and also climate change concerns make energy issues a key factor.

Drying forestalls certain biochemical changes but, at the same time, it can give rise to other alterations that affect herb quality, such as changes in appearance and alterations in aroma caused by losses in volatiles or the formation of new volatiles as a result of oxidation or esterification reactions.

There are few reports on the effect of drying methods on the essential oil compounds of thyme. Venskutonis (1997) took into account two methods, freezedrying and oven dryingat two temperatures $\left(30^{\circ} \mathrm{C}\right.$ and $\left.60^{\circ} \mathrm{C}\right)$, when examining the effect of the drying method on the essential oil composition of Thymus vulgaris $\mathrm{L}$. Rahimmalek and Hossein-Golib (2013) analyzed the effect of six different drying treatments on the essential oil components, finding that a high temperature $(70 \circ \mathrm{C})$ leads to an increase in the content of the major constituents of Thymus daenensis subsp. Daenensis, thymol/carvacrol. Rodríguez et al. (2013) found that the best drying temperature to increase the antioxidant capacity of Thymus vulgaris $L$ was $70 \stackrel{\circ}{\circ}$. Hamrouni-Sellami et al. (2011) reported that the appearance of new compounds in Laurus nobilis might be caused by the treatment time and high drying temperatures. Air temperatures of over $70^{\circ} \mathrm{C}$ could improve the drying kinetic, thereby reducing drying time; nevertheless, a long-time application results in volatile compounds and a decrease in the antioxidant capacity (Rodríguez et al. 2013), which could be due to the degradation of compounds with antioxidant capacity, while at the same time significant changes in the material structure and color appear (Fletcher et al. 2005; Rahimmalek and Hossein-Golib., 2013). Therefore, it can be considered that drying time and temperature are crucial parameters for the preservation of the main compounds of the essential oil.

A significant amount of effort has been put into researching and developing ways of reducing the energy consumption of drying technologies (Ould Ahmedou et al. 2008) for three reasons: the need to improve product quality, reduce operating costs and lessen the environmental impact (Mujumdar and Law 2010). Therefore, 
the selection of a suitable drying method and a good management process, the development of an appropriate mathematical model and the determination of the optimum operating conditions are all essential in order to achieve high quality, minimum cost products with a maximum yield.

As a management procedure, the application of a drying strategy time-varying temperature profile can be considered during the drying process; this approach could result in the reduction of the effective drying time (Chou et al. 2008; Chua et al. 2003), and the preservation of the final quality (Venskutonis, 1997; Rahimmalek and Hossein-Golib, 2013; Rodríguez et al. 2013).

A mathematical model is necessary to establish the operating conditions in the drying strategy. The complexity of the drying process arises from the simultaneous heat and mass transfer between the air and the product. In order to address this complexity, it is necessary to model the process adequately. A number of drying models have been proposed, which can be classified into empirical (Doymaz, 2011; Rodríguez et al 2012), and mechanistic models (Herman et al. 2001; Sitompul et al. 2003; Herman-Lara et al. 2005). There is no information in the literature about a time-varying boundary conditions model, permitting a description of the effects on the drying kinetics of a bed of thyme leaves.

The aim of this work was to address a two-step drying strategy, one which allows the process to be managed, for the purposes of decreasing drying time and increasing the antioxidant capacity. To that end, the influence that the temperature, air velocity and proposed drying strategy had on the drying kinetics and antioxidant capacity was analyzed.

\section{Materials and methods}

\subsection{Sample preparation}

This study was carried out with fresh thyme leaves (Thymus vulgaris L.) that were obtained locally (Vivarium Albogarden in Valencia, Spain). The leaves of the plant were plucked manually. In order to preserve their original quality, fresh plant material was placed in a closed container and stored in refrigeration at $4{ }^{\circ} \mathrm{C}$ until drying experiments. The initial moisture content was determined according to the AOAC standards (1997). The toluene displacement method (Konak et al. 2002; Nimkar and Chattopadhyay, 2001) was used to determine the density of the dry solid.

The physical properties of thyme, dry air and water vapor needed in the model are summarized in Table 1. 
Table 1. Properties of thyme and air considered in the model

\begin{tabular}{|c|c|}
\hline Thyme properties & Air properties \\
\hline $\begin{array}{l}\text { Water activity (Soysal and Oztekin, 2001). } \\
a_{w}=\exp \left[-\exp \left(2.97977-0.00258492 T_{a}^{1.37743}\right) \tau_{e q}^{-1.44139}\right] \\
\text { Thermal conductivity }\left(\mathrm{kJ} \mathrm{m}^{-1} \mathrm{~s}^{-1} \mathrm{~K}^{-1}\right) \text { for fruits } \\
\text { and vegetables (Singh and Heldman, 2001) } \\
\kappa=1.41810^{-1}+\frac{4.9310^{-1} \tau}{(1+\tau)}\end{array}$ & $\begin{array}{l}\text { Specific heat of dry air }\left(\mathrm{kJ} \mathrm{kg}^{-1} \mathrm{~K}^{-1}\right) \\
\text { (Pelegrina et al., } 1999) \\
C p_{d a}=2.927510^{-7} T_{a}^{3}+4.704710^{-4} T_{a}^{2}+ \\
\qquad 1.78210^{-2} T_{a}+1005.3 \\
\text { Diffusivity of water in the air phase }\left(\mathrm{m}^{2} \mathrm{~s}^{-}\right. \\
\left.{ }^{1} \text { ) (Perry et al., } 1997\right) \\
D_{A B}=1.473810^{-4} \exp \left(\frac{-523.78}{T_{p p}}\right) \\
\text { Specific heat of water vapor }\left(\mathrm{kJ} \mathrm{kg}^{-1} \mathrm{~K}^{-1}\right) \\
\text { (Pelegrina et al., 1999) } \\
C p_{v}=10384.59-50.37 T_{a}+7.410^{-2} T_{a}^{2}\end{array}$ \\
\hline
\end{tabular}

\subsection{Drying experiments}

A completely automatic laboratory scale convective drier was used, as already described in previous works (Sanjuán, et al. 2003). Thyme samples of approximately $20 \mathrm{~g}$ were subjected to different drying experiments. The thyme leaves were distributed uniformly inside the drying chamber, forming a bed with a thickness of $3 \pm 0.3 \mathrm{~cm}$, with through air flow. For each condition tested, the drying experiments were carried out at different air velocities $(v)\left(1,2 \mathrm{~m} \mathrm{~s}^{-1}\right)$ until the final moisture content was under $10 \%$ (w.b.). All the experiments were run in triplicate.

\subsection{Modeling}

In order to know the evolution of the temperature on the leaf surface, a mathematical model was developed taking into account the simultaneous heat and mass transfer phenomena both in the bed and in the thyme leaves.

The governing equations (Table 2) were obtained from the mass and energy balance in the bed and leaves and considering the following assumptions: wellmixed air in the bed; temperature-dependent transport properties in the leaves (effective diffusivity and thermal conductivity); initially uniform temperature and moisture in the bed; isotropic material in the bed; the balances of heat and mass transfer in the leaves were performed considering the behaviour as that of an infinite slab and the shrinkage effect was negligible. 
Table 2. Governing equations and initial and boundary conditions considered for modeling the drying kinetics of fixed bed of thyme leaves

\begin{tabular}{|c|c|c|}
\hline Governing equations & $\begin{array}{c}\text { Initial } \\
\text { conditions }\end{array}$ & Boundary conditions \\
\hline \multicolumn{3}{|l|}{ Air temperature $\left(T_{a}\right)$ evolution in the bed. } \\
\hline $\begin{array}{l}m_{a} \int_{T_{a e}}^{T_{a i}}\left(C p_{d a}\left(T_{a}\right)+X_{e} C p_{v}\left(T_{a}\right)\right) d T_{a}+\left[\left(X_{e}-X_{a}\right) m_{a}-\varepsilon \rho_{d a} V \frac{d X_{a}}{d t}\right] \int_{T(1, t)}^{T_{a e}} C p_{v}\left(T_{a}\right) d T_{a} \\
=-(1-\varepsilon) V \frac{h}{L}\left[T(1, t)-T_{a}\right]+\varepsilon \rho_{d a} V\left[C p_{d a}\left(T_{a}\right)+X_{a} C p_{v}\left(T_{a}\right)\right] \frac{d T_{a}}{d t}\end{array}$ & $\begin{array}{l}T_{a}(t=0)=T_{a 0} \\
T(t=0)=T_{0}\end{array}$ & \\
\hline Air moisture content evolution $\left(X_{a}\right)$ in the bed & $X_{a}(t=0)=X_{a 0}$ & \\
\hline$m_{a}\left(X_{e}-X_{a}\right)=\rho_{d a}\left(T_{a i}, X_{a}\right) \varepsilon V \frac{d X_{a}}{d t}+M_{d s} \frac{d \bar{\tau}}{d t}$ & $\bar{\tau}(t=0)=\tau_{0}$ & \\
\hline Local moisture content $(\tau)$ evolution in the leaves & & $\frac{\partial \tau}{\partial z}(0, t)=0$ \\
\hline$\frac{\partial}{\partial z}\left(\frac{D}{L^{2}} \rho_{d s} \frac{\partial \tau}{\partial z}\right)=\rho_{d s} \frac{\partial \tau}{\partial t}$ & $\tau(z, 0)=\tau_{0}$ & $-\frac{D}{L^{2}} \rho_{d s} \frac{\partial \tau}{\partial z}(1, t)=\frac{h_{m v}}{L}\left[\rho_{d a i} X_{e q}-\rho_{d a} X_{a}\right]$ \\
\hline $\begin{array}{l}\text { Temperature }(T) \text { evolution in the leaves } \\
\frac{D}{L^{2}} \rho_{d s} \frac{\partial \tau}{\partial z} C p_{w}(T) \frac{\partial T}{\partial z}=\frac{\partial}{\partial z}\left(\frac{\kappa(\tau)}{L^{2}} \frac{\partial T}{\partial z}\right)+\rho_{d s}\left[C p_{d s}(T)+\tau C p_{w}(T)\right] \frac{\partial T}{\partial t}\end{array}$ & $T(z, 0)=T_{0}$ & $\begin{array}{l}\frac{\partial T}{\partial z}(0, t)=0 \\
\begin{aligned}-\frac{h}{L}\left[T(1, t)-T_{a}\right] & =\frac{\kappa(\tau)}{L^{2}} \frac{\partial T}{\partial z}(1, t) \\
& -\frac{D}{L^{2}} \rho_{d s} \frac{\partial \tau}{\partial z}(1, t) \lambda(T(1, t))\end{aligned}\end{array}$ \\
\hline
\end{tabular}


A dimensionless distance was considered (Eq. 1) for the leaves in the respective governing equations.

$$
z=\frac{x}{L} \wedge z \in[0,1]
$$

The governing equations obtained (Table 2) represent the unsteady-state heat and mass balances describing the evolution of the air temperature $\left(T_{a}\right)$ and air moisture content $\left(X_{a}\right)$ in the bed, and the evolution of the local moisture content $(\tau)$ and temperature $(T)$ in the leaves.

Equation 2 was applied to calculate the average moisture content in the leaves.

$$
\bar{\tau}=\int_{0}^{1} \tau(z, t) d z
$$

The initial and boundary conditions were considered to complete the drying model (Table 2). As boundary conditions (Table 2), the distribution of the moisture content and the temperature in the leaves are assumed to be symmetrical. For the specific case of two drying periods, the final conditions in the first drying period are the initial conditions of the second drying period. For the mass transfer boundary condition on the leaf surface, it is assumed that the liquid water that diffuses into the surface per unit area is evaporated at the same rate (dynamic equilibrium) and is transported by convection to air. The equilibrium moisture content of the air $\left(X_{e q}\right)$ was estimated using an isotherm (Table 1) and considering that air behaves as an ideal gas.

The heat boundary conditions assume that the heat transmitted by convection from the air to the leaf surface increases the temperature of the leaf and evaporates the water reaching the surface.

The effect of temperature on the diffusivity is described by an Arrhenius type equation. In order to analyze the results, a dimensionless average moisture content was considered for the leaves in the bed (Eq. 3).

$$
\omega=\frac{\bar{\tau}-\tau_{e q}}{\tau_{0}-\tau_{e q}}
$$

\section{Heat and mass transfer coefficient}

The values of the heat and mass transfer coefficients $\left(h\right.$ and $\left.h_{m v}\right)$ can be calculated from empirical equations involving dimensionless numbers (Perry et al. 1997). 


$$
h_{m v}=\frac{S h D_{A B}}{L_{c}}, \quad h=\frac{N u \kappa_{a}}{L_{c}}
$$

In early works, (Treybal, 1980) a mathematical expression was established as being one of the best for calculating those dimensionless numbers for a porous bed of particles (Herman et al. 2001).

$$
N u=\frac{a}{\varepsilon} \operatorname{Re}^{b} \operatorname{Pr}^{1 / 3}, \quad S h=\frac{a}{\varepsilon} \operatorname{Re}^{b} S c^{1 / 3}
$$

$\varepsilon=\frac{V_{a}}{V}$

To establish the effect that air velocity and air temperature during the drying process have on transport phenomena, an optimization problem was formulated to identify $D / L^{2}$ and the parameters $a$ and $b$ (Eq. 5). In the optimization problem, the parameters were considered as the decision variables, and the objective function was the mean relative error calculated through the comparison of experimental and calculated average moisture contents.

\subsection{Computational tools}

The "fmincon" function of Matlab® R2011a was used (The Mathworks, 2011) to solve the optimization problem. It was necessary to solve the mathematical model for the drying process in order to calculate the objective function. For this purpose, the COMSOL Multiphysics ${ }^{\circledR} 3.4$ tool was applied using the finite element method. The "nlinfit" function was applied to estimate the parameter values of the Arrhenius equation by means of non-linear regression.

\subsection{Drying strategy}

The drying strategy consisted of applying two consecutive drying periods. During the first drying period, the product is subjected to a high air temperature $\left(80{ }^{\circ} \mathrm{C}\right)$ for a given time, preventing the surface of the leaves from reaching a temperature of over $70^{\circ} \mathrm{C}$. In the second drying period, the product is subjected to a lower air temperature $(40,50,60,70 \stackrel{\circ}{\circ})$ than the first drying period, until the desired final moisture content is reached. The application of high temperature drying during the first period could reduce the total drying time $(t)$, compared with processes where the heat is supplied continuously at lower air temperatures, therefore improving energy efficiency.

To prevent any damage or degradation to compounds of interest caused by excessive exposure to drying at temperatures of $80^{\circ} \mathrm{C}$, the length of exposure to air at this temperature necessary for the sample surface to reach $68^{\circ} \mathrm{C} \pm 2{ }^{\circ} \mathrm{C}$ must be established. Given the difficulty of experimentally measuring the surface temperature of the leaves during the drying process, the evolution of the temperature was determined by means of a mathematical model. 
From modeling, the time of exposure to air at $80 \stackrel{\circ}{ } \mathrm{C}$ needed for the sample surface to reach a temperature of $68{ }^{\circ} \mathrm{C}$ was determined. For a drying process at $80{ }^{\circ} \mathrm{C}$ and air velocities of 1 and $2 \mathrm{~m} \mathrm{~s}^{-1}$, no significant differences were found in the evolution of the surface temperature. Therefore, the time of exposure the sample surface needs to reach a temperature of approximately $68^{\circ} \mathrm{C}$ was $600 \mathrm{~s}$.

To extend the application to other temperatures, corroborate contradictory results (other air temperatures), and to test the accuracy of the model developed, the exposure time of $600 \mathrm{~s}$ and the shortest time of $300 \mathrm{~s}$ at $80 \stackrel{\circ}{\mathrm{C}}$ were applied to different drying experiments. The drying strategy considered was conducted in two consecutive drying periods. The first drying period was $80 \stackrel{\circ}{\circ}$ for $300 \mathrm{~s}\left(T_{a l 1}\right)$ or $600 \mathrm{~s}\left(T_{a 12}\right)$ and immediately set to $40,50,60$ and $70{ }^{\circ} \mathrm{C}$ (second drying period $\left.\left(T_{a 2}\right)\right)$ until the final moisture content was less than $10 \%$ (d.b.) at 1 and $2 \mathrm{~m} \mathrm{~s}^{-1}$, the results of this drying strategy were compared with a drying experiment carried out at a constant air temperature $\left(40,50,60\right.$, and $\left.70^{\circ} \mathrm{C}\right)$.

\subsection{Extraction of the essential oils}

The Supercritical Fluids Extraction method (SFE) was used to extract the essential oil of the dried thyme in order to analyze the influence of the proposed drying strategy on the AC (Velasco et al. 2007; Aarus et al. 2009). SFE has been applied for the extraction of essential oils of medicinal plants, and its results compared favorably (Better quality and greater quantity of essential oils) with other conventional extraction processes (Reverchon, 1997; Mukhopadhyay, 2000; Reverchon and De Marco, 2006), and its low operating temperature allows the essential oil characteristics to be preserved compared with other extraction methods whose high operating temperatures can degrade essential oil components (Prado et al. 2009).

From each dried batch, a sample of $3.5 \mathrm{~g}$ was taken, mixed with $7 \mathrm{~mL}$ of ethanol as co-solvent and placed in the extraction cartridge (capacity of $200 \mathrm{~mL}$ ). The extraction process was carried out under constant conditions of pressure and temperature: 350 bar and $35 \stackrel{\circ}{C}$ for $1 \mathrm{~h}$ (previously established). The extract ( $3-5$ $\mathrm{mL}$ ) was collected from the bottom of the vessel and was kept refrigerated at $4{ }^{\circ} \mathrm{C}$ in opaque flasks until the analyses were carried out.

\subsection{Determination of the antioxidant capacity}

The FRAP (ferric reducing activity power) method was used to estimate the antioxidant capacity (AC) of the extracts. The FRAP is a method commonly used to measure the antioxidant activity of plant extracts (Hossain et al. 2010; SauraCalixto and Goñi, 2006; Stratil et al. 2006).

\subsection{Statistical analysis}

The data were reported as the means and standard deviation of at least three replicates. The differences were tested for significance by using the ANOVA procedure, using a significance level of $p \leq 0.05$. For that, the function "anoval" of Matlab® R2011a (The Mathworks, 2011) was applied. The average value of the relative errors (ER) and the explained variance (VAR) statistics were used to 
evaluate the accuracy of fit. To test the goodness of the fit, the t-test and Lilliefors test were carried out by applying the "ttest" "lillietest" function of Matlabß R2011a (The Mathworks, 2011)

\section{Results}

\subsection{Drying kinetics}

As an example, Figure 1 shows the drying kinetics of thyme leaves at $1 \mathrm{~m} \mathrm{~s}^{-1}$. The drying experiments shown are carried out at constant air temperature $(40,70$ and $\left.80^{\circ} \mathrm{C}\right)$ and over two periods at different temperatures. The length of the initial high temperature period $\left(80^{\circ} \mathrm{C}\right)$ was either 300 or $600 \mathrm{~s}$. As expected, the longer the first drying period, the greater the drying kinetics. Therefore, the total drying time is reduced (between 7.9 and $39.2 \%$ ) when compared with a drying experiment performed at a constant air temperature of under $80^{\circ} \mathrm{C}$ (Table 3 ). For a better understanding, the effect of drying on the drying kinetics will be addressed from the parameters identified in the modeling process.

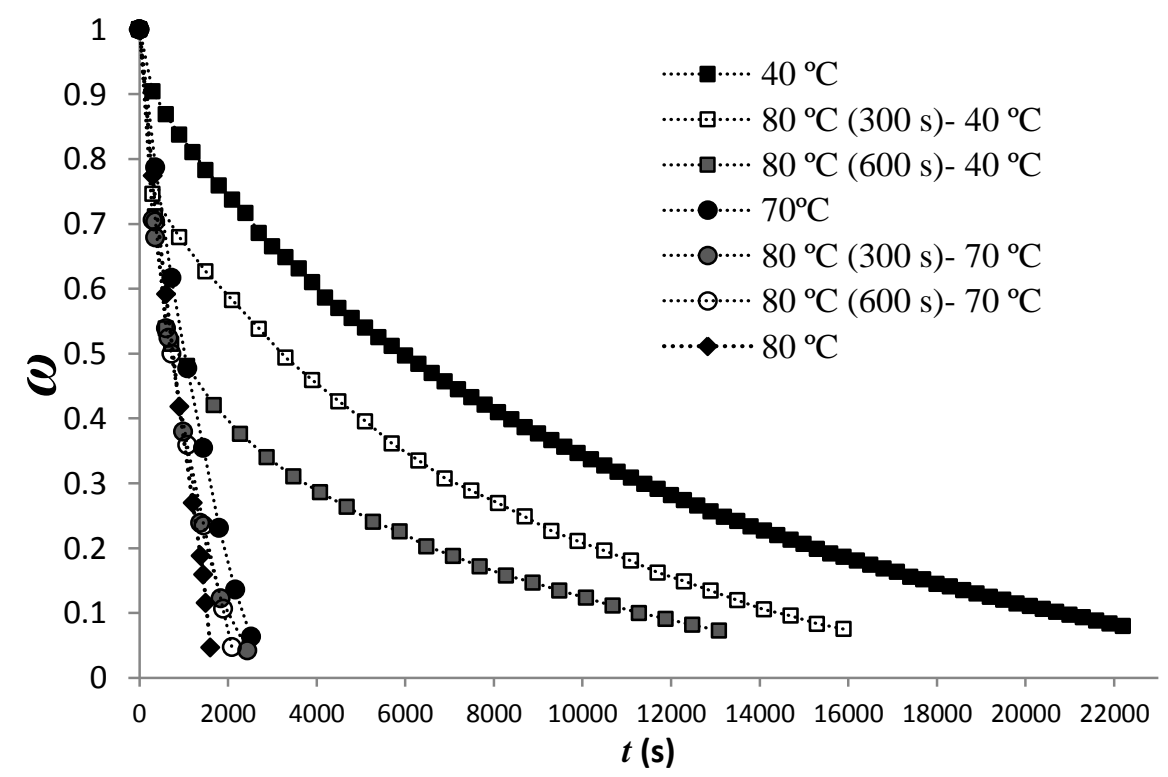

Figure 1. Convective drying kinetics of thyme at $v=1 \mathrm{~m} \mathrm{~s}^{-1}$, different air temperatures, and drying strategy. 
Table 3. Total drying time for each drying experiment, explained variance and mean relative error from model fitting.

\begin{tabular}{|c|c|c|c|c|}
\hline$v(\mathrm{~m} / \mathrm{s})$ & $\mathbf{T}\left({ }^{\mathbf{o}} \mathbf{C}\right)$ & $t(s)$ & $\operatorname{ER}(\%)$ & $\operatorname{VAR}(\%)$ \\
\hline \multirow{13}{*}{1} & 40 & $22200 \pm 300$ & 3.3 & 99.8 \\
\hline & $T_{a 11}-40$ & $18303 \pm 183$ & 3.1 & 99.9 \\
\hline & $T_{a 12}-40$ & $16364 \pm 238$ & 3.8 & 99.8 \\
\hline & 50 & $11241 \pm 120$ & 1.5 & 99.9 \\
\hline & $T_{a 11}-50$ & $9681 \pm 95$ & 3.8 & 99.9 \\
\hline & $T_{a 12}-50$ & $8206 \pm 125$ & 3.7 & 99.9 \\
\hline & 60 & $5733 \pm 97$ & 2.4 & 99.9 \\
\hline & $T_{a 11}-60$ & $4715 \pm 68$ & 0.9 & 99.9 \\
\hline & $T_{a 12}-60$ & $4387 \pm 64$ & 3 & 99.9 \\
\hline & 70 & $2720 \pm 55$ & 2.4 & 99.9 \\
\hline & $T_{a 11}-70$ & $2506 \pm 90$ & 1.3 & 99.9 \\
\hline & $T_{a 12}-70$ & $2326 \pm 50$ & 3.8 & 99.9 \\
\hline & 80 & $1700 \pm 60$ & 2.6 & 99.8 \\
\hline \multirow{13}{*}{2} & 40 & $20800 \pm 450$ & 2.2 & 99.9 \\
\hline & $T_{a 11}-40$ & $16800 \pm 220$ & 2.2 & 99.9 \\
\hline & $T_{a 12}-40$ & $13283 \pm 160$ & 5.9 & 99.7 \\
\hline & 50 & $10100 \pm 95$ & 3.8 & 99.7 \\
\hline & $T_{a 11}-50$ & $8102 \pm 150$ & 3 & 99.9 \\
\hline & $T_{a 12}-50$ & $7420 \pm 90$ & 3.1 & 99.9 \\
\hline & 60 & $3780 \pm 105$ & 3.8 & 99.7 \\
\hline & $T_{a 11}-60$ & $2865 \pm 65$ & 3.4 & 99.8 \\
\hline & $T_{a 12}-60$ & $2300 \pm 63$ & 3.8 & 99.8 \\
\hline & 70 & $1400 \pm 58$ & 3.1 & 99.8 \\
\hline & $T_{a 11}-70$ & $1290 \pm 35$ & 2.6 & 99.9 \\
\hline & $T_{a 12}-70$ & $1180 \pm 46$ & 2.2 & 99.9 \\
\hline & 80 & $1060 \pm 32$ & 3.9 & 99.6 \\
\hline
\end{tabular}

\subsection{Modeling}

The models developed were fitted to the experimental results, showing a good agreement (Table 3, VAR $\geq 99.7 \%$; ER $\leq 5.9 \%$ ) as can be seen in Figure 2. In every case, the t-test showed a high probability that the residual vectors were in the confidence interval with mean 0 , and the Lilliefors test failed to reject the corresponding null hypothesis at the default 0.05 significance level. As a consequence, the normality of the residuals is established. 


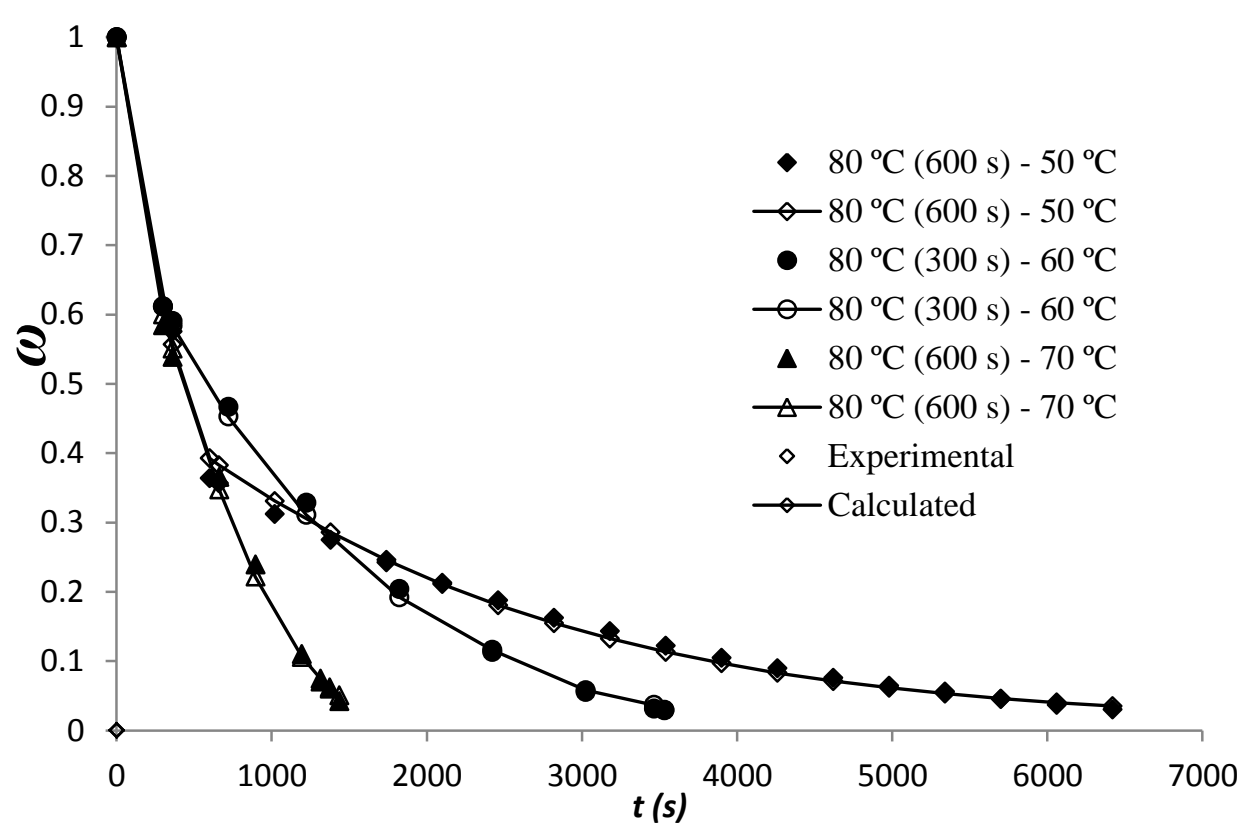

Figure 2. Experimental and calculated moisture content evolution at $2 \mathrm{~m} / \mathrm{s}$

Table 4 reports the average values of the total drying time $t$ and the identified parameters, $D / L^{2}, h_{m v}$ and $h$, for a drying experiment carried out at a constant air temperature $\left(40,50,60,70\right.$ and $\left.80^{\circ} \mathrm{C}\right)$. It can be observed that the identified parameters were linked to air temperature and air velocity. The influence of air velocity on the drying kinetics is mainly related to external resistance; no significant differences in $D / L$. ${ }^{2}$ were found at 1 or $2 \mathrm{~m} \mathrm{~s}^{-1} . D / L^{2}$ increased as the air temperature rose, which means that the internal resistance to mass transfer decreased as the air temperature went up.

Air velocity is mainly connected to external resistance. As the velocity increases, there is a reduction in the thickness of the boundary layer around the body (Mulet, 1994). Therefore, the mass transfer coefficient grew as air velocity increased. The external resistance was also affected by air temperature (Table 4); the mass transfer coefficient increased as the air temperature rose, which implies a reduction of external resistance to mass transfer. Therefore, the mass transfer mechanisms involved in the drying of thyme leaves were significantly affected by both air velocity and air temperature. It could be deduced that the heat transfer coefficient behaves similarly to the mass transfer coefficient. From results at $80{ }^{\circ} \mathrm{C}$ (Table 4), it could be explained the effect of the intensity and time length at $80{ }^{\circ} \mathrm{C}$ in rapid processes for mass and heat transport on drying kinetics. 
Table 4. Identified parameters from model fitting, relative error and explained variance.

\begin{tabular}{|c|c|c|c|c|c|c|}
\hline \multirow{2}{*}{$\begin{array}{c}v \\
(\mathrm{~m} / \mathrm{s})\end{array}$} & \multirow{2}{*}{$\mathbf{T}\left({ }^{\circ} \mathrm{C}\right)$} & \multirow{2}{*}{$D / L^{2}\left[10^{4}\right]\left(\mathrm{s}^{-1}\right)$} & $h_{m v}\left[10^{4}\right]$ & $h\left[10^{1}\right]$ & \multirow{2}{*}{ ER (\%) } & \multirow{2}{*}{$\operatorname{VAR}(\%)$} \\
\hline & & & $\left(\mathrm{kWm}^{-2} \mathrm{~K}^{-1}\right)$ & $\left(\mathrm{kWm}^{-2} \mathrm{~K}^{-1}\right)$ & & \\
\hline \multirow{5}{*}{1} & 40 & $0.46 \pm 0.06$ & $1.37 \pm 0.11$ & $1.45 \pm 0.13$ & 3.3 & 99.8 \\
\hline & 50 & $0.90 \pm 0.09$ & $1.75 \pm 0.21$ & $1.79 \pm 0.16$ & 1.5 & 99.9 \\
\hline & 60 & $2.02 \pm 0.38$ & $2.03 \pm 0.03$ & $2.13 \pm 0.05$ & 2.4 & 99.9 \\
\hline & 70 & $4.98 \pm 0.63$ & $2.53 \pm 0.12$ & $2.51 \pm 0.10$ & 2.4 & 99.9 \\
\hline & 80 & $7.39 \pm 0.18$ & $3.81 \pm 0.22$ & $4.12 \pm 0.14$ & 2.6 & 99.8 \\
\hline \multirow{5}{*}{2} & 40 & $0.54 \pm 0.02$ & $2.82 \pm 0.02$ & $1.97 \pm 0.06$ & 2.2 & 99.9 \\
\hline & 50 & $0.89 \pm 0.01$ & $3.06 \pm 0.03$ & $2.19 \pm 0.02$ & 3.8 & 99.7 \\
\hline & 60 & $2.08 \pm 0.08$ & $3.41 \pm 0.06$ & $3.19 \pm 0.03$ & 3.8 & 99.7 \\
\hline & 70 & $5.02 \pm 0.08$ & $4.11 \pm 0.09$ & $3.88 \pm 0.09$ & 3.1 & 99.8 \\
\hline & 80 & $7.52 \pm 0.19$ & $4.62 \pm 0.15$ & $4.07 \pm 0.11$ & 3.9 & 99.6 \\
\hline
\end{tabular}

\subsection{Antioxidant capacity}

The drying process affects the AC values in function of how intense the operating conditions are and how long they are applied for. Table 5 shows the average AC values of the dried product extracts. These values showed varied greatly from sample to sample, from $39.9 \pm 0.6$ to $114.1 \pm 1.6 \mathrm{mmol} / \mathrm{LTrolox}$ equivalents. Two consecutive drying periods allowed the AC to increase from 4.7 to $27.4 \%$ with respect to $A C$ values obtained from dried product extracts obtained under constant drying conditions. It can be observed in Table 5 that AC values showed a direct relationship with the length of time of the first drying period and the air temperature of the second drying period. Nevertheless, at a constant air temperature of $80^{\circ} \mathrm{C}$, the AC decreases, which could be due to the degradation of compounds with antioxidant capacity and changes in their structure, as already pointed out in the literature (Fletcher et al. 2005; Rahimmalek and Hossein-Golib., 2013). 
Table 5. Average values of the antioxidant capacity of dried product extracts (AC) under different experimental conditions.

\begin{tabular}{|c|c|c|c|c|c|}
\hline$v(\mathrm{~m} / \mathrm{s})$ & $\mathbf{T}\left({ }^{\circ} \mathbf{C}\right)$ & $\begin{array}{c}\mathrm{AC} \\
{[\text { Trolox] }} \\
(\mathrm{mmol} / \mathrm{L})\end{array}$ & $v(\mathrm{~m} / \mathrm{s})$ & $\mathbf{T}\left({ }^{\circ} \mathrm{C}\right)$ & $\begin{array}{c}\text { AC [Trolox }] \\
(\mathbf{m m o l} / \mathrm{L})\end{array}$ \\
\hline \multirow{13}{*}{1} & 40 & $39.9 \pm 0.6$ & \multirow{13}{*}{2} & 40 & $44.1 \pm 2.5$ \\
\hline & $T_{a 11}-40$ & $42.2 \pm 0.9$ & & $T_{a 11}-40$ & $51.8 \pm 1.5$ \\
\hline & $T_{a 12}-40$ & $44.1 \pm 0.7$ & & $T_{a 12}-40$ & $56.2 \pm 1.6$ \\
\hline & 50 & $49.4 \pm 0.5$ & & 50 & $63.6 \pm 0.4$ \\
\hline & $T_{a 11}-50$ & $51.7 \pm 0.7$ & & $T_{a 11}=50$ & $69.0 \pm 0.5$ \\
\hline & $T_{a 12}-50$ & $62.9 \pm 4.3$ & & $T_{a 12}-50$ & $76.1 \pm 1.5$ \\
\hline & 60 & $72.9 \pm 0.8$ & & 60 & $79.7 \pm 0.8$ \\
\hline & $T_{a 11}-60$ & $79.1 \pm 0.7$ & & $T_{a 11}-60$ & $84.9 \pm 1.2$ \\
\hline & $T_{a 12}-60$ & $81.4 \pm 1.3$ & & $T_{a 12}-60$ & $89.5 \pm 1.3$ \\
\hline & 70 & $86.1 \pm 2.1$ & & 70 & $99.7 \pm 1.8$ \\
\hline & $T_{a 11}-70$ & $94.6 \pm 0.7$ & & $T_{a 11}=70$ & $104.6 \pm 1.9$ \\
\hline & $T_{a 12}-70$ & $97.2 \pm 0.6$ & & $T_{a 12}-70$ & $114.1 \pm 1.6$ \\
\hline & 80 & $84.4 \pm 2.2$ & & 80 & $96.9 \pm 4.2$ \\
\hline
\end{tabular}

The major components of the essential oil of thyme are the aromatic monoterpenes, p-cymene $\mathrm{y}$-terpinene and thymol. Rahimmalek and Hossein-Golib, (2013) reported an increase in thymol/carvacrol at $70{ }^{\circ} \mathrm{C}$. Although the enzyme responsible for converting $p$-cymene, $\gamma$-terpinene, is less active at higher temperatures, an enzymatic reaction (monooxygenases) induced by these higher temperatures might be what leads to the conversion of $p$-cymene to thymol. At low temperatures therefore, the conversion of $p$-cymene to thymol is negligible.

In previous studies, the importance of phenolic monoterpenes and aromatic volatile compounds has been emphasized as they contribute significantly to the total antioxidant capacity (Shan et al. 2005). A correlation between the total phenolic content and antioxidant capacity assays has been reported (Shan et al. 2005; Zheng and Wang, 2001). These results suggest that phenolic compounds are key contributors to the antioxidant capacity of the herb extracts. Ruberto and Barratta, (2000), who tested the antioxidant activity of about 100 pure components of essential oils, pointed out that the phenolic compounds, such as thymol and carvacrol, showed the highest antioxidant activity. On the other hand, HamrouniSellami et al. (2012) found moderate antioxidant activity on monoterpene hydrocarbons. To some extent, it would represent the level of participation of the phenolic compound in the antioxidant activity. 
Therefore, the antioxidant capacity values determined in the extracts in this study can be mainly attributed to the active compounds present in them, mainly constituents such as thymol and carvacrol.

Drying not only led to the disappearance of some compounds but also to the appearance of others which were absent in fresh leaves. According to HamrouniSellami et al. (2012), some compounds, such as $\beta$ myrcene and $\gamma$-terpinene, seem to have more affinity with the water fraction contained in thyme leaves and, thereby, they were lost with the water during the drying process. Hamrouni-Sellami et al. (2011) reported that the appearance of new compounds in Laurus nobilis might be caused by the length of time and high drying temperatures. Therefore, the increase in drying velocity influences the formation or degradation of certain compounds, which could explain why the AC values at $2 \mathrm{~m} \mathrm{~s}^{-1}$ were higher than those at $1 \mathrm{~m} \mathrm{~s}^{-1}$. The drying rate is higher at $2 \mathrm{~m} \mathrm{~s}^{-1}$.

Finally, we should point out that the consequences of food processing and preservation procedures on the overall antioxidant activity of foods are generally the results of different, and sometimes contrasting, events which can take place consecutively or simultaneously. Processing methods may also improve the properties of naturally occurring antioxidants or induce the formation of new compounds with antioxidant properties, so that the overall antioxidant activity of raw plant material may remain unchanged, or even increase, despite the eventual loss of active ingredients (Tomaino et al. 2005).

Based on these results, it seems that the greater antioxidant activity observed when two consecutive drying periods are considered, is probably due both to the particular composition of these essential oils and to time/temperature effects on their main constituents which, by effect of the first drying period, allow the rapid formation of compounds with antioxidant properties.

Therefore, by employing a drying strategy, the time needed by the leaf surface to reach $70{ }^{\circ} \mathrm{C}$, which the literature suggests is the most suitable temperature, can be shortened (Rahimmalek and Hossein-Golib, 2013; Rodríguez et al. 2013). Therefore, the compounds with antioxidant capacity increase and there is an improvement in the drying kinetics, thus reducing the total drying time which is linked to energy consumption and productivity. More research needs carrying out for a better understanding of $A C$ and temperature relationship in the drying of thyme.

\section{Conclusion}

Managing the drying process by means of applying two consecutive drying periods at different temperatures appears to be an important tool as a way of intensifying the convective drying of a bed of thyme leaves, and increasing its antioxidant capacity. 
This drying strategy design allowed the drying time to be shortened in comparison with a continuous drying process, and may contribute to increasing the process efficiency and reducing the total drying time; therefore, if antioxidant capacity is taken into account, the productivity and the final product quality may be increased. For a better understanding of the drying process, a time- varying boundary conditions model was found to be necessary. This model will allow the length of the first drying period to be established according to product characteristics, like initial moisture content, and bed characteristics, like thickness. In that way, the drying operation may be managed successfully and optimal operating management can even be undertaken.

\section{Reference}

Aarus, K., Uquihe, E., \& Del Valle, J.M. (2009). Matrix effects in supercritical CO2 extraction of essential oils from plant material. Journal of Food Engineering, 92, 438-447.

AOAC. (1997). Official methods of analysis of AOAC International, 16th edn, (Association of Official Analytical Chemist International AOAC, Gaithersburg, USA).

Chou, S. K.; Chua, K. J.; Mujumdar, A. S.; Hawlader, M. N. A. \& Ho, J. C. (2008). On the Intermittent Drying of an Agricultural Product. Food and Bioproducts Processing, 78, 193-203.

Chua, K.J., Mujumdar, A.S., Chou, S.K. (2003). Intermittent drying of bioproducts an overview, Bioresource Technology, 90, 285-295.

COMSOL AB. (2007). COMSOL multiphysics user's guide version 4.2, (COMSOL AB., Stockholm, Sweden).

Doymaz, I. (2011). Drying of Thyme (Thymus Vulgaris L.) and selection of a suitable thin-layer drying model. Journal of Food Processing and Preservation, 35, 458-465.

Fletcher, R.S., Slimmon, T., McAuley, C.Y., Kott, L.S. (2005). Heat stress reduces the accumulation of rosmarinic acid and the total antioxidant capacity in spearmint (Mentha spicata L). Journal of the Science of Food and Agriculture, 85, 24292436.

Hamrouni-Sellami, I., Bettaieb Rebey, I., Sriti, J., Zohra Rahali, F., Limam, F., Marzouk, B. (2012). Drying sage (Salvia officinalis L.) plants and its effects on content, chemical composition, and radical scavenging activity of the essential oil. Food and Bioprocess Technology, 5, 2978-2989.

Hamrouni-Sellami, I., Wannes, W.A., Bettaieb, I., Berrima, S., Chahed, T., Marzouk, B., Limam, F. (2011). Qualitative and quantitative changes in the 
essential oil of Laurus nobilis L. leaves as affected by different drying methods. Food Chemestry, 126, 691-769.

Herman-Lara, E., Salgado-Cervantes, M.A., García-Alvarado, M.A. (2005). Mathematical simulation of convection food batch drying with assumptions of plug flow and complete mixing of air. Journal of Food Engineering, 68 (3), 321-327.

Herman, E., Rodríguez, G.C., García, M.A. (2001). Mathematical modeling for fixed bed drying considering heat and mass transfer and interfacial phenomena. Drying Technology, 19 (9), 2343-2362.

Hossain, M. B., Brunton, N. P., Barry-Ryan, C., Martin-Diana, A. B., Wilkinson, M. (2008). Antioxidant activity of spice extracts and phenolics in comparison to synthetic antioxidants. Rasayan Journal of Chemistry, 1(4), 751-756.

Hossain, M.B., Barry-Ryan. C., Martin-Diana, A.B., Brunton, N.P. (2010). Effect of drying method on the antioxidant capacity of six Lamiaceae herbs. Food Chemestry, 123, 85-91.

Konak, M., Carman, K., Aydin, C. (2002). Physical properties of chickpea seeds. Biosystems Engineering, 82(1), 73-78, doi:10.1006/bioe.2002.0053.

Mujumdar, A. S., Law, C. L. (2010). Drying technology: Trends and applications in postharvest processing. Food and Bioprocess Technology, 3(6), 843-852.

Mukhopadhyay, M. (2000). Natural Extracts Using Supercritical Carbon Dioxide. CRC Press, Boca Raton, FL.

Mulet, A. (1994). Drying modelling and water diffusivity in carrots and potatoes. Journal of Food Engineering, 22, 329-348.

Nimkar, P. M., Chattopadhyay, P. K. (2001). Some physical properties of green gram. Journal of Agricultural Engineering Research, 80(2), 183-189, doi:10.1006/jaer.2000.0664.

Ould Ahmedou, S. A., Rouaud, O., \& Havet, M. (2008). Assessment of the electrodynamic drying process. Food and Bioprocess Technology, 2 (3), $240-247$.

Pelegrina, A.H., Echarte, R.E., Crapiste, G.H. (1999). Calculo de las propiedades del aire húmedo y su aplicación en la simulación de procesos: VII taller de herramientas de cálculo en ingeniería de alimentos. Santiago de Chile.

Perry, R.H., Green, D.W., Maloney, J.O. (1997). Perry's Chemical Engineers Handbook, seventh ed. McGraw-Hill, USA. 
Prado, J.M., Leal, P.F., Meireles, M.A.A. (2009). Comparison of manufacturing cost of thyme extract obtained by supercritical fluid extraction and steam distillation, in: 9th International Symposium on Supercritical Fluids, Arcachon- France, May 1820, 2009, p. P135, Full paper available in ISSF 2009 CD-ROM.

Rahimmalek, M., Hossein-Goli, S.A. (2013). Evaluation of six drying treatments with respect to essential oil yield, composition and color characteristics of Thymys daenensis subsp. daenensis. Celak leaves. Industrial Crops and Products, 42, 613-619.

Reverchon, E. (1997). Supercritical fluid extraction and fractionation of essential oils and related products. Journal of Supercritical Fluids, 10 (1), 1-37.

Reverchon, E., De Marco, I. (2006). Supercritical fluid extraction and fractionation of natural matter. Journal of Supercritical Fluids, 38 (2), 146-166.

Rodríguez, J., Clemente, G., Sanjuán, N., Bon, J. (2012). Modelling drying kinetics of thyme (Thymus vulgaris L.): Theoretical and empirical models, and neural networks. Food Science and Technology International. DOI: $10.1177 / 1082013212469614$.

Rodríguez, J., Ortuño, C., Benedito, J., Bon J. (2013). Optimization of the antioxidant capacity of thyme (Thymus vulgaris L.) extracts: Management of the drying process. Industrial Crops and Products, 46, 258 - 263.

Ruberto, G., Baratta, M. T. (2000). Antioxidant activity of selected essential oil components in two lipid model systems. Food Chemestry, 69, 167-174.

Sanjuán, N., Lozano, M., Garcia-Pascual, P., and Mulet, A. (2003). Dehydration kinetics of red pepper (Capsicum annuum $L$ var Jaranda). Journal of the Science of Food and Agriculture, 83(7), 697-701.

Saura-Calixto, F., Goñi, I. (2006). Antioxidant capacity of the Spanish Mediterranean diet. Food Chemestry, 94, 442-47.

Shan, B., Cai, Y. Z., Sun, M., Corke, H. (2005). Antioxidant capacity of 26 spice extracts and characterization of their phenolic constituents. Journal of Agricultural and Food Chemistry, 53, 7749-7759.

\section{Nomenclature}

$\begin{array}{lll}a & \text { Parameter equation } 5 & \\ a_{w} & \text { Water activity } & \\ b & \text { Parameter equation } 5 & \\ C p_{d a} & \text { Specific heat of dry air } & \mathrm{J} \mathrm{kg}^{-1} \mathrm{~K}^{-1}\end{array}$




\begin{tabular}{|c|c|c|}
\hline$C p_{v}$ & Specific heat of water vapor & $\mathrm{J} \mathrm{kg}^{-1} \mathrm{~K}^{-1}$ \\
\hline$C p_{w}$ & Specific heat of liquid water & $\mathrm{J} \mathrm{kg}^{-1} \mathrm{~K}^{-1}$ \\
\hline$C p_{d s}$ & Specific heat of the dry solid & $\mathrm{J} \mathrm{kg}^{-1} \mathrm{~K}^{-1}$ \\
\hline$D$ & Effective water diffusivity in the leaves & $\mathrm{m}^{2} \mathrm{~s}^{-1}$ \\
\hline$D_{A B}$ & Diffusivity of water in air & $\mathrm{m}^{2} \mathrm{~s}^{-1}$ \\
\hline$E R$ & Relative error & $\%$ \\
\hline$h$ & Heat transfer coefficient & $\mathrm{kW} \mathrm{m} \mathrm{K}^{-1}$ \\
\hline$h_{m v}$ & Mass transfer coefficient & $\mathrm{kW} \mathrm{m}{ }^{-2} \mathrm{~K}^{-1}$ \\
\hline$L$ & Half thickness of the leaves & $\mathrm{m}$ \\
\hline$L_{c}$ & Thickness of the bed & $\mathrm{m}$ \\
\hline$M_{d s}$ & Mass of the dry solid & $\mathrm{kg}$ \\
\hline$m_{a}$ & Dry air mass flow & $\mathrm{kg} \mathrm{s}^{-1}$ \\
\hline$P M_{\mathrm{v}}$ & Molecular weight of water vapor & $\mathrm{kg} \mathrm{mol}^{-1}$ \\
\hline$R$ & Ideal gas constant & $\mathrm{kJ} \mathrm{kmol}^{-1} \mathrm{~K}^{-1}$ \\
\hline$T$ & Temperature of the solid & ${ }^{\circ} \mathrm{C}$ \\
\hline$T(1, t)$ & Temperature on the leaf surface & ${ }^{\circ} \mathrm{C}$ \\
\hline$T_{0}$ & Initial temperature of the solid & ${ }^{\circ} \mathrm{C}$ \\
\hline$T_{a}$ & Air temperature & ${ }^{\circ} \mathrm{C}$ \\
\hline$T_{a e}$ & Air temperature bed exit & ${ }^{\circ} \mathrm{C}$ \\
\hline$T_{a i}$ & Air temperature bed inlet & ${ }^{\circ} \mathrm{C}$ \\
\hline$T_{p p}$ & Temperature on the gas-solid interface & ${ }^{\circ} \mathrm{C}$ \\
\hline$T_{a 11}$ & Air temperature of the first drying period ( $80{ }^{\circ} \mathrm{C}$ for $300 \mathrm{~s}$ ) & ${ }^{\circ} \mathrm{C}$ \\
\hline$T_{a 12}$ & Air temperature of the first drying period ( $80 \stackrel{\circ}{ } \mathrm{C}$ for $600 \mathrm{~s}$ ) & ${ }^{\circ} \mathrm{C}$ \\
\hline$T_{a 2}$ & Air temperature of the second drying period & ${ }^{\circ} \mathrm{C}$ \\
\hline$t$ & Time & $\mathrm{s}$ \\
\hline$V$ & Volume of the bed & $\mathrm{m}^{-3}$ \\
\hline$V_{a}$ & Air volume in the bed & $\mathrm{m}^{-3}$ \\
\hline VAR & Explained variance & $\%$ \\
\hline$x$ & Coordinate & $\mathrm{m}$ \\
\hline$X_{a 0}$ & Initial air moisture content & $\mathrm{kg}$ water $(\mathrm{kgdB})^{-1}$ \\
\hline$X_{a}$ & Air moisture content & $\mathrm{kg}$ water $(\mathrm{kgdB})^{-1}$ \\
\hline$X_{e}$ & Moisture content of hot air & $\mathrm{kg}$ water $(\mathrm{kgdB})^{-1}$ \\
\hline
\end{tabular}




\begin{tabular}{|c|c|c|}
\hline$X_{e q}$ & Equilibrium moisture content of hot air & $\mathrm{kg}$ water $(\mathrm{kgdB})^{-1}$ \\
\hline$z$ & Dimensionless coordinate & \\
\hline \multicolumn{3}{|c|}{ Greek symbols } \\
\hline$\varepsilon$ & Bed porosity & \\
\hline$\kappa$ & Thermal conductivity of thyme & $\mathrm{kWm} \mathrm{m}^{-1} \mathrm{~K}^{-1}$ \\
\hline$\kappa_{a}$ & Thermal conductivity of air & $\mathrm{kWm} \mathrm{m}^{-1} \mathrm{~K}^{-1}$ \\
\hline$\lambda$ & Latent heat of water vaporization & $\mathrm{kJ} \mathrm{kg}^{-1}$ \\
\hline$v$ & Air velocity & $\mathrm{m} \mathrm{s}^{-1}$ \\
\hline$\rho_{d a}$ & Density of the dry air & $\mathrm{kg} \mathrm{m}^{-3}$ \\
\hline$\rho_{d a i}$ & Density of the dry air at surface temperature & $\mathrm{kg} \mathrm{m}^{-3}$ \\
\hline$\rho_{d s}$ & Density of the dry solid & $\mathrm{kg} \mathrm{m}^{-3}$ \\
\hline $\bar{\tau}$ & Average moisture content of the product & $\mathrm{kg}$ water $(\mathrm{kgds})^{-1}$ \\
\hline$\tau$ & Moisture content of the product & $\mathrm{kg}$ water $(\mathrm{kgds})^{-1}$ \\
\hline$\tau_{e q}$ & Equilibrium moisture content & $\mathrm{kg}$ water(kgds $)^{-1}$ \\
\hline$\tau_{0}$ & Initial moisture content of the product & $\mathrm{kg}$ water $(\mathrm{kgds})^{-1}$ \\
\hline$\omega$ & Dimensionless moisture content & \\
\hline \multicolumn{3}{|c|}{ Dimensionless numbers } \\
\hline$N u$ & Nusselt number & \\
\hline $\operatorname{Pr}$ & Prandtl number & \\
\hline$R e$ & Reynolds number & \\
\hline$S c$ & Schmidt number & \\
\hline$S h$ & Sherwood number & \\
\hline
\end{tabular}



5. DISCUSION DE RESULTADOS 

Como ya se ha señalado en la introducción, el secado por aire caliente, a pesar de ser un método ampliamente utilizado, presenta ciertas limitaciones de calidad y consumo de energía, que pueden considerarse como desafíos para la mejora del proceso. En base a esta consideración, la metodología propuesta en esta tesis doctoral se realizó con el fin de intensificar el secado convectivo en un producto de elevado interés, como es el tomillo, aplicando ultrasonidos de potencia y la metodología de secado intermitente. La intensificación del secado convectivo se abordó desde el punto de vista de mejora de las cinéticas de secado, reduciendo el tiempo de proceso, y preservar la mayor cantidad de compuestos sensibles al calor, incrementando la capacidad antioxidante de los extractos del tomillo seco $(\mathrm{AC})$.

La obtención de productos de alta calidad a un costo mínimo, pero con un rendimiento máximo, es un reto para las industrias alimentarias y farmacéuticas. Para este propósito es necesario identificar las condiciones óptimas de operación a partir de un modelo matemático apropiado. Durante el proceso de secado de hojas de tomillo, algunos compuestos sensibles al calor pueden variar en cuanto a concentración y actividad; estos cambios están relacionados con varios factores, como el método de secado y las condiciones de funcionamiento, tales como la temperatura. A partir de estas consideraciones se planteó el objetivo de estudiar el efecto de la temperatura y de la velocidad del aire sobre las cinéticas de secado, así como desarrollar modelos matemáticos que permitan describir la evolución de la humedad durante el proceso y de la AC.

Para abordar este objetivo, se estudió el secado de hojas de tomillo en lecho fijo, bajo condiciones de secado constantes y se analizó el tipo de modelo a aplicar. De los resultados preliminares obtenidos se observó que la velocidad de secado aumentó con la temperatura y la velocidad del aire, por lo que el tiempo de calentamiento se reduce. De los modelos empleados para predecir la evolución de la humedad durante el proceso de secado, las redes neuronales (ANN) resultaron ser los modelos de mejor precisión, proporcionando una buena correlación de los parámetros de entrada (Input) con los valores de salidas (Target), pero sin proporcionar una relación causal. Este tipo de modelos computacionales pueden ser herramientas de mucha utilidad pues permiten describir procesos de alto grado de complejidad y de difícil descripción teórica, siendo además útil para optimizar o controlar procesos en línea por su tiempo corto de resolución y alto potencial de adaptación y rendimiento. El modelo difusivo sin considerar resistencia externa no resulto adecuado por lo que esta hipótesis no parece pertinente en el secado de tomillo.

De la misma manera se estudió el efecto de las condiciones de operación sobre la AC. Del análisis de los resultados de la AC se dedujo la existencia de una relación de AC con las condiciones de operación del proceso de secado. Se pudo observar una relación directa de la temperatura y de la velocidad del aire sobre la AC. El tiempo de secado es un parámetro importante que influye sobre el valor de la AC, y que a su vez depende de la temperatura y de la velocidad del aire y la humedad final fijada. Es decir la relación tiempo/temperatura aparece como importante a 
considerar. En base a estos resultados, se desarrolló una herramienta de gestión que permitía establecer las condiciones óptimas de operación que maximizaran la AC. Para poder describir la evolución de la AC y predecir la humedad final de muestra en función de las condiciones de operación se desarrollaron dos ANNs. La herramienta de gestión fue probada con datos experimentales obteniendo mejoras entre el 4.9 y el $360.4 \%$, adicionalmente la herramienta de gestión fue validada con experiencias no utilizadas en el desarrollo del modelo, a diferentes humedades del aire y humedad inicial de la muestra. A partir de los resultados se puede concluir que la herramienta desarrollada es muy útil para la gestión del proceso de secado determinando los valores óptimos de las condiciones de operación.

Una vez analizada la influencia de las condiciones de operación sobre las cinéticas de secado y sobre AC bajo condiciones constante de secado, se procedió a intensificar el secado convectivo mediante la aplicación de ultrasonidos de potencia (US). Para analizar el efecto de los US sobre las cinéticas de secado, fue necesario desarrollar un modelo que considerara transferencia de calor y de materia simultáneamente en un lecho de hojas de tomillo, con condiciones de contorno variables en el tiempo. Los resultados del ajuste indicaron que las hipótesis asumidas en el desarrollo del modelo fueron adecuadas, permitiendo identificar los parámetros relacionados el de transporte de materia y calor, como $D / L^{2}, h_{m v}$ y $h$. Al ser un lecho poroso los US afectaron la resistencia interna en las hojas a pesar de tener una baja porosidad. La resistencia interna a la transferencia de materia se relacionó con el parámetro $D / L^{2}$. La velocidad del aire influía sobre las resistencias externas; y, por lo tanto, sobre los valores de los parámetros correspondientes ( $h_{m v}$ y $h$ ) la temperatura afectaba a la resistencia interna a la transferencia de materia, disminuyendo a medida que aumentaba la temperatura. El parámetro $D / L^{2}$ aumentó con la aplicación de los US, pero a temperatura del aire de secado superior a $60{ }^{\circ} \mathrm{C}$ dicho efecto era despreciable, esto se debería a que por efecto de la temperatura la resistencia interna habría disminuido. Los US penetran en el lecho y afectan la resistencia externa en las hojas, a nivel interno el efecto de los US fue menor debido a los pequeños espacios intercelulares característicos de productos de baja porosidad, como las hojas de tomillo. Por consiguiente, para obtener un mayor efecto de los US sobre la resistencia interna sería necesario aplicar niveles más altos de intensidad ultrasónica.

La influencia de los US, fue mayor a bajas velocidades de aire $\left(1 \mathrm{~m} \mathrm{~s}^{-1}\right)$, siendo despreciable a la velocidad más alta $\left(3 \mathrm{~m} \mathrm{~s}^{-1}\right)$. Esto se puede deber a que el espesor de la capa limite es menor a altas velocidades de aire, y a la perturbación del campo acústico como consecuencia del movimiento del aire. Adicionalmente, la influencia de los US disminuyó al aumentar la temperatura del aire. Esto podría estar relacionado con el hecho que la energía ultrasónica aplicada es constante, mientras que el efecto de la temperatura aumenta con el incremento de su magnitud y por lo tanto el efecto relativo de los ultrasonidos es menor. Cuando el efecto relativo de los US es significativo la cinética de secado en lecho fijo de hojas de tomillo se mejora por la aplicación de US, obteniendo una reducción del 
tiempo de secado alrededor del $30 \%$ como sucede para hojas secadas a una velocidad del aire de $1 \mathrm{~m} \mathrm{~s}^{-1}$ a 40 o $50 \stackrel{\circ}{\circ} \mathrm{C}$. Debido al efecto de las variables de operación se deduce que debe existir un valor óptimo del consumo energético, aunque sería necesario introducir consideraciones de calidad.

De la misma manera que se estudió el efecto de las condiciones de secado sobre la AC bajo condiciones de secado constantes, se estudió para el proceso de secado asistido por US. La AC variaba significativamente en función de la magnitud de las condiciones de operación aplicadas en el proceso de secado. A velocidad de aire de $1 \mathrm{~m} \mathrm{~s}^{-1}$, la AC aumentaba con la temperatura entre valores de 40 - $70 \stackrel{\circ}{\circ}$, pero la influencia de los US sobre AC solo se observó hasta $60 \stackrel{\circ}{ }$ C. Para una velocidad del aire de secado de $2 \mathrm{~m} \mathrm{~s}^{-1}$, AC aumentaba en comparación con los valores obtenidos a $1 \mathrm{~m} \mathrm{~s}^{-1}$, observando el mismo efecto de la temperatura y de los US sobre la AC. Sin embargo a temperaturas superiores a $70^{\circ} \mathrm{C}$, a $2 \mathrm{~m} \mathrm{~s}^{-1}$ la AC disminuyó; este comportamiento podría ser debido a la degradación del aceite esencial. Para una velocidad del aire de $3 \mathrm{~m} \mathrm{~s}^{-1}$, AC disminuyó en comparación con los valores obtenidos a velocidades de aire de $2 \mathrm{~m} \mathrm{~s}^{-1}$, lo que podría ser debido a la pérdida de compuestos causado por un mayor calentamiento. El efecto de los US a $3 \mathrm{~m} \mathrm{~s}^{-1}$ sobre la AC no fue significativo. La AC se debe a la contribución significativa de monoterpenos fenólicos y compuestos aromáticos volátiles. El efecto de la temperatura, la velocidad del aire y los ultrasonidos de potencia contribuyen a la velocidad de secado, y por tanto a la temperatura superficial de la hoja. Esto afecta a la degradación o desaparición de compuestos que o bien se degradan y pierden actividad o promueven la formación de nuevos compuestos con mayor capacidad antioxidante. Este fenómeno estaría ligado a la variación tiempo-temperatura de la superficie de la hoja que es donde se localiza los compuestos de interés.

A partir de las experiencias de secado, se desarrolló una herramienta de gestión para establecer los valores de las variables decisorias (condiciones de operación manipulables) que maximizaran AC. Para predecir la evolución de AC y la evolución de la humedad del producto, se desarrollaron dos ANNs. La herramienta de gestión fue probada y validada permitiendo establecer la fiabilidad de la herramienta. Esta herramienta de gestión tendría gran utilidad en procesos de optimización de secado asistido por ultrasonidos en tiempo real, por la rapidez de la ejecución de la herramienta y la fiabilidad de los resultados. El valor óptimo de las variables de decisión depende de las restricciones consideradas. A partir de los resultados de la herramienta de optimización se puede ver que para alcanzar el valor máximo de $\mathrm{AC}$, el tiempo de secado es el más corto posible y en consecuencia el consumo energetico puede ser optimizado.

Se abordó también intensificar el proceso de secado por intermitencia considerando la temperatura de la superficie del sólido. Esta metodología de secado puede contribuir a la reducción del tiempo eficaz de secado, y la calidad final del producto puede ser preservada. Se evaluó el efecto de la intermitencia diseñada a partir de la temperatura de la superficie del sólido, en la intensificación y sobre la AC. Para abordar este objetivo se desarrolló una herramienta de gestión 
del secado a partir del diseño de una estrategia, la cual consistió en aplicar dos periodos consecutivos de secado a temperaturas diferentes. Para poder gestionar el proceso, fue necesario desarrollar un modelo matemático para determinar el tiempo requerido para que la superficie de la hoja no sobrepasara los $70{ }^{\circ} \mathrm{C}$. El modelo difusional con resistencia variable consideraba transferencia de calor y materia simultáneamente y con condiciones de contorno variables en el tiempo. De los resultados obtenidos del modelado a $80{ }^{\circ} \mathrm{C}, 1$ y $2 \mathrm{~m} \mathrm{~s}^{-1}$ no se observaron diferencias en la evolución de la temperatura de la superficie de las hojas. En ambos casos el tiempo requerido para que la superficie de la hoja alcance una temperatura de $68 \stackrel{\circ}{ } \mathrm{C}$ fue $600 \mathrm{~s}$. A partir del valor del tiempo obtenido se diseñó la estrategia de secado que permitiría mejorar las cinéticas de secado y aumentar la AC. El primer periodo de secado se realizó a $80 \stackrel{\circ}{ } \mathrm{C}$ durante $600 \mathrm{~s}$, y otros experimentos a $300 \mathrm{~s}$ (para el análisis del efecto tiempo/temperatura), a continuación comenzaba el segundo periodo de secado con temperaturas de 40 , 50,60 y $70 \circ \mathrm{C}$, hasta que el contenido final de humedad fuera inferior al $10 \%$ (d.b), a 1 y $2 \mathrm{~m} \mathrm{~s}^{-1}$. Las diferentes temperaturas ensayadas en el segundo periodo de secado fueron consideradas para comparar los resultados obtenidos al aplicar dos periodos consecutivos de secado con los obtenidos considerando un único perìodo. Como era de esperar, el aumento del tiempo del primer período de secado mejoró la cinética de secado. El tiempo total de secado considerando un primer periodo de secado a $T_{a} 80 \stackrel{\circ}{ } \mathrm{C}$ se redujo de un 7 a un $39 \%$ en comparación con las experiencias de secado donde la temperatura del aire se mantenía constante.

El modelo difusivo con resistencia variable desarrollado mostró un buen ajuste para las cinéticas obtenidas considerando tanto un solo período como dos periodos. Por otro lado, este modelo permitió estimar el efecto del primer período, a una temperatura del aire de $80 \stackrel{\circ}{\circ}$ por un tiempo dado, sobre las características del transporte interno y externo. Los parámetros del modelo identificados, fueron afectados por la temperatura y la velocidad del aire. La influencia de la velocidad del aire en la cinética de secado está principalmente ligada a la resistencia externa. Para la resistencia interna $(D / L)^{2}$ no se encontraron diferencias significativas aplicando las velocidades del aire consideradas, pero sí se observó una relación con la temperatura del aire. Los coeficientes externos de transferencia de calor y materia, mostraron una relación con la temperatura y velocidad del aire. La mejora de AC mostró una relación directa con la duración del primer período de secado, y con la temperatura del aire del segundo período de secado. Sin embargo, a temperatura del aire constante de $80 \stackrel{\circ}{\circ}$, la AC disminuyó; corroborando los resultados ya señalados en la bibliografía sobre degradación a temperaturas superiores a $70{ }^{\circ} \mathrm{C}$. El aumento de la $\mathrm{AC}$ se debe principalmente a dos parámetros cruciales, como son tiempo y temperatura. Una temperatura del aire de $70 \stackrel{\circ}{ } \mathrm{C}$ favorece la actividad del enzima que se encarga de convertir el $p$ cimeno a timol, mientras que el enzima responsable de la conversión, de $p$-cimeno $\gamma$-terpineno, tiene menor actividad a temperaturas altas. El timol es un componente mayoritario del aceite esencial de tomillo con una alta actividad antioxidante. Por lo tanto, la aplicación del primer periodo de secado favorece el aumento de la cantidad de timol en el aceite esencial, aumentándose la AC. Este comportamiento 
se puede corroborar con el efecto contrario a bajas temperaturas de secado de 40 y $50 \stackrel{\circ}{ } \mathrm{C}$, donde el enzima responsable de convertir $p$-cimeno a timol tiene una actividad baja, y el enzima responsable de la conversión, $p$-cimeno a $\gamma$-terpineno (moderada actividad antioxidante) tiene actividad alta. Por otro lado, algunos compuestos, como el $\gamma$-terpineno, tienen afinidad con la fracción de agua contenida en las hojas de tomillo, pudiéndose perder durante el proceso de secado, aumentando entonces la cantidad relativa de timol con respecto al $\gamma$ terpineno. Este comportamiento podría explicar que AC a $2 \mathrm{~m} \mathrm{~s}^{-1}$ eran mayores que a un $1 \mathrm{~m} \mathrm{~s}^{-1}$ al aumentar la temperatura superficial. Basándose en estos resultados, parece que el aumento de la AC cuando se aplica dos períodos consecutivos de secado, se debe probablemente a la composición particular del aceite esencial y al efecto tiempo/temperatura del primer periodo de secado sobre sus componentes principales, lo cual favorece la rápida formación de compuestos que tienen propiedades antioxidantes. Por lo tanto, una estrategia de secado diseñada con dos periodos permite aumentar los compuestos con capacidad antioxidante entre el 4 y el $27 \%$ y mejorar la cinética de secado reduciendo el tiempo de secado total entre el 7 y el $39 \%$, el cual está vinculado al consumo de energía y la productividad. 

6. CONCLUSIONES 

De los estudios realizados se pueden extraer las siguientes conclusiones sobre diferentes aspectos considerados en este trabajo:

\section{Modelización}

- Los modelos de redes neuronales fueron capaces de relacionar con exactitud la dependencia de la humedad del producto y de la AC con las condiciones de operación. No ofrecen una relación causal de la variable output con la variable input. Podría considerarse como modelos adecuados para describir procesos de difícil descripción teórica, y de especial interés en la formulación de problemas de optimización en el funcionamiento y/o control de procesos en tiempo real, por su precisión y rápida resolución.

- El modelo difusivo de lámina infinita sin considerar resistencia externa ni contracción no presento un ajuste satisfactorio. Al considerar simultáneamente los fenómenos de transferencia de calor y de materia en la hoja y en lecho de hojas, con condiciones de contorno variables en el tiempo, se describió adecuadamente tanto la evolución del proceso de secado convectivo, del proceso de secado convectivo asistido con US como del proceso de secado convectivo intermitente.

\section{Intensificación del secado convectivo por la aplicación de ultrasonidos.}

- La intensificación de secado por convección mediante la aplicación de ultrasonidos de potencia aumentó la velocidad de secado, para velocidades del aire 1 y $2 \mathrm{~m} \mathrm{~s}^{-1}$ y temperatura del aire de secado menor o igual a $60 \stackrel{\circ}{\circ}$. A partir de los valores de los parámetros identificados se observó un efecto más pronunciado en los fenómenos de trasporte externos, mientras que el efecto sobre los fenómenos de trasporte internos eran menores debido a las características del material.

\section{Intensificación del secado convectivo por secado intermitente.}

- La aplicación del secado en dos periodos consecutivos tiene un efecto significativo sobre la cinética de secado, disminuyendo el tiempo de calentamiento efectivo, mejorando la eficiencia energética del proceso en comparación con un proceso donde el suministro de energía térmica es continuo. El análisis de los parámetros identificados del modelo teórico, permitió estimar el efecto tiempo/temperatura del primer periodo de secado sobre la capacidad antioxidante.

\section{Efecto de las variables del proceso sobre la capacidad antioxidante}

- La variación de la AC, se debe probablemente a la composición del aceite esencial, y de los parámetros que influyen en la degradación o formación de 
compuestos con propiedades antioxidantes, en particular la temperatura superficial de la hoja de tomillo.

- La aplicación de los ultrasonidos en el secado convectivo influye principalmente sobre las resistencias externas a la transferencia de calor y materia y por tanto sobre la velocidad de secado. Esto influiría en la temperatura de la superficie de la hoja de tomillo y por tanto incide sobre la AC obtenida.

\section{Gestión del proceso de secado}

- La optimización del proceso de secado se ha establecido como un paso necesario para la identificación de las condiciones de operación que permitan minimizar el consumo energético y maximizar la calidad del producto. La metodología de la herramienta desarrollada podría aplicarse para gestionar el proceso, determinando los valores de las condiciones de operación que maximicen la AC. La herramienta de gestión desarrollada permitió aumentar el los valores de AC entre $4.9 \%$ y $360.4 \%$ con respecto a valores obtenidos sin realizar el proceso de optimización.

- Los extractos de tomillo de muestras secadas a $70 \stackrel{\circ}{\circ}$ fueron los que mayor capacidad antioxidante mostraron, corroborando lo resultados de la bibliografía. Por lo tanto, la temperatura de $70 \stackrel{\circ}{ } \mathrm{C}$ se sugiere como la adecuada para maximizar la capacidad antioxidante de los extractos del tomillo seco, precedida de un periodo de calentamiento a mayor temperatura para alcanzar esta temperatura en la superficie de la hoja en un tiempo corto. 


\section{RECOMENDACIONES}



A partir de la metodología desarrollada y de los resultados obtenidos parece interesante continuar la investigación centrándose en los siguientes aspectos:

- Profundizar en el estudio de la intensificación del proceso de secado mediante la aplicación de ultrasonidos aplicando niveles de potencia ultrasónica más altos, con el fin de analizar la influencia sobre los parámetros cinéticos del modelo, específicamente sobre la resistencia interna a la transferencia de materia.

- Realizar una identificación y cuantificación de los componentes volátiles de los extractos del tomillo seco para identificar los responsables de las variaciones de AC observadas.

- Analizar el efecto de cada una de las metodologías aplicadas para intensificar el proceso de secado, sobre cada uno de los componentes mayoritarios de los extractos del tomillo seco.

- Establecer en el modelo matemático la cinética de degradación de algún compuesto con alta capacidad antioxidante, y formular un problema de optimización que tenga como objetivo optimizar el efecto de las condiciones tiempo-temperatura sobre este compuesto. 

8. BIBLIOGRAFÍA 

Aarus, K., Uquihe, E., Del Valle, J.M. (2009). Matrix effects in supercritical CO2 extraction of essential oils from plant material. Journal of Food Engineering, 92: 438-447.

Aghbashlo, M., Kianmehr, M.H., Samimi-Akhijahani, H. (2009). Evaluation of thinlayer drying models for describing drying kinetics of barberries (Barberies vulgaris). Journal Food Process and Engeneering, 32, 278-293.

Akpinar, E.K. (2006). Mathematical modelling of thin layer drying process under open sun of some aromatic plants. Journal of Food Engineering, 77, 864-870.

Alibas, I. (2006). Characteristics of chard leaves during microwave, convective, and combined microwave-convective drying. Drying Technology, 24: 1425-1435.

AOAC. (1997). Official methods of analysis of AOAC International, 16th edn, (Association of Official Analytical Chemist International AOAC, Gaithersburg, USA).

Aquerreta, J., Iguaz, A., Arroqui, C., Virseda, P. (2007). Effect of high temperature intermittent drying and tempering on rough rice quality. Journal of Food Engineering, 80(2): 611-618.

Arabhosseini, A., Padhye, S., Huisman, W., van Boxtel, A., \& Müller, J. (2010). Effect of drying on the color of tarragon (Artemisia dracunculus L.) Leaves. Food and Bioprocess Technology, doi:10.1007/s11947-009-0305-9.

Arslan, D., Ozcan, M.M. (2008). Evaluation of drying methods with respect to drying kinetics, mineral content and colour characteristics of rosemary leaves. Energy Conversion and Management, 49:1258-1264

ASAE. (1999). Psychrometric data, D271.2 DEC99. American Society of Agricultural Engineers ASAE, USA.

Aversa, M., Curcio, S., Calabrò, V., \& Iorio, G. (2010). Experimental Evaluation of quality parameters during drying of carrot samples. Food and Bioprocess Technology, doi:10.1007/s11947-009-0280-1.

Badi, H.N., Yazdani, D., Ali, S.M. Fatemeh, N. (2004). Effects of spacing and harvesting time on herbage yield and quality/quantity of oil in thyme, Thymus vulgaris L. Industrial Crops and Products, 19: 231-236.

Baehr, H.D., Stephan, K. (2006). Heat and mass transfer, 2 edn., (Springer, Berlin, Alemania).

Baini, R., Langrish, T. A. G. (2007). Choosing an Appropriate Drying Model for Intermittent and Continuous Drying of Bananas. Journal of Food Engineering, 79: 340-343. 
Baş, D., Boyaci IH. (2007). Modeling and optimization II: comparison of estimation capabilities of response surface methodology with artificial neural networks in a biochemical reaction. Journal of Food Engineering, 78: 846-854.

Basu, S., Shivhare, U.S., Mujumdar, A.S. (2006). Models for sorption isotherms for foods, A Review. Drying Technology, 24: 917-930.

Benzie I. E. F. and Strain J. J. (1996). The ferric reducing ability of plasma (FRAP) as a measure of "antioxidant power": The FRAP assay. Analytical Biochemistry. 239:70-76.

Bhaskaracharya, R.K., Kentish, S., Ashokkumar, M. (2009) Selected applications of ultrasonics in food processing. Food Engineering Reviews, 1: 31-49.

Bon, J.,Váquiro, H., Benedito, J. and Telis-Romero, J. (2010). Thermophysical properties of mango pulp (Mangifera indica L. cv. Tommy Atkins). Journal of Food Engineering, 97: 563-568.

Bon, J., Kudra, T. (2007). Enthalpy-driven optimization of intermittent drying. Drying Technology, 25(4): 523-532.

Bon, J., Rosselló, C., Femenia, A., Eim, V., Simal, S. (2007). Mathematical modeling of drying kinetics for apricots: Influence of the external resistance to mass transfer. Drying Technology, 25(11): 1829-1835.

Bon, J. (1998). Modelización y optimización de cámaras de maduración. (Departamento de Tecnología de Alimentos, Universidad Politécnica de Valencia). Tesis Doctoral.

Bruni, A., Modenesi, P. (1983) Development, oil storage and dehiscence of peltate trichomesin Thymus vulgaris (Lamiaceae). Nordic Journal of Botany, 3: 245-251.

Bucinski, A., Zielinski, H., Kozzowska, H. (2004). Artificial neural networks for prediction of antioxidant capacity of cruciferous sprouts. Trends Food Science \& Technology, 15: 161-169.

Calín-Sánchez, A., Figiel, A., Lech, Krzysztof., Szumny, A., Carbonell-Barrachina, A. A. (2013). Effects of drying methods on the composition of thyme (Thymus vulgaris L.) essential oil. Drying Tecnhology, 31: 224-235.

Cárcel, J.A., García-Pérez, J.V., Benedito, J., Mulet, A. (2012) .Food process innovation through new technologies: Use of ultrasound. Journal of Food Engineering, 110:200-207.

Cárcel, J. A., García-Pérez, J. V., Riera, E., Mulet, A. (2007a). Influence of High Intensity Ultrasound on Drying Kinetics of Persimmon. Drying Technology, 25:185193. 
Cárcel, J. A., Benedito, J., Rosselló, C., and Mulet, A. (2007b). Influence of ultrasound intensity on mass transfer in apple immersed in a sucrose solution. Journal of Food Engineering, 78: 472-479.

Cárcel, J. A., Benedito, J., Bon, J., and Mulet, A. (2007c). High intensity ultrasound effects on meat brining. Meat Science, 76, 611-619.

Chou, S. K., Chua, K. J., Mujumdar, A. S., Hawlader, M. N. A., Ho, J. C.(2008). On the Intermittent Drying of an Agricultural Product. Food Bioproducts and Process, 78:193-203.

Chou, S.K., Chua, K.J. (2001). New hybrid drying technologies for heat sensitive foodstuffs. Trends in Food Science \& Technology, 12: 359-369.

Chua, K.J., Mujumdar, A.S., Chou, S.K. (2003). Intermittent drying of bioproducts an overview. Bioresource Technology, 90: 285-295.

Chua, K.J., Chou, S.K., Ho, J.C., Mujumdar, A.S., Hawlader, M.N.A.(2000a). Cyclic air temperature drying of guava pieces: effects on moisture and ascorbic acid contents. Transactions of the Institution of Chemical Engineers, 78 (Part C):72-78.

Chua, K.J., Mujumdar, A.S., Chou, S.K., Hawlader, M.N.A., Ho, J.C.(2000b). Heat pump drying of banana, guava and potato pieces: effect of cyclical variations of air temperature on convective drying kinetics and color change. Drying Technology An International Journal, 18 (5):907-936.

Cohen, J.S., Yang, T.C.S. (1995). Progress in food deshydration. Trends in Food Science and Technology, 6:20-25.

COMSOL AB. (2007). COMSOL multiphysics user's guide version 3.4, (COMSOL AB., Stockholm, Sweden).

Cuevas, R., Cheryan, M. (1978). Thermal conductivity of liquid foods, A Review. Journal of Food Process Engineering, 2:283-306.

Da-Mota, V. M., Palau, E. (1999). Acoustic drying of onion. Drying Technology, 17: 855- 867.

Datta, A.K. (1990) Heat and mass transfer in the microwave processing of food. Chemical Engineering Progress, 86(6): 47-53.

Demir, V., Gunhan, T,. Yaggioglu, A.K. (2007). Mathematical modelling of convection drying of green table olives. Biosystems Engineering, 98: 47-53.

Díaz-Maroto, M.C. Díaz-Maroto Hidalgo, I.J., Sánchez-Palomo, E., Pérez-Coello, M.S.,(2005). Volatile Components and Key Odorants of Fennel (Foeniculum vulgare Mill.) and Thyme (Thymus vulgaris L.) Oil Extracts Obtained by 
Simultaneous Distillation-Extraction and Supercritical Fluid Extraction. Journal Agricultura Food Chemestry, 53(13):5385-9.

Diaz-Maroto, M. C., Perez Coello, M. S., Cabezudo, M. D. (2002). Effect of different drying methods on the volatile components of parsley (Petroselinum crispum L.). European Food Research Technology, 215: 227-230.

Dick, A.J. Starmans., Herry, H., Nijhuis. (1996). Extraction of secondary metabolites from plant material, A Review. Trends Food Science Technology, 7:191-197.

Do Carmo, J.E.F., De Lima, A.G.B. (2008). Modeling and simulation of the continuous and intermittent drying (tempering) of lentil grains. En: Thorat, B.N. (ed.). Proceedings of the 16th International Drying Symposium IDS 2008 (UICT, Mumbai, India), pp. 468-473.

Dong, R.J., Lu, Z.H., Liu, Z.Q., Nishiyama, Y., Cao, W. (2009). Moisture distribution in a rice kernel during tempering drying. Journal of Food Engineering, 91(1): 126132.

Doymaz, I. (2011). Drying of Thyme (Thymus Vulgaris L.) and selection of a suitable thin-layer drying model. Journal of Food Processing and Preservation. doi: 10.1111/j.1745-4549.2010.00488.x.

Erenturk S. and Erenturk K., (2007). Comparison of genetic algorithm and neural network approaches for the drying process of carrot. Journal of Food Process Engineering 78(3): 905-912.

Esclapez, M. D., García-Pérez J. V., Mulet, A., Cárcel J. A. (2011). UltrasoundAssisted Extraction of Natural Products. Food Engineering Reviews, 3:108-120.

Fairbanks, H.V. (1975). Applying ultrasound to continuous drying process. Ultrasonic International 1975 Conference Proceedings, Guildford, Reino Unido.

Falade, K. O., Omojola, B. S. (2010). Effect of processing methods on physical, chemical, rheological, and sensory properties of okra (Abelmoschus esculentus). Food and Bioprocess Technology, doi:10.1007/s11947-008-0126-2.

Fang, Y. C., Wu, B.W. (2007). Neural network application for thermal image recognition on flow-resolution objects. Journal Optical Applied: Pure and Applied Optics, 9 (2):134-144.

Fernández, F. A. N., Rodrigues, S., Law, C. L., \& Mujumdar, A. S. (2010). Drying of exotic tropical fruits: A comprehensive review. Food and Bioprocess Technology, doi:10.1007/s11947-010-0323-7. 
Fernández, F. A. N., Rodrigues, S (2007. Ultrasound as pre-treatment for drying of fruits: Dehydration of banana. Journal of Food Engineering, 82:261-267.

Figura, L.O., Teixeira, A.A. (2007). Food physics, (Springer, Berlin, Alemania).

Gallego-Juárez, J.A., Rodríguez-Corral, G., Gálvez-Moraleda, J.C., Yang, T.S. (1999). A new high intensity ultrasonic technology for food dehydration. Drying Technology, 17:597-608.

Garau, M.C. (2008). Optimización del proceso de secado de diferentes productos agrícolas para la obtención de concentrados de frutas y hortalizas de elevada calidad, (Universidad Politécnica de Valencia, Valencia, España). Tesis Doctoral.

García-Pascual, P., Sanjuán, N., Melis, R., Mulet, A. (2006). Morchella esculenta (morel) rehydration process modeling. Journal of Food Engineering, 72(4): 346353.

García-Pérez, J.V. (2007a). Contribución al estudio de la aplicación de ultrasonidos de potencia en el secado convectivo de alimentos, (Universidad Politécnica de Valencia, Valencia, España). Tesis Doctoral.

García-Pérez, J.V. Carcel, J. A., Benedito, J., Mulet, A. (2007b). Power ultrasound mass transfer enhancement in food drying. Food and Bioproducts Processing, 85:247-254.

García-Pérez, J. V., Cárcel, J. A., de la Fuente-Blanco, S., Riera-Franco de Sarabia, E. (2006a). Ultrasonic drying of foodstuff in a fluidized bed: Parametric study. Ultrasonics, 44, 539:543.

García-Pérez, J. V., Rosselló, C., Cárcel, J. A., de la Fuente, S. and Mulet, A. (2006b). Effect of air temperature on convective drying assisted by high power ultrasound. Defect and Diffusion Forum, 258-260, 563-574.

Genskow, L.R., Beimesch, W.E., Hecht, J.P., Kemp, I.C., Langrish, T.,Schwartzbach, C., Smith, L. (2008). Psychrometry, evaporative cooling, and solids drying. En: Green, D.W., Perry, R.H. (eds.), Perry's Chemical Engineers' Handbook, 8 edn. (McGraw-Hill, USA).

Ghodake, H.M.,Goswami, T.K., Chakraverty, A. (2006). Mathematical modeling of withering characteristics of tea leaves. Drying Technology, 24: 159-164.

Gunasekaran, S. (1999). Pulsed Microwave-Vacuum Drying of Food. Drying Technology, 17: 395-412.

Hallström, B., Gekas, V., Sjöholm, I., Romulus, A.M. (2007). Mass transfer in foods. En: Heldman, D.R., Lund, B.B. (eds.), Handbook of food engineering (CRC Press, New York, USA). 
Hanci, S., Sahin, S. and Yilmaz, L. (2003). Isolation of volatile oil from thyme (Thymbra spicata) by steam distillation. Nahrung, 47, 252-255.

Handa, S.S., Preet, S., Khanuja, S., Longo, G., Rakesh, D.D. (2008). Extraction Technologies for Medicinal and Aromatic Plants, (United Nations Industrial Development Organization and the International Centre for Science and High Technology), Trieste.

Hayakawa, K.I., Furuta, T. (1988). Thermodynamically interactive heat and mass transfer coupled with shrinkage and chemical reaction. In Food Properties and Computer-aided Engineering of Fodd-processing System, Ed R.P. Singh \& A.G. Medina. Kluwer Academic Pub., Dordrecht, Boston \& London.

Herman, E., Rodríguez, G. C., García, M. A. (2001). Mathematical modelling for fixed-bed drying considering heat and mass transfer and interfacial phenomena. Drying Technology, 9(1), 137-154.

Hossain, M.B., Barry-Ryan, C., Martin-Diana, A. B., Brunton, N. P. (2010). Effect of drying method on the antioxidant capacity of six Lamiaceae herbs. Food Chemistry, 123: 85-91.

Hossain, M. B., Brunton, N. P., Barry-Ryan, C., Martin-Diana, A. B., Wilkinson, M. (2008). Antioxidant activity of spice extracts and phenolics in comparison to synthetic antioxidants. Rasayan Journal of Chemistry, 1(4): 751-756.

Hottel, H.C., Noble, J.J., Sarofim, A.F., Silcox, G.D., Wancat, P.C., Knaebel, K.S. (2008). Heat and mass transfer. En: Green, D.W., Perry, R.H. (eds.), Perry's chemical engineers' handbook, 8 edn. (McGraw-Hill, New York, USA).

Islam, R., Ho, J.C., Mujumdar, A.S. (2003). Convective drying with time varying heat input: Simulation results. Drying Technology, 21(7): 1333- 1356.

Jarén, C. (2005). Perfil del consumidor de frutas, hábitos y tendencia. Fruticultura Professional, 149: 72-78.

Jayaraman, K.S., Das Gupta, D.K. (2006). Drying of fruits and vegetables.En: Mujumdar, A.S. (ed.), Handbook of Industrial Drying, 3 edn. (CRC Press, Boca Raton, FL, USA).

Jumah, R. (2005a). Modelling and simulation of continuous and intermittent radio frequency-assisted fluidized bed drying of grains. Food and Bioproducts Processing, 83: 203-210.

Jumah, R., Mujumdar, A.S. (2005b). Modeling intermittent drying using an adaptive neuro-fuzzy inference system. Drying Technology, 23: 1075- 1092. 
Jumah, R.Y., Mujumdar, A.S., Raghavan, G.S.V. (1996). A mathematical model for constant and intermittent batch drying of grains in a novel rotating jet spouted bed. In: Turner, I., Mujumdar, A.S. (Eds.), Mathematical modeling and numerical techniques in drying technology. Marcel Dekker, New York, pp. 339-380.

Kajuna, S., Silayo, V., Mkenda, A., Makungu, P. (2001). Thin layer drying of diced cassava roots. African Journal of Science and Technology, 2:94-100.

Kaloustian, J., Abou, L., Mikail, C., Amiot, M. J., Portugal, H.( 2005). Southern french thyme oils: Chromatographic study of chemotypes. Journal of the Science of Food and Agriculture, 85(14): 2437-2444.

Karathanos,V.T. (1999). Determination of water content of dried fruits by drying kinetics. Journal of Food Engineering, 39: 337-344.

Konak, M., Carman, K., Aydin, C. (2002). Physical properties of chickpea seeds. Biosystems Engineering, 82(1): 73-78, doi:10.1006/bioe.2002.0053.

Krokida, M. K., Panagiotou, N. M., Maroulis, Z. B., Saravacos, G. D. (2001). Thermal conductivity: literature data compilation for foodstuffs. International Journal of Food Properties, 4(1), 111-137.

Kutta, G., Pluhár, Zs., Sárosi, Sz. (2007). Yield and composition of supercritical fluid extracts of different Lamiaceae herbs. International Journal of Horticultural Science, 13 (2): 79-82.

Law, C. L., Waje, S., Thorat, B. N., \& Mujumdar, A. S. (2008). Innovation and recent advancement in drying operation for postharvest processes. Stalwart Postharvest Review, 4(1), 1-23.

Lee, J.H. and Kim, H.J. (2008). Drying kinetics of onion slices in a hot-air dryer. Journal of Food Science \& Nutrition, 13: 225-230.

Lee, S.J.,Umano,K., Shibamoto, T., Lee, K.G. (2005). Identification of volatile components in basil (Ocimum basilicum L.) and thyme leaves (Thymus vulgaris L.) and their antioxidant properties. Food Chemestry, 91: 131-137.

Levenberg, K, A. (1944). Method for the solution of certain non-linear problems in least squares. Quarterly of Applied Mathematics. 2 (2): 164-168.

Li, Y. B., Cao, C. W., Yu, Q. L., Zhong, Q. X. (1999). Study on Rough Rice Fissuring during Intermittent Drying. Drying Technology, 17:1779- 1793.

Liang, H. (1993). Modelling of ultrasound assisted and osmotically induced diffusion in plant tissue. Doctoral dissertation, Perdue University. 
López, J., Uribe, E., Vega-Gálvez, A., Miranda, M., Vergara, J., Gonzalez, E. (2010). Effect of air temperature on drying kinetics, vitamin C, antioxidant activity, total phenolic content, non-enzymatic browning and firmness of blueberries variety O’Neil. Food and Bioprocess Technology.,doi:10.1007/s11947-009-0306-8.

Lu, H.F., Zheng, H., Lou, H.Q., Jiang, L.L,, Chen, Y., Fang, S.S. 2010. Using neural networks to estimate the losses of ascorbic acid, total phenols, flavonoid, and antioxidant activity in asparagus during thermal treatments. Journal of Agriculture and Food Chemistry, 58, 2995-3001.

Marinos-Kouris, D., Maroulis, Z.B. (2006). Transport properties in the drying of solids. En: Mujumdar, A.S. (ed.), Handbook of Industrial Drying, 3 edn. (CRC Press, Boca Raton, FL, USA), pp. 81-119.

Marinos-Kouris, D., Maroulis, Z. B. (1995). Transport properties in the drying of solids. En: Handbook of Industrial Drying (Mujumdar A S, ed), Vol. 1 (2nd Edn.), pp 13-159. Marcel Decker, Inc., New York.

Marquardt, DW. (1963). An algorithm for least-squares estimation of nonlinear parameters. Journal of the Institute of Mathi-matics and its Application, 2 (2): 431441.

Mason, T. J., Riera, E., Vercet, A., and Lopez-Buesa, P. (2005). Applications of ultrasound. In: Sun, D. (ed.), Emerging technologies for food processing, pp. 323351. Amsterdam, Elsevier.

Mikleš, J., Fikar, M. (2007). Process modelling, identification, and control, (Springer, NY, USA).

Molnár, K. (2006). Experimental techniques in drying. En: Mujumdar, A.S. (ed.), Handbook of Industrial Drying, 3 edn. (CRC Press, Boca Raton, FL, USA).

Moyler, D.A. (1993). Extraction of flavours and fragrances with compressed CO2. In:King, M.B., Bott, T.R. (Eds.), Extraction of Natural Products Using Near Critical Solvents. Blackie Academic \& Professional, Glagow, UK, pp. 140-183.

Mujumdar, A. S. (2007). An overview of innovation in industrial drying: Current status and R\&D needs, Transport in Porous Media, 66: 3-18.

Mujumdar, A.S. (2006). Principles, classification and selection of dryers. En: Mujumdar, A.S. (ed.), Handbook of Industrial Drying, 3 edn. (CRC Press, Boca Raton, FL, USA), pp. 3-32.

Mujumdar, A.S. (2004). Research and developments in drying: recent trends and future prospects. Drying Technology, 22(1): 1-26. 
Mukhopadhyay, M. (2000). Natural Extracts Using Supercritical Carbon Dioxide. CRC Press, Boca Raton, FL.

Mulet, A., Blasco, M., García-Reverter, J., García-Pérez, J.V. (2005). Drying kinetics of Curcuma longa rhizomes. Journal of Food Science, 7: 318-323.

Mulet, A., Cárcel, J., Benedito, J., Rosselló, C., Simal, S. (2003). Ultrasonic mass transfer enhancement in food processing, In Transport Phenomena in Food processing, (Ed. Welti-Chanes, J., Vélez-Ruiz, J., Barbosa-Canova, G., CRC Press, New York, EEUU).

Mulet, A., García-Pascual, P., Sanjuán, N., García-Reverter, J. (2002). Equilibrium isotherms and isosteric heats of morel (Morchella esculenta). Journal of Food Engineering, 53: 75-81.

Mulet, A. (1994). Drying modelling and water diffusivity in carrots and potatoes. Journal of Food Engineering, 22: 329-348.

Muñoz F. (1993). Plantas medicinales y aromáticas, Estudio del cultivo y procesado, (Mundi Prensa, Madrid).

Nimkar, P. M., Chattopadhyay, P. K. (2001). Some physical properties of green gram. Journal of Agricultural Engineering Research, 80(2): 183-189, doi:10.1006/jaer.2000.0664.

Ortuño, C., Pérez-Munuera, I., Puig, A., Riera, E., García-Pérez, J.V. (2010). Influence of power ultrasound application on mass transport and microstructure of orange peel during hot air drying. Physics Procedia, 3:153-159.

Ozcan, M., Arslan, D., Unver, A. (2005). Effect of drying methods on the mineral content of basil (Ocimum basilicum L.). Journal of Food Engineering, 69:375-379.

Ozuna, C. Cárcel., García-Pérez, J.V., Mulet, A. (2011). Improvement of water transport mechanisms during potato drying by applying ultrasound. Journal Science Food Agriculture, DOI 10.1002/jsfa.4344.

Pan, Y. K., Zhao, L. J., Dong, Z. X., Mujumdar, A. S., Kudra, T.(1999a). Intermittent Drying of Carrot in a Vibrated Fluid Bed: Effect on Product Quality. Drying Technology, 17: 2323-2340.

Pan, Y.K., Zhao, L.J., Hu, W.B. (1999b). The effect of tempering-intermittent drying on quality and energy of plant materials. Drying Technology, 17(9): 1795-1812.

Parlak, A., Islamoglu, Y., Yasar, H., Egrisogut. A. (2006). Application of artificial neural network to predict specific fuel consumption and exhaust temperature for a diesel engine. Applied Thermal Engineering, 26: 824-828. 
Perera, C.O. (2005). Selected quality attributes of dried foods. Drying Technology, 23(4): 717-730.

Perry, R.H.; Green, D.W.; Maloney, J.O. Perry's Chemical Engineers Handbook; seventh ed. McGraw-Hill: USA, 1997.

Pierce, Andrea. (1999). American Pharmaceutical Association Practical Guide to Natural Medicines, (New York: Stonesong Press. P. 338-340).

Poling, B.E., Prausnitz, J.M., O'Connell, J.P. (2000). The properties of gases and liquids, 5 edn., (McGraw-Hill, USA).

Pugin, B., Turner, A. T. (1990). Influence of ultrasound on reaction with metals. In: Mason, T. J. (ed.), Advances in sonochemistry, pp. 81-118. London, JAI Press.

Raghavan, G.S.V., Orsat, V. (2006). Recents advances in drying of biomaterials for superior quality bio-products, Proceedings of the 15th International Drying Symposium IDS, A: 44-53.

Rahimmalek, M., \& Hossein-Goli, S.A. (2013). Evaluation of six drying treatments with respect to essential oil yield, composition and color characteristics of Thymys daenensis subsp. daenensis. Celak leaves. Industrial Crops and Products, 42: 613-619.

Rahman, M. S. (1995). Food properties handbook. Boca Raton, FL: CRC Press.

Raj, B., Rajendran, V., Palanichamy, P. (2004). Science and technology of ultrasonics. Alpha Science International, Oxford, Reino Unido.

Ramaswamy, H., Marcotte, M. (2005). Food processing: principles and applications, (Taylor \& Francis, Boca Raton, FL, USA).

Ramaswamy, H.S., Wil, T.P., Fakhauri, M. (1991). Distribution and equalization of temperature in a microwave heated food model. ASAE paper No. 91-3518, ASAE, St. Joseph, MI 49085.

Ramsewak, R. S., Nair, M. G., Stommel, M. Selanders, L. (2003). In vitro antagonistic activity of monoterpenes and their mixtures against 'toe nail fungus' pathogens, Phytotherapy Research,17 (4): 376-379.

Reverchon, E., De Marco, I. (2006). Supercritical fluid extraction and fractionation of natural matter. Journal Supercritical Fluids, 38 (2): 146-166.

Reverchon, E. (1997). Supercritical fluid extraction and fractionation of essential oils and related products, The Journal of Supercritical Fluids, 10 (1): 1-37. 
Reyes, A., Alvarez, P.I., Marquardt, F.H. (2002). Drying of carrots in a fluidized bed. I. Effects of drying conditions and modeling. Drying Technology, 20(7): 14631483.

Rhim, J.W., Kim, J.H. Jeong, W.C. (2007). Dehydration kinetics of rehmannia (Rehmannia glutinosa Liboschitz). Food Science Biotechnology, 16:771-777.

Riera, E., Golás, Y., Blanco, A., Gallego, J.A., Blasco, M., Mulet, A. (2004). Mass transfer enhancement in supercritical fluids extraction by means of power ultrasound. Ultrasonics Sonochemistry, 11: 241-244.

Riera, E., Gallego-Juárez, J. A., Rodríguez, G., Acosta, V. M., and Andrés, E. (2002). Applications of high-power ultrasound for drying vegetables, Revista de Acústica, 33:1-6.

Roberts, J.S., Kidd, D.R., Padilla-ZAkour, O. (2008). Drying kinetics of grape seeds. Journal of Food Engineering, 89: 460-465.

Rocha, R., Melo, E. C., Bon, J. Radünz L. L., Berbert, P.A., Donzeles, S., Tabar, Jon. (2012). Cinética del secado de tomillo. Revista Brasileira de Engenharia Agrícola e Ambiental, 16 (6):675-683.

Rosselló, C., Simal, S., Sanjuán, N., and Mulet, A. (1997). Nonisotropic mass transfer model for green bean drying. Journal of Agriculture and Food Chemistry, 45: 337-342.

Sablani, S.S. (2006). Drying of fruits and vegetables: Retention of nutritional/functional quality. Drying Technology, 24(2): 123-135.

Sahena, F., Zaidul, I.S.M., Jinap, S. Karim, A.A., Abbas, K.A, Norulaini, N.A.N., Omar, A.K.M. (2009). Application of supercritical CO2 in lipid extraction. A Review Journal of Food Engineering, 95:240-253.

Sahin, S., Sumnu, S.G. (2006). Physical properties of foods, (Springer, USA).

Sajas, J. F., Gorbatow, W. M. (1978). Use of ultrasound in meat technology, Fleischwirtschaft, 58:1009-1021.

Sanjuán, N., Cárcel, J.A., Clemente, G., Mulet, A. (2001). Modelling of the rehydration process of brocolli florets. European Food Research and Technology, 212(4): 449-453.

Santos, P.H.S.; Silva, M.A. (2009) Kinetics of L-ascorbic degradation in pineapple drying under ethanolic atmosphere. Drying Technology, 27, 947-954.

Saravacos, G.D., Maroulis, Z.B. (2001). Transport properties of foods, (Marcel Dekker, New York, USA). 
Saura-Calixto, F., \& Goñi, I. (2006). Antioxidant capacity of the Spanish Mediterranean diet. Food Chemistry, 94, 442-47.

Shan, B., Cai, Y. Z., Sun, M., Corke, H. (2005). Antioxidant capacity of 26 spice extracts and characterization of their phenolic constituents. Journal Agriculture Food Chemistry, 53: 7749-7759.

Sharma, G.P., Prasad, S. (2004). Effective moisture diffusivity of garlic cloves undergoing microwave-convective drying. Journal of Food Engineering, 65: 609617.

Shati, A.A., Elsaid, F.G. (2009). Effects of water extracts of thyme (Thymus vulgaris) and ginger (Zingiber officinale Roscoe) on alcohol abuse. Food and Chemical Toxicology, 47: 1945-1949.

Simal, S., Garau, M.C., Femenia, A., Rosselló, C. (2006). A diffusional model with a moisture-dependent diffusion coefficient. Drying Technology, 24: 1365-1372.

Simal, S., Femenia, A., Garau, M.C., Rosselló, C. (2005). Use of exponential, Pages and difusional models to simulate the drying kinetics of kiwi fruit. Journal of Food Engineering, 66: 323-328.

Simal, S., Sánchez, E., Bon, J., Femenia, A., and Rosselló, C. (2001). Water and salt diffusion during cheese ripening: Effect of external and internal resistance to mass transfer. Journal of Food Engineering, 48:269-275.

Simal, S., Benedito, J., Sánchez, E. S., and Rosselló, C. (1998). Use of ultrasound to increase mass transport rates during osmotic dehydration. Journal of Food Engineering, 36:323-336.

Simeon de Bouchberg, M., Allegrini, J., Bessiere, C., Attisso, M., Passet, J., Granger, R. (1976). Proprietes microbiologiques des huiles essentielles de chimiotypes de Thymus vulgaris Linnaeus, Riv Ital EPPOS, 58: 527 - 36.

Singh, R.P.; Heldman, D.R. (2001).Introduction to Food Engineering; third ed. Academic Press: Glasgow, Great Britain.

Soysal Y. and Oztekin S. (2001a). Comparison of seven equilibrium moisture content equations for some medicinal and Aromatic. Journal of Agricultural Engineering Research, 78(1):57-63.

Soysal, Y., Oztekin S. (2001b). Sorption Isosteric Heat for some Medicinal and Aromatic Plants. Journal of Agricultural Engineering Research, 78 (2): 159-166.

Stahl, E., Quirin, K.W., Gerard, D. (1988). Dense Gases for Extraction and Refining, (Springer-Verlag, Berlin, Germany). 
Sun, D.W., Woods, J. L. (1994). The selection of sorption isotherm equations for wheat based on the "fitting of available data. Journal of Stored Product Research, 30(1):27-43.

Sun, D. W. Woods, J. L. (1993). The moisture content/relative humidity equilibrium relationship of wheat, A Review. Drying Technology, 11(7): 1523-1551.

Sutar, P.P., Prasad, S. (2008) Microwave Drying Technology-Recent Developments and R\&D Needs in India. In proceedings of 42nd ISAE Annual Convention.

Suvarnakuta, P.; Devahastin, S.; Mujumdar, A.S. (2005). Drying kinetics and bcarotene degradation in carrot undergoing different drying processes. Journal of Food Science, 70(8), s520-s526.

Tarleton, E.S., Wakeman, R.J.,(1998). Ultrasonically assisted separation process, in: M.J.W. Povey, T.M. Mason (Eds.), Ultrasounds in Food Processing, Blackie Academic and Professional, London.

Tarleton, E.S. (1992). The role of field-assisted techniques in solid/liquid separation, Filtr. Sep. 246-253.

The MathWorks (2009). MATLAB User's Guide. SouthNatick, MA: The MathWorks Inc.

Timoumi, S.; Mihoubi, D.; Zagrouba, F. (2007). Shrinkage, vitamin C degradation and aroma losses during infra-red drying of apple slices. Swiss Society of Food Science and Technology, 40, 1648-1654.

Treybal, R. E. (1980). Mass-transfer operations (2nd ed.). USA: McGraw-Hill.

Tripathy, P.P., Kumar, S. (2009). Neural network approach for food temperature prediction during solar drying. International Journal of Thermal Sciences, 48: 14521459 .

Van den Berg, C., Bruin, S. (1981). Water activity and its estimation in food systems: theoretical aspects. In: Water Activity: Influences on Food Quality (Rockland L B; Steward G F, eds). Academic Press, New York, USA.

Van den Broucke, C.O. (1983). The therapeutic value of Thymus species, Fitoterapza, 54:171-174.

Váquiro, H., (2009). Contribución al estudio y optimización del secado intermitente: aplicación al secado de mango (Mangifera indica $L$ var. Tommy Atkins), (Universidad Politécnica de Valencia, Valencia, España). Tesis Doctoral. 
Varnalis, A.I.; Brennan, J.G.; Macdougall, D.B. (2001). A proposed mechanism of high temperature puffing of potato. Part I. The influence of blanching and drying conditions on the colume of puffed cubes. Journal of food Engeneering, 48: 361367.

Venskutonis, R. (1997). Effect of drying on the volatile constituents of thyme (Thymus vulgaris L.) and sage (Salvia officinalis L.). Food Chemistry, 59: 219-227.

Walde, S.G., Velu, V., Jyothirmayi, T., Math, R.G. (2006). Effects of pretreatments and drying methods on dehydration of mushroom. Journal of Food Engineering, 74: 108-115.

Walstra, P. (2003). Physical chemistry of foods, (Marcel Dekker, New York).

Wang, Z., Sun, J., Liao, X., Chen, F., Zhao, G., Wu, J., Hu, X. (2007). Mathematical modeling on hot air drying of thin layer apple pomace. Food Research International, 40:39-46.

Xanthopoulos, G., Lambrinos, G.R., Manolopoulou, H. (2007). Evaluation of thinlayermodels formushroom (Agaricus bisporus) drying. Drying Technology, 25:1471-1481.

Yaldiz, O., Ertekin, C. ( 2001). Thin layer solar drying of some different vegetables. Drying Technology, 19:586-596.

Zhang, M., Tang, J., Mujumdar, A.S., Wang, S. (2006). Trends in microwave related drying of fruits and vegetables. Trends in Food Science \& Technology, 17: 524-534.

Zhou, W. and Therdthai, N. (2010). Special topics in Food Engineering: Artificial neural networks in food processing, In D. Sun (Ed), Mathematical Modeling of Food Processing (pp. 901-920). Boca Raton: CRC Press. 
9. ANEXOS 



\section{ANEXO 1. MODELO DE TRANSFERENCIA DE CALOR Y DE MATERIA EN EL LECHO}

\section{i. Fenómenos de transporte en la hoja de tomillo}

Transferencia de materia

A partir del balance de agua en régimen no estacionario en un volumen control de la hoja (Figura 3.6) se obtiene la ecuación 9.1,

$0=\frac{\partial\left(m_{w} A\right)}{\partial x} d x+\frac{\partial M_{w}}{\partial t}$

donde $m_{w}$ es el flujo de materia por unidad de área, $A$ es el área de sección transversal de la hoja y $M_{w}$ es la masa de agua de la hoja de tomillo.

Considerando que el sólido no se contrae durante el proceso de secado y definiendo la masa de agua en el volumen control de la hoja como $M_{w}=\rho_{d s} \tau d x$, se deduce la ecuación 9.2, donde $\tau$ es el contenido de humedad de la hoja, y $\rho_{d s}$ es la densidad del sólido seco.

$0=\frac{\partial\left(m_{w} A\right)}{\partial x} d x+\rho_{d s} \frac{\partial \tau}{\partial t}$

Asumiendo que el principal mecanismo de transporte de humedad a través del material es la difusión, el flujo de materia puede ser expresado aplicando la ley particular de Fick (Ec. 9.3), donde $D$ representa la difusividad efectiva.

$m_{w}=-D \rho_{d s} \frac{\partial \tau}{\partial x}$

Introduciendo la ecuación 9.3 en la ecuación 9.2 se obtiene la ecuación de gobierno que representa el balance de materia en la hoja.

$0=-\frac{\partial}{\partial x}\left(D \rho_{d s} \frac{\partial \tau}{\partial x}\right)+\rho_{d s} \frac{\partial \tau}{\partial t}$

Transferencia de calor

Según el balance de energía en régimen no estacionario para la hoja (Figura 3.6), la transferencia de calor al interior del sólido, al considerar tanto la energía térmica transferida por conducción como la energía térmica asociada a la masa que se difunde, se puede expresar como:

$$
0=\frac{\partial\left(m_{w} h_{w}\right)}{\partial x} d x+\frac{\partial(q A)}{\partial x} d x+\frac{\partial H}{\partial t}
$$


donde $q$ es el flujo de calor por unidad de área, $h_{w}$ es la entalpía específica asociada a la cantidad de materia que se transfiere y $H$ es la entalpía en el volumen control de la hoja.

Relacionado la entalpía del volumen control $(H)$ con las entalpías específicas del agua pura $\left(h_{w}\right)$ y del sólido seco $\left(h_{d s}\right)$, se obtiene,

$$
0=\frac{\partial\left(m_{w} h_{w}\right)}{\partial x} d x+\frac{\partial(q A)}{\partial x} d x+M_{d s} \frac{\partial}{\partial t}\left(h_{d s}+\tau h_{w}\right)
$$

Al ser la entalpía una función de estado pueden ser definidas como,

$$
h_{w}=h_{w T_{r e f}}+\int_{T_{r e f}}^{T} C p_{w} d T \wedge h_{d s}=h_{d s T_{r e f}}+\int_{T_{r e f}}^{T} C p_{d s} d T
$$

donde $T_{r e f}$ es una temperatura de referencia; y $C p_{w}$ y $C p_{d s}$ son los calores específicos del agua pura y de la materia seca, respectivamente.

Los flujos de calor por unidad de área pueden ser expresados aplicando la ley particular de Fourier (Ec. 9.8), ya que se considera transferencia de calor por conducción en el interior del sólido.

$$
q=-\kappa \frac{\partial T}{\partial x}
$$

Sustituyendo las Ecs. (9.3), (9.7) y (9.8) en la Ec. (9.6), y reorganizando se obtiene,

$$
\begin{aligned}
& D \rho_{d s} \frac{\partial \tau}{\partial x} C p_{w}(T) \frac{\partial T}{\partial x}+\frac{\partial}{\partial x}\left(-\kappa \frac{\partial T}{\partial x}\right)= \\
& \rho_{d s}\left[C p_{d s}(T)+C p_{w} \tau(T)\right] \frac{\partial T}{\partial t}
\end{aligned}
$$

Considerando una distancia adimensional, como muestra la ecuación 9.10, finalmente se obtiene la ecuación de gobierno para la transferencia de calor en la hoja (Ec. 9.11)

$$
z=\frac{x}{L} \wedge z \in[0,1]
$$




$$
\begin{aligned}
\frac{D}{L^{2}} \rho_{d s} \frac{\partial \tau}{\partial z} C p_{w}(T) \frac{\partial T}{\partial z}= & -\frac{\partial}{\partial z}\left(\frac{\kappa}{L^{2}} \frac{\partial T}{\partial z}\right)+ \\
& \rho_{d s}\left[C p_{d s}(T)+C p_{w} \tau(T)\right] \frac{\partial T}{\partial t}
\end{aligned}
$$

Condiciones iniciales y de contorno

Para resolver las ecuaciones en derivadas parciales que definen las ecuaciones de gobierno, es necesario establecer condiciones iniciales y las condiciones físicas que existen en la frontera del sólido.

Si se asume que la distribución de la humedad y de la temperatura dentro del sólido al inicio del proceso es uniforme, las condiciones iniciales son:

$t=0 \rightarrow \mid \begin{aligned} & \tau(z, 0)=\tau_{0} \\ & T(z, 0)=T_{0}\end{aligned}$

Como el origen del sistema de coordenadas se encuentra en el centro de la lámina (volumen control de la hoja), se asume que existe simetría en la distribución de la humedad y de la temperatura.

$t>0 \rightarrow \mid \begin{aligned} & \frac{\partial \tau}{\partial z}(0, t)=0 \\ & \frac{\partial T}{\partial z}(0, t)=0\end{aligned}$

La transferencia de materia entre el sólido y el aire que está en contacto con él puede ser expresada asumiendo que el agua que se difunde hacia la superficie por unidad de área se evapora a la misma velocidad (equilibrio dinámico) (Ec. 9.14),

$$
m_{w}(1, t)=m_{v}(1, t)
$$

siendo $m_{w}$ el flujo de agua por unidad de área hacia la superficie del material, y $m_{v}$ el flujo convectivo de vapor de agua por unidad de área desde la superficie del material hacia el aire de secado, los cuales se definen matemáticamente como

$$
\begin{aligned}
& m_{w}=-\frac{D}{L^{2}} \rho_{d s} \frac{\partial \tau}{\partial z}(1, t) \\
& m_{v}=\frac{h_{m v}}{L}\left[C_{s}-C_{\alpha}\right]
\end{aligned}
$$


donde $L$ es el semi-espesor de la lámina; $h_{m v}$ es el coeficiente promedio de transferencia de materia por convección, $C_{s}$ es la concentración de vapor de agua en la interfase con el sólido, y $C_{\alpha}$ es la concentración media de vapor de agua en el aire fuera de la capa límite.

Considerando que la humedad del aire que está en contacto con el sólido se encuentra en equilibrio $\left(X_{e q}\right)$ con la humedad de la superficie del sólido, se obtiene la ecuación 9.17, que representa el equilibrio dinámico del agua que se difunde hacia la superficie por unidad de área y que se evapora a la misma velocidad.

$$
-\frac{D}{L^{2}} \rho_{d s} \frac{\partial \tau}{\partial z}(1, t)=\frac{h_{m v}}{L}\left[\rho_{d a i} X_{e q}-\rho_{d a} X_{a}\right]
$$

Por otro lado, la ecuación 9.18 expresa la consideración de que el calor transmitido por convección entre el aire y el sólido es utilizado tanto para elevar la temperatura del material como para evaporar el agua que llega a la superficie,

$$
q_{s}(1, t)=q_{c}(1, t)+q_{v}(1, t)
$$

siendo el flujo de calor por convección por unidad de área desde el aire hacia la superficie $\left(q_{s}\right)$ puede expresarse a través de la ley particular de Newton,

$$
q_{s}(1, t)=h\left(T(1, t)-T_{a}\right)
$$

donde $h$ es el coeficiente promedio de transferencia de calor por convección, $T$ es la temperatura en la superficie del sólido y $T_{a}$ es la temperatura en el aire fuera de la capa límite.

El flujo de calor por conducción por unidad de área desde la superficie hacia el interior del sólido $\left(q_{c}\right)$ puede ser expresado con la ley particular de Fourier,

$$
q_{c}(1, t)=-\frac{\kappa}{L^{2}} \frac{\partial T}{\partial z}(1, t)
$$

El flujo de calor por unidad de área necesario para evaporar el agua que llega a la superficie $\left(q_{v}\right)$, se describe en la ecuación 9.21, donde $\lambda$ es el calor latente de de cambio de estado del agua.

$$
q_{v}(1, t)=m_{v}(1, t) \lambda=-\frac{D}{L^{2}} \rho_{d s} \frac{\partial \tau}{\partial z}(1, t) \lambda
$$

Sustituyendo las Ecs. (9.19) - (9.21) en la Ec. (9.18), se obtiene la condición de contorno para la transferencia de calor en el volumen de control. 


$$
-\frac{\kappa}{L^{2}} \frac{\partial T}{\partial z}(1, t)=h\left(T(1, t)-T_{a}\right)-\frac{D}{L^{2}} \rho_{d s} \frac{\partial \tau}{\partial z}(1, t) \lambda
$$

\section{i.i. Fenómenos de transporte en el lecho}

\section{Transferencia de calor}

Realizando un balance de energía en régimen no estacionario para el lecho poroso (Figura 3.6),

$$
m_{a} h_{a i}=m_{a} h_{a e}+\frac{d H_{b}}{d t} \Rightarrow m_{a}\left(h_{a i}-h_{a e}\right)=\frac{d H_{b}}{d t}
$$

donde $m_{a}$ es el flujo de aire a través del lecho (se considera constante), $h_{a i}$ y $h_{a e}$ son las entalpías específicas del aire a la entrada y salida del lecho (el subíndice $i$ denota condición de entrada y $e$ condición de salida) y $H_{b}$ es la entalpía de todo el lecho.

La entalpía específica del aire $\left(h_{a}\right)$ puede expresarse como función de la entalpía del aire seco $\left(h_{d a}\right)$ y la entalpía del vapor de agua $\left(h_{v}\right)$, siendo $X$ la humedad del aire en base seca

$$
h_{a}=h_{d a}+X h_{v}
$$

Por lo tanto:

$$
h_{a i}-h_{a e}=h_{d a i}-h_{d a e}+X_{i} h_{v i}-X_{e} h_{v e}
$$

donde $X_{i}$ y $X_{e}$ son la humedad del aire a la entrada y la salida del lecho respectivamente, y $h_{v i}$ y $h_{v e}$ son la entalpía del vapor de agua a la entrada y a la salida del lecho.

Al ser la entalpía una función de estado:

$$
\begin{gathered}
h_{d a i}=h_{d a e}+\int_{T_{a e}}^{T_{a i}} C p_{d a} d T_{a} \\
h_{v i}=h_{v e}+\int_{T_{a e}}^{T_{a i}} C p_{v} d T_{a}
\end{gathered}
$$

donde $T_{a}$ es la temperatura del aire, $T_{a i}$ es la temperatura del aire a la entrada, y $C p_{d a}$ y $C p_{v}$ son los calores específicos del aire seco y del vapor de agua, respectivamente. 
Reemplazando las ecuaciones 9.26 y 9.27 en la ecuación 9.25 y agrupando términos se obtiene,

$$
h_{a i}-h_{a e}=\int_{T_{a e}}^{T_{a i}}\left(C p_{d a}+X_{i} C p_{v}\right) d T_{a}+h_{v e}\left(X_{i}-X_{e}\right)
$$

Definiendo la energía térmica almacenada en el lecho $\left(H_{b}\right)$ en función de las entalpías específicas del aire $\left(H_{a}\right)$ y de todas las hojas del lecho $\left(H_{s}\right)$, se obtiene,

$$
H_{b}=H_{a}+H_{s}
$$

Por lo tanto,

$$
\frac{d H_{b}}{d t}=\frac{d H_{a}}{d t}+\frac{d H_{s}}{d t}
$$

$H_{a}$ estárelacionada con la entalpía del aire seco y la del vapor de agua y $H_{s}$ con la entalpía del sólido seco y el agua del lecho.

$$
\begin{aligned}
& H_{a}=m_{a}\left(h_{d a}+\bar{X} h_{v}\right) \\
& H_{s}=H_{d s}+H_{w}=M_{d s}\left(h_{d s}+\bar{\tau} h_{w}\right)
\end{aligned}
$$

De la ecuación 9.31 se deduce,

$$
\frac{d H_{a}}{d t}=m_{a}\left[\frac{d h_{d a}}{d t}+\bar{X} \frac{d h_{v}}{d t}+h_{v} \frac{d \bar{X}}{d t}\right]
$$

y por definición de entalpía a presión constante,

$$
\frac{d H_{a}}{d t}=m_{a}\left[C p_{d a}\left(T_{a}\right) \frac{d T_{a}}{d t}+\bar{X} C p_{v}\left(T_{a}\right) \frac{d T_{a}}{d t}+h_{v} \frac{d \bar{X}}{d t}\right]
$$

Reagrupando términos finalmente se obtiene la ecuación 9.35:

$$
\frac{d H_{a}}{d t}=m_{a}\left[C p_{d a}\left(T_{a}\right)+\bar{X} C p_{v}\left(T_{a}\right)\right] \frac{d T_{a}}{d t}+m_{a} h_{v} \frac{d \bar{X}}{d t}
$$

Al ser un lecho poroso, y definiendo la porosidad como la relación del volumen del aire en el lecho $\left(V_{a}\right)$ y el volumen del lecho $(V)$

$$
\varepsilon=\frac{V_{a}}{V}=\frac{\left(V-V_{s}\right)}{V}=1-\frac{M_{d s}}{\left(\rho_{d s} V\right)}
$$


la masa del sólido seco $\left(M_{d s}\right)$ puede ser expresada en función de la porosidad.

$$
M_{d s}=(1-\varepsilon) \rho_{d s} V
$$

Para determinar $H_{s}$, se requiere estimar el número de hojas de tomillo en el lecho $\left(N u_{s}\right)$ y a entalpía de cada hoja en el lecho $\left(H_{s u}\right)$

$$
H_{s}=N_{u s} H_{s u}
$$

El número de hojas se puede estimar a partir de la relación del volumen del sólido en el lecho $\left(V_{p)}\right.$ y del volumen de una hoja $\left(V_{u}\right)$.

$$
N u_{S}=\frac{V_{p}}{V_{u}}=\frac{(1-\varepsilon) V}{2 A L}
$$

Considerando $h_{u}$ como la entalpia (en base seca) del volumen control diferencial de la hoja:

$$
H_{s u}=2 \int_{0}^{L} \rho_{d s} A h_{u} d x=2 \rho_{d s} A \int_{0}^{L} h_{u} d x=2 \rho_{d s} A \int_{0}^{L}\left(h_{d s}+\tau h_{w}\right) d x
$$

Al agrupar las ecuaciones $9.38,9.39$ y 9.40 se obtiene

$$
H_{s}=\frac{(1-\varepsilon) V \rho_{d s}}{L} \int_{0}^{L}\left(h_{d s}+\tau h_{w}\right) d x
$$

Considerando la distancia adimensional (Ec. 3.11)

$$
\begin{aligned}
& H_{s}=\frac{(1-\varepsilon) V \rho_{d s}}{L} \int_{0}^{1}\left(h_{d s}+\tau h_{w}\right) L d z= \\
& (1-\varepsilon) V \rho_{d s} \int_{0}^{1}\left(h_{d s}+\tau h_{w}\right) d z=M_{d s} \int_{0}^{1}\left(h_{d s}+\tau h_{w}\right) d z
\end{aligned}
$$

Para definir la evolución de la entalpía de sólido en el lecho en función del tiempo:

$$
\begin{aligned}
& \frac{d H_{s}}{d t}=M_{d s} \int_{0}^{1}\left(\frac{d h_{d s}}{d t}+\tau \frac{d h_{w}}{d t}+h_{w} \frac{d \tau}{d t}\right) d z \\
& \frac{d H_{s}}{d t}=M_{d s} \int_{0}^{1}\left(C p_{d s} \frac{d T}{d t}+\tau C p_{w} \frac{d T}{d t}\right) d z+M_{d s} \int_{0}^{1} h_{w} \frac{\partial \tau}{\partial t} d z \\
& \frac{d H_{s}}{d t}=M_{d s} \int_{0}^{1}\left(C p_{d s}+\tau C p_{w}\right) \frac{d T}{d t} d z+M_{d s} \int_{0}^{1} h_{w} \frac{\partial \tau}{\partial t} d z
\end{aligned}
$$


Para resolver la segunda integral y considerando la ecuación 9.4 (ecuación de gobierno de transferencia de materia en una hoja) resulta:

$\int_{0}^{1} h_{w} \frac{\partial \tau}{\partial t} d z=\int_{0}^{1} h_{w} \frac{\partial}{\partial z}\left(\frac{D}{L^{2}} \frac{\partial \tau}{\partial z}\right) d z$

Por lo tanto, resolviendo la integral, y considerando la ecuación 9.14, (ecuación de contorno para establecer el equilibrio dinámico), y la ecuación 9.13 (condición de simetría):

$\int_{0}^{1} h_{w} \frac{\partial}{\partial z}\left(\frac{D}{L^{2}} \frac{\partial \tau}{\partial z}\right) d z=h_{w}(T(1, t)) \frac{D}{L^{2}} \frac{\partial \tau}{\partial z}(1, t)-\int_{0}^{1} \frac{D}{L^{2}} \frac{\partial \tau}{\partial z} C p_{w} \frac{\partial T}{\partial z} d z$

Al sustituir en la ecuación 9.45 y reagrupando términos:

$$
\begin{gathered}
\frac{d H_{s}}{d t}=M_{d s} \int_{0}^{1}\left[\left(C p_{d s}+\tau C p_{w}\right) \frac{\partial T}{\partial t}-\frac{D}{L^{2}} \frac{\partial \tau}{\partial z} C p_{w} \frac{\partial T}{\partial z}\right] d z+ \\
M_{d s} h_{w}(T(1, t)) \frac{D}{L^{2}} \frac{\partial \tau}{\partial z}(1, t)
\end{gathered}
$$

Considerando la ecuación 9.11:

$$
\frac{d H_{s}}{d t}=\frac{M_{d s}}{\rho_{d s}} \int_{0}^{1} \frac{\partial}{\partial z}\left(\frac{\kappa}{L^{2}} \frac{\partial T}{\partial z}\right) d z+M_{d s} h_{w}(T(1, t)) \frac{D}{L^{2}} \frac{\partial \tau}{\partial z}(1, t)
$$

Por lo tanto, considerando también la ecuación 9.13 (condición de simetría),

$$
\frac{d H_{s}}{d t}=\frac{M_{d s}}{\rho_{d s}} \frac{\kappa}{L^{2}} \frac{\partial T}{\partial z}(1, t)+M_{d s} h_{w}(T(1, t)) \frac{D}{L^{2}} \frac{\partial \tau}{\partial z}(1, t)
$$

Teniendo en cuenta la 9.20 (condición de contorno):

$$
\begin{gathered}
\frac{d H_{s}}{d t}=-\frac{M_{d s}}{\rho_{d s}} \frac{h}{L}\left[T(1, t)-T_{a}\right]+\frac{M_{d s}}{\rho_{d s}} \frac{D}{L^{2}} \rho_{d s} \frac{\partial \tau}{\partial z}(1, t) \lambda(T(1, t))+ \\
M_{d s} h_{w}(T(1, t)) \frac{D}{L^{2}} \frac{\partial \tau}{\partial z}(1, t)
\end{gathered}
$$

Reorganizando se obtiene: 


$$
\begin{aligned}
\frac{d H_{s}}{d t}=-\frac{M_{d s}}{\rho_{d s}} \frac{h}{L}\left[T(1, t)-T_{a}\right]+ & \\
& M_{d s} \frac{D}{L^{2}} \frac{\partial \tau}{\partial z}(1, t)\left[\lambda(T(1, t))+h_{w}(T(1, t))\right]
\end{aligned}
$$

Considerando que la entalpía del vapor $\left(h_{v}\right)$ es igual a la entalpía del agua $\left(h_{w}\right)$ más el calor latente de cambio de estado del agua $(\lambda)$ :

$$
\frac{d H_{s}}{d t}=-\frac{M_{d s}}{\rho_{d s}} \frac{h}{L}\left[T(1, t)-T_{a}\right]+M_{d s} \frac{D}{L^{2}} \frac{\partial \tau}{\partial z}(1, t) h_{v}(T(1, t))
$$

Reemplazando las ecuaciones 9.53 y 9.35 en la ecuación 9.30 , y la ecuación resultante en la 9.23 , y sustituyendo en la ecuación 9.28 en la ecuación 9.23 se obtiene la ecuación de gobierno para la transferencia de calor en el lecho.

$$
\begin{aligned}
& m_{a} \int_{T_{a e}}^{T_{a i}}\left(C p_{d a}+X_{i} C p_{v}\right) d T+h_{v s}\left(X_{i}-X_{e}\right) m_{a}=-\frac{M_{d s}}{\rho_{d s}} \frac{h}{L}\left[T(1, t)-T_{a}\right]+ \\
& M_{d s} \frac{D}{L^{2}} \frac{\partial \tau}{\partial z}(1, t) h_{v}\left(T_{p}(1, t)\right)+m_{a}\left[C p_{d s}\left(T_{a}\right)+\bar{X} C p_{v}\left(T_{a}\right)\right] \frac{d T_{a}}{d t}+m_{a} h_{v} \frac{d \bar{X}}{d t}
\end{aligned}
$$

Transferencia de materia

Al realizar un balance de agua en el lecho se obtiene.

$$
m_{a i} X_{i}=m_{a e} X_{e}+\frac{d M_{w}}{d t}
$$

Desglosando la masa de agua en el lecho $\left(M_{w}\right)$ en masa de agua en aire $\left(M_{v a}\right)$ y en el sólido $\left(M_{w s}\right)$, y considerando la humedad del aire y del sólido en base seca:

$$
\begin{aligned}
& M_{w}=M_{v a}+M_{w s} \\
& M_{v a}=\bar{X} M_{d a} \\
& M_{w s}=\bar{\tau} M_{d s}
\end{aligned}
$$

Por lo tanto:

$$
m_{a i} X_{i}-m_{a e} X_{e}=\bar{X} \frac{d M_{d a}}{d t}+M_{d a} \frac{d \bar{X}}{d t}+M_{d s} \frac{d \bar{\tau}}{d t}
$$

Del balance del aire seco en el lecho, considerando que todo el aire seco que entra sale: 


$$
\frac{d M_{d a}}{d t}=0 \wedge m_{a i}=m_{a e}=m_{a}
$$

Finalmente,

$$
m_{a}\left(X_{i}-X_{e}\right)=M_{d a} \frac{d \bar{X}}{d t}+M_{d s} \frac{d \bar{\tau}}{d t}
$$

Considerando la definición de la porosidad del lecho, finalmente se obtiene:

$$
m_{a}\left(X_{i}-X_{e}\right)=\rho_{d a}\left(T_{a}, X\right) \varepsilon V \frac{d \bar{X}}{d t}+M_{d s} \frac{d \bar{\tau}}{d t}
$$

\section{Condiciones iniciales}

Para resolver las ecuaciones de gobierno de transferencia de calor y materia en el lecho es necesario establecer condiciones iniciales.

Asumiendo que la temperatura y la humedad en el aire del lecho y en la hoja eran inicialmente uniformes:

$$
\begin{aligned}
& T_{a}(t=0)=T_{a 0} \\
& T(t=0)=T_{0} \\
& \bar{X}(t=0)=X_{0} \\
& \bar{\tau}(t=0)=\tau_{0}
\end{aligned}
$$




\section{ANEXO 2. HERRAMIENTAS COMPUTACIONALES}

El software Matlab®R2011a (The Mathworks, 2011) se utilizó para el desarrollo de algoritmos generales para el ajuste del modelo y la resolución de los problemas de optimización.

La función "nlinfit" y la funcion "nlparci" de Matlab® R2011a se aplicaron para estimar los valores de los parámetros de los modelos empíricos, por medio de regresiones no lineales, y para estimar los intervalos de confianza de los parámetros.

Para el desarrollo de las ANNs se usó el Toolbox de Matlab®R2011a. La función "newff" permitió crear la ANN con la arquitectura seleccionada y la función "train" se usó para el entrenamiento de la ANN, identificando el número de capas ocultas y neuronas por capa oculta.

Para analizar la influencia de los ultrasonidos sobre la velocidad de secado, se ajustaron los valores experimentales de la evolución del contenido de humedad de las muestras mediante "least-squares spline approximation", usando la función "spap2" y la función "fnder" de Matlab® R2011a.

Para el análisis de la varianza (ANOVA) se utilizó la función "anovan" de Matlab ${ }^{\circledR}$ R2011a; esta función realiza un análisis de efectos de múltiples factores en la media del vector dependiente.

Para probar la hipótesis de que el vector residual proviene de distribuciones normales, se utilizaron las pruebas de test de hipótesis nula y lilliefors, usando las funciones "ttest" y "lillietest" de Matlab® R2011a.

La software COMSOL Multiphysics $\AA 3.4$ fue utilizada para resolver el sistemas de ecuaciones diferenciales y de derivas parciales que definen el modelo del proceso, aplicando el método de elementos finitos. La software Matlab® R2011a fue empleada en el ajuste del modelo usando la función "fmincon", la cual utiliza un método basado en el gradiente para encontrar mínimos locales de problemas no lineales, multivariantes y con restricciones. 
ANEXO 3. HERRAMIENTA PARA LA SIMULACIÓN DEL PROCESO DE SECADO

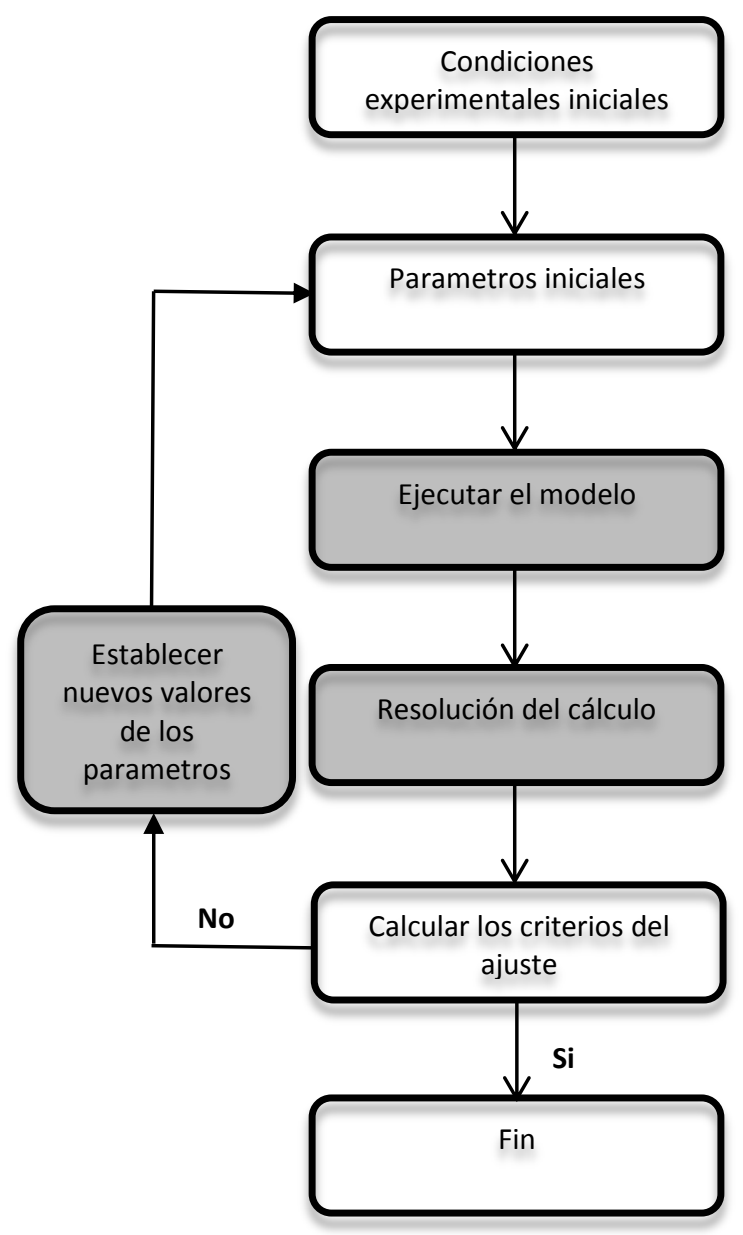

Organigrama del algoritmo para la simulación del proceso secado e identificación de los parámetros del modelo 


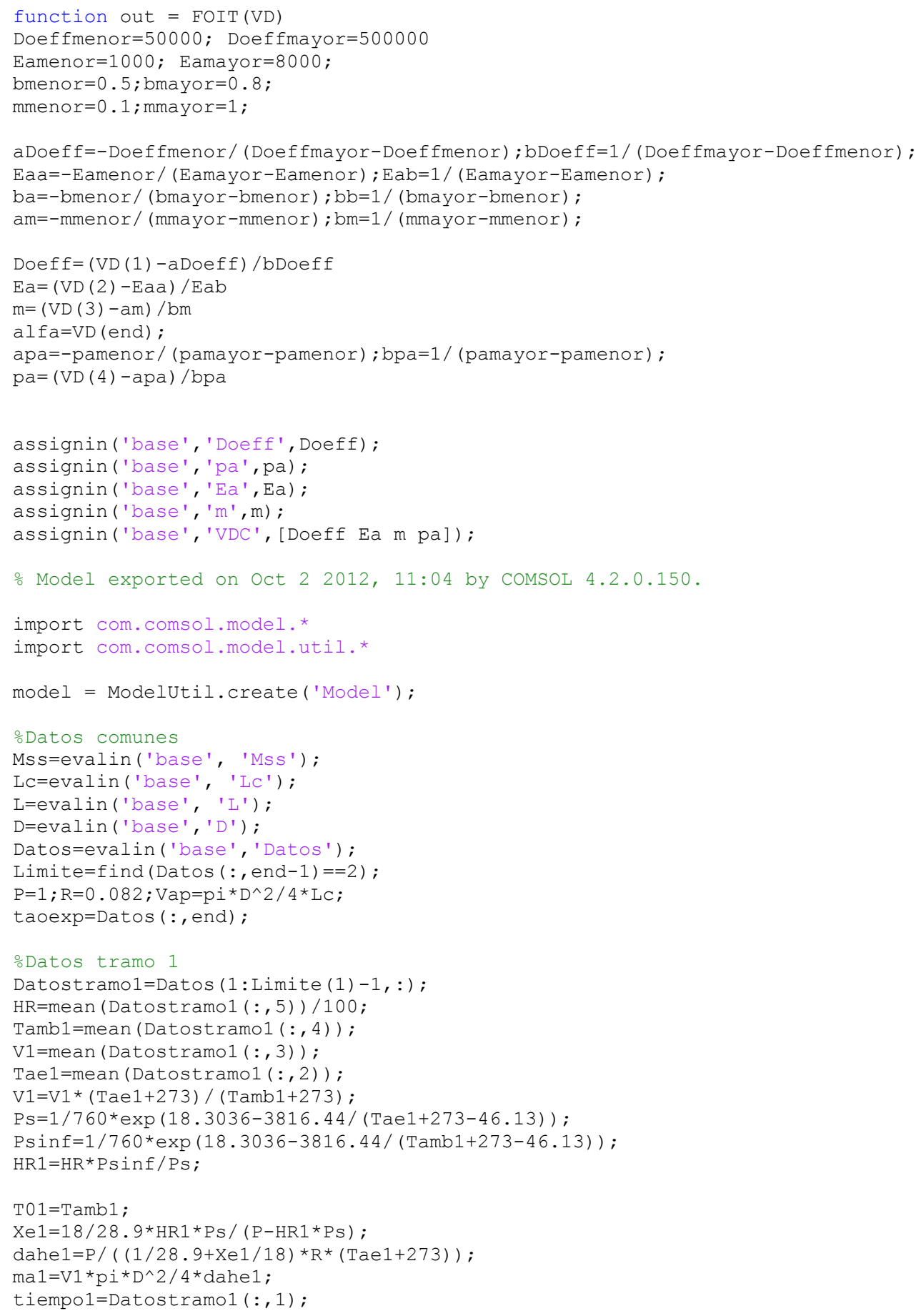




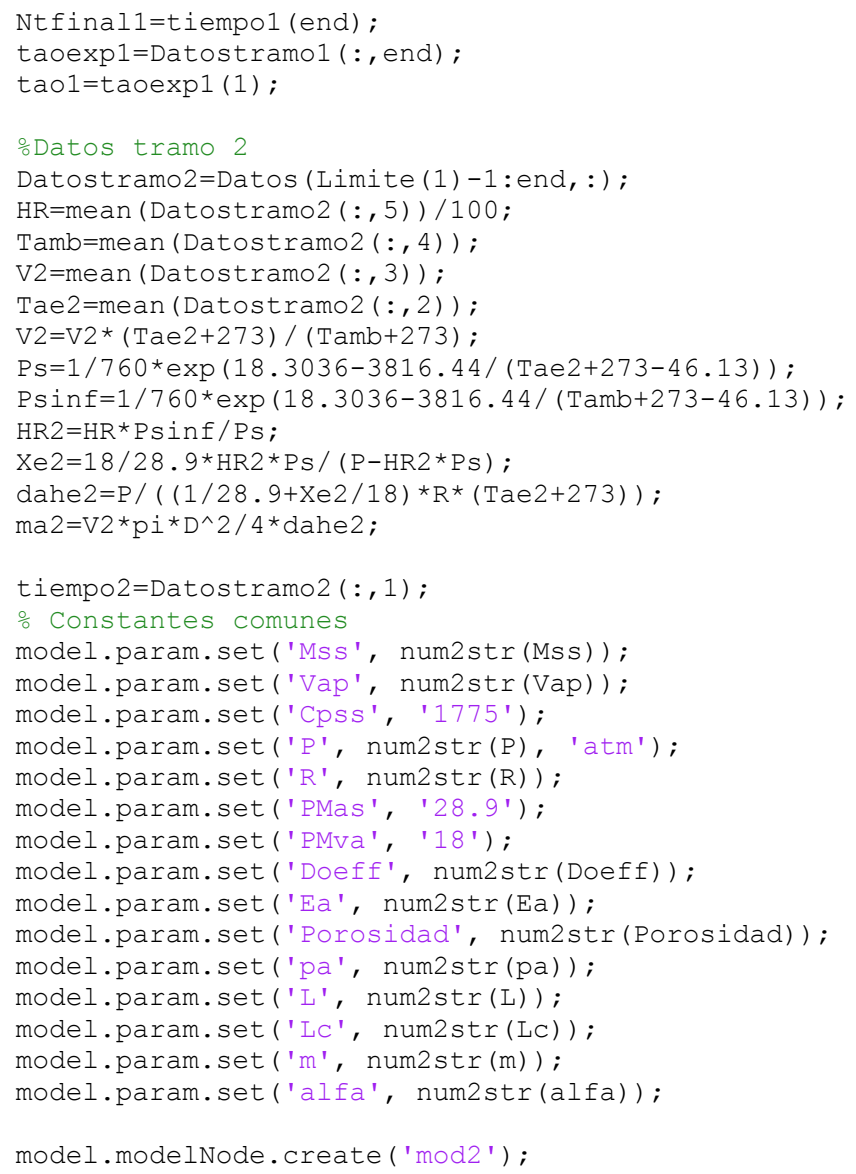




\section{Anexos}

text $(\operatorname{Datos}($ end, 1$) * .1, \operatorname{Datos}(1$, end $) * 0.75,[$ 'R = ', num2str $(R), ' \quad E R R=$

', num2str(Errores),' Cittest $=$ ', num2str(ci(1)), ' ', num2str(ci(2)), ' pttest $=$ ', num2str $(\mathrm{p})])$;

text $(\operatorname{Datos}($ end, 1)*.1, Datos $(1$, end $) * 0.65,[$ 'kstat $=$ ', num2str(kstat), ' critval $=$ ', num2str(critval) ] );

assignin('base', 'R', R) ; assignin('base' , 'Err', Errores) ; assignin('base', 'Cites t', ci); assignin('base', 'ptest', p) ; assignin('base', 'kstat', kstat); assignin('b ase', 'critval', critval);

drawnow;

out $=\mathrm{FO}$;

function [Humedad Ta Xa modelo]

=resolucion (T0, Ta0, XaO, Tae, tao0, HR, Xe, ma, V, periodo, tiempo, model, Ntfinall)

model.param.set ('V', num2str(V));

model.param.set ('TO', num2str(T0));

model.param.set('TaO', num2str(TaO));

model.param.set('Tae', num2str(Tae));

model.param.set ('taoo', num2str(tao0));

model.param.set ('aw', num2str(HR)) ;

model.param.set ('Xe', num2str(Xe));

model.param.set ('ma', num2str(ma));

model.param.set ('XaO', num2str(XaO));

OVariables

if periodo==1

model.geom. create ('geom1', 1);

model.geom('geom1').feature.create ('il', 'Interval');

model.geom ('geom1').run;

model.variable.create ('varl');

model.variable ('varl').model ('mod2');

model.variable ('var1'). set('das', 'P/((1/28.9+Xa/18)*R*(Ta+273))');

model.variable('varl'). set

('Cpas', ' - 0.00000029275*Ta^3+0.00047047*Ta^2+0.01782*Ta+1005.3') ;

model.variable ('varl'). set ('Cpv', '10384.59-

$\left.50.37 *(\mathrm{Ta}+273)+0.074 *(\mathrm{Ta}+273)^{\wedge} 2^{\prime \prime}\right)$;

model.variable ('varl') .set ('IntCpasCpv', '1005.3*(Tae-Ta)+0.01782/2*(Tae^2-

$\left.\mathrm{Ta}^{\wedge} 2\right)+0.00047047 / 3 *\left(\mathrm{Tae}^{\wedge} 3-\mathrm{Ta} \wedge 3\right)-0.00000029275 / 4 *\left(\mathrm{Ta}^{\wedge} 4-\right.$

$\left.\mathrm{Ta}^{\wedge} 4\right)+\mathrm{Xe}(10384.59 *(\mathrm{Tae}-\mathrm{Ta})-50.37 / 2 *((\mathrm{Tae}+273) \wedge 2-$

$\left.\left.\left.(\mathrm{Ta}+273)^{\wedge} 2\right)+0.074 / 3 *((\mathrm{Ta}+273) \wedge 3-(\mathrm{Ta}+273) \wedge 3)\right)^{\prime}\right) ;$

model.variable('var1').set('IntCpv', '10384.59*(Ta-Tsup) -

$\left.50.37 / 2 *\left((\mathrm{Ta}+273) \wedge 2-(\mathrm{Tsup}+273)^{\wedge} 2\right)+0.074 / 3 *\left((\mathrm{Ta}+273) \wedge 3-(\mathrm{Tsup}+273)^{\wedge} 3\right)^{\prime}\right)$;

model.variable ('var1'). set('Tas', '2*Ta-Tae');

model.variable('varl'). set('Xas', '(Xa-(1-alfa)*Xe)/alfa');

model.variable ('var1'). set('IntCpvas', '10384.59*(Tas-Tsup) -

$\left.50.37 / 2 *\left((\text { Tas }+273)^{\wedge} 2-(\text { Tsup }+273)^{\wedge} 2\right)+0.074 / 3 *\left((\operatorname{Tas}+273)^{\wedge} 3-(\operatorname{Tsup}+273)^{\wedge} 3\right)^{\prime}\right) ;$

model.variable ('varl'). set ('Tpp', '(Tsup+Ta)/2');

model.variable('varl') . set ('vah',

'vas/(1+Xa*PMas/PMva*fas) +vva*Xa/(1*PMva/PMas+Xa*fva) ') ;

model.variable('varl'). set('vas', '-

$\left.0.000000000041531 *(\mathrm{Tpp})^{\wedge} 2+0.000000050378 *(\mathrm{Tpp})+0.000017148^{\prime}\right)$;

model.variable('varl'). set ('fas',

' ( (1+abs (vas/vva)^0.5*(PMva/PMas)^0.25)^2)/(8*(1+PMas/PMva))^0.5');

model.variable('varl').set ('fva', 'vva/vas*PMas/PMva*fas');

model.variable('varl'). set('vva', '-1.758e-006+3.7e-008*(Tpp+273)');

model.variable('varl'). set('Pr', 'Cpas*vah/Kah');

model.variable ('varl') . set ('Kah',

'kas/(1+Xa*PMas*fas/PMva)+kva*Xa/(PMva/PMas+Xa*fva)') ;

model.variable ('varl'). set('kas', '0.024121-3.6525e-008*(Tpp)^2+7.9811e-

$005 *($ Tpp ) ') ;

model.variable('var1').set ('kva', '0.07028-0.000355*(Tpp+273)+6.11e-

$\left.007 *(\mathrm{Tpp}+273)^{\wedge} 2^{\prime}\right)$; 
model.variable('varl'). set('dah', 'P/((1/28.9+Xa/18)*R*(Tpp+273))'); model.variable ('varl'). set ('Re', 'V*Lc*dah/vah'); model.variable ('varl'). set('SC', 'vah/(dah*DAB)'); model.variable ('varl'). set ('DAB', '0.00014738*exp (-523.78/(Tpp+273)) '); model.variable('varl'). set('Sh', 'pa*(1/Porosidad* $\left.\operatorname{Re}^{\wedge} \mathrm{m}^{*} \mathrm{SC}^{\wedge}(1 / 3)\right)$ ') ; model.variable ('varl'). set ('Nu', 'pa*(1/Porosidad*Re^m*Pr^(1/3))'); model.variable('varl'). set('Keff', 'Sh*DAB/LC') ; model.variable ('varl'). set('dss', 'Mss/((1-Porosidad)*Vap)'); model.variable ('varl'). set ('hcv', 'Nu*Kah/Lc'); model.variable ('var1'). set ('kt', '1.418e-1+4.93e-1*tao/(1+tao) '); model.variable ('varl'). set ('aweTp', 'exp (-if (taop<=0, 1e-3, taop)^ ($1.44139) * \exp (2.97977-0.00258492 *(T \mathrm{p}+273) \wedge 1.37743)) ') ;$ model.variable ('var1').set('PsTp', '1/760*exp (18.3036-3816.44/(Tp+27346.13 ))' ); model.variable ('var1').set ('Xaeq', 'aweTp*PsTp/(P-aweTp*PsTp)*PMva/PMas') ; model.variable ('varl'). set ('daseq', 'P/((1/28.9+Xaeq/18)*R*(Tp+273)) '); model.variable ('varl'). set ('CpwTp', '1.89E-06*Tp^4-5.27E-04*Tp^3+6.06E$\left.02 * \mathrm{Tp}^{\wedge} 2-2.66 \mathrm{E}+00 * \mathrm{Tp}+4.21 \mathrm{E}+03^{\prime}\right) ;$ model.variable('varl').set('LrTp', 'if(Tp<65,2502535.259-2385.76424* $\left.\mathrm{Tp},(7329155978000-15995964.08 *(\mathrm{TP}+273.16) \wedge 2) \wedge(1 / 2))^{\prime}\right)$; model.variable ('var1') .set ('ALandaTp', '8314.472*((Tp+273)^2)*(1/aweTp)*d (aweTp, Tp) / PMva' ); model.variable ('varl'). set('LandaTp', 'LrTp+ALandaTp') ;

\section{Modelos}

model.physics.create ('g', 'GeneralFormPDE', 'geom1'); model.physics ('g'). feature.create ('fluxl', 'FluxBoundary', 0); model.physics ('g'). feature ('fluxl'). selection.set ([2]); model.physics.create ('ge2', 'GlobalEquations') ; model.physics ('ge2'). identifier('ge2'); model.physics.create ('g2', 'GeneralFormPDE', 'geom1') ; model.physics ('g2'). feature.create ('flux1', 'FluxBoundary', 0) ; model.physics ('g2'). feature ('flux1'). selection.set([2]); model.mesh.create ('mesh1', 'geom1'); model.mesh ('mesh1'). feature.create ('edg1', 'Edge'); model.probe.create ('pdom1', 'DomainPoint'); model.probe ('pdom1') .model ('mod2') ; model.cpl.create ('intopl', 'Integration', 'geoml'); model.cpl ('intopl'). selection.set ([1]); model.physics ('g'). field('dimensionless'). component ( $\{$ taop'\}); model.physics ('g').field('dimensionless').field('taop'); model.physics ('g'). feature('gfeq1'). set ('f', '0'); model.physics ('g'). feature ('gfeq1'). set ('Ga', '-Doeff*exp ($\mathrm{Ea} /(\mathrm{Tp}+273)) * \mathrm{dss} *$ taopx');

model.physics('g'). feature('gfeq1'). set('da', 'dss'); model.physics ('g'). feature('init1'). set('taop', 'taoo'); model.physics ('g'). feature('initl'). name('Initial Values 1'); model.physics ('g'). feature ('fluxl'). set ('g', '-Keff/L* (Xaeq*daseq-Xa*das) ') ; model.physics('ge2'). feature('ge1'). set('name', \{'tao'; 'Ta'; 'Xa'\}); model.physics('ge2'). feature('gel'). set('equation', \{'tao-intopl(taop)'; 'ma*IntCpasCpv+(Xe-Xas)*ma*IntCpvas-

das*Porosidad*Vap*Xat*IntCpv+Mss/dss*hcv/L* (Tsup-Ta) -

das*Porosidad*Vap* (Cpas+Xa*Cpv)*Tat'; 'ma* (Xe-Xas)-das*Porosidad*Vap*XatMss*taot'\});

model.physics('ge2'). feature('gel'). set('initialvalueU', \{'taoo'; 'Ta0'; ' $\mathrm{XaO}$ ' \}) ; model.physics ('ge2'). feature('ge1'). set('initialvalueut', \{' '; ' '; ''\}); model.physics ('ge2'). feature ('ge1'). set('description', \{''; ''; '' $\}$ ); model.physics ('g2'). field('dimensionless'). component ( $\{\mathrm{Tp}$ ' $\}$ ); model.physics ('g2').field('dimensionless').field('Tp'); 
model.physics('g2'). feature('gfeq1'). set('f', 'Doeff*exp ($\left.\mathrm{Ea} /(\mathrm{Tp}+273)) * \mathrm{dss} * \mathrm{taop}{ }^{*} \mathrm{CpwTp} * \mathrm{Tpx} \mathbf{p}^{\prime}\right)$; model.physics ('g2'). feature('gfeq1'). set ('Ga', '-kt/L^2*Tpx'); model.physics ('g2'). feature('gfeq1'). set ('da', 'dss*(Cpss+taop*CpwTp) '); model.physics ('g2'). feature('init1'). set('Tp', 'T0'); model.physics ('g2'). feature('fluxl'). set('g', '-hcv/L*(Tp-Ta)Keff/L* (Xaeq*daseq-Xa*das) *LandaTp');

model.mesh ('meshl'). feature ('size'). set('hauto', 2); model.mesh ('mesh1').run; model.probe ('pdom1'). set ('coords1', 1); model.probe ('pdom1'). set('bndsnapl', true); model.probe ('pdom1'). feature ('ppb1'). set ('probename', 'Tsup'); model.probe ('pdom1'). feature ('ppb1'). set ('expr', 'Tp') ; model.probe('pdom1'). feature('ppb1'). set('descr', 'Variable dependiente TP') ; model.study.create ('std2'); model.study('std2').feature.create('time', 'Transient'); model.sol.create ('sol1'); model.sol ('soll'). study ('std2'); model.sol ('soll'). attach('std2'); model.sol ('sol1').feature.create('st1', 'studystep'); model.sol ('soll'). feature.create('v1', 'Variables'); model.sol ('sol1').feature.create('t1', 'Time'); model.sol ('soll'). feature('tl').feature.create('fcl', 'Fullycoupled'); model.sol ('soll'). feature ('t1'). feature.remove ('fcDef'); model.study ('std2'). feature('time'). set('tlist', tiempo); odel.sol('soll'). feature('st1'). name('Compile Equations: Time Dependent'); model.sol('sol1'). feature('stl'). set('studystep', 'time'); model.sol ('soll').feature('v1'). set('control', 'time'); model.sol ('soll').feature('t1'). set('control', 'time'); model.sol('soll'). feature('v1'). set('scalemethod', 'init'); model.sol ('soll'). feature('tl'). set('tlist', model.sol ('soll').runAll; end if periodo==2

model.study ('std2'). feature('time'). set('geomselection', 'geom1'); model.study ('std2'). feature ('time'). set('physselection', 'g2');

model.study('std2'). feature ('time'). set('mesh', \{'geom1' 'mesh1'\}); model.study ('std2'). feature('time'). set('tlist', tiempo); model.sol('soll').feature('t1').set('tlist', tiempo); model.sol ('sol1'). feature ('v1'). set('initmethod', 'sol'); model.sol ('soll'). feature('v1'). set('initsol', 'soll'); model.sol ('sol1'). feature ('v1'). set('t', num2str(Ntfinal1)); model.sol ('soll').runAll;

end

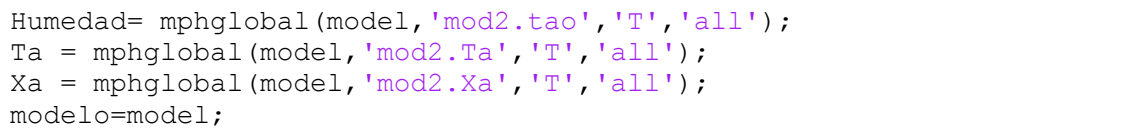




\section{ANEXO 4. HERRAMIENTA DE PROGRAMACIÓN DE UNA RED} NEURONAL

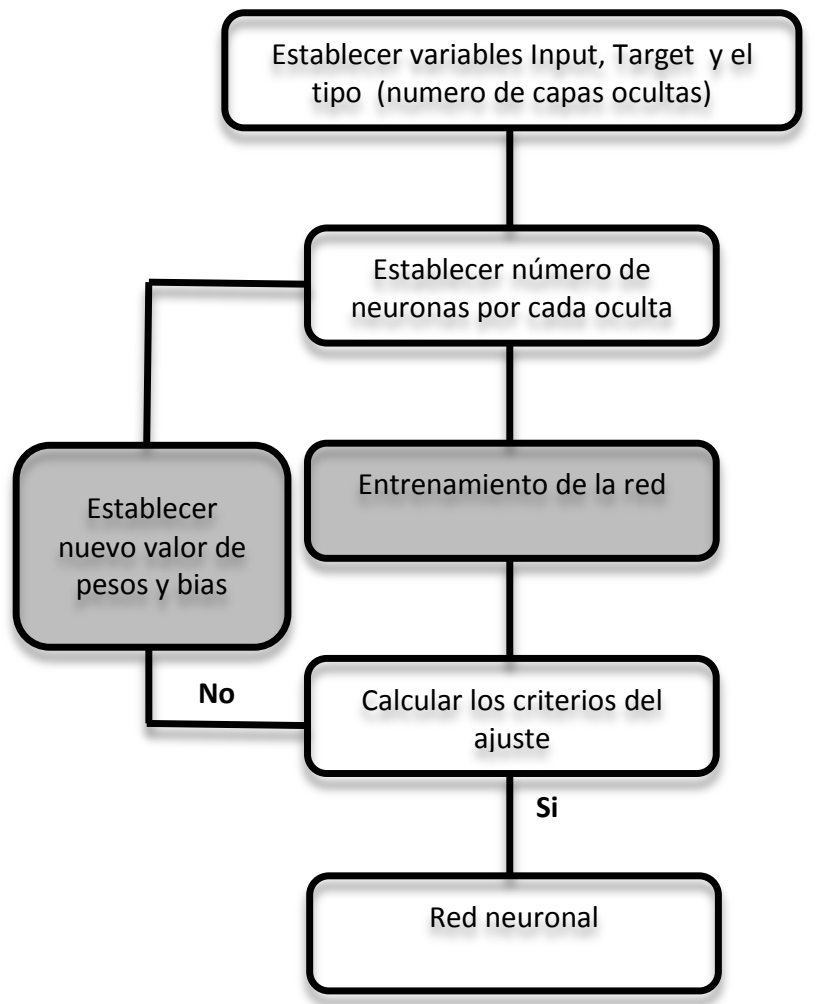

Organigrama del algoritmo para proceso de simulación de una ANN 


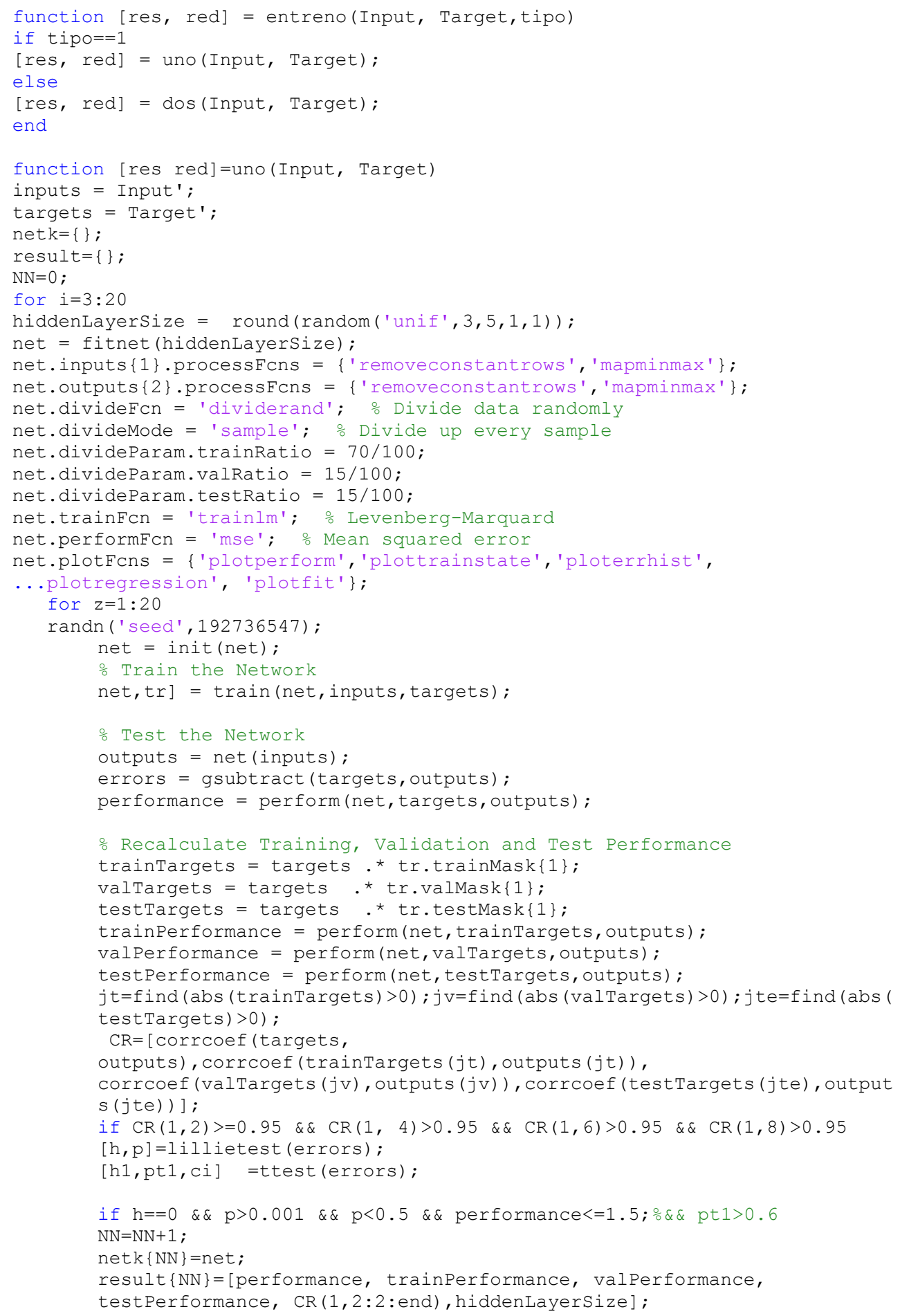




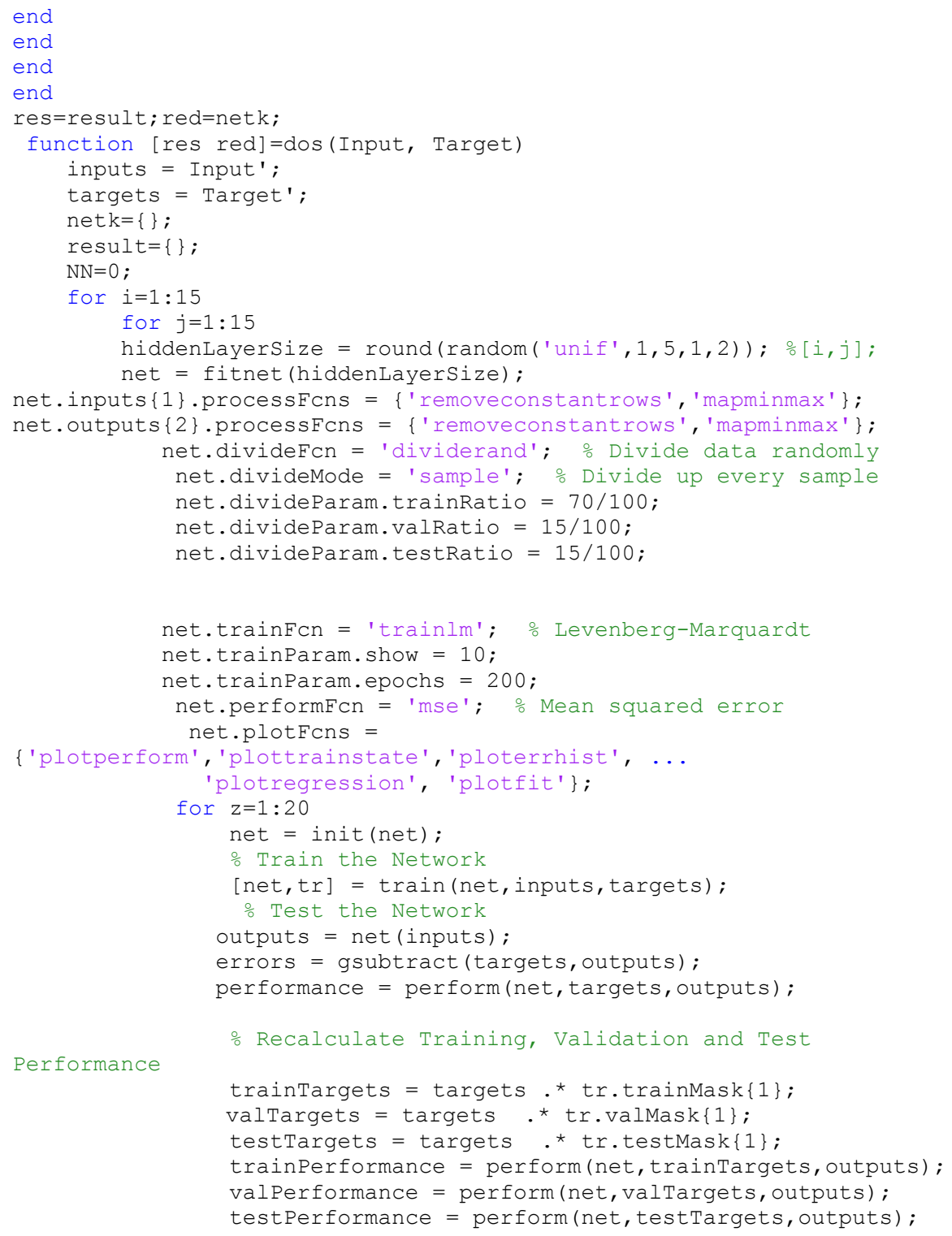


Anexos

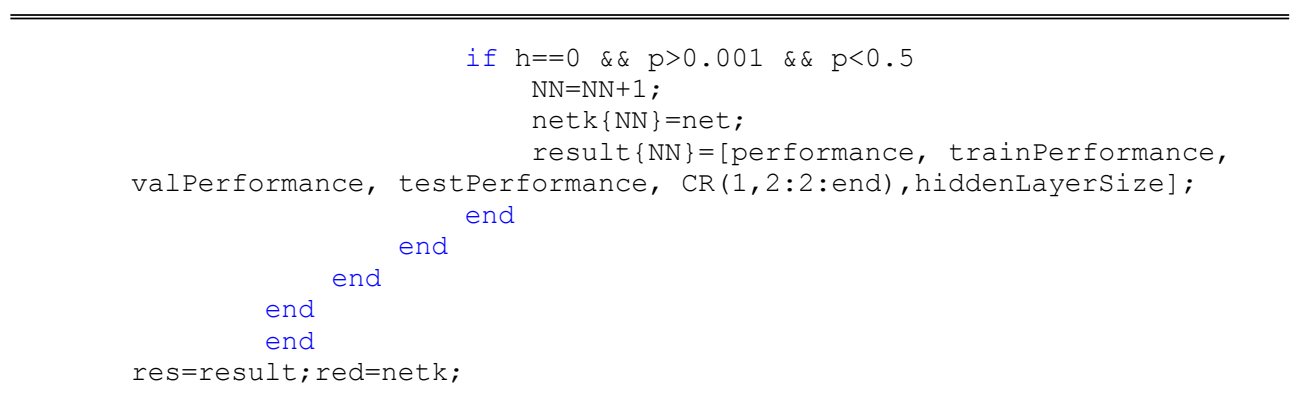



